\title{
Bryozoarios Marinhos Brasileiros - III -
}

\author{
POR \\ Ernst Marcus \\ (Departamento de Zoologia da Universidade de São Paulo).
}

A. Parte especial

I. O material e a sua proveniencia $\ldots \ldots \ldots \ldots \ldots \ldots \ldots \ldots \ldots \ldots \ldots \ldots$ 113

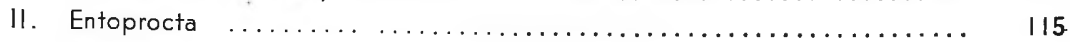

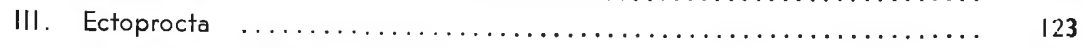

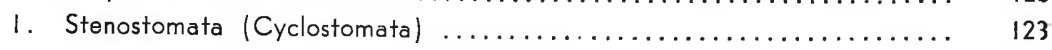

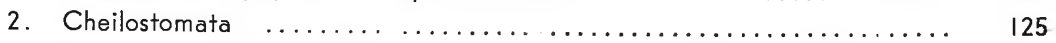

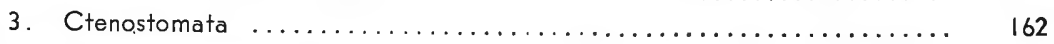

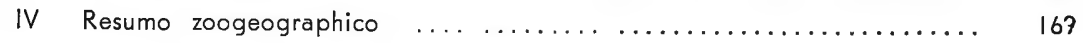

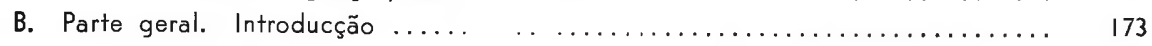

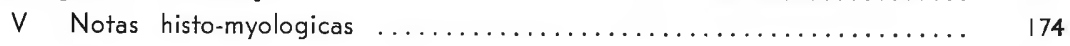

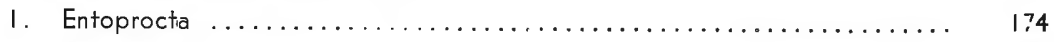

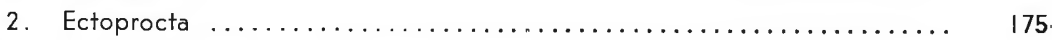

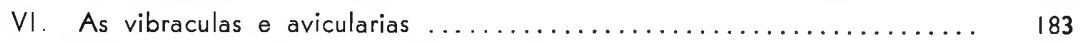

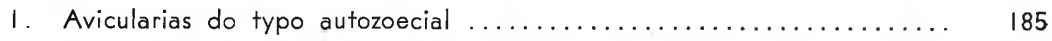

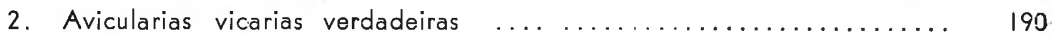

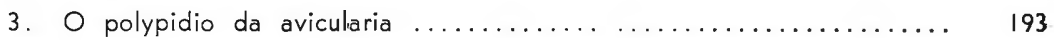

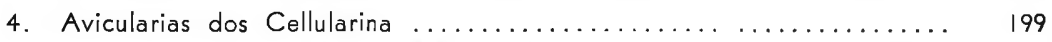

5. Glandulas aviculariaes e avicularias dos Ascophora ............. 204

VII. Os orgãos generativos dos Entoprocta ... ................. 208

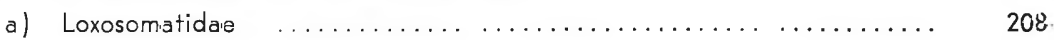

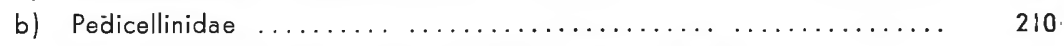

I Hermaphroditismo em Pedicellina cernua (Pall.) .......... 212

2. Gonochorismo em Pedicellina cernua (Pall.) .. $\ldots$......

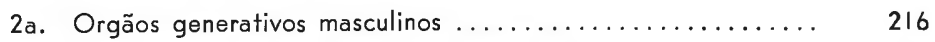

2b. Orgãos generativos femininos ................... 220

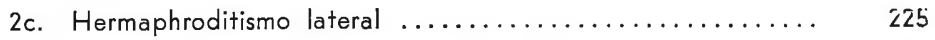

VIII. O desenvolvimento de Pedicellina cernua (Pall.) ... ........... 225

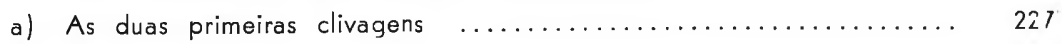

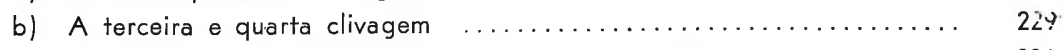

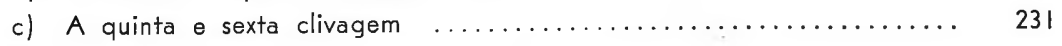

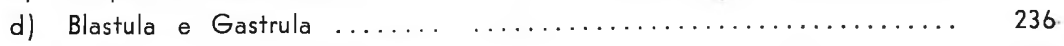

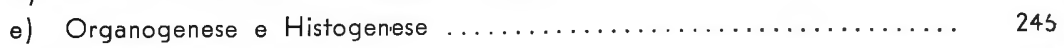

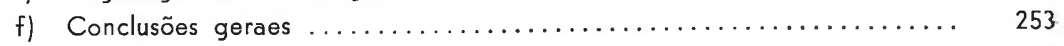

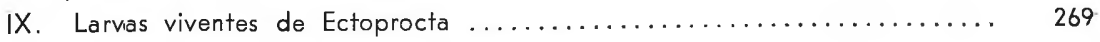

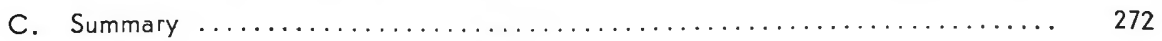

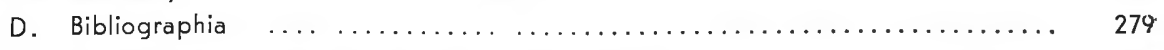

E. Registro dos nomes dos generos e das especies .................. 295

F. Estampas ....................................... 300 



\section{A.}

\section{PARTE ESPEC.IAL.}

\section{I. \\ O material e a sua proveniencia.}

Conjunctamente com a minha esposa Exma. Sra. D. EVELINE DU BOIS. REYMOND MARCUS communico a seguir a $3 .^{a}$ contribuição á historia natural dos Bryozoa marinhos brasileiros, especialmente da bahia de Santos. As Terebriporidae, Ctenostomata perfuradores de conchas, foram no entretanto publicados em outro lugar (Marcus 1938b). O material para a parte geral do trabalho presente foi colleccionado em duas excursões realizadas em janeiro de 1938 e de 1939, e facilitadas pelos Snrs. Directores do Clube de Pesca e pelo Snr. Director da Escola de Pesca, todos em Santos. Agradeço aos mencionados Snrs. o seu auxilio generoso, e com profunda gratidão ao meu caro amigo Dr. Paulo Sawaya, professor de Physiologia geral e animal da nossa Universidade, toda a sua actividade excellente prestada para o bem da nossa obra commum e a revisão linguistica da parte geral do trabalho presente. Valerosissima foi tambem a collaboração do Snr. João de Paiva Carvalho que contribuiu essencialmente para o successo da excursão de 1939.

As especies tratadas na parte especial proveem, em parte, da collecção malacologica do Snr. F. Lange de Morretes que amavelmente pôs á nossa disposição as conchas de Gastropoda e Lamellibranchiata incrustadas por Bryozoa. As especies classificadas por nós em conchas da collecção do Snr. Lange de Morretes e procedentes do litoral brasileiro, fóra do Estado de São Paulo, são enumeradas na pagina 172.

Outra parte do material discutido no capitulo systematico devemos ao Snr. Dr. Otto Schubart-Rio de Janeiro que colleccionou na barra de Serinhaem, Recife (Est. de Pernambuco) as 18 especies seguintes:

* Crisevia pseudosolena Marc.

Stomatopora major (Johnst.) Idmonea atlantica Johnst.

* Aetea anguina (L.)

* Membranipora tuberculata (Bosc)

* Electra bellula (Hcks.)
* Beania intermedia (Hcks.) Nellia oculata Bsk.

* Catenicella contei (Aud.) Hippothoa divaricata Lmx. Escharoides costifera (Osb.) Gemelliporina glabra (Smitt) 
Hippopodina feegeensis (Bsk.)

Holoporella schubarti, spec, nov.

* Nolella gigantea (Bsk.)
* Nolella dilatata (Hcks.)

Mimosella verticillata (Hell.) var. firmata Marc.

* Buskia repens (O'Don.)

As especies marcadas ja foram encontradas por nós no litoral de Santos e descriptas nas publicações precedentes (Marcus 1937; 1938). O fragmento de Idmonea atlantica possibilitou a classificação certa, mas não justificaria uma figura. Por isso falta esta especie na parte systematica do presente trabalho, embora até agora não tenha sido tratada nas duas contribuições anteriores.

Outras especies que serão tambem aqui descriptas foram colleccionadas na excursão de 1938 ou offerecidas pelas alumnas Srtas. D. Berta Lange de Morretes, D. Marta Vannucci e pelos Snrs. prof. Barão Dr. O. de Fiore Cropani, Ivan Hauff e João de Paiva Carvalho, aos quaes fico summamente grato.

O Snr. Lic. Michel Pedro Sawaya, assistente scientifico da catedra de Zoologia geral da Universidade de São Paulo, encarregou-se amavelmente da revisão linguistica da parte especial e da leitura das provas; sou-lhe muito reconhecido.

Ainda não foi possivel dragar em profundidades além de 20 metros, de modo que o inventario da bryozoofauna de Santos se restringe ao litoral superior. Na ultima resenha (Marcus 1938, p. 4) o numero total das especies de Santos importava em 95 . N'este numero não foram incluidas as variedades daquellas especies, cuja forma typica foi verificada na região de Santos. Actuaimente temos de accrescentar 5 especies da familia Terebriporidae (Marcus 1938b), Bowerbankia caudata (Hcks.), na primeira publicação indicada do Rio de Janeiro (Marcus 1937. p. 138), mas, no entrefanto encontrada na bahia de Santos e 9 especies da lista seguinte, pela primeira vez assignaladas do nosso litoral. Eleva-se assim a 110 ○ numero das especies dos Bryozoa conhecidos do litoral superior de Santos e dos seus arredores.

\section{Lista das especies tratadas}

\section{Entoprocta}

Loxocalyx sawayai, spec. nov., litoral paulista.

Loxosomatoides evelinae, spec. nov., litoral paulista.

\section{Ectoprocta}

Stomatopora major (Johnst.), Recife.

Membranipora tuberculata (Bosc.), Recife.

Conopeum commensale Kirkp. \& Metzel., litoral paulista.

Thalamoporella evelinae, spec. nov., litoral paulista. 
Nellia oculata Busk, Recife.

Hippothoa divaricata Lmx., Recife.

Pasythea tulipifera (Ell. Sol.), litoral paulista.

Escharina krampi Marc., litoral paulista.

Schizoporella horsti (Osb.), litoral paulista.

Gemelliporina glabra (Smitt). Recife.

Mastigophora pes-anseris (Smitt), litoral paulista e Est. de Santa Câtharina.

Smittina trispinosa (Johnst.) var. loxa Marc., litoral paulista.

Microporella ciliata (Pall.) var. coronata (Aud.), região de Vancouver, U.S.A.

Adeona violacea (Johnst.), litoral paulista.

Adeona tubulifera Can. \& Bassl., Estado do Paraná.

Rhynchozoon verruculatum (Smitt), litoral paulista.

Siniopelta langei, spec. nov., Estado de Santa Catharina.

Holoporella carvalhoi, spec. nov., iitoral paulista.

Holoporella schubarti, spec. nov., Recife.

Alcyonidium mamillatum Ald., litoral paulista.

Alcyonidium hauffi, spec. nov., litoral paulista.

Buskia repens (O' Don.), Recife.

II.

\section{Entoprocta.}

Loxocalyx sawayai, spec. nov. (Est. V - Fig. 1).

Trata-se de uma forma pequena, cujo comprimento varia entre 170-400 $\mu$. calice, cuja longura é approximadamente o duplo da largura, mede 1/5-225 $\mu$ de comprimento, 60-130 $\mu$ de largura. O diametro do lophophoro e a largura do calice são iguaes. Os 8 tentaculos são curtos e largos, possivelmente por causa da fixação. Cellulas glandulares especiaes ou orgãos sensoriaes no calice não foram observados. Nunca ha mais que um botão em cada lado ao mesmo tempo, portanto, não mais que dois simultaneos. O fundo do estomago occupa proximalmente a largura inteira do calice.

O pedunculo, que mede $110-190 \mu$, inclusive o pé, 50-110 $\mu_{1}$ sem este, acha-se no material fixado aqui em mão, por via de regra, fortemente contrahido, grosso $(60 \mu)$ ligeiramente pregueado. Em alguns exemplares é estendido e mais delgado $(40 \mu)$, sendo irregularmente dispostas as cellulas epitheliaes d'elle.

O pé possúe sola concava, quasi rhombica, marcando-se o percurso longitudinal do ducto glandular por uma fenda central. O pedunculo levanta-se quasi no meio do pé, sendo situadas as duas dilatações aliformes em plano 
transversal igual ao ponto basal do pedunculo. Cada uma das dilatações alludidas tem largura menor que a metade da largura do pedunculo. As dilafações pódem ser retrahidas, quer dizer, enroladas na concavidade do pé. E' igualmente muito contractil o proprio pé, variando o seu comprimento de 70-140 $\mu$. Caracter especifico de primeira ordem é fornecido pelo comprimento consideravel do prolongamento do pé para o lado oral. Embora seja sujeita a certa variação, conforme o gráo de contraç̧ão, sempre é nitida a extensão do pé na direcção oral, podendo até tornar-se quasi igual á da direcção opposta.

A glandula do pé (Fig. I g), situada no terço distal d'elle, não se torna muito notavel nos nossos preparados corados, sendo mais distinctas as quatro series de cellulas que formam o ducto excretor da glandula. Dos orgãos propagativos, vimos no material presente sómente ovarios $(0)$ em typica posição e ordem dos ovocytos (Atkins 1932, p.371).

TABELA DAS MEDIDAS EM MICRA DE 7 EXEMPLARES DE LOXOCALYX SAWAYAI, SPEC. NOV. TOMADAS EM BALSAMO DE CANADÁ.

\begin{tabular}{|c|c|c|c|c|c|c|}
\hline $\begin{array}{l}\text { Comprimento } \\
\text { total, da mar- } \\
\text { gem superior } \\
\text { do calice até } \\
\text { a ponta do } \\
\text { pé }\end{array}$ & $\begin{array}{l}\text { Compri- } \\
\text { mento de } \\
\text { calice }\end{array}$ & $\begin{array}{l}\text { Largura } \\
\text { do } \\
\text { calice }\end{array}$ & $\begin{array}{l}\text { Comprimento } \\
\text { do peduculo } \\
\text { da base do } \\
\text { calice até o } \\
\text { meio do pé }\end{array}$ & $\begin{array}{c}\text { Largura } \\
\text { do pedun- } \\
\text { culo }\end{array}$ & $\begin{array}{c}\text { Compri- } \\
\text { mento do } \\
\text { pé }\end{array}$ & \\
\hline 400 & 200 & 120 & 110 & 40 & 130 & $\begin{array}{l}\text { o maior exem- } \\
\text { plari o peduncu- } \\
\text { lo, acha-se esten- } \\
\text { dido. }\end{array}$ \\
\hline 350 & 225 & 130 & 90 & 60 & 120 & $\begin{array}{l}\text { quasi de tamanho } \\
\text { igual, porém, de } \\
\text { pedunculo contra- } \\
\text { hido. }\end{array}$ \\
\hline 315 & 190 & 120 & 70 & 60 & 120 & \\
\hline 290 & 180 & 120 & 50 & 40 & 110 & \\
\hline 250 & 130 & 60 & 50 & 40 & 140 & \\
\hline 230 & 115 & 60 & 40 & 60 & 80 & \\
\hline 170 & 120 & 90 & 50 & 40 & 70 & $\begin{array}{c}\text { o menor exemplar } \\
\text { de vida indepen- } \\
\text { dente. }\end{array}$ \\
\hline
\end{tabular}


E' muito difficil classificar uma especie da familia Loxosomatidae sem ter em mão o material das especies descriptas nos primeiros trabalhos sobre - grupo. O genero Loxocalyx (Mortensen 1911, p. 405) é bem definido e não foi posto em duvida por Harmer (19/5), como Cori (1936, p. III) pretende. Acha-se tambem mantido pela Dra. Hastings (1932, p. 404), offerecendo a glandula do pé caracter generico bem distincto (Nitsche 1869, p. 33). Já Kowalewsky (1866, p. 9) tinha considerado o seu Loxosoma neapolitanum como genericamente separado de singulare Keferst. Dentro do genero Loxocalyx ha numerosas especies que habitam esponjas (Harmer 1915, p. 7), aproveitando-se provavelmente das particulas alimenticias trazidas pela corrente produzida pelos flagellos dos choanocytos. A unica especie de Loxocaly $x$ que possúe sómente 8 tentaculos é L. cochlear (Schmidt 1876, p. 3), cuja unica

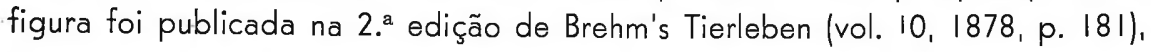
fóra do meu alcance. A literatura mostra que se trata em $L$. cochlear de uma especie cujo pedunculo é mais comprido que o calice (Schmidt 1878, p. 69; Harmer 1915, p. 8). Barrois (1877, p. 9) colloca L. co ch le ar na synonymia de L. neapolitanum Kow., mas isto é inverosimil, porque o ultimo possúe 10 tentaculos (Kowalewsky 1866, p. 3) e pedunculo muito mais curto que o calice (ibid., f. I, 2), apesar de indicar Cori (1936, p. 106) o contrario. A synopse de Leunis-Ludwig (1886, p. 32) muito segura, dá 700-800 $\mu$ como comprimento total de L. cochlear, de modo que esta especie não póde ser identificada com a presente.

Das outras especies, L. raja (Schmidt I876, p. 3 t. I f. I) tem 12 tentaculos, o calice é mais curto que o pedunculo e a largura maxima do calice se encontra na ponta proximal d'elle (Cori 1936, p. 106; Harmer 1915, p. 7-8). L. leptoclini (Harmer 1885, p. 263; 1915, p. 8) possúe, além de certas cellulas glandulares, não presentes em a nossa especie actual, as medidas seguintes: comprimento do calice $180 \mu$, do pedunculo $320 \mu$. As duas especies de pedunculos mais longos ainda, L. lineatus (Harmer 1915, p. 6) e L. tethyae (Salensky 1877. p. 3, 6), não precisam ser discutidas.

Restam, portanto, L. a latus (Barrois 1877. p. 9 t. 16 f. 4) e L. pes (Schmidt 1878, p. 69). Seja frizado que na ultima monographia dos Entoprocta (Cori 1936, p. 107) se precisa trocar as illustrações das figs. 96 e 97. Além disso, a figura de Loxosoma singulare, quer dizer, a esquerda da pagina 107 de Cori não foi reproduzida, como se acha indicado "segundo Keferstein mas, sim "segundo Claparède" (1862, t. 2 f. 6). "Loxosoma alata" (se fosse Loxosoma, deveria ser alatum" sendo realmente $L \circ \times 0, c a \mid y \times$ deve ser "ala tus") foi introduzido como denominação nova daquelle Loxocalyx que Schmidt (1876, o. I. 3) 
estudou e erroneamente identificou com Loxosoma singulare Kef. Sem duvida, Loxosoma singulare (Keferstein 1862, p. I31 t. II f. 29) da costa da Normandia (St. Vaast) e o Loxocalyx singulare de Napoles de Schmidt (1876, t. I f. 2), mais tarde designado por elle Loxosoma (hoje Loxocalyx) pes (Schmidt 1878, p. 69) são differentes, de maneira que Barrois (1877. p. 8-9) tinha razão em exigir nova denominação do singula re Schmidt 1876 (non Keferstein 1862). Infelizmente, porém, Barrois não se contentou com a emendação da nomenclatura, mas, pretendeu ter reencontrado a especie de Schmidt em St. Vaast; chamando-a alata. Publicou uma figura (t. 16 f. 4) muito geral e, praticamente, nenhuma diagnose especifica. Schmidt evidentemente não conhecia a publicação de Barrois (1877), quando um anno mais tarde introduziu o nome pes" (Schmidt 1878). Sendo assim, seria ao meu vêr impossivel hoje estabelecer a identidade de alatus e pes, porque realmente, L. alatus (Barr.) poderia ser qualquer Loxocalyx de pedunculo longo. O comprimento do pedunculo de alatus (Barr.) contraindicaria até a sua união com L. pes de pedunculo curto (Schmidt 1876 . p. 3). Tão pouco verosimil é tambem a identidade de L. ala tus (Barr.) e Loxosoma alata" (Jullien \& Calvet 1903, p. 29 t. 2 f. 4a-4d). igualmente um $\mathrm{Loxocalyx}$, mas de pedunculo muito curto. Apesar de Waters (1879, p. 280) e Mortensen (1911, p. 404), ambos sem discussão, considerarem identicos alatus e pes, prefiro deixar com Harmer (1885, p. 267; 1915, p. 8) Loxocalyx al a tus (Barr.) de lado, por não se achar sufficientemente caracterisado. Sómente depois de ser reencontrado no lugar original na esponja indicada por Barrois (1877 p. 9), L. a la tus. (Barr.) poderia ser emendado.

Loxocalyx alatus (Jull. Calv.), do golfo da Gasconha, que deveria ser denominado novamente, possúe pedunculo curto, mais curto que o material de Santos, pé largo e curto, e 8,10 e 12 tentaculos. A configuração do pé e o comprimento do pedunculo distinguem este $L \circ \times \circ \mathrm{c}$ a l y $x$ do material presente.

numero dos tentaculos, como criterio da differenciação das especies. das Loxosomatidae, é sem duvida importante; admitte, porém, certa amplitude de variação. Já por Harmer (1885) foram mencionadas excepções nas diagnoses de Loxocalyx te thyae (Sal.) (p. 26I) e Loxosoma crassicauda Sal. (p. 263), e Ehlers (1890, p. 140) dlisse: "parece duvidoso que se possa confiar em o numero dos cirros para a distincção das especies" Prouho notou pequena variação do caracter alludido em Loxosoma annelidicola (1891, p. 97), dando-se certa fluctuação tambem em L. annulatum (Harmer 1915, p. 1I), L. velatum (ibid., p. 13), cirriferum (ibid., p. 14) pusillum (ibid., p. 16). 
loricatum (ibid., p. 21) e cocciforme (ibid., p. 22). Em Loxosoma loxalinum, pelo contrario, o numero dos tentaculos é constante, em L. saltans quasi constante (Assheton 1912, p. 120, 124), e em L. davenporti a variação é muito grande (Osburn 1912, p. 212). Os resultados obtidos por Harmer $(1915$, I. c.), i. é, augmento do numero dos tentaculos com a idade do individuo, dentro de um certo limite especifico, são confirmados pelos estudos eximios de Daphne Atkins (1932, p. 324, 338, 349, 355). Ella, porém, verificou em L. obesum constancia muito grande (p. 356). Trata-se, portanto, quanto ao numero dos tentaculos, de um caracter subtil, que nem deveria ser descuidado, nem exagerado, nomeadamente quando se trata de pequeno material.

Quanto á distribuição, as especies das Loxosomatidae parecem ser um tanto mais restrictas que a maioria das especies dos Bryozoarios, sendo, sem duvida, tal juizo prematuro, em virtude de serem raramente assignaladas em mares extra-europeus. Em todo o caso, podemos notar sómente duas especies européas, Loxosoma singulare (Waters 1914, p. 855) e Loxocalyx leptoclini (Harmer 1915, p. 8), encontradas no oceano indico (exclusive o mar Vermelho), sendo que Loxosoma crassic a u da Sal. (Kirkpatrick 1890, p. 17), do mar sulchinez, verosimilmente não pertence a esta especie (Hastings 1932, p. 405). Tamberm a lista das Loxosomatidae das zonas arcticas (Krumbach 1932) mostra muito pequena relação com as regiões confinantes.

Naturalmente as deliberações zoogeographicas não influenciaram sobre a classificação do material presente. Mas, não posso apresentar com o nome de $L \circ x \circ c a l y x$ pes uma grande população homogenea, da qual, em 28 animaes, cujos tentaculos foram contados, estes sempre appareceram $\mathrm{em}$ numero de 8 . Com respeito a $L$. pes introduzido na literatura com 10 tentaculos (Schmidt 1876, p. 3 t. 2 f. 6) diz Harmer (1885, p. 262): "the tentacles. were ten in number in all the individuals examined. A importancia do numero dos tentaculos evidencia-se tambem pelo facto de se zchar mantido como especie independente Loxosoma nitschei Vig. por Harmer (1915, p. 20) e Daphne Atkins (1932, p. 386). Esta especie, esquecida na monographia de Cori (1936), distingue-se segundo a diagnose e as figuras originaes (Vigelius 1882, p. 19 f. 4a-5), de L. singulare Kef. sómente pelo numero dos tentaculos e pelo hospedeiro. Do mesmo modo, os 8 tentaculos do material de Santos já seriam sufficientes para distinguil-o de L. pes. Accrescenta-se a isso a configuração do pé. O prolongamento dirigido para o lado oral, na especie santense sempre nitidamente desenvolvido, não se encontra em L. pes. A semelhança com o pé humano levou Schmidt $(1878$, p. 69, 72) á escolha do nome scientifico do seu animal. Não se daria o mesmo com a especie de Santos, cujo pé é 
approximadamente rhombico. Baseando, assim, no numero dos tentaculos e na forma do pé a differenciação d'essa primeira Loxosomatida sul-americana de Loxocalyx pes (O. Schmidt), separo-a especificamente, dedicando-a ao meu amigo Paulo Sawaya.

Bahia de Santos, Sangava, em ca. de $15 \mathrm{~m}$ de profundidade, em uma esponja (Cornacuspongida) do genero Mycale (prof. Dr. W. Arndt do Museu Zoologico de Berlin det.).

\section{I.oxosomatoides evelinae, spec. nov (Est. V - Fig. 2 A-C).}

A colonia, que cresce em Bugula neritina (L.), consiste em um estolão (diametro: $30 \mu$ ) segmentado, do qual se erguem perpendicularmente os zoécios. Segmentos estoloniaes providos de individuos ramificam-se em muitos casos, occorrendo até 4 ramificações. O comprimento dos segmentos sem individuos varia muito, ás vezes são muito curtos e sempre alternam com os que possúem zoécios. Os pedunculos curtos e grossos sómente raras vezes attingem ou ultrapassam a longura dos calices; frequentemente são consideravelmente mais curtos. Acham-se cobertos por cuticula grossa e rugosa, aculeada, encontrando-se os acúleos de preferencia nos lados anal e distal. O pedunculo tem, de baixo para cima, diametro quasi igual e acha-se provido de fibras musculares longitudinaes. Estas são direitas e parallelas, faltando, portanto, fibras obliquas.

O calice, lateralmente um pouco comprido, é I 1 $1 / 2$ vezes mais alto que largo. Todo o seu lado aboral acha-se coberto por grande escudo cuticular, que se encurva tambem proximalmente sobre a zona marginal do outro lado, de maneira que deixa livre no lado oral apenas um campo approximadamente em forma de raquette de pingue-pongue. Dorso-lateralmerte nota-se ligeira constriç̧ão symetrica do escudo, que assim se torna triangular quanto ao seu corte transversal. O aspecto lateral lembra muito o de uma Lepas.

Além dos acúleos escassamente distribuidos sobre o escudo, não se nota n'elle esculptura especial. Os tentaculos são em numero de 8-10. O intestino sahe do estomago no plano mediano, portanto, no mesmo plano em que o esophago entra. A colonia presente é feminina, contendo varios indivíduos até 6 embryões situados em bolsas incubadoras de epithelio alto. Um individuo masculino pertence a uma outra colonia; os dois testiculos d'elle são sacculiformes e conteem poucos espermatozoides maduros. Quando o animal está com os tentaculos dobrados para dentro, a membrana do calice acha-se dirigida obliquamente em direcção distal, resaltando para fóra uma papilla côniforme. Na tabella seguinte foi medida em confor- 
midade com a posição do individuo respectivo na lamina, ora a largura. (a estensão dextro-sinistral), ora a profundidade (estensão antero-posterior).

MEDIDAS (EM MICRA) DE 8 INDIVIDUOS DE LOXOSOMATOIDES EVELINAE, SPEC. NOV., TOMADAS EM OLEO DE CRAVO.

\begin{tabular}{|c|c|c|c|c|}
\hline $\begin{array}{l}\text { Comprimento } \\
\text { do calice }\end{array}$ & $\begin{array}{l}\text { Largura do } \\
\text { calice }\end{array}$ & $\begin{array}{l}\text { Profundidade } \\
\text { do calice }\end{array}$ & $\begin{array}{l}\text { Comprimento } \\
\text { do pedunculo }\end{array}$ & $\begin{array}{c}\text { Largura do } \\
\text { pedunculo }\end{array}$ \\
\hline 250 & - & 180 & 270 & 60 \\
\hline 270 & - & 180 & 140 & 70 \\
\hline 270 & 150 & - & 90 & 70 \\
\hline 270 & 160 & - & 120 & 65 \\
\hline 250 & 140 & - & 180 & 75 \\
\hline 280 & - & 200 & 170 & 65 \\
\hline 320 & 170 & - & 170 & 80 \\
\hline 300 & 180 & - & 120 & 90 \\
\hline
\end{tabular}

Bahia de Santos, nas rochas da Praiinha, em Bugula neritina (L.). Os Ectoprocta cheilostomata alludidos crescem em profundidade menor de $1 \mathrm{~m}$, onde se acham sujeitos ao movimento das ondas, sem serem geralmente batidos pela ressaca. Da mesma biocenose proveem entre outras especies Victorella sibogae Harm. e Arachnoidea evelinae Marc. (Marcus 1937, p. 129, 130).

O genero Loxosomatoides (Annandale 1908, p. 14) pertence á familia Pedicellinidae e abrangia até agora 2 especies, L. colonialis. Ann. (l. c.) e L. I a evis Annandale (1915, p. 129), ambas das aguas marinha e salobra da costa oriental da India anterior. A especie actual distingue-se por muitos caracteres das anteriormente descriptas, dos quaes. sejam mencionados: estolão segmentado (nas duas outras especies não segmentado) e regularmente ramificado (parcamente ou não ramificado); pedunculo aculeado (sem acúleos no pedunculo); 8-10 tentaculos (colonialis. 12-16, la evis 14); escudo entre os acúleos liso (em colonialis retıculado, em la evis sem acúleos); a largura do calice é menor que a: 
es ensão antero-posterior (profundidade) na nova especie, (maior nas duas outras); a corôa tentacular tem, quando encurvada para dentro, mesma direcção obliquamente para cima, como geralmente nas Pedicellinidae (na phase mencionada é parallela com o eixo longitudinal do calice como nas Loxosomatidae; Annandale 1908, p. 16; 1915, p. 130); o intestino sahe no plano mediano do estomago (lateralmente em L. colonialis; 1908, p. 14, f. 5); os testiculos são sacculiformes (ramificados em L. colo n i alis: 1908, p. 18). Annandale descreveu ausencia de septos no estolão de L. c oIonialis (1908, p. 14), concordando com isso o seu unico desenho do estolão que se refere ao L. la e vis $(1915, \mathrm{f}$. I). Tal crescimento é excepcional em Entoprocta estoloniferos, e a segmentação do estolão na especie presente poderia talvez recommendar a sua separação generica das duas outras, visto ter sido collocado em genero especial Chitaspis athleticus, em virtude de differir a musculatura do pedunculo de Loxosoma to ides (Annandale 1916, p. 16). A especie nova, descoberta por minha esposa Snra. Da. Eveline du Bois-Reymond Marcus e dedicada a ella, distingue-se á primeira vista de Loxosomatoides laevis, e, pelos caracteres mencionados, tambem nitidamente de L. colonialis. Apresenta a occorrencia de um Loxosomatoides na bahia de Santos mais um exemplo da distribuição zonal dos generos dos Bryozoarios tropicaes.

A systematica dos Entoprocta não progrediu pelas duas monographias de Cori $(1929,1936)$. O segundo trabalho repete a logica subdivisão principal de Hincks (1880), que distinguiu Entoprocta solitarios e coloniaes, mas, Cori esqueceu de oppôr á familia Loxosomatidae Hincks 1880 a 2a. familia Pedicellinidae Johnston 1847, assim faltando esta no "Bronn dos Entoprocta! A omissão da 3a. familia Urnatellidae Annandale 1915 deu-se talvez deliberadamente, embora pareça ella justificada, restricta, sem duvida, ao genero Urnatella Leidy 185I. As passagens sobre Loxosomatoides (Cori 1929, p. 60; 1936, p. 113) fallam uma vez em estolão não segmentado, outra vez em estolão segmentado, faltando cado vez L. la evis, achando-se mal interpretada a descripção de Annandale quanto á posição da corôa tentacular, escripto incorrectamente o lugar da proveniencia de L. colonialis, e confundidas as figuras de L. colonialis e Chitaspis athleticus (1929, f. 59 e 61; 1936, f. 66 e 69). Os dois trabalhos fazem parte de tratados motivadamente muito espalhados e consultados por leitores que não dispõem da litteratura dos Entoprocta muito dispersa. E' incommodo quando se póde usar sómente com certo cuidado a parte especial de um livro d'este typo, a saber datas, nomes, diagnoses, figuras. Refere-se esta critica nomeadamente ao "Bronn" (Cori 1936). 
III.

Ectoprocta.

\section{Stomatopora major (Johnst.) (Est. VII - Fig. 3 A-B).}

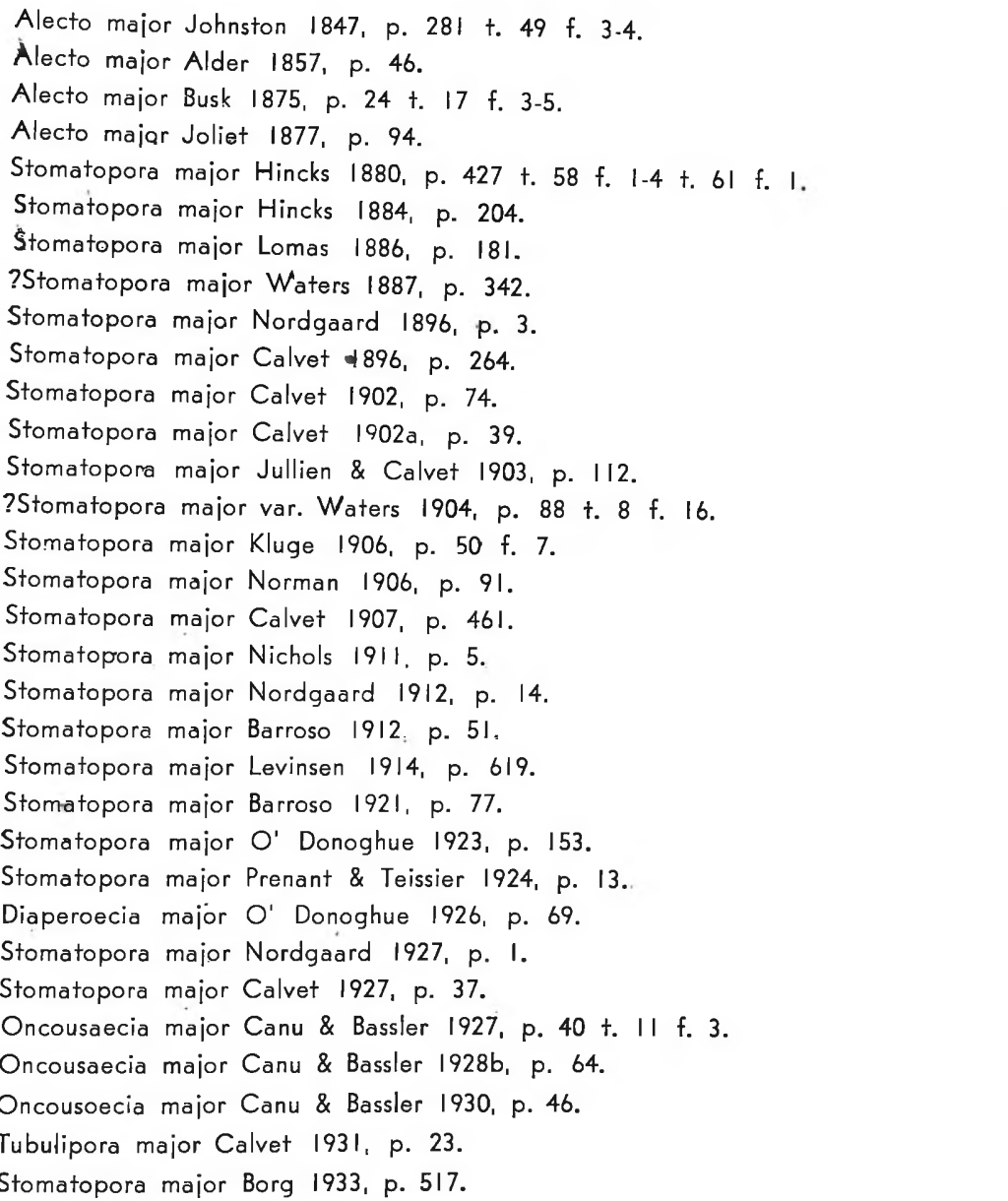

As colonias rasteiras adherem a Algas molles e calcareas, Bryozoa, conchas, frequentemente de Lamellibranchiata mortos encontrados em agua profunda, e pedras. No material presente as duas colonias encontradas cresceram em bexigas natatorias de Sargassum. Colonias adultas compõem-se por varios ramos chatos, divergentes do centro commum, perto da 
ancestrula (disco primario). Os ramos bifurcam-se irregularmente, terminando frequentemente claviformes. Cada ramo apresenta successão de numero variavel de zoécios, dos quaes 2-4 occorrem no mesmo nivel transversal. Onde a calcificação é pouco forte, seja por causa das condições do meio ambiente, seja que se trate das partes jovens da colonia, os zoécios são contiguos, ao passo que são nas colonias intensamente calcificadas immersos em massa calcarea commum, firmemente adherente ao substrato.

Os zoécios compridos possúem diametro de $240-400 \mu$, a saber, $240 \mu$ no material presente, $240-300 \mu$ no material havaiano e $300-400 \mu$ nas colonias dos Galapagos. Os zoécios são dispostos parallelamente, erguendo-se os seus tubos distaes, muitas vezes quebrados, em series ou em alternação irregular perpendicularmente dos tubos deitados. O diametro da abertura oscilla entre $140-200 \mu$, a saber, $200 \mu$ nas colonias aqui em mão. e nas havaianas, 140-180 $\mu$ no material dos Galapagos. As paredes transparentes dos tubos zoeciaes são providos de pseudoporos muito pequenos, sendo a transparencia evidentemente signal de se tratar nas nossas colonias de material vivo no momento da fixação e de calcificação fracamente desenvolvida.

Os gonozoidios frontaes apparecem nas pontas dos ramos ou por baixo. da ramificação, são estreitos proximal e largos distalmente. Autozoécios vizinhos estreitam o gonozoidio, mas, o seu tecto não se acha atravessado. por elles, porque o gonozoidio não circumda os autozoécios por todos os lados. A superficie do tecto gonozoidial possúe grandes pseudoporos densamente dispostos. O oeciostôma (tubo do gonozoidio) approxima-se no material aqui em mão ao autozoécio central e distal; na figura de Hincks. (1880, t. 58 f. 1), o oeciostôma occupa posição quasi central no gonozoidio. Apesar de ser quebrado o tubo do gonozoidio do nosso material, o seu bordo mostra-se de tal maneira encurvado que é possivel reconstruir abertura (oeciopóro) dirigida para o lado frontal, não para cima (o lado distal).

A base das colonias presentes parece achar-se na phase inicial do desenvolvimento da base adhesiva commum. Ainda se distinguem claramente as series longitudinaes formadas pelas porções prox.maes dos tubos zoeciaes. Mas, já se notam faixas calcareas transversaes estendidas sobre - lado basal inteiro. Os grandes pseudoporos regular e densamente dispostos das faixas basaes difficilmente poderiam exercer a funç̧ão ordinaria dos pseudoporos, a saber, respiração e nutrição (Borg 1926, p. 198, 201); poder-se-ia antes pensar em conducção do calcio dissolvido que cimenta a colonia ao substrato.

Recife, barra de Serinhaen, em Sargassum do mar raso. 
Apesar da longa lista das referencias dada aqui, que sem duvida nem mesmo está completa, os nossos conhecimentos sobre a especie quasi acabam com Hincks (1880). Das figuras modernas nenhuma contem gonozoidio, sendo a de Kluge (1906) caracteristica para material intensamente calcificado, a de Canu \& Bassler (1927) mais semelhante ao material actual de calcificação fraca. Quanto á separação dos generos Stomatopora e Tubulipora, refiro-me a Borg (1926, p. 275, 476). Segundo o criterio do crescimento geralmente uniserial em $\mathrm{S}$ tomatopora, a especie actual deveria ser collocada no gen. Tubulipora, mas, tendo Borg mesmo (1933) conservado o nome Stomatopor a para major (Johnst.). parece conveniente por emquanto continuar assim.

Não deveria ser deitada ao esquecimento a caracterisação dada por Johnston (1847, p. 28I), cujo livro é uma mina d'ouro em attestações do intenso interesse pessoal que o preclaro scientista dedicou aos seus objecłos: "o especime jovem e não ramificado parece-se á lagrima que desce pela face - apta comparação esta que furtei do meu amigo o Rev. Dr. Landsborough" Refere-se isto á dilatação distal, visivel, p. e., na fig. 3 da est. 17 de Busk (187.5), indicada por Hincks (1880, p. 427) como sendo muito caracteristica.

O material antarctico de Waters $(1904$, I. c.) não deveria ser tomado em consideração na resenha geographica em virtude da abertura muito estreita $(\mid 20 \mu)$ dos seus zoécios. Dá-se o mesmo com os especimes pliocenicos da Nova Zeelandia (Waters 1887).

Distribuição geographica: Da região arctica estende-se na costa americana pacifica para o sul até a região de Vancouver, as ilhas de Hawaii e os Galapagos, mas até agora não foi verificada no litoral canadense ou norte-americano aflantico. Nas costas europeas foi encontrada desde a Noruega até o mar Mediterraneo occidental em toda a parte, excepto o mar Baltico. Conhece-se do Atlantico subtropical, a saber das Canarias, das ilhas do Cabo Verde e dos Açores. Occorre em algas do litoral superior, como tambem em profundidades até $1250 \mathrm{~m}$.

\section{Membranipora tuberculata (Bosc) (Est. VI - Fig. 4A-B).}

Membranipora tuberculata Marcus 1937, p. 33 t. 5 f. 12.

Material crescido em algas do litoral de Recife (Pernambuco) mostra 2-4 pentezinhos calcareos pedunculados internos $(p)$, primeiramente descriptos em especimes de Angola (Waters 1898, p. 675), cuja funcção até agora ignorada possivelmente poderia ser esclarecida pelo estudo de indi- 
viduos viventes. Talvez sirvam para a conducção dos musculos retractores do polypidio, como foi supposta tal funcção de espinhos semelhantes em Nellia oculata (Harmer 1926, p. 244). Mas, occorrendo os pentezinhos nem sempre em $M$. tuberculata, esta funcção não poderia deixar de ser sómente accessoria. Espaços chitinicos (c), isentos de calcificação, foram assignalados em Membraniporidae pela primeira vez por Nitsche (1871, p. 6-7), no seu estudo fundamental sobre M. membran a cea (L.). Considerou estes espaços como articulações que possibilitam aos zoécios participarem no movimento do seu substrato preferido ( $\mathrm{L}$ a m in a rial nas ondas, sem que se quebrem. Na especie presente, formações semelhantes foram discutidas por Waters (l. c.) e Kluge (1914, p. 664). Permanece chitinosa e fina a ectocysta de M. tuberculata nos pontos onde se toca uma parede transversal com uma longitudinal. Separam-se por isso nas colonias mortas, já no inicio da decomposição da materia organica, os zoécios de tal modo que as paredes transversaes separadoras de dois zoécios successivos e a parte proximal das paredes lateraes se manteem coherentes com a parede frontal calcarea. Certamente não se trata nos espaços chitinicos de pontos quebrados pela agitação do mar, como foi supposto por Waters (1898, p. 676), mas, de verdadeiras articulações, como descriptas por Nitsche em M. membranace $a_{1}$ onde se encontram distantes das paredes transversaes.

Fortemente desenvolvidos são no material de Recife, além dos pentezinhos, tambem os espinhos internos (e), irregularmente ramificados, que se ajustam a formações semelhantes de Conopeum commensale (Marcus 1938, p. 16) e que, como estas, provisoriamente poderiam ser interpretados como absorventes do calcio da agua do mar.

Para completar a classificação de um trabalho brasileiro (Gliesch 1925, p. 58 t. 9), seja frizado que a Membranipora spec." alli mencionada é M. tuberculata (Bosc).

Conopeum commensale Kirkp. \& Metz. (Est. VI - Fig. 5A-B, 6).

Conopeum commensale Kirkpatrick \& Metzelaar 1922, p. 985 t. I f. 1, 4-7, 9.

Conopeum commensale Marcus 1937, p. 35 t. 5 f. 13.

Conopeum commensale Marcus 1938, p. 16 t. 3 f. 6A-6C.

Centenas de colonias d'esta especie, muito commum no mar razo da bahia de Santos e nas praias vizinhas, obrigam-nos novamente a discutir sua variabilidade e relação com outras especies. Nem sempre se vê a coalescencia dos tuberculos da gymnocysta que caracterisa o material original e os 
zoécios adultos até agora figurados do litoral de Santos. E' claro que taes tuberculos, quando separados, tornam difficil a separação da especie de Conopeum reticulum (L.) e ainda mais de Membranipora tuberculata (Bosc), especies igualmente occorrentes na bahia de Santos (Marcus 1938, p. 13; 1937, p. 33).

São caracteres distinctivos improprios, porque frequentemente ausente $\mathfrak{i}_{\text {, }}$ entre C. commensale e C. reticulum, os espinhos chitinicos ra membrana frontal de C. commensalei se occorrerem, definem bem C. commensale. Do mesmo modo é inconstante a apparencia de duas areas circulares, claras por causa da falta de calcificação, na região diștal da parede basal de C. reticulum (Waters 1898, p. 679 t. 48 f. 14). Os espinhos da cryptocysta de C. reticulum (Est. VI Fig. 7) nem sempre se acham desenvolvidos (Marcus 1938, t. 2 f. 5B). Por outro lado pódem as depressões triangulares em C. reticulum manter-se cobertas pelos tectos convexos e salientes de modo que quasi attingem o typo da figura 5B, que mostra $C$. commensale com pequenos tuberculos nãe confluentes.

Ao que parece, são as medidas zoeciaes o unico criterio, absolutamen. te seguro para a differenciação, de C. commensale e C. reti. culum. Seja considerada como altura do zoécio a distancia entre as suas paredes basal e frontal, como longura a distancia entre as paredes proximal e distal. Está, então em C. commensale, a altura do zoécio para a sua longura como I está para 2 e como I para 5 em C. reticulum. São, portanto, as paredes lateraes muito mais altas em C. commensale que em C. reticulum. Correspondentemente, são mais chatas as crostas formadas por C. reticulum e, por via de regra, de calcificação mais fraca. Como exemplo typico, cito das varias colonias da bahia de Santos as medidas seguintes:

C. reticulum, longura: $600-700 \mu$; altura $140 \mu$; C. commen sale, longura: $500-600 \mu$, altura: $250-300 \mu$.

Com a distincção entre C. commensale e Membranipora tuberculata (Bosc) Kirkpatrick \& Metzelaar (1922, p. 985) não se importaram muito, considerando-a facillima. Tal, porém, absolutamente não se dá, como se evidencia logo pelo facto que "uma alta autoridade, a quem foi enviado o material" (i. é, de Conopeum commensale), "identificou a especie como Membranipora tehuetcha (d'Orb.)" O nome attribuido ao material faz suppôr que foi Waters que o teve em mão. Conhecem-se as suas razões para supprimir o nome tuberculata" (Waters 1898, p. 675), como tambem as opiniões contrarias de Norman (1909, p. 827) e de muitos outros autores (veja a lista dos synonymos: Marcus 1937 p. 33). Mettendo ao lado essa divergencia de opiniões sobre 
a nomenclatura, devemos realçar que Waters não considerou $M$. tuberculata (Bosc) e M. tehuelcha (d'Orb.) como especies differentes, mas, sómente abandonou o primeiro nome, por se achar unido a uma diagnose insufficiente, desprovida de figura accompanhadora. Kirkpatrick e Metzelaar, por outro lado, tratam de M. tuberculata e de M. tehuelcha, como se fossem duas especies distinctas (1922, p. 985, 986-987 t. I f. II, I2) differenciando, porém, o C. commensale unicamente de M. tehuelcha. Mas, como expuz anteriormente (Marcus 1937 p. 35), a M. tehuelcha Kirkp. \& Metz. não é a M. tehuelcha d'Orb., mas, sim M. hyadesi Jull. Sem duvida, é facil, distinguir C. commensale de M. hyadesi, mas, pelo contrario, muito difficil separar C. commensale de M. tehuelcha (d'Orb.) (= tuberculata Bosc).

Caracter, ao meu ver, de certa importancia é fornecido pelas placas em roseta terminaes, havendo uma serie de uniporosas (septulas) em M. tuberculata e duas placas multiporosas em C. commensale. Como foi indicado por Kluge (1914, p. 665) e Harmer (1926, p. 209-210), a serie das septulas terminaes de $M$. tuberculata póde ser descontînua no centro, de maneira que se formam dois grupos separados, cada um situado em um lado da parede terminal. Harmer considera o typo de communicação interzoécial formado por dois grupos de septulas "apenas distinguivel de duas placas multiporosas" Sendo que a placa em roseta multiporosa se acha delimitada da parede restante por um nitido contorno oval ou circular (Fig. 6), não posso concordar completamente com a opinião citada de Harmer. Quanto á M. tuberculata de Valparaiso, do Museu Britannico, com duas placas em roseta multiporosas (Harmer 1926, p. 209) na parede terminal, acho que a classificação talvez necessite de uma revisão. Provem a Membranipora hyadesi, mencionada por Kirkpatrick \& Metzelaar sob o nome de M. tehuelcha (d'Orb.) (veja acima) justamente tambem de Valparaiso. Nem nos materiaes de M. tuberculata da bahia de Santos e de Recife, nem em uma colonia da nossa collecção, do mar do Sargasso, portanto, da localidade typica, encontramos terminaes placas em roseta multiporosas.

M. tuberculata possúe cryptocysta distal mais larga que C. commensale, entendendo-se assim a bôa observação de Harmer (1926, p. 209) na diagnose de M. tuberculata: "operculo não completamente distal" A calcificação da parede basal, ligeiramente desenvolvida em C. commensale, ausente em M. tuberculata, contribue tambem para a differenciação das especies. E' claro que toda essa discussão seria superflua, quando se tratar de distinguir as rendas brancas, delicadas, compostas pelos zoécios rectangulares de $M$. tubercula ta 
sobre Sargassum bacciferum das crostas castanhas, multi-estrati. ficadas e compactas, formadas pelos zoécios ovaes de Conopeum commensale sobre conchas e outros substratos solidos. Mas, em virtude da occorrencia de um bloco unico da gymnocysta proximal em M. tuberculata (Kirkpatrick \& Metzelaar 1922, t. | f. |I) e de dois tuberculos separados em C. commensale (Fig. 5), não é mais possivel contentar-se com a distinç̧ão simples notada por Canu \& Bassler (1925, p. II) no fim da sua descripção de Membranipora fusca $(=$ commensale): differe da Membranipora tuberculata pela presença de um grosso tuberculo proximal e não de dois tuberculos distantes um do outro" Ao passo que em C. commensale está á altura do zoécio para a sua longura como I está para 2, está em M. tuberculata (material de Recife, v. p. 113) como I para 5.

Não posso, finalmente, deixar de chamar a attenção dos especialistas sobre a semelhança entre C. commensale e Membranipora denticulata (Busk 1856, p. 176 t. 7 f. 1, 2) do litoral tropical da costa pacifica americana (Hastings 1930, p. 707). Evidencia-se a semelhança alludida mais pela diagnose que indica a delimitação dos zoécios por estreita linha castanha ( $=$ chitinica) e nos tuberculos proximaes (um ou dois!) do que pelas figuras algo geraes.

Thalamoporella evelinae, spec. nov. (Est. VII - (Fig. 8A-B).

As colonias crescem em algas e conchas. Nas algas as colonias ora formam crostas uni-estratificadas, ora as camadas sobrepõem-se uma á outra occorrendo até laminas erectas, certamente, pouco extensas. Tambem nas conchas se encontram colonias uni- e pluri-estratificadas. Os zoécios dispostos em series longitudinaes, bifurcadas, são collocados em quinconcio e na maioria possuem configuração de rectangulos compridos e estreitos; raramente são um tanto mais largos. O lado frontal é plano e se acha coberto pela cuticula, resaltando-se sómente os tuberculos pequenos das areas adoraes. A cryptocysta frontal, densamente granulosa, é composta por estreitos bordos salientes e zona central deprimida, provida de póros na região proximal. Lateralmente é ingreme o declive do bordo á cryptocysta central; proximalmente a cryptocysta abaixa-se pouco a pouco, subindo ella da mesma maneira até a sua concava margem distal, onde, por causa da elevação successiva, não se forma ponte suborificial distincta nos zoécios sem oécios.

As duas opesiulas são asymetricas, attingindo, na maioria dos casos ambas a parede basal, onde, por via de regra, as suas linhas de inserção se unem. D'este modo, forma-se tubo completo em redor da bainha tentacular. Rara- 
mente occorre inserção basal sómente de uma opesiula ou de ambas, sendo em taes casos as linhas de inserção abertas e, quanto aos pormenores variadamente configuradas. Vêem-se na Fig. $8 \mathrm{~B}$ alguns casos de inserção unilateral e um de inserção bilateral, sem união central. Encontram-se taes variações da inserção especifica principalmente na zona de gemmação da colonia, evidenciando-se pelas phases de transição presentes que se inicia d'esta maneira o contacto das opesiulas com a parede basal nos zoécios jovens. Com a calcificação progressiva, dá-se normalmente a confluencia das duas inserções nos zoécios adultos.

A opesia é quasi orbicular e de proporções muito variaveis. A estreita orla calcarea que circumda o orificio sobrepõe-se ao zoécio seguinte. O operculo tem bordos distal e lateraes reforçados e escleritos basaes muitas vezes completa ou approximadamente unidos no centro. Das espiculas internas occorrem quasi exclusivamente agulhas de marcar ("compasses"), sendo raros, em muitos individuos ausentes os arcos ("bows, "curves", "calipers"). Avicularias faltam. Nos espaços interzoeciaes e nas bifurcações das series longitudinaes dos zoécios apparecem frequentemente zoécios aberrantes, desprovidos de operculo, polypidio e cryptocysta central, como foram observados em posição identica em Thal a moporella gothica (Bsk.) var. prominens Lev. (Marcus 1938, p. 23). Os oécios volumosos, de brilho mate de perolas, são lisos, notando-se sutura longitudinal no meio, e nos dois hemispherios ligeira esculptura concentrica provinda da calcificação successiva. Os operculos do gonozoécio e oécio são typicos nada mostrando de peculiaridades. Encontram-se até 6 embryões dentro de um oécio, tendo verificado Waters (1909, p. 124, 142) até 3 no gen. Thala moporella

Bahia de Santos, ilha das Palmas, em algas do mar muito raso; ilha de S. Sebastião, ca. de $100 \mathrm{~km}$. ao norte de Santos, em conchas de Margaritifera radiata (Leach) (coll. Lange de Morretes).

Das especies do genero Tha la mo por ell a mencionadas por Levinsen (1909, p. 178 e seguintes), sómente duas, a saber, Th li otich a (Ortm.) e Th harmeri Lev. mostram união basal das inserções opesiulares. Th lioticha (I. c., p. 179-18I) possúe curtos escleritos basaes do operculo, não unidos no meio, espiculas dos dois typos, agulhas de marcar e arcos e finalmente areas adoraes lisas, desprovidas de quaesquer saliencias. Em Th. harmeri (I. c., p. 186-188) occorrem póros pyriformes nos oécios e os operculos são approximadamente triangulares, não semicirculares, como na especie presente. Desde a synopse de Levinsen foi publicado por Harmer (1926, p. 289-306) o mais importante trabalho acerca de Thalamopo rella Especies de inserção basal contínua das duas opesiulas não se encontram no material estudado por Harmer. Muito valiosas são as suas observações (I. c., p. 305) acerca das variações da inserção opesiular em Th 
gothica (Bsk.) var. prominens Lev. Estas variações devidamente referidas tambem por mim (Marcus 1937. p. 54) não abrangem o caso da linha contínua transversal formada pelas duas opesiulas. Isto é muito importante, visto que se approxima a nova especie em varios outros caracteres á Th gothica var. prominens.

Os póros da cryptocysta central, presentes especialmente na metade proximal, a altura da opesia que se acha contida 3 até 4 vezes na longura do zoécio, os escleritos basaes do operculo unidos no centro e o bordo crenulado do seio da opesia, são taes elementos concordantes em Th. e velinae e Th gothica var. prominens Differenças sem duvida de importancia secundaria, verificaveis nas regiões orificiaes das duas especies, são: corcovas adoraes menores em Th evelinae e ausencia de verdadeira ponte sub-orificial na nova especie. Caracter distinctivo de primeira ordem entre as duas especies apresenta-se pelo typo de inserção da cryptocysta opesiular na parede basal. Linha contínua identica com a encontrada em Th evelinae foi descripta de uma especie provisoriamente innominada de St. Helena (Marcus 1938a, p. 205), cujo operculo, porém, possúe escleritos basaes muito curtos e cujas espiculas internas apparecem em dois typos, a saber, agulhas de marcar e arcos presentes em proporções numericas approximadamente iguaes. Th line aris (Canu \& Bassler 1929, p. 152) distingue-se pela longura $(850-900 \mu$ ) dos seus zoécios. e pelo crescimento uniserial sem delongas da nova especie. Th. dizodoe $n$ s is (Sakakura 1935, p. 14) possúe tambem zoécios muito longos (830-920 u) e bordo recto da opesia. D'este modo revelam-se as duas especies descriptas desde a publicação de Harmer sem averiguação da linha de inserção. opesiular distinctas da presente que dedico á minha esposa Exma. Snra. D. Eveline du Bois-Reymond Marcus.

\section{Nclia oculata Busk (Est. VIII - Fig. 9A-C).}

Nellia oculata Busk 1852, p. 18 t. 64 f. 6, t. 65 (bis) f. 4.

Nellia oculata Smitt 1873, p. 3 t. I f. 53-54.

Nellia oculata P.H. MacGillivray 1880, p. 51 t. 49 f. 5-5b.

Nellia oculata Busk 1884, p. 27.

Farcimia oculata Waters 1909, p. 167.

Nellia tenella Levinsen 1909, p. 120 t. I f. 13a-13e.

Farcimia oculata Waters 1913, p. 489 . t. 67 f. 8-9.

Nellia oculata Osburn 1914, p. 191.

Nellia oculata Canu \& Bassler 1920, p. 196 t. 82 f. 6-10.

Nellia oculata Marcus 1921, p. 5.

Nellia oculata Marcus 1922, p. 423.

Nellia oculata Canu \& Bassler 1923, p. 55 t. 2 f. 5-7. 
Nellia oculata Harmer 1926. p. 240 f. 3 B, D; 4 A, B, t. 14 f. 18.

Nellia oculata Osburn 1927, p. 125.

Nellia oculata Gravely 1927, p. 91 t. 11 f. 2.

Nellia oculata Canu \& Bassler 1928, p: 26.

Nellia oculata Canu \& Bassler 1929, p. 185 t. 5. f. 12-13.

Nellia oculata Hastings 1932, p. 410.

As colonias erectas albugineas (nos liquidos de fixação) ou vitreas ramificam-se com muita regularidade dichotomicamente, alcançando altura até $25 \mathrm{~mm}$. Erguem-se de um estolão rasteiro fixo ás algas, esponjas, Hydrozoa ou conchas. Com intervallos variaveis brotam colonias secundarias do estolão. Cada colonia acha-se composta por successivos segmentos separados por articulações chitinicas. Cada segmento representa uma columna formada por quatro series de 1-12 zoécios dispostos alternadamente, quer dizer, os zoécios oppostos são situados em niveis iguaes, os zoécios confinantes, em niveis differentes (Fig. 9C). Os segmentos inferiores (proximaes), mais velhos da colonia, são mais curfos que os superiores (distaes) nas pontas livres do crescimento.

Os zoécios oblongos, rectangulares, mas de cantos arredondados, possúem campo de abertura oval, proximalmente do operculo apertado pelos dentes suspensores. Estes são productos da cryptocysta, aliás minuscula nos bordos lateraes e sómente desenvolvida proximalmente, onde forma meia lua estreita, finamente granulada. A gymnocysta lisa e saliente circumda o campo de abertura. O operculo alongado, reforçado distal e lateralmente, é provido de escleritos proximaes, rectos, que não se tocam no meio da margem proximal. Visto do lado distal, o operculo, quando aberto, mostra-se alargado nos seus bordos livres por uma chapa chitinica interna (veja o operculo do zoécio B da Fig. 9 C). A communicação inter-zoecial dá-se por septulas, i. é, placas em roseta uniporosas, havendo uma na parede distal, uma na parede proximal e duas em cada parede lateral (Fig. 9 B, s). Ha II-I2 tentaculos.

No campo proximal da gymnocysta, encontram-se em posição symetrica nos dois lados as avicularias, cujas camaras se estendem para dentro até o centro do segmento. Nas suas paredes lateraes internas occorrem espinhos, que entram na cavidade do cystidio autozoecial sobreposto. Esta se torna muito estreita quasi tubuliforme, entre as avicularias, achando Harmer (1926, p. 244) possivel funccionarem os espinhos avicularigenos como ordenadores das fibras do musculo retractor do polypidio. A ponta externa e distal da camara da avicularia é saliente e obliquamente truncada, sendo situada no declive d'esta ponta a abertura oval, cuja metade inferior é occupada pela mandibula semicircular ou triangular. Como é muito pequena a mandibula, medindo 6-10 $\mu$ ○ seu diametro maior, fala Harmer em avicularia vestigial e, real- 
mente, não poderia defender efficazmente a colonia contra quaesquer Metazoa. lgnora-se tambem a funç̧ão da janella coberta por membrana, que se nota na região proximal de todas as avicularias. Levinsen (1909, p. 120) disse que ahi se originam as fibras radiculares, mas, no material aqui presente, tal não se dá. Em concordancia com Smitt (1873, f. 53), vê-se na Fig. 9 a origem da fibra radicular $\langle r|$ na parede frontal do zoécio, entre as avicularias e independentemente d'ellas. Nas regiões proximaes da colonia os segmentos são envolvidos por varias fibras radiculares que se fixam ao substrato.

Waters (1913) descreveu os segmentos principiantes de colonias secundarias erguidas do estolão rasteiro, semelhantes ás de Buguía turrita (Des.) como sendo tubos calcareos sem campo de abertura. Em cada colonia secundaria ha geralmente 3-4 de taes segmentos successivos unidos por articulações chitinicas, sahindo de cada tubo 4 fibras radiculares para os quatro lados.

Os zoécios ferteis não se distinguem dos estereis pela largura. O seu oécio é endozoécial e formado por um sacco situado na região distal da parede basal. Endo- e ecto-oécio calcareos cobrem, á maneira de capuz, o sacco, notando-se frequentemente no ecto-oécio uma janella transversal não calcificada.

Nas bifurcações origina-se cada um dos dois novos segmentos em um dos dois zoécios inferiores (Fig. 9C, A) e um dos superiores (B). Tal origem obliqua produz posição algo torcida dos novos ramos, cujos planos não são dispostos perpendicularmente sobre os planos do precedente segmento qua-

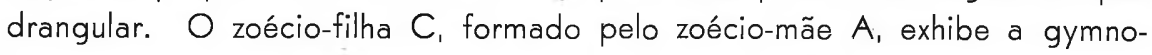
cysta e as avicularias dispostas de tal maneira que prolongam exactamente - segmento precedente á bifurcação. Pela flexão do tubo chitinico (t), origina-se a direcção divergente do ramo novo, lembrando este tubo estructuras correspondentes nas Scrupocellariidae. O campo de abertura do individuo C é menor que o dos zoécios communs e desprovido de operculo, tratando-se, portanto, de kenozoécio. O individuo seguinte da mesma serie é o autozoécio normal $G$. O zoécio-mãe superior $B$ emitte 2 tubos chitinicos $\left(t^{\prime}\right)$, muito mais finos que o tubo $t$. Um dos tubos $t^{\prime}$ continúa no lado opposto do kenozoécio $C$ com kenozoécio semelhante, visivel no novo ramo esquerdo em vista lateral $\left(D^{\prime}\right)$, no ramo direito da frente (D). Na serie de $D$ e $D^{\prime}$ a colonia continúa com um autozoécio normal $(H)$. Considerando os kenozoécios $C$ e $D$ como anteriores e posteriores respectivamente o autozoécio $E$ seria o externo em relação á ramificação. A origem de $E$ dá-se por um dos tubos finns $\left(t^{\prime}\right)$, ambos originados do zoécio-mãe superior (B). O zoécio inicial da 4. ${ }^{\mathrm{a}}$ serie dos novos ramos, que é a interna, começa sem tubo chitinico, sendo o zoécio respectivo $(F)$ entalado entre os kenozoécios $C$ e $D^{\prime}$

Recife, barra de Serinhaem, em algas no mar raso. 
O nome generico Farcimia Fleming 1828, usado por Waters para a especie actual, não póde ser mantido, porque é synonymo de $\mathrm{C}$ ell a ria Ell. Sol. 1786 (Johnston 1847 p. 365, nota; Harmer 1923, p. 308). C el Iaria tenella Lamarck (1816, p. 135) não póde ser identificada certamente com $\mathrm{N}$ oculata nem com qualquer outra especie erecta $e$ articulata, recommendando-se asssim abandonar o nome te nell a completamente (Waters 1913, p. 490; Harmer 1926, p. 242).

Como já foi salientado por Harmer (1926, p. 245), N oculata mostra descontinuidade singular na sua distribuição. A costa occidental da Africa é quasi incognita quanto á sua bryozoofauna, mas o litoral da região do Cabo da Boa Esperança é bem explorado, de modo que a ausencia da especie notavel n'esta região póde ser considerada como certa. A occorrencia de Nellia oculata na ilha de Heard, na costa meridional da Australia, e no mar sulchinez (Amoy, Hastings, I. c.), mostra que está muito longe de ser uma especie stenotherma da agua quente, e não deveria ser chamada "uma especie tropical" (Canu \& Bassler 1929, I. c.). As temperaturas moderadas do litoral sul-africano não significariam uma barreira para a distribuição de $\mathrm{Nelli}$ a o c ula ta A occorrencia de $\mathrm{Nelli}$ a ocula ta no mar Vermelho e no Mioceno inferior do Egypto talvez indiquem depender a sua distribuição actual da Tethys terciaria. Nellia oculata é como poucas especies de Bryozoarios, facilmente distinguivel e chama logo a attenção durante o sortimento de qualquer material colleccionado. Justifica-se assim inclui-la nos exemplos dados por Ekman (1935, p. 80-84) para elucidar as relações entre a fauna do litoral do Atlantico occidental tropical e do Indo-Pacifico occidental. Os achados na região do Nordeste da America do Sul são de interesse especial no sentido da theoria de. Ihering, que considerou esta região como um refugio da fauna das Indias occidentaes durante o Plioceno e o inicio do Pleistoceno (Ekman 1935, p. 104).

Distribuição geographica: Bahia; golfo do Mexico; Florida; Indo-Pacifico occidental: do mar Vermelho e da costa da Africa oriental ingleza para o sul até as ithas de Crozet e Heard, Indico central e archipelago malayo, Philippinas e até Amoy (estreito de Formosa), costas meridionaes, orientaes, occidentaes (Sharks Bay, R. Hartmeyer leg.) e septentrionaes da Australia. Do mar raso (5 metros e menos) até $1.000 \mathrm{~m}$.

Hippothoa divaricata Lmx. (Est. VIII - Fig. 10).

Hippothoa divaricata Lamouroux 1821, p. 82 t. 80 f. 15, 16.

Catenicella divaricata Blainville 1834, p. 462-463.

Hippothoa lanceolata Couch 1844, p. 102 t. 18 f. 6.

Hippothoa divaricata Johnston 1847, p. 291 t. 51 f. 3-4. 


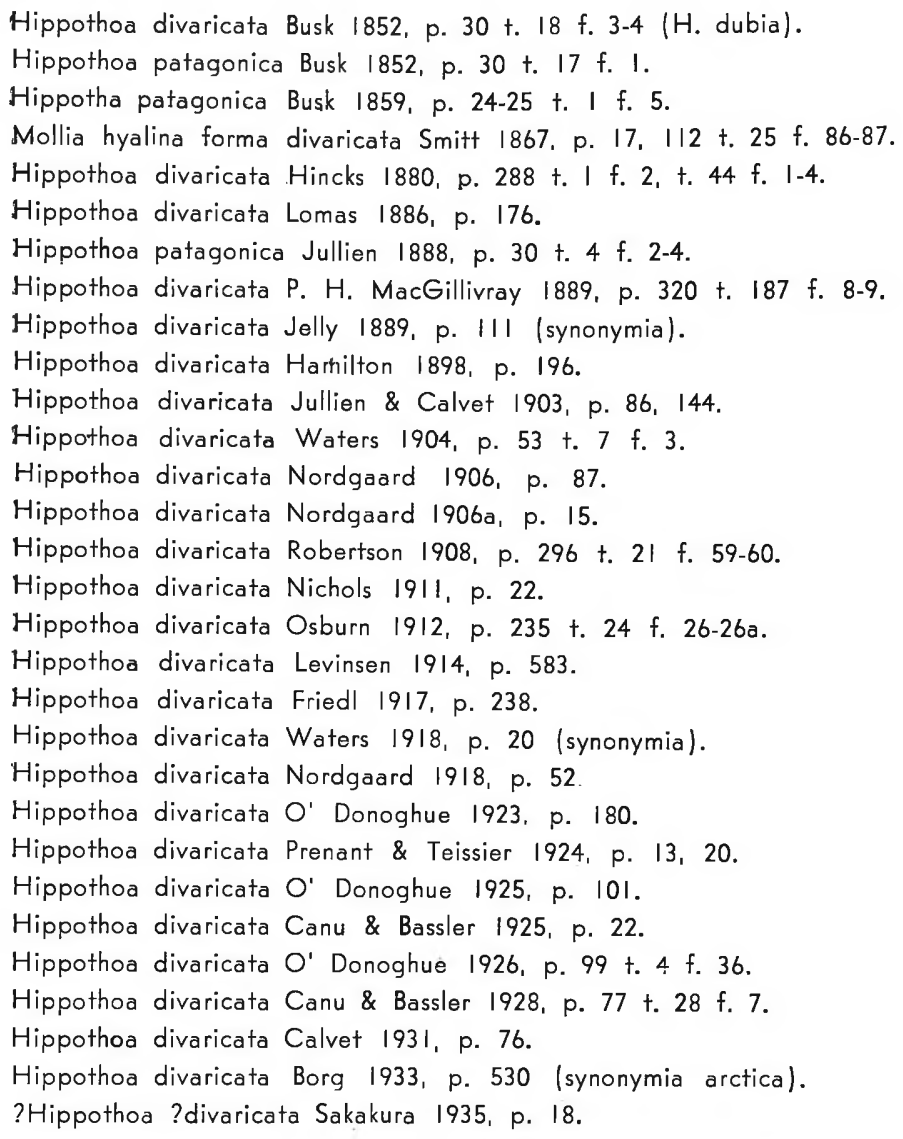

As colonias vitreas, prateadas, ou mate-brancas como perolas, incrustam algas, Hydrozoa, Bryozoa, conchas, nomeadamente de Lamellibranchiata, mas, tambem de Gastropoda e Brachiopoda (Busk 1855, p. 254). Ascidias e pedras. Os zoarios compõem-se de series distantes de zoécios, regular ou irregularmente ramificadas (forma ty pi c a Hcks.), podenelo originar-se uma nova successão de zoécios na parte distal ou lateral dos velhos zoécios. Onde occorrem, p. e., 1-3 zoécios novos no bordo distal de um velho e, alem d'isso, talvez, linhas de zoécios originadas lateral e asymetricamente nos velhos individuos, formam-se redes complicadas sem clara polaridade do crescimento da colonia. Realiza-se configuração regular da colonia, quando esta consiste em compridas linhas uniseriaes unidas por ramos lateraes, que sahem nos dois lados oppostos dos zoécios formando angulos rectos com elles.

$\mathrm{Na}$ forma conferta Hcks. que cresce especial ou talvez exclusivamente (Johnston 1847. I. c.) em algas, os zoécios acham-se agrupados mais densamente, formando até crostas coherentes de individuos contiguos. Pó- 
dem sahir de taes aggregações linhas de zoécios uniseriaes em forma de raios, que por sua vez pódem confundir-se por ramos transversaes.

Conforme a densidade da associação dos zoécios, varia a configuração d'elles: nas successões uniseriaes são pedunculados, nitidamente differenciados em pedunculo proximal tubuliforme e porção distal, oviforme que contem - polypidio. Nos conjunctos mais coherentes, os pedunculos são curtos ou mesmo ausentes, assumindo os zoécios feição fusiforme ou pyriforme. A parede frontal é lisa ou finamente sulcada transversalmente. Além d'isso, póde ser dotada de quilha ("carina") média longitudinal, que se estende nos zoécios pedunculados tambem sobre o tubulo proximal (forma c.a rina ta Norm.). Na forma patagonica Bsk. as paredes são grossas e os sulcos ligeiros das outras formas se acham substituidos por verdadeira annelação.

O orificio zoécial é orbicular, com excepção da margem proximal, recta, que é provida de um seio ("sinus") central. Este falta nos individuos femininos (Fig. 10, $q$ ) e na ancestrula (a). A ancestrula póde, como mostram as figuras citadas de Jullien (1888), apresentar aspecto differente da Fig. 10, a saber, possuir campo de abertura orbicular, circumdado por espinhos. Onde apparece um tuberculo sub-orificial na parede frontal, como nos dois zoécios superiores do lado esquerdo da Fig. 10, esta saliencia esconde o seio orificial. A parede frontal tem, segundo Levinsen (1909, p. 274-275), caracter de gymnocysta desprovida de qualquer membrana de cobertura.

Avicularias faltam. Das camaras de póros, visiveis sem preparação especial nos dois lados dos zoécios, originam-se tubos de communicação interzoéciaes. Os individuos femininos, ás vezes um pouco menores que os auto.. zoécios communs, em outros casos (p.e. na forma conferta Hcks.) de tamanho igual, possuem volumosos oécios globosos, que pódem ser providos frontalmente de uma gibba oblonga disposta central ou mais proximalmente. Ás vezes a gibba faz parte de uma costella longitudinal (O'Donoghue 1926).

Recife, barra de Serinhaem; em algas do mar raso.

Apesar de ter sido confundida a especie, talvez occasionalmente, com $H$ distans P H. MacG. I= flagellum Manz., Marcus 1937a. p. 2|3), como foi indicado por Hincks (1880) e Levinsen (19|4), ella deve ser considerada como cosmopolita. A var. a r ctica separada por Kluge (1906, p. 39) nãc foi mercicialada particularmente por Borg (1933). A synonymia acima compilada não pretende ser completa, mas visa apenas completar a lista das citações já existentes e assim justificar a indicação zoogeographica no seguinte. Das figuras de Jullien (1888) colloquei anteriormente (Marcus 1937, p. 79) t. 4 f. I-4 na synonymia de $H$ hyalina (L.), approveitando agora da opportunidade para corrigir essa indicação. Sómente a fig. I refere-se á $H$ hyalina (L.), ao passo que 2-4 devem ser reunidas com $H$ 
divaricata Lmx. H. I a n ceolata Gray 183 I foi incluida na synonymia da especie actual em virtude da opinião de summa autoridade contemporanea, G. Johnston (1847, p. 292). H longica uda Fischer (1870, p. 349), considerada por Hincks (1880, p. 288) e Jelly 1889, p. 112) como synonymo de $H$ divaricata Lmx., é, segundo Jullien \& Calvet (1903, p. 86), A etea recta Hcks., i. é, A sica (Couch), desprovida da porção erecta do cystidio.

Distribuição geographica: Cosmopolita, da região arctica até a antarctica. Da zona das marés até $1.829 \mathrm{~m}$ de profundidade.

\title{
Pasythea tulipifera (Ell. Sol.) (Est. VIII - Fig. 11A, C; Est. IX - Fig. 11B).
}

\author{
Cellaria tulipifera Ellis \& Solander 1786, p. 27-28 t. 5 f. a, A. \\ Sertularia tulipifiera Linné-Gmelin 1791, p. 3862 n. 72. \\ Pasythea tulipifera Lamouroux 1816, p. 156 t. 3 f. 7. a. \\ Liriozoa caribaea Lamarck 1816, p. 133, n. 1. \\ Pasythea tulipifera Lamouroux 182I, p. 9 †. 5 f. a, A. \\ Pasythea tulipifera Lamouroux 1824, p. 67 t. 3 f. 7a. \\ Tuliparia tulipifera de Blainville 1834, p. 485 t. 83 f. I. \\ Pasythea tulipifera Busk 1884, p. 5. \\ Pasythea tulipifera Marcus 1938, p. 37 t. 9 f. 20.
}

Material mais rico d'esta rara especie foi agora encontrado crescido no tubo vazio de um verme (Polychaeta), possibilitando completar as diagnoses anteriores quanto aos caracteres zoariaes e zoeciaes. A base commum da colonia é formada por um estolão chato, ligeiramente calcificado e irregularmente ondulado, como foi desenhado na bôa figura original. D'ahi sahem, com articulações chitinicas, os ramos, em que os zoécios se originam. Como já foi indicado por Hincks (188 I p. 157), os primeiros ou infimos segmentos, que compõem os ramos, frequentemente são desprovidos de zoécios. No material de Hincks os segmentos são mais grossos que nas colonias presentes. Estas mostram, além disso, ramificações lateraes dos segmentos, não mencionadas por Ellis \& Solander e Hincks. Taes ramos lateraes sahem com base chitinica, mas, sem camara especial do respectivo segmento, proximalmente da origem das duas triades de zoécios. As triades originam-se em camaras proeminentes em que são implantadas por meio de um tubo chitinico.

Os zoécios do material presente mostram frequentemente o curto espinho apical, notado por Hincks e ausente na nossa primeira triade descripta anteriormente (Marcus 1938, p. 37). O operculo, que lembra o de Catenicella contei é provido de esclerito marginal, inserindo os musculos occlusores no terço distal. O poster menos fortemente chitinizado fecha a abertura (a chamada vanna) do espaçoso sacco compensatorio. O orificio. 
total dos zoécios nas nossas colonias é maior em comparação com as outras dimensões zoeciaes que no material de Hincks. Os póros dos zoécios são côniformes e irregularmente dispostos. Os zoécios são revestidos por uma epitheca.

No mar raso do litoral da ilha de Santo Amaro, perto de Santos.

Quanto ao anno $(18 \mid 6)$ da publicação tanto de $\mathrm{P}$ a sythe a Lamouroux como de Liriozoa Lamarck as indicações de Canu \& Bassler (1928, p. 150) e de Bassler (1935, p. 140, 164; 1936, p. 161 sob Gemelliporina) variam, até na mesma pagina (Canu \& Bassler 1929, p. 436). Para evitar discussões futuras seja assim lembrada a exposição de Busk $(1884$, p. 5) e mantido o nome do genero no sentido d'elle.

Escharina krampi Marc. (Est. IX - Fig. 12A-B).

Escharina krampi Marcus 1937 a, p. 216 fig. 17 A-C.

A colonias são prateadas ou cinzentas, no material aqui em mão algum tanto vitreas, transparecendo os polypidios de verde claro atravez das paredes frontaes mediocremente calcificadas. Os zoarios incrustam com uma camada substratos solidos, sendo os zoécios de configuração approximadamente rectangular ou arredondados. A esculptura, uniformemente desenvolvida em zoécios e oécios, consiste em covinhas e gibbazinhas, tornando-se as gibbazinhas mais notaveis no material de St. Helena, emquanto que as covinhas são mais nitidas nas colonias presentes, menos intensamente calcificadas. São isentos de esculptura os arredores do orificio e as camaras das avicularias. O orificio, desprovido de espinhos, possúe largo seio proximal, delimitado por dentes suspensores acuminados. Os musculos occlusores inserem no esclerito marginal do operculo que fecha o oécio e se acha concordantemente desenvolvido em autozoécios communs e em zoécios providos de oécios. As avicularias, raras no material presente, são situadas ao lado do orificio ou um pouco mais proximalmente, formando a camara uma proeminencia bastante convexa. A mandibula esbelta, ponteaguda e ligeiramente encurvada, dirige-se para dentro, i.é, em direcção medial. Os oécios volumosos são um pouco mais largos que altos e resaltam frontalmente sem que sejam, porém, nitidamente demarcados da parede do zoécio subjacente, i.é, o zoécio distal. Ilha de São Sebastião (ca. de $100 \mathrm{~km}$. do norte de Santos) em $4 \mathrm{~m}$ de profundidade; bahia de Santos, Guarujá em concha lançada á praia.

Reencontrando essa especie ha pouco descripta pela primeira vez de St. Helena, ilha oceanica muito distante do litoral paulista e de condições 
mesologicas completamente differentes do mar calmo e quente da praia do Sombrio, onde E. krampi agora foi verificada, a classificação tinha de ser rigorosissima. Levou a minha Senhora ao exame dos pormenores anatomicos cujo resultado inesperado foi o descobrimento de uma unica glandula oral tanto no material original como nos especimens de S. Sebastião. E' - primeiro achado de glandula oral impar e especialmente interessante, porque, nas avicularias, a glandula tida por homologa ás oraes sempre é impar.

$47,4 \%$ das especies verificadas de St. Helena foram reencontradas no litoral paulista. Mas, $n$ este calculo, acham-se incluidas especies vastamente distribuidas. Assim a alta porcentagem de especies identicas sem delongas não justificaria conclusões zoogeographicas, precar.as no Atlantico meridional, emquanto se ignora de todo a bryozoofauna da Africa occidental.

Distribuição geographica: St. Helena em ca. de $36 \mathrm{~m}$ e $46 \mathrm{~m}$ de profundidade.

\section{Schizoporella horsti (Osb.) (Est. IX - Fig. 13).}

Schizoporella horsti Osburn 1927, p. 127f. 3-5.

Schizoporella horsti Marcus 1937, p. 87; 1938, p. 39.

Amplo material de colonias viventes de São Sebastião (ca. de $100 \mathrm{~km}$. do norte de Santos) permittiu preparar as estructuras chitinicas, ainda não publicadas. Nota-se agora semelhança consideravel entre o operculo de horsti e o de Smittina signata (Waters 1889, p. 17), novamente figurado por Anna B. Hastings (1932, fig. 12D, E no texto, p. 430). O operculo de horsti é fracamente chitinisado, descrevendo Canu \& Bassler (1929, p. 309) o operculo de Lacerna signata (Wat.), sendo muito tenue e de preparação difficil. O esclerito do material de signa ta do Grande Recife de Barreira (Queenslandia) é contínuo, em horsti de São Sebastião interrupto e os pormenores do esclerito na região do poster differem, se bem que inconsideravelmente. Indicando a autora certa variação quanto á configuração do esclerito, as differenças alludidas tornam-se menos significativas ainda. Além disso, Anna B. Hastings indica variação do peristôma. Deste modo a descripção da situação muito profunda da rimula, i.é do seio orificial, no material das Philippinas (Canu \& Bassler, I. c.), inadequada ao material de S. Sebastião, possivelmente não contem caracter decisivo de separação. Sendo pequeno o augmento usado para as figuras dos especimens das Philippinas (t. $42 \mathrm{f} .10,1 \mathrm{l}$ ), não possibilita juizo definitivo sobre a relação entre horsti e signata Os zoécios do nosso material de horsti são um pouco maiores. As medidas do orificio são differentes em signata (material das Philippinas e da Queenslandia) e horsti sendo 
as de horsti nitidamente maiores. Além disso, são iguaes a longura (direcção proximo-distal) e a largura (direcção dextro-sinistral) do operculo de signata ao passo que em horsti a longura é maior que a largura.

Figura especial da mandibula de signata não existe; a de Waters (1889, t. 3 f. 5) é semelhante á avicularia de horsti Na photographia (t. 42 f. 10) do material das Philippinas, as avicularias acham-se irregularmente retocadas, o zoécio proveniente do Grande Recife (Hastings 1932, fig. I2E no textol possúe mandibula da avicularia de largura igual em toda a sua extensao e arredondada na ponta. Em horsti, a mandibula estreita-se algum tanto para a ponta distal. Se bem que este caracter, as medidas do orificio e as do operculo não recommendem sem delongas unir signata e horsti não se póde negar que a especie do Indico e Pacifico occidental e a do Atlantico occidental, ambas até agora somente encontradas nas aguas quentes, sejam muito vizinhas. Em todo o caso, deveriam ser collocadas no mesmo genero. $\bigcirc$ operculo não é do typo schizoporelloide, mas, tão pouco, é smittinoide. Não sómente a ausencia de lyrula, que já na diagnose original causou difficuldade a Waters quanto á posição generica de sign a ía (1889, p. 18), mas, tambem o operculo, ao meu vêr, obsta á collocação das duas especies na familia Smittinidae. Ali se encontra, por via de regra, direito o bordo proximal do operculo, não havendo commummente valvula especial que feche o poster. Abstraindo da tenuidade do operculo e do seu esclerito, as duas especies melhor poderiam entrar num genero das Escharellidae do grupo Schizoporellae (Canu \& Bassler 1920, p. 335). Sendo os operculos dos zoécios ordinarios os mesmos como nos zoécios providos de oécios - gen. Schizomavella (Canu \& Bassler 1917 p. 40; 1920, p. 353; Hastings 1932, p. 4I5) não se presta para abranger horsti e signata.

Canu \& Bassler (1929, p. 308) collocaram signata no genero $L$ a cerna Jull., e Sakakura (1935, p. 22) adoptou esta systematisação. As especies recentes de La cerna (Canu \& Bassler 1920, p. 346), porém, são todas muito differentes de signata e horsti p.e., são desprovidas de avicularias. Em L hosteensis (Jullien 1888, p. 48), genotypo de La cerin a a communicação entre os zoécios realiza-se por camaras de póros. Dos outros generos das Escharellidae, sómente $\mathrm{Schizoporella} \mathrm{Hincks}$ entra em questão, occorrendo em $S$ elmwoodiae (Waters 1900, p. 66) esclerito de inserção dos occlusores, distante do bordo do operculo.

\section{Gemelliporina glabra (Smitt) (Est. IX - Fig. 14A, B).}

Gemellipora glabra Smitt 1873, p. 37 t. If f. 208-210 (non f. 207).

Gemellipora glabra Busk 1884, p. 176 t. 25 f. 3.

Gemellipora glabra Canu \& Bassler 1928, p. 98 f. 16 t. 12 f. $1-7$ 
As colonias esbranquiçadas ou amarelladas são erectas e cylindricas. Crescem no material actual em $\mathrm{S}$ argassum sempre nos angulos entre o eixo principal e os ramos lateraes do thallo plumoso da Fucacea. Na literałura anterior não houve menção de substratos de $G$ glabra $A$ ancestrula é um zoécio do typo commum, muito pequeno, mas, no restante sem caracteres especiaes. Ella acha-se circumdada por outros zoécios incrustantes, que formam uma base irregularmente estrellaria, com o avanço da idade disciforme, da qual se ergue a arvorezinha escassa e dichotomicamente ramificada da colonia. O material de Busk mostra ramificação irregular. Tanto a haste principal como os ramos lateraes possúem igual diametro de ca. de I mm. No côrte transversal encontram-se em toda a parte ca. de 6 zoécios dispostos com ligeira alternação. Os zoécios jovens são volumosos e garrafaes, sendo a parede frontal provida de uma esculptura martellada e de alguns. póros marginaes. Além disso acha-se coberta por fina ectocysta chitinica (epitheca, Marcus 1937. p. 11). Pela calcificação progressiva desapparecem os limites interzoéciaes, de maneira que se torna lisa e grossa a superficie colonial, perfurada sómente pelos orificios zoéciaes. $\bigcirc$ orificio assemelha-se a um buraco de chave e é circumdado por bordo liso e algo saliente, que representa um fraco peristôma. Distal e lateralmente o peristôma é guarnecido de 4-6 espinhos curtos, que são ôcos e na ponta frequentemente um pouco encurvados. Originam-se em bases chitinicas. $\bigcirc$ operculo amarello, por ser fortemente chitinisado, possúe bordo reforçado no anter e nos dois. lados do poster, ficando mais fraco o bordo central do poster. Os musculos. occlusores inserem-se em escleritos rectos.

As avicularias de mandibulas quasi orbiculares e dirigidas proximalmente, occupam no material original o centro da parede frontal dos zoécios; nas colonias presentes a sua posição regular é inter-zoécial e obliqua. As camaras das avicularias da zona de gemmação teem forma de barrilzinho, desapparecendo, porém, a sua convexidade conforme a idade, quando a espessura crescendo das paredes aplaina a superficie.

Os oécios, ausentes no material actual, são salientes e providos de póros (Canu \& Bassler). A cobertura calcarea ulterior deixa livre apenas uma centraí janella circular, pela qual se vê o endo-oécio liso.

Recife, barra de Serinhaem, em mar raso.

Tendo Anna B. Hastings (1932, p. 415) esclarecido que $G$ e mel lipora Smitt tem de ser ligada a $G$ eburnea Smitt 1873, p. 35), cuer entrasse na synonymia de $\mathrm{P}$ as y the a Lmx. (Busk 1884, p. 5), quer fosse mantida como genero independente, foi indispensavel a introducção de 
um novo nome para o genero representado pela especie actual (Bassler 1936, p. |61).

A distribuição actualmente conhecida é restricta, mas, ainda descontínua; os lugares de occorrencia no golfo do Mexico são situados todos perto da Florida. A indicação "John Adams Bank" segundo Harmer (1900, p. 254-255) refere-se ao Banco de Victoria, ao sul das ilhas Abrolhos.

Distribuição geographica: Costa brasileira: Estado do Espirito Santo e Bahia; golfo do Mexico, Florida. Em profundidades entre 18 e 102 metros.

\title{
Mastigophora pes-anseris (Smitt) (Est. X - Fig. 15A-C).
}

\author{
Hippothoa pes anseris Smitt 1873, p. 42 t. 7 f. 159-160. \\ Escharina pesanseris Osburn 1914, p. 207. \\ Mastigophora pesanseris Canu \& Bassler 1923, p. 172 t. 45 f. 10. \\ Mastigophora pesanseris Osburn 1927, p. 130. \\ Mastigophora pesanseris Canu \& Bassler 1928. p. 133 t. 21 f. 9, t. 34 f. 4. \\ Mastigophora pes anseris Canu \& Bassler 1928a, p. 96 t. 9 f. I \\ Mastigophora pes-anseris Hastings 1930, p. 722. \\ Matsigohora(err. pro Mastigophora) pesangelis (err. pro pesanseris) Sakakura \\ 1935, p. 31. \\ Mastigophora pes anseris Marcus 1937a, p. 219 f. 19.
}

As colonias quasi sempre pequenas e compostas por uma unica camada de zoécios, incrustam algas molles e calcareas, Bryozoa, conchas, pedras e outros substratos. São brancas quando conservadas, excepto uma indicação de especime verde (Canu \& Bassler 1928, 1.c.). Os zoécios são ovaes largos ou polygonos, ligeiramente convexos e dotados de parede frontal lisa (Smitt 1873, I.c.) ou finamente porosa. No material actual e no de St. Helena (Marcus 1937a, I.c.), os póros são simples, tendo descripto Levinsen (1909, p. 326), em colonias siamezas e outra de procedencia ignota, póros estrellados, quer dizer, póros providos de rede minuscula formada por bastonetes calcareos, cuja calcificação contínua resulta em confluencia e d'este modo em obturação do póro. A parede frontal póde ser coberta por camada calcarea secundaria dotada, como a primeira, de póros finos.

O orificio é quasi orbicular, excepto o seio proximal longo e dilatado na extremidade. Os dentes suspensores que estreitam o orificio foram descriptos por Smitt (1873, p. 43-44) como sendo denteados (f. 160), falando Levinsen (1909, p. 327) tambem em dentes cujos bordos são finamente recortados em pontas. No material actual, como nas colonias de St. Helena (Marcus 1937 a f. 19), os dentes supensores são practicamente lisos, de modo que 
esse caracter evidentemente varia. O operculo é bem chitinisado, inserindo os musculos occlusores lateralmente dentro do proprio bordo opercular, sendo a listra de inserção muito pouco saliente e curta. O seio do orificio é um tanto mais largo que o poster do operculo, notando-se no bordo proximal do anter duas pequenas pontas lateraes. Por baixo do operculo se faz ver arco vestibular calcareo, que orla o vestibulo, i. é, o trecho entre parede frontal e bainha tentacular. A certa distancia do orificio ergue-se baixo peristôma de bordos agudos distal e lateralmente nos zoécios estereis, provido de espinhos que pódem ser um pouco dilatados para cima. O numero dos espinhos varia de 4-8, havendo nos individuos estereis geralmente 7. nos ovicelligeros 6 .

Os heterozoécios dispostos nos dois lados do orificio possúem camara oval, saliente, cujo campo de abertura se acha subdividido por vara calcarea transversal ("cross-bar' "pivot"). Como se vê do lado basal da colonia, a cavidade da camara do heterozoécio tem ampla connexão aberta com a cavidade do autozoécio em que a musculatura poderosa do operculo transformado do heterozoécio entra. A configuração geral d'este operculo transformado e a base delle (Waters 1899, p. 12) lembram mais a mandibula da! avicularias que a cerda (flagello, "saeta") da vibracula, ao passo que o fact. de sobresahir o operculo transformado da area opercular da camara poder.a levar a denominar o heterozoécio da especie presente de vibracula (Levinsen 1909 , p. 46). No material actual faltam, como muitas vezes, os operculos heterozoéciaes; quando normalmente desenvolvidos (Fig. $15 \mathrm{C}$ ), parecem-se de certo modo com os pés das Anatidae (patos e gansos). A camara é chanfrada na ponta da região opercular conforme a base forte do operculo. transformado.

Dos oécios salienta-se sómente a metade frontal, coberta por pequena cupola calcarea lisa, frequentemente connexa com o peristôma. Mesmo nas. pequenas colonias que da especie actual, por via de regra, foram encontradas, os oécios são numerosos, havendo p.e. 12 no zoario aqui em mão. composto por 26 autozoécios. O operculo do zoécio não fecha o oécio. cujo orificio se acha situado acima do bordo distal do operculo zoécial.

A ancestrula é um autozoécio algo menor que os outros zoécios e geralmente sem heterozoécios, mas, aliás, normal e provida de 7 espinhos orificiaes.

Iha de S. Sebastião, ca. de $100 \mathrm{~km}$. do norte de Santos e Itapema lestada de S. Catharina), cada vez em Lyropecten nodosus (Coll. Lange de Morretes); ca. de 15-20 m de profundidade.

O operculo e a camara do heterozoécio, desprovida da chanfradura distal (Levinsen 1909, t. 18 f. 2a, 2c), distinguem M. dutertrei (Aud.). 
em aguas brasileiras (Fernando Noronha) indicada por Kirkpatrick (1888a, p. 504), de M. pes anseris. M. parviseta (Canu \& Bassler 1928a, p. 98), descripta tambem da costa do Brasil, possúe operculo do heterozoécio em forma de cerda, de modo que se distingue da especie actual. Quanto ás relações entre M. parviseta e M. dutertrei (Aud.), abstenho-me de formular opinião definitiva, aguardando a opportunidade de encontrar material. M. scopae da região bahiana parece bem caracterisada pela vassoura de espinhos orificiaes (Canu \& Bassler 1928a, p. 97), ao passo que M. porosa (Smitt) do banco de Victoria, Estado do Espirito Santo, considerada por Canu \& Bassler (1928, p. 134; 1928a, p. 93) como sendo especie independente, se approxima muito á $M$. hyndmanni (Johnston 1847. p. 306; Hincks 1880, p. 281).

Das especies de Mastigophora descriptas de outras regiões, considero Schizoporella dutertrei var. foliacea (Robertson 1921, p. 55) como variedade de pes-anseris distincta pela saliencia suborificial, que ás vezes possúe avicularia. M grandicella (Canu \& Bassler 1929, p. 414) mostra dimensões maiores que $M$ pes-anseris mas, duvido da necessidade da sua separação especifica, enunciando Sakakura (I. c.) a mesma opinião. $M$ ho nolule ns is (Canu \& Bassler 1927. p. 37) cuja identidade com a especie de Busk (1884, p. 148), ao meu vêr, não é comprovada pelas descripções e figuras correspondentes, talvez possa ser mantida por causa do peristôma duplo, mas, aliás, é muito parecida com $M$ pes: anseris.

Distribuição geographica: Brasil, Bahia, costas central-americanas atlantica e pacifica (Colombia); Atlantico oriental (Madeira) e central (St. Helena); mar Vermelho; Indico occidental (Providence), central (Ceylão), meridional (Mauritius) e oriental (Sião, Philippinas). Pacifico occidental, Grande Recife de Barreira; ithas de Hawaii. Pleistoceno inferior do Japão. Em profundidades de $14-439 \mathrm{~m}$.

Smittina trispinosa (Johnst.) var. lo.ra Marc. (Est. X--- Fig. 16).

Smittina trispinosa var. loxa Marcus 1937a, p. 225 f. 23C, 24.

As colonias, côr de marfim, ou brancas, formam no material abundante aqui em mão, crostas extensas sobre uma colonia de Schizoporella pungens (Canu \& Bassler), crescida livremente, como foi figurada originalmente (Canu \& Bassler 1928, t. 27 f. 5) e reencontrada na bahia de Santos (Marcus 1937. p. 86). Os zoécios acham-se dispostos em geral assáz regularmente em series longitudinaes, sendo a parede frontal ora lisa, ora 
granulosa ou provida de pequenas gibbas. No material de St. Helena, as margens dos zoécios são guarnecidas com póros e as listras separadoras dos zoécios são fracas. Nas colonias de Santos, os póros marginaes tornam-se areolas de dimensões consideraveis e as listras interzoéciaes são bem salientes. No bordo superior do orificio 2 espinhos, ou raramente até 4, pódem apparecer; no material actual são raros. $O$ peristôma resalta-se nos dois lados do orificio á maneira de um collarinho de pontas triangulares, visiveis especialmente em vista obliqua. Proximalmente a chanfradura larga do peristôma deixa vêr a lyrula estreita e alta e os dois dentes suspensores. As medidas médias do operculo são $97 \mu$ de largura, $83 \mu$ de altura, variando a largura entre 87 e $101 \mu$, a altura entre 76 e $87 \mu$.

No material original ha uma pequena avicularia situada obliqua e unilateralmente no peristôma, dirigindo-se a esbelta mandibula ponteaguda para o lado distal. Os zoécios de Santos mais ricos em avicularias mostram variação maior quanto á disposição, á direcção e ao numero das avicularias. Além das avicularias de mandibula triangular, das quaes até 4 pódem apparecer em um unico zoécio, occorrem avicularias compridas, cuja mandibula espatulada se dirige obliquamente para cima.

O material de Santos, collecionado no inicio de outubro, portanto, na primavera, acha-se completamente desprovido de oécios. Estes apresentam-se no material original providos de póros irregulares, mais numerosos que na typica S. trispinosa (Johnst.). A cobertura calcarea oecial salienta-se ás vezes frontalmente no bordo proximal do oécio.

Bahia de Santos, no mar muito raso.

Apesar das divergencias alludidas entre o material de St. Helena e da bahia de Santos, a identidade systematica, baseada nos caracteres do orificio, do peristôma e das medidas do operculo e dos zoécios, ao meu vêr, está fóra de qualquer duvida. Quanto ao numero das avicularias ad-orificiaes e á transformação de uma d'estas em avicularia de mandibula espatulada, o material de Santos approxima-se á Smittina tripora'(Canu \& Bassler 1929, p. 350), que deveria ser denominada novamente, em virtude da pre-occupação do nome especifico (Waters 1904, p. 67; Livingstone 1928 , p. 63). S. tripora C. \& B. possúe lyrula larga e baixa, em opposição á estreita e alta da var. I ox a. Os zoécios de S. tripora C. \& B. teem longura de 500-850 $\mu$, medindo os da var. Ioxa geralmente menos que $500 \mu$. Em essas especies da parentela de Smittina trispinosa (Johnst.), as medidas dos zoécios e dos orificios são taxonomicamente significantes.

A occorrencia na bahia de Santos da var. I o xa, primeiramente encontrada na costa de St. Helena, enquadra-se bem no facto resultante das 
nossas pesquisas, de uma semelhança evidente das duas bryozoofaunas. Das 38 especies registradas de St. Helena 18 ou $47,4 \%$ já se acham verificadas no litoral paulista.

Distribuição geographica: St. Helena, $36-75 \mathrm{~m}$ de profundidade.

\section{Microporella ciliata (Pall.) var coronata (Aud.) (Est. X - Fig. 17).}

Material da costa pacifica norte-americana, que devo ao Snr. Lange de Morretes, possibilita estabelecer até certo ponto a synonymia intricada d'esta forma. Corresponde o material actual perfeitamente á diagnose de Lepralia californica Busk (1856, p. 310), cujas avicularias são situadas acima do ascoporo ou ao mesmo nivel com elle. Occorre igualmente a saliencia frontal, descripta por Busk, pela qual se produz a posição horizontal do ascoporo. Gibba nos oécios e saliencia zoecial modificam o aspecto consideravelmente, não obstante se tratar de $M$. ciliata var. coronata, que tenho em mão, de Santos (Marcus 1937, p. 113) e St. Helena (Marcus 1937a, p. 113), de maneira que a região de Vancouver tem de ser incluida na resenha geographica da variedade presente. Zoogeographicamente, isto não corresponde muito bem ao caracter faunistico da região de Vancouver, relativamente pobre em elementos tropicaes e subtropicaes (Ekman 1935, p. 215 e seg.).

O material da California, descripto por Hincks (1880, p. 209, nota, fig. 9 no texto p. 2(0), possúe ascoporo redondo occupado por placa crivada. Além d'isto os oécios são descriptos como sendo grandes, o que não corresponde perfeitamente á M. ciliata var. coronata, cujos oécios geralmente são menores em proporção aos autozoécios que os da typica M. ciliata. Mais ainda se afaste M. ciliata var. californica das ilhas da Queen Charlotte (Hincks 1883, p. 444 t. 17 f. 3) da especie actual pela esculptura do oécio e a posição proximal das avicularias.

Microporella californica (Robertson 1908, p. 28I) possúe o ascoporo occupado por placa crivada, descripto por Hincks (1880) do material da California, e as duas avicularias na mesma posição proximal como os especimes das ilhas da Queen Charlotte. A synonymia indicada pola autora norte-americana faz vêr que considera as especies de Busk e Hincks identicas com a sua. Como Waters (1909, p. 143), ainda não posso corivencer-me d'isso, nomeadamente por causa do ascoporo crivado. A pissibilidade de se approximar ascoporo semilunar orlado por denticulos, como occorre em M. ciliata (Pall.), pela calcificação progressiva ao typo de 
californica (Hincks 1880, Robertson 1908), não se póde negar, mas, por emquanto, não vi tal transformação. Tambem Waters (1887a, p. 188) alludiu em ascoporo crivado como sendo caracter especial.

Canu \& Bassler (1923, p. 123) reunem as especies de Busk (1856). Hincks (1883) e Robertson (1908) e escrevem M californica Hincks, embora mencionem Busk no primeiro lugar na lista de synonymia.

O'Donoghue escreve primeiramente (1923, p. 174) "M. californica Busk" accentuando a relação estreita com a var californica de Hincks (1883) e a especie de Robertson; mais tarde refere-se ao material de Hincks e Robertson e escreve Microporella californica Hincks" (O'Donoghue 1925, p. 103) e finalmente (O'Donoghue 1926, p. III) denomina o seu material M. californica (Hincks)" Provindo o material de O'Donoghue em parte da mesma localidade como o actual, a reunião das especies de Hincks (1880, 1883) e de Robertson (1908) com M. cili a ta (Pall.) var. coronata (Aud.) torna-se algo mais verosimil do que pensei anteriormente (Marcus 1937. p. 114). M. tractabilis (Canu \& Bassler 1930, p. 22), das ilhas dos Galapagos, ao meu vêr, entra na synonymia de M. ciliata (Pall.) var. coronata (Aud.).

Região de Vancouver, San Juan islands (State of Washington, U. S. A.) em Murex foliatus (Martyn) (Coll. Lange de Morretes).

Distribuição geographica: veja Marcus 1937. p. 115.

Adeona violacea (Johnst.) (Est. X - Fig. 18).

Lepralia violacea Johnston 1847, p. 325 t. 57 f. 9.

Lepralia violacea Busk 1854, p. 69 t. 87 f. 1-2.

Lepralia violacea Busk 1859, p. 43 t. 4 f. 3 a, b.

Lepralia plagiopora Busk 1859, p. 44 t. 4 f. 5 a, b.

Lepralia violacea Heller 1867, p. 103.

Porina violacea Fischer 1870, p. 348.

Porina violacea Smitt 1873, p. 30.

Porina plagiopora Smitt 1873, p. 30 t. 6 f. 134-135.

Lepralia violacea Joliet 1877, p. 98.

Lepralia violacea Waters 1879, p. 34.

Microporella violacea Hincks 1880, p. 216 t. 30 f. I-4.

Reptadeonella violacea Busk 1884, p. 179, 180.

Microporella violacea Lomas 1886, p. 175.

Microporella violacea form plagiopora Hincks 1887, p. 131 .

Microporella violacea Waters 1887 a, p. 188.

Microporella violacea Kirkpatrick 1888a, p. 504.

Microporella heckeli Jelly 1889, p. 184.

Microporella violacea Whitelegge 1889, p. 286.

Microporella violacea var. plagiopora Kirkpatrick 1890, p. 16. 
Microporella Heckeli Calvet 1900, p. 150, 168 etc. t. 7 f. I. t. 8 f. 15.

Adeonellopsis violacea var. plagiopora Philipps 1900, p. 440.

Microporella Heckeli Calvet 1902, p. 39.

Microporella Heckeli Calvet 1902a, p. 20

Reptadeonella violacea Norman 1903, p. 104.

Adeonella insidiosa Jullien \& Calvet 1903, p. 54 t. 6 f. 4.

Microporella violacea Canu 1904, p. 21 t. 34 f. 25-26.

Microporella Heckeli Waters 1905, p. II.

Microporella violacea form plagiopora Thornely 1905, p. 112.

Microporella Heckeli Calvet 1907, p. 404.

Adeona insidiosa Calvet 1907, p. 408.

Microporella violacea form plagiopora Thornely 1907, p. 188.

Reptadeonella violacea Norman 1909, p. 296.

Adeona violacea Levinsen 1909, p. 283 t. 14 f. Ia-lg.

Reptadeonella violacea Nichols 1911, p. 19.

Adeonella insidiosa Barroso 1912, p. 30.

Microporella Heckeli Barroso 1912, p. 62.

Adeona violacea Osburn 1914, p. 199.

Microporella Heckeli Barroso 1915, p. 4I5.

Adeona violacea \& var. insidiosa Friedl 1917, p. 239.

Adeona Heckeli Barroso 1917, p. 498.

Adeona violacea Canu \& Bassler 1920, f. 164 F (p. 554), f. 167 (p. 560;.

Adeona heckeli Canu \& Bassler 1920, p. 560.

Adeona Heckeli Cipolla 1921, p. 136 t. 7 f. 16.

Adeonella insidiosa Cipolla 1921, p. 138 t. 7 f. 13.

Adeona heckeli Canu \& Bassler 1923, p. 158 t. 24 f. $1-2$.

Microporella violacea Prenant \& Teissier 1924, p. 14.

Adeona Heckeli Canu \& Bassler 1925, p. 50.

Adeona insidiosa Canu \& Bassler 1925, p. 51.

Microporella Heckeli Calvet 1927, p. 14.

Microporella Heckeli Calvet 1927a, p. 4.

Microporella Heckeli Calvet 1928, p. 7.

Adeona plagiopora Canu \& Bassler 1928, p. 126 †. 23 f. 4.5.

Adeona Heckeli Canu \& Bassler 1928a, p. 93, t. 8 f. 5-6.

Microporella violacea Frattarelli 1929, p. 385.

Adeona violacea Hastings 1930, p. 728.

Adeona heckeli Canu \& Bassler 1930a, p. 66 t. 8 f. 14-17

Adeona Heckeli Calvet 1931, p. 110.

Adeona insidiosa Calvet 1931, p. 110.

Adeonella Heckeli Canu 1931, p. 8.

Microporella violacea Prenant 1931, p. 2, 5.

Microporella Heckeli Neviani 1939, p. 38.

As colonias formam crostas sobre varios substratos, geralmente solidos, p. e., algas calcareas, Cnidaria (coraes, Gorgonaria), Bryozoa, tubos de Polychaeta sesseis, conchas, pedras etc. Pódem tambem chegar a um crescimento de expansões livres, compostas em geral por uma camada de zoécios, que, por via de regra, tambem forma as crostas. A côr das co- 
lonias vivas varia de purpura escura quasi preta, violeta e carmim até cor de creme. Material morto e conservado perde a côr, fornando-se branco brilhante por se desfazer a membrana (epitheca) preta iridescente que reveste o esqueleto.

Os zoécios dispostos em quinconcio são chatos ou salientes distalmente (var. plagiopora), variando a sua forma, que póde ser oval, rhombica, ou oblonga - polygonal. São ás vezes circumdados por largas listras marginaes e geralmente delimitados por numerosos póros dispostos nos bordos zoeciaes. Entre os póros encontram-se listras ou gibbas, podendo os póros desapparecer com calcificação progressiva. Nos angulos entre os zoécios notam-se, ás vezes, nomeadamente na var. insidiosa, kenozoécios tubuliformes, frontalmente cobertos por membrana. A parede basal dos zoécios é fracamente calcificada, firmemente adherente ao substrato, indicando-se as communicações inter-zoeciaes por radioso desenho diversicolor. Estas communicações compõem-se de 14-16 placas em roseta uniporosas (septulas), situadas na metade distal de cada zoécio, ás quaes correspondem outros tantos buracos na metade proximal.

No centro da parede frontal ou um pouco mais proximalmente encontra-se o grande orificio do sacco compensatorio (ascóporo). Normalmente occorre um unico arredondado ou oval, mas, ha tambem dois (var. insidiosal ascóporos ou um semilunar. O lugar do ascóporo acha-se marcado por ligeira depressão da parede frontal que é lisa ou finamente granulosa.

O orificio primario do zoécio é semicircular, ligeiramente convexo no bordo proximal e desprovido de dentes suspensores. Com excepção de estreita orla marginal mais fortemente chitinisada, é membranoso o operculo. Em zoécios velhos nota-se na região distal do operculo um ovalo de chitina grossa. O peristôma estreito e alto cinge o orificio de todos os lados; o orificio secundario é mais largo que alto e provido de bordo proximal quasi recto. A ancestrula é um menor autozoécio normal.

$\mathrm{Na}$ linha mediana da parede frontal está situada distalmente do ascóporo a grande avicularia de mandibula triangular, ponte-aguda, cuja camara se encosta ao peristôma. A mandibula é um tanto encurvada lateralmente, dirigindo-se, porém, principalmente para cima. A avicularia póde ser substituida por kenozoécio tubuloso, ás vezes intumescido. Na var. pla giopora ha avicularia obliqua entre ascóporo e orificio. Como nas outras especies da familia Adeonidae, falta tambem na presente vara calcarea transversal ("cross bar") no campo de abertura da avicularia.

Os gonozoécios singulares ou dispostos em grupos teem approximada. mente duplo tamanho dos autozoécios e póros marginaes mais numerosos. Possúem dois, e mais (Nichols 1911, I. c.) ascóporos confluentes e orificio 
largo, chato, transversalmente oval. Muitas vezes a avicularia dos gonozoécios é substituida pelo kenozoécio, acima descripto.

Ilha de S. Sebastião, ca. de $100 \mathrm{~km}$. do norte de Santos, em Ly ro pe cte n nodosus (L.); (Coll. Lange de Morretes); ca. de $15-20 \mathrm{~m}$ de profundidade.

A lista dos synonymos dada no precedente, embora incompleta, nomeadamente quanto á litteratura paleontologica, todavia, possibilitará justificar a seguinte indicação da distribuição da especie. Quanto ao nome generico, a lista permitte vêr que entre os especialistas predomina desde Levinsen (1909) a systematisação :ntroduzida por elle, ao passo que está longe de reinar unanimidade acerca do nome especifico. Resulta isso da indicação erronea do catalogo de Jelly (1889, p. 184), que deu 1849 como data em que foi publicada a especie de Johnston. Acha-se isto em contradicção com a sua propria bibliographia (Jelly 1889, p. 278), com o catalogo de Nickles \& Bassler $(1900$, p. 504,598$)$ e as listas de Harmer (1915, p. 171) e da Snra. Hastings (1930, p. 735; 1932, p. 452). O exemplar da 2. a edição da "History of the British Zoophytes" que tenho em mão, igualmente mostra a data 1847, no frontispicio tanto do $1 .^{\circ}$ como do $2 .^{\circ}$ volume. Sendo o prefacio datado de 6 de abril de 1847 e tendo, segundo Friedl (1917, p. 239), o trabalho de Reuss (1847), em que foi publicada Cellepora Heckeli, sahido em 29 de maio, a prioridade de Johnston é fóra de duvida. Canu \& Bassler $(1923$, I. c.) iniciam a sua lista dos synonymos de Adeon a heckeli, como escrevem, com outro nome ainda, usado por Lonsdale (1845) para material fossil, americano. A publicação respectiva não tenho em mão, mas, acho podemos sem delongas negligenciar esse nome, não respeitado pelos proprios Canu \& Bassler. Senão acompanhada por figura indubitavel, diagnose de material fossil por via de regra não tem as qualidades necessarias para servir como base da denominação de uma especie recente.

Tendo Osburn (1914) encontrado colonias, cujos zoécios possúem avicularias dispostas de modo intermediario entre a posição de violacea e plagiopora, mesmo material uniformemente de um ou outro typo. (Canu \& Bassler 1928) deveria ser denominado A. violace a (Johnston). Ao meu ver, é recommendavel proceder como a Snra. Hastings (1930) e collocar A. plagiopora directamente na synonymia de A. violacea.

A var. a de Hincks (1880, p. $216-217$ t. 30 f. 3) parece á primeira vista merecer gráo de especie independente (insidiosa Jull. Calv.). nomeadamente em virtude do ascóporo duplo. Levinsen (1909, p. 284), porém, verificou a coalescencia de dois ascóporos nos gonozoécios de especimes providos de úm unico ascóporo nos autozoécios e encontrou os. 
kenozoécios tubiformes, descriptos de insidiosa, tambem em violac e a que era com respeito aos outros caracteres typica. A incorporação de A. insidiosa em A. violacea, realizada por Levinsen, foi impugnada por Waters (1912, p. 494) e Calvet (1931, p. III). Mas, Waters deixa de motivar a sua opinião contraria á de Levinsen, e a unica differença notada por Calvet não existe. Disse ser A. insidios a exclusivamente atlantica, faltando no mar Mediterraneo, onde A. violacea é commum. Friedl (1917. I. c.), porém, menciona entre os Bryozoa da Adria tambem a var. insidiosa. Por isso, prosigo mantendo a synonymia estabelecida por Levinsen; mesmo a separação em nada modificaria a resenha geographica.

Esta abrange aqui tambem a Australia, mas, foi, sómente com certa hesitação que inclui Adelaide e Port Jackson. As referencias correspondentes são Hincks (1880, p. 218) e Waters (1887a, I. c.) respectivamente, ambos certamente de alta competencia. O material de Waters foi mais uma vez publicado por Whitelegge $(1889$, I. c.). Por outro lado, não faz menção de A. violace a a ampla litteratura restante sobre os Bryozoa da Australia; falta, p. e., no catalago da Victoria ( $P$ H. MacGillivray 1887) e na lista moderna da bryozoofauna da Queenslandia (Livingstone 1927). Waters (1881, p. 329, t. 15 f. 26 t. 17. f. 73) identifica material terciario australiano com A. fiss a (Hincks 1880a, p. 381 t. 17 f. 4), considerando-a variedade de A. violacea. Os outros trabalhos sobre Bryozoa terciarios da Australia publicados por Waters e citados por Jelly (1889, p. 185) não conteem figuras ou notas morphologicas acerca de A. violacea var. fissa. Esta foi descripta por P. H. MacGillivray (1895, p. 68-69 t. 9 f. 7-11) como especie independente. Seja como fôr, a relação entre a especie do Terciario australiano e a recente do oceano indico, não poderia, ao meu vêr, nem uma, nem outra ser unida com A. violacea, em virtude do ascóporo alongado, presente em A. fissa e A. obliqua.

Distribuição geographica: Brasil, costa dos estados do Espirito Santo e da Bahia, Fernando Noronha; mar caraiba; golfo do Mexico; Florida; Bermudas; costa central-americana pacifica: Mexico (Mazatlan) e Colombia (Gorgona); Atlantico oriental: ilhas do Cabo Verde, Madeira, costas marroquinas atlanticas e mediterraneas. Mar mediterraneo occidental até a costa de Tunes; Adria até o Quarnero e Trieste. Costas atlanticas da França, Belgica, Inglaterra e Irlanda. Oceano indico central e oriental, até - mar sulchinez. Pacifico occidental, ilhas de Loyalty (Lifu). Australia, nas proximidades de Porf Jackson (Sydney) e de Adelaide (South Australia). Em profundidades entre 9 e $261 \mathrm{~m}$. 
Adeona tubulifera (C. \& B.) (Est. XI - Fig. 19A, B).

Adeona tubulifera Canu \& Bassler 1930, p. 34 t. 5 f. 6-9.

As colonias, uni-estratificadas, incrustam algas calcareas e conchas. Os zoécios são alongados, ovaes, rhombicos ou polygonaes, segregados por sulcos distinctos. A parede frontal é convexa e orlada por póros areolares, cujas listras separadoras se prolongam como costellas altas dirigidas radial e centripetalmente. Permanece isenta de costellas uma area estreita, central que é lisa. Ahi se encontra o ascóporo dentro de um campo concavo. O peristôma é alto e tubulado, em zoécios jovens não raramente muito obliquo, mostrando-se mais curto e mais recto com calcificação progressiva. Em todo o caso, offerece o peristôma grosso e liso o caracter que se destaca mais nessa especie. O orificio secundario ("peristomice" de Canu \& Bassler) foi descripto no material original como sendo quasi orbicular, emquanto que a largura $(100-140 \mu)$ dos orificios secundarios do material actual sempre ultrapassa a altura $(70-90 \mu)$. Tal differença, porém, torna-se menos importante, quando se examinar a f. 8 de Canu \& Bassler, que apresenta peristômas especialmente tubiformes, cujos orificios são nitidamente transversaes. No seu bordo proximal o peristôma avança-se frequentemente com uma ponta para dentro do orificio secundario, onde provoca bipartição ligeira.

A camara saliente da avicularia, contigua com o lado frontal do peristôma, possúe abertura oval ou triangular, em geral pequena. As mandibulas faltam no material presente, indicando a ponta do triangulo da aberiura que deviam ser dirigidas recta ou obliquamente para baixo, em contraste com o material original, onde se dirigem para cima. A abertura larga das avicularias nos primeiros zoécios (Fig. 19B) provem da polição post-mortem.

Os gonozoécios muito largos, ausentes nas colonias actuaes, são desprovidos de peristômas e avicularias. O seu orificio primario é semicircular, do bordo proximal recto, não possuindo a parede frontal, porosa, areolação especial nas margens.

Nota-se em duas colonias presentes occorrencia de ancestrula-gemea (Fig. 19B), como não é rara nas Membraniporidae (Marcus 1938, p. 66), mas, pelo que sei, ainda não assignalada na secção dos Cheilostomata Ascophora.

As medidas dos zoécios encontradas por Canu \& Bassler são: 600-700 $\mu$ de comprimento e $440-480 \mu$ de largura, podendo a ultima excepcionalmente attingir até $600 \mu$; os individuos do material presente medem $530-630 \mu$ de longura, $380-410 \mu$ de largura. A relação entre comprimento e largura é, 
portanto, de 1,40: I no material original e de 1,41: I no material presente. A ancestrula tem comprimento de $300 \mu$, largura de $200 \mu$, sendo o orificio. primario de altura de $60 \mu$, de largura de $70 \mu$.

Guaratuba, na costa do estado do Paraná (Brasil); em Crepidula. a cule ata (Gmel.); (Coll. Lange de Morretes).

Não foi possivel classificar as 4 colonias disponiveis de modo inteiramente satisfactorio, porque todas ellas já estavam mortas quando colleccionadas, dando-se o mesmo com o material original. Por outro lado, além de A. tubulifera, não ha, ao que parece, nenhuma outra das numerosas. especies de Adeona, até agora publicadas, merecedora de discriminação comparativa. Como foi dito, a direcção da mandibula involve certa discrepancia entre a especie de Canu \& Bassler e a actual. Varias mandibulas são retocadas nas microphotographias, que acompanham a diagnoseoriginal; todavia, é inverosimil que Canu \& Bassler tivessem deixado desapercebida variabilidade da posição das mandibulas, se tal houvesse occorrido no seu material. Existe, portanto, differença indubitavel entre os especimes. pacificos e os atlaníicos, mas, ao nosso vêr, não sufficiente para justificar separação especifica.

Distribuição geographica: Ilhas dos Galapagos, em profundidade até. $73 \mathrm{~m}$.

Rhynchozoon verruculatum (Smitt) (Est. XI - Fig. 20 A-C).

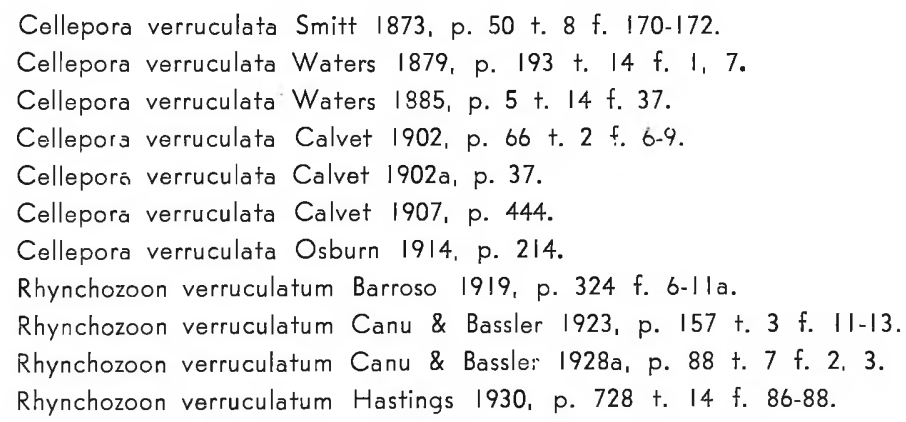

A especie até agora encontrada incrustando algas calcareas, Hydrozoarios a conchas, cresce em comparaçāo com outras especies do genero. Rhynchozoon em disposição relativamente regular. Os elementos fortemente calcificados e por isso brancos, a saber, as esculpturas margi.. 
naes dos zoécios, os peristômas orificiaes, tuberculos e gibbas frontaes e as camaras das avicularias, contrastam com a apparencia geral esverdeada lo material presente) ou azulada (o material de Smitt) da colonia. As listras interzoeciaes das quaes partem costellas radiaes, separadoras das areolas profundas marginaes, desapparecem com $\circ$ progresso da calcificação. Ao mesmo tempo, as areolas tornam-se póros simples, não mais separados por costellas, de modo que o aspecto varía consideravelmente com a idade. O orificio primario é provido no seu bordo proximal, entre os dentes suspensores, de seio largo e assáz profundo, notando-se distalmente calcareo arco vestibular, densamente crenulado, não mais visivel sem preparação, quando o orificio secundario se acha desenvolvido. Em um lado orificial está situada uma avicularia, cuja mandibula triangular aponta obliquamente para cima. Conforme a calcificação progressiva o numero das saliencias dentiformes em redor do orificio augmenta, podendo finalmente apparecer 6 d'estes tuberculos. Torna-se tambem muito grossa a camara da avicularia incorporada no peristôma, á maneira de estreitar no lado respectivo o seio do orificio secundario (a pseudorimula). Além da avicularia orificial, occorrem 1-2 frontaes, algum tanto maiores, variadamente dispostas, cujas mandibulas concordam com as da avicularia orificial. O operculo. (Fig. $20 \mathrm{~B}$ ) é provido de pontos musculares (i) no seu terço distal e de entalhos de suspensão (e) no terço proximal; no material de Napoles occorre usualmente, nem sempre, granulação da chitina do operculo. Os entalhos de suspensão são campos semicirculares, de chitina delgada, delimitados por sinuosidade do esclerito lateral do operculo. A camada calcarea que cobre o oécio ("ooecial cover") deixa livre no material presente uma zona hemispherica ou triangular, não desenhada para os especimes das Tortugas (Smitt) a ausente nas colonias da costa bahiana. A camada subjacente do oécio, portanto, o ectooécio, mostra, nas colonias aqui em mão, varias vezes uma sutura mediana longitudinal, figurada de R. rostratum (Bsk.) (Hastings 1930, t. 14 f. 93, 96). Aos lados da sutura occorrem ás vezes regiões menos calcificadas, que por isso se apresentam como manchas transparentes. Na cobertura do oécio e na parede frontal dos autozoécios de calcificação adiantada, apparecem gibbas e tuberosidades de configuração e disposição irregulares.

Ilha de São Sebastião (ca. de $100 \mathrm{~km}$. do norte de Santos), em $4 \mathrm{~m}$ de profundidade.

Apezar da litteratura relativamente grande que se acha publicada sobre R. verruculatum, a especie não é completamente clara. O material da itha de Heard do Indico antiboreal foi revistado por Anna B. Hestings (1930, p. 729) e classificado como pertencente a R. Iongirosire 
(Hcks.) (Hastings 1932, p. 439). Torna-se com isso duvidosa a classificação do material de Ceylão (Thornely 1905, p. 122), e este lugar de achado foi supprimido na lista seguinte da distribuição total da especie. Canu \& Bassler (1923, l. c.) puseram em duvida a identidade dos especimes do golfo do Mexico e do mar Mediterraneo, por serem os zoécios figurados por Calvet $(1902$, I. c.) algo maiores. Dá-se isso tambem com o material de Napoles, segundo a figura I de Waters $(1879$, I. c.), mas, as medidas dos zoécios da costa do estado da Bahia (Canu \& Bassler 1928a, l. c.) igualam, como tambem o material presente, ás dos especimes mediterraneos. A falta de uma area oecial livre da calcificação sobreposta na figura de Smitt (l. c. f. 170, um unico oécio) e no material da costa bahiana (Canu \& Bassler 1928a, p. 88) contrasta, sem duvida, com os especimes de Napoles e de Cette (golfo do Leão). Mas, como se vê na figura de Rhynchozoon nasutum (Marcus 1937a, fig. 30 A no texto, p. 238), a cobertura oecial póde, em especies em geral providas de uma area no oécio, proceder de tal maneira que cubra a parede frontal do oécio quasi totalmente. Por isso, não convem separar os representantes centralamericanos e mediterraneos de R. verruculatum.

Graças á Snra. A. B. Hastings (1930, p. 728), cuja revisão de Lepralia rostrata (Busk 1856, p. 178) esclareceu esta especie até então obsoleta, sabemos agora que R. rostratum (Bsk.) da costa pacifica centralamericana é extremamente vizinho ao R. verrucul a tu m. Possuindo - material presente esclerito basal da mandibula quasi direito, portanto, desprovido da convexidade central que provoca "the curved outline of the area below the lucida" tão caracteristica de R. rostratum, tem de ser determinado como R. verruculatum. Na indicação da largura do operculo dos especimes de Napoles (Waters 1879, p. 194) convém corrigir um erro typographico, substituindo 0,24 por $0,14 \mathrm{~mm}$.

Distribuição geographica: Ilhas das Tortugas, Florida; Brasil, litoral do -estado da Bahia; mar Mediterraneo occidental: bahia de Gibraltar (Algeciras), Cette, Corsega, Napoles. Do mar raso até $77 \mathrm{~m}$. de profundidade.

Siniopelta langei, spec. nov. (Est. XI - Fig. 21 A; Est. XII Fig. 21 B-D).

As colonias disponiveis são velhas e volumosas, medindo a maior ca. de $15 \times 30 \mathrm{~mm}$. Incrustam conchas de Mytilus. Apezar de serem fortemente calcificadas, são vitreas, transparentes. Nas zonas marginaes das colonias os zoécios são decumbentes e acham-se dispostos em quinconcios e em uma unica camada; no centra da colonia são erectos e amontoados nor 
causa da gemmação frontal, peculiar ás Celleporidae. Os zoécios marginaes, ligeiramente convexos, possúem nos seus bordos grandes póros separados por costellas resaltadas, havendo, porém, tambem zoécios, cuja parede frontal quasi inteira é provida de póros menores. Tal typo de esculptura zoecial se encontra nomeadamente nas zonas centraes da colonia nos zoécios erectos com orificio terminal.

- o orificio primario é mais comprido (alto) que largo, sendo profundo e largo o seu seio proximal. A esta configuração corresponde o operculo (Fig. 2। B), cujos bordos distal e lateraes são na região do anter reforçados. Sendo a orla de chitina mais forte relativamente larga e os pontos musculares nitidamente distantes d'essa orla, approximam-se bastante á linha mediana do anter. O desenvolvimento do peristôma em redor do orificio primario varia muito; póde até faltar quasi completamente. Ao peristôma appõem-se as camaras das duas avicularias orificiais, nem sempre presentes. A altura d'estas camaras é inconstante nos varios zoécios; ellas dirigem-se para cima e mais ou menos obliquamente para fóra. As mandibulas (Fig. $2 \mathrm{IC|}$ são pequenas, arredondadas e de bordos lisos, quer dizer, não denteados. Nos zoécios providos de oécios é geralmente o peristôma mais alto, e n'estes individuos nota-se orificio secundario mais largo que alto.

As avicularias independentes, ás vezes cumuladas e outras vezes ausentes em districtos estendidos da colonia, variam quanto ao seu comprimento. O seu aspecto, porém, é uniforme (Fig. 2| D), sendo a forte mandibula amarella distalmente arredondada e quasi parallelos os bordos lateraes; é desprovida de columella. A lucida (area central de chitina tenue) dista-se algo do bordo proximal e confina distalmente com a zona semilunar, em que a musculatura occlusora da mandibula insere. A vara calcarea basal ("transverse bar' pivot") compõe-se de dois gonzos não completamente unidos no centro.

A area frontal dos oécios volumosos e mais largos que altos é nitidamente convexa. A esculptura do endo-oécio calcareo consiste em póros de diametro e configuração heterogeneos. O ecto-oécio, lateralmente confluente com o peristôma, apresenta bordo livre irregular, ás vezes provido de uma ponta central.

A unica ancestrula encontrada é um zoécio com oval orificio primario espaçoso, mas, não mostra espinhos nem peristôma. Lembra, assim a ancestrula de Cellepora dichotoma (Marcus 1938, t. II f. 26 B) e de Siniopelta diota (ibid., p. 5I), sendo, porém, o orificio algo maior.

Brasil, ilha de S. Francisco (Lat. 26 $16^{\circ}$ S., estado de Sta. Catharina) em Mytilus perna L., crescido em boia fluctuante; (Coll. Lange de Morretes). 
Em virtude da difficuldade de separar a especie nova de S. costazii (Aud.) (Est. XII - Fig. 22 A-D) e S. diota (Marcus 1938, p. 49), das quaes, porém é seguramente differente, foi organisada a tabella seguinte:

\begin{tabular}{|c|c|c|c|}
\hline especie & Sinıopelta langei & S. costazii & S. diota \\
\hline parede & vitrea & de porcellana & vitrea \\
\hline operculo & $\begin{array}{l}\text { mais alto que } \\
\text { largo } \\
\text { altura: } 130-150 \mu \\
\text { largura: } 90-105 \mu\end{array}$ & $\begin{array}{l}\text { mais alto que } \\
\text { largo } \\
\text { altura: } 112-135 \mu \\
\text { lergura: } 90-110 \mu\end{array}$ & $\begin{array}{c}\text { mais largo que alto } \\
\text { ou de medidas } \\
\text { iguaes } \\
\text { altura: } 110-130 \mu \\
\text { largura: } 110-130 \mu\end{array}$ \\
\hline $\begin{array}{c}\text { esclerito opercular } \\
\text { laterodistal }\end{array}$ & presente & ausente & presente \\
\hline pontos musculares & quasi no meio & no bordo distal & no bordo distal \\
\hline $\begin{array}{l}\text { seio ("sinus") do } \\
\text { orificio primario }\end{array}$ & distincto & $\begin{array}{c}\text { muito pouco demar- } \\
\text { cado }\end{array}$ & distincto \\
\hline peristôma & fraco & mediocre & enorme \\
\hline $\begin{array}{c}\text { mandibula das avicu- } \\
\text { larias orificiaes }\end{array}$ & $\begin{array}{c}\text { arredondada; a luci- } \\
\text { da distali sem } \\
\text { dentes }\end{array}$ & $\begin{array}{c}\text { quasi triangulari a } \\
\text { lucida distali com I } \\
\text { dente na ponta }\end{array}$ & $\begin{array}{l}\text { arrendondada; a lu- } \\
\text { cida central; numero- } \\
\text { sos dentes pequenos }\end{array}$ \\
\hline $\begin{array}{l}\text { mardibula da avicti- } \\
\text { lária independente }\end{array}$ & $\begin{array}{l}\text { posteriormente larga, } \\
\text { fortemente chitinisa- } \\
\text { dé; lucida distante } \\
\text { do bordo proximali } \\
\text { uma zona de inser- } \\
\text { ção muscular }\end{array}$ & $\begin{array}{l}\text { posteriormente estrei- } \\
\text { ta, fracamente chiti- } \\
\text { nisada; a lucida toca } \\
\text { no bordo proximali } \\
2 \text { pontos de inserção } \\
\text { muscular }\end{array}$ & $\begin{array}{c}\text { avicularia indepen- } \\
\text { dente não encon- } \\
\text { trada. }\end{array}$ \\
\hline $\begin{array}{c}\text { comprimento da man- } \\
\text { dibula da avicularia } \\
\text { independente }\end{array}$ & $150-200 \mu$ & | $80-225 \mu$ & \\
\hline $\begin{array}{l}\text { bordo proximal des- } \\
\text { sa mandibula }\end{array}$ & $150-120 \mu$ & $55-60 \mu$ & \\
\hline $\begin{array}{l}\text { maxima largura da } \\
\text { mandibula }\end{array}$ & $135-150 \mu$ & $127-150 \mu$ & 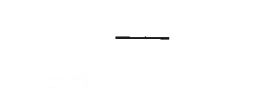 \\
\hline oécio & area frontal convexa & àrea frontal plana & area frontal convexa \\
\hline
\end{tabular}


As especies anteriormente discriminadas de Siniopelta diota (Marcus 1938, p. 49-50) foram novamente confrontadas com a especie actual, da qual, porém, todas differem nitidamente. Dedico a nova Sin io pelta ao Snr. Lange de Morretes, que pôs á minha disposição varias conchas habitadas por Bryozoa da sua collecção.

Holoporella carvalhoi, spec. nov. (Est. XII - Fig. 23 A-D).

A especie, representada por duas colonias, cresce sobre pedaços de coraes, que incrusta multi-estratificadamente. Tratando-se de material jovem e de média idade, é relativamente regular a disposição dos zoécios. Estes são polygonos largos de paredes frontaes bastante convexas, resaltando-se debaixo do orificio uma calota larga e alta, fortemente abobadada, que lembra uma consola ou a metade de uma gamella. Possue carina medial, que acaba no bordo livre com protuberancia obtusa ou ponta espinhosa. Destaca-se já nos zoécios jovens, onde se apresenta como campo liso semilunar, provido de convexa ourela distal. Nos zoécios jovens occorrem 2-4 grossos espinhos basalmente chitinicos, distalmente aguçados, cujos botãozinhos de inserção se veem ainda nos zoécios velhos. Os grandes póros dos zoécios jovens e a esculptura radial d'elles, canellada ou formada por lisins serpenteantes, acham-se substituidos nos zoécios velhos por gibbas uniformes. Estas occupam, conforme o progresso da calcificação, a inteira parede frontal, inclusive a calota superficial, de modo que os zoécios acabam de mostrar esculptura martellada, dentro da qual os póros marginaes pódem conservar-se. $O$ orificio primario semicircular é fechado por operculo de chitinisação fraca (Fig. $23 \mathrm{~B}$ ), provido de dois escleritos, nos quaes os occlusores inserem. Peristôma verdadeiro não se desenvolve, visto que o crescimento da calota suborificial cinge sómente a metade proximal do orificio, formando assim um tubo peristomial incompleto. Avicularias oraes propriamente ditas faltam, em virtude de se achar inerme a calota suborificial. Sobre a parede frontal encontram-se avicularias zoéciaes (dependentes) de porte, posição e direcção variadas, mas, todas de mandibula esbelta, triangular. Exhibem igualmente mandibula pontuda e approximadamente triangular as enormes avicularias (zoariaes), cuja mandibula attinge longura de $600 \mu$. D'estas avicularias ha ca. de 6 por centimetro quadrado da superficie da colonia; são, portanto, raras. Columella falta nas mandibulas de todas as avicularias, inserindo os 2 tendões dos musculos occlusores da avicularia vicaria nos dois lados do campo central de chitina tenue, da chamada lucida (Fig. 23 C, u). Nas mandibulas das avicularias zceciaes encontra-se um unico tendão dos dois occlusores. No material presente faltam os oécios. 
Iha de São Sebastião (ca. de $100 \mathrm{~km}$ do norte de Santos), em $4 \mathrm{~m}$ de profundidade.

A especie, muito bem caracterisada pela saliencia convexa suborificial, desprovida de avicularias, e pela mandibula ponteaguda da avicularia vicaria, não precisa confrontação com demasiadamente muitas especies. Rostro desarmado occorre, p. e., em Cellepora vitrea (P $H$. MacGillivray 1887a, p. 186), mas, esta pertence ás "Celleporidae Schizostomata portanto ás Celleporidae do systema actual. Cellepora magnirostris (P. H. MacGillivray 1888, p. 25I), que evidentemente pertence ao gen. Holoporell a, é talvez a especie mais vizinha á nova. Distingue-se, porém, pela configuração differente da mandibula da avicularia vicaria e pela saliencia suborificial muito menos desenvolvida. Holoporella apiculata (Busk 1884, p. 196) possúe rostro armado; H. descostilsii (Waters 1909, p. 162) tem operculo alto e menos largo e avicularias vicarias de mandibula espatulada. H. pusilla (Waters 1918, p. 22), cujas avicularias dependentes lembram as da especie actual, tem operculo e rostro differentes, sendo espatuladas e ellipticas as mandibulas das avicularias de $\mathrm{H}$. m a $\mathrm{g} \mathrm{n}$ ifica (Osburn 1914, p. 216) e o operculo mais alto (Canu \& Bassler 1928. f. 32 D. p. 144). Mandibulas largas, espatuladas, occorrem tambem em H. capensis (O'Donoghue \& Watteville 1935, p. 215) e em Mucronella anatirostris, talvez uma Holoporella (O'Donoghue 1924. p. 47). Em H. quadrispinosa (Canu \& Bassler 1930, p. 37) encontra-se rostro provido de avicularia oral, dando-se em $H$. erectorostris (id. 1929, p. 425) ○ mesmo caracter, orificio denteado e mandibula da avicularia vicaria de forma espatulada.

Dedico a especie nova ao prezado collaborador do Departamento de Zoologia da Universidade de São Paulo, Snr. João de Paiva Carvalho, que a dragou e, juntamente com outro material valioso, presenteou a collecção do Departamento com as colonias actuaes.

\section{Itoloporella schubarti, spec. nov (Est. XII - Fig. 24A-D).}

As duas pequenas colonias, cujo diametro attinge $3 \mathrm{~mm}$, crescem nas bexigas natatorias de Sargassum. A côr do material fixado em alcool é acastanhada-clara, provindo tal coloração dos tecidos. As partes calcareas, nomeadamente os rostros compridos sub-orificiaes, sobresaem brancos do fundo pardacento. A colonia menor consiste em uma unica camada, divergindo os zoécios bastante regularmente e para todos os lados da ancestrula. Na colonia maior inicia-se a formação de uma segunda camada 
sobreposta á primordial. Pertencem á camada superior os dois zoécios volumosos (Fig. $24 \mathrm{~A}$, s), dispostos sobre a ancestrula e sobre alguns dos pequenos zoécios confinantes com esta. Os zoécios, que nas jovens colonias presentes ainda não são amontoados irregularmente como em velhos zoarios das Celleporidae, apresentam-se como polygonos pouco convexos, excepto o rostro suborificial. Os rostros são pontas compridas, dirigidas obliquamente para diante e para cima, cuja base larga mostra esculptura de noduíos oblongos. Unilateralmente no rostro, encontra-se perto da base uma pequena avicularia, cuja mandibula arredondada se dirige para cima.

A parede frontal dos zoécios é lisa ou fraca e irregularmente esculpturada, notando-se nos bordos zoeciaes grandes póros circulares, muitas vezes situados perto dos angulos das paredes. O orificio, desprovido de quaesquer vestigios de espinhos, é espaçoso e approximadamente semicircular. $O$ peristôma liso é fracamente desenvolvido nos zoécios estereis. Sómente nos zoécios ferteis poder-se-ia falar em orificio secundario, porque o oécio se sobrepõe á maneira de capuz ao orificio primario. O operculo de chitina fraca faz ver a linha transversal de inserção da membrana basal do sacco compensatorio. Os escleritos, em que os musculos occlusores se inserem, são rectos e claramente distantes do bordo do operculo.

As avicularias zoariaes são escassas; no material presente encontram-se especialmente nas proximidades dos oécios. A pequena camara mostra saliencia comparavel ao rostro zoecial, situada, porém, distalmente do campo de abertura da avicularia. D'este modo a mandibula da avicularia fechada dirige-se para a saliencia. A mandibula oblonga e regularmente arredondada possue lucida oval, sendo ausente uma columella. Os oécios volumosos são compostos por endo-oécio membranoso e ecto-oécio granuloso, cujo bordo frontal é reforçado. Occorre ás vezes gibba ou ponta no ecto-oécio. O ecto-oécio é formado pelo zoécio distalmente situado, e como alli geralmente ha dois zoécios confinantes, estes contribuem ambos para o ecto-oécio. Por isso permanece visivel em oécios jovens sutura longitudinal, que desapparece com o progresso da calcificação. A contribuição desigual dos dois zoécios distaes resulta em irregularidades do bordo livre do ecto-oécio. Este não cobre completamente o endo-oécio, que assim permanece visivel na sua parte proximal.

Recife, barra de Serinhaen, em Sargassum do mar raso.

A região tropical do Atlanticc occidental é rica em especies do genero Holoporella de modo que $\mathrm{H}$ schubarti precisa de discriminação pormenorisada. H albirostris (Smitt 1873, p. 70) possúe espinhos e avicularias interzoeciaes não linguiformes como a especie presente, mas, pro- 
vidas de esquinas latero-basaes prolongadas (Canu \& Bassler 1928, f. 31 no texto, p. 142) e de columella (Hastings 1932, p. 446). Differem tambem as mandibulas das avicularias oraes (Fig. 24D e Canu \& Bassler 1928, f. 3ID). $H$ magnifica Osburn $(1914$, p. 216) é muito semelhante a $H$ albi rostris com excepção das dimensões maiores, afastando-se assim ainda mais da pequena $H$ schubarti $H$ pusilla (Smitt 1873, t. 12 f. 233) separada por Busk (1884, p. 194), Osburn (1914, p. 215) e Waters (1918, p. 22) de $H$ albirostris é especie espinhosa e as avicularias são triangulares (veja tambem Calvet 1907. t. 27 f. II). Holoporella turrita (Smitt 1873, p. 65) possúe no operculo e oécio, como tambem na ausencia de avicularias orificiaes, caracteres que impossibilitam a sua incorporação no genero Holoporella (Hastings 1930, p. 732).

H. imbellis (Busk 1884, p. 195), cujas partes chitinicas (l. c., †. 35 f. 20) mostram contornos semelhantes aos dos elementos correspondentes da nova especie não possue escleritos no operculo e rostro sub-orificial muito menor. Além da indicação de se tratar de um zoario lamelloso, flexuoso e fino, a diagnose de $\mathrm{H}$ imbellis introduzida com ponto de interrogação e baseada em um especime, evidentemente velho e morto, não contem muitos elementos concretos. A largura do orificio (ca. de $150 \mu$ ) é quasi a mesma em $\mathrm{H}$ schubarti a esculptura frontal, $e_{\text {, como foi }}$ dito, o rostro differem completamente. Sem re-examinação do material de Busk, seria francamente inopportuno reunir as duas especies.

H mamillata var. atlantica (Busk 1884, p. 199) mostra no material da Bahia (l. c., t. 35 f. 4) columella das avicularias. $H$ pigmen taria (Waters 1909, p. 163) muito perto da var. a tla ntica (Hastings 1932, p. 445) foi descripta sem columella, mas, as mandibulas das avicuiarias inter-zoeciaes são serradas, e a unica figura de $\mathrm{H}$ pigmentaria que talvez possa ser comparada á especie actual: possue granulações mamil. losas e grandes póros interzoeciaes (Waters 1909, t. I5 f. 16). Os operculos da var. atlantica e da $H$ pigmentaria são mais largose menos altos que o operculo da nova especie.

Especies de outras regiões, que deveriam ser confrontadas com $\mathrm{H}$ schubarti encontrei apenas duas, a saber, $H$ pygmaea Canu \& Bassler (1929, p. 429) e $H$ quadrispinosa Canu \& Bassler (1930, p. 37). H pygmaea de operculo e medidas sem duvida semelhantes, possúe o seu orificio em posição quasi medial; as mandibulas de H. pyg mae a não são descriptas. $H$ quadrispinosa cujo operculo e. avicularia interzoecial (I. c., f. 8D, E) correspondem bem aos elementos da nova especie, tem 4 espinhos no peristôma, rostro pequeno e mandibula triangular da avicularia oral. Assim é nitidamente distincta de $\mathrm{H}$ schu barti, que dedico ao Dr. Otto Schubart a quem devo o material. 


\title{
Aicyonidium mamillatum (Ald.) (Est. XIII — Fig. 25A-C).
}

\author{
Alcyonidium mamillatum Alder 1857, p. 64 t. 5 f. 3-4. \\ Alcyonidium mamillatum Marcus 1937, p. 126 t. 25 f. 67.
}

Adoptando os caracteres offerecidos pelos zoécios como fundamentaes para a classificação de uma especie que cresce como crosta coherente (Hincks 1880, p. 485) erecta (Andersson 1902, p. 553) e linearmente (Hincks 1880, p. 496; Calvet 1931, p. I1; Borg 1933, p. 546), não posso deixar de incluir as colonias presentes, que crescem de outra maneira ainda. Uma, proveniente da Praia Grande, perto de Santos, forma um ninho intricado (Fig. 25-A), fixado a um Hydropolypo e se acha composto por caules curtos e pouco ramificados. Os caules, de espessura de $1-3 \mathrm{~mm}$., pódem ser grudados um ao outro, parecendo-se o zoario com um tufo de musgo talvez do gen. Hypnum ou Grimmia Outras colonias encontradas sobre tubos de Serpulidae, conchas e pedrinhas, na propria bahia de Santos (Fortaleza, Sangava, ilha das Palmas etc.), são decumbentes, como a forma typica, mas, a cobertura do substrato formada por estes zoécios mostra lacunas mais ou menos numerosas, tornando-se em varios lugares reticulada (Fig. 25 B). Tal crescimento de certo modo liga o typico com o de $A$. I ine are e torna mais provavel ainda a necessidade de incorporar esta especie na synonymia de A. mamillatum As colonias reticuladas mostram phenomenos singulares quanto á sua gemmação e regeneração. Entre os zoécios normaes (Fig. 25B,a) apparecem menores, cegos" i.é, desprovidos de polypidios e de orificios (Fig. 25B,z). E' verdade que ás vezes apresentam esboço de orificio, mas, nunca o cône orificial comprido, resaltado, que caracterisa $A$. mamillatum Foram descriptos individuos semelhantes em $A$ albidum (Prouho 1892, p. 573) e zoécios degenerados em Arachnidium fibrosum (Marcus 1938, p. 5I), que se parecem com os zoécios "cegos" de A mamillatum

Nos casos actuaes certamente não se trata de degeneração, visto que não ha corpo bruno nos pequenos zoécios intercalares. Tal corpo bruno caracterisa zoécios degenerados e em regeneração (Fig. 25B, r). Nos Cheilostomata e Ctenostomata, como é sabido, precede a formação do cystidio á do polypidio (Borg 1926, p. 324) $(*$ ). A zona de gemmação lança nas colonias presentes uma serie de cystidios vazios, cobrindo com tal crescimento, que se póde denominar de colonisação extensiva, certo espaço do

(*) Silén (1938, p. 190) considera como excepcional a sua observação de um botão polypidial antes da formação completa da parede separadora entre zoécio-mäə e zoéciofilha, mas, tal phenomeno não é tão raro (Agatz 1912, p. 8). 
substrato. No fim de uma serie de zoécios cegos, pódem apparecer cystidios normaes providos de polypidios, cuja actividade alimenticia poderia proporcionar á colonia occupação rapida de nova zona do substrato, talvez por meio de novos zoécios cégos.

Ignoram-se as causas d'esse crescimento. A irregularidade da distribuição dos zoécios cegos, como tambem das malhas (Fig. 25B, m), impossibilitam assumir que se trata de um caracter genotypicamente fixado, que requereria denominação especial. Analyse do substrato não revelou factores externos que obrigaram a colonia á formação de malhas, talvez em redor de obstaculos ou de cobrir certo espaço com zoécios cégos. Aliás, é muito difficil, antes da descalcificação do substrato, observar os pormenores do crescimento das colonias incolores. Tratando-se de material fixado no lugar, onde foi colleccionado, os factores internos subtrahem-se, é claro, a qualquer interpretaçáo. Temos actualmente de nos contentar com a descripção e de mencionar certos casos talvez analogos ou de certo modo comparaveis aos. aqui apresentados.

Descriptivamente convem accrescentar que varias vezes brotam primordios de polypidios, nos zoécios cegos (Fig. 25B, b), tornando-se assim intensiva a colonisação inicialmente extensiva. E' de se suppôr que os esboços. orificiaes acima assignalados como presentes em varios zoécios cegos se tornem cônes orificiaes de funç̧ão normali pelo menos não faltam exemplos. semelhantes na literatura como o de recuperarem zoécios cegos a totalidade das capacidades de um individuo de Bryozoario ordinario. Penso especialmente na transformação suppletoria em autozoécios communs observada nos tubos adhesivos de Electra pilos a como resposta á falta do normal estimulo de contacto (Marcus 1926a, p. 46-48). Como foi dito, nada se póde proferir acerca da causa da formação dos zoécios cegos em Alcyonidium mamillatum ou A albidum mas, a plasticidade dos processos morphogenicos na gemmação dos Bryozoa tanto como facto geral (Buchner 1924, p. 181; Marcus 1938, p. 70) como no caso concreto de Electra pilos a permitte considerar, p.e., o zoécio c da Fig. 25B como tendo percorrido a phase de zoécio cégo.

Nas discussões theoricas de Silén (1938, p. 261 e seguintes) attribue-se importancia ao ponto do primeiro apparecimento do botão polypidial. Mostra-se situado centralmente nos polypidios das avicularias, proximalmente nos autozoéc.ós communs. Em analogia, digna de ser mencionada, formam-se centralmente os polypidios dos zoécios cegos (b). proximalmente em autozoécios normaes de A. mamillatum e A. polyoum. Quanto á ultima especie (sob a denominação de $A$. mytili). e A gelatinosum ha indicações contrarias na literatura (Römer !906, p. 451; Herwig 1913, p. 4), tratando-se evidentemente em ambos os casos. 
de gemmação suppletoria, que resulta em zoécios intercalados. Todavia, foi possivel observar issso em A gelatinosum (material dinamarquez)i por outro lado verificámos posição proximal do primordio polypidial em autozoécios communs de uma colonia jovem de A polyoum

O zoécio da Fig. 25B e os da Fig. 25C mostram casos de regeneração anormal, que em varias colonias são numerosos. Duplicidades e triplicidades dos cônes orificaes causam aspecto muito singular dos respectivos zoécios. Estes sempre conteem um unico polypidio, de modo que o phenomeno nada tem que ver com os polypidios masculino e feminino simultaneamente. presentes, mas, successivamente maduros de Alcyonidium duplex (Prouho 1892, p. 581) ou com a observação de Waters (1913, p. 488). Os casos de regeneração total até hoje descriptos (Levinsen 1907; Buchner 1918; Marcus 1938, p. 73) mostram ser fixo o lugar do primordio polypidial no botão regenerativo e por isso é inalteravel a sua polaridade. Vê-se agora que na regeneração parcial póde occorrer inversão da polaridade, possuindo os zoécios respectivos (Fig. 25B, C, d) dois orificios oppostos. Em ambos os casos, formou-se depois do periodo do corpo bruno o novo orificio perto da parede proximal, portanto, no lado opposto á direcção principal do crescimento da colonia.

Não convem, é claro, denominar a anormalidade descripta, concordando os caracteres morphologicos geraes e as medidas de todos os materiaes apresentados aqui. O numero dos tentaculos oscilla entre 17-20, sendo 17-18 o numero mais frequente. Ha indicação identica para o primeiro material descripto da bahia de Santos (Marcus 1937. p. 129), discutindo-se no lugar citado a largura de variação. A longura dos zoécios varia nas colonias actuaes entre 600-1.000 $\mu$, sendo $800 \mu$ a longura mais frequente. As papillas orificiaes medem 200-600 $\mu$, na maioria dos casos 300-400 $\mu$. As figuras originaes de Alder (1857, t. 5 f. 3-4), com os cônes orificiaes salientes, concordam bem com certas colonias do material actual, onde estas proeminencias são especialmente bem desenvolvidas. Nas figuras correspondentes de Hincks (1880, t. 69 f. 7-8) as papillas orificiaes são menos altas, não faltando, porém, no nosso material, tambem exemplos d'este typo (Marcus 1937. t. 25 f. 67).

\section{Alcronidium hauffi, spec. nov. (Est. XIII - Fig. 26A-B).}

Tres colonias acham-se á disposição, cobrindo a l. a o hydrocaule e todas as suas ramificações de um Hydroide da Fam. Campanulariidae, a 2. ${ }^{a}$ e 3. ${ }^{a}$ os eixos corneos desprovidos da cortex de Gorgonariidas (Ficy 26B). A primeira colonia, que evidentemente é jovem, tem $5 \mathrm{~cm}$ de comprimento e cobre com uma camada de zoécios uniformemente o substrato. 0 dame- 
tro dos zoécios varia entre 250-300 $\mu_{1}$ a sua configuração é polygonal e os orificios não se resaltam para fóra, faltando, portanto, papillas orificiaes. O numero dos tentaculos oscilla entre 15-17. A 2. colonia é um fragmento de $12 \mathrm{~cm}$ de longura e $4 \mathrm{~mm}$ de largura, cujas partes mais velhas crescem com algumas camadas sobrepostas. Formam-se n'esta colonia numerosas protuberancias (Fig. 26 A), na sua maioria dirigidas para dois lados oppostos. Attingem estas até $4 \mathrm{~mm}$ de longura (distancia entre a colonia e a ponta livre da protuberancia), $3 \mathrm{~mm}$ de altura (o eixo parallelo ao eixo maior do substrato) e $6 \mathrm{~mm}$ de largura (espessura). A $3 .^{\text {a }}$ colonia mede $21 \mathrm{~cm}$ e contem, como tambem a primeira, a zona de gemmação, de modo que se acha completa. As protuberancias são menos numerosas que na 2. ${ }^{a}$ colonia, embora sejam presentes na região mais velha e mais larga. Nas colonias 2 e 3, o diametro dos zoécios varia entre $300-350 \mu$, de modo que $250-350 \mu$ indicariam a largura de variação ałé agora verificada. Quanto á ausencia de papillas orificiaes e o numero dos tentaculos, as tres colonias concordam. Ao passo que a jovem colonia I incrusta o hydrocaule do Hydropolypo com zoécios pavimentosos, o typo do crescimento das colonias adultas é bem differente. Como Plumatella fungosa (Pall.) envolve com as suas colonias massiças substratos cylindricos fornecidos por plantas aquaticas (raizes ou as partes submersas de Thypha Phragmites etc.), assim crescem tambem os zoécios semi-erectos da especie presente n esse fio delicado, mas firme, que é o eixo corneo das Gorgonariidae. Não havendo vestigios da cortex, nem mesmo nas partes do eixo ainda não colonisadas pelo Bryozoario, a larva do Alcyonidium presumivelmente tem-se fixado sobre o eixo já desprovido de polypos.

Perto de Santos, Praia grande (colonia I, 2); Caraguatatuba, ca. de $100 \mathrm{~km}$ do norte de Santos (colonia 3).

O numero total das especies até agora conhecidas do genero Al c y onidium importa $\mathrm{em} \mathrm{24.} \mathrm{N'este} \mathrm{calculo} \mathrm{sigo} \mathrm{as} \mathrm{synonymias} \mathrm{estabelecidas}$ por Borg (1933, p. 546-547) quanto ao A brucei (Calvet 1903, p. 33) e ao A. I ineare (Hincks 1880, p. 496). Além disso, A. cervicornis (Robertson 1900, p. 330) e A. sp in ifer a (O'Donoghue 1923, p. 192), que são identicos (O'Donoghue 1926, p. 56), pertencem á Flustrella corniculata (Smitt) (Nordgaard 1905, p. 173-174). Não foi incluido no numero dado acima Alcyonidium flustrelloides (Barroso 1920, p. 353; 1922, p. 901 que, ao meu vêr, é identico á Pherusa tubulos a (Ell. Sol.). Como a descripção e as figuras do Alcyonidium $m y+i l i$ do Porto Phillip (Kirkpatrick 1888, p. 17) não possibilitam separa-lo de A mytili dos autores restantes, esta especie não foi contada separadamente, embora Harmer (1915, p. 37) alluda na necessidade de separa-la 
de A polyoum (Hass.). Quanto aos outros autores que mencionam A mytili não indicam, nem mesmo Silbermann (1906, p. 6), caracteres distinctivos entre $A$ mytili e A.polyoum $A$ subviride Couch (1844, p. 133-134; Jelly 1889, p. 10; Waters 1904a, p. 179), uma especie obsoleta, foi descuidada aqui, e Paralcyonidium vermiculare (Okada 1925, p. 28I) incluido na lista, cuja compilação foi indispensavel para a classificação do material aqui em mão.

Especies de 20 tentaculos e mais não precisam ser postas em confronto pormenorizado; são as seguintes: A antarcticum Wat., A flabelliforme Kirkp., A. flustroides Bsk., A. variegatum Prouho. Tambem não entram na discussão as especies seguintes, cujas colonias sempre são erectas: A. chondroides O'Don. \& de Wattev. (zoario bilaminado), A excavatum Hcks. (zoécios unilateralmente dispostos na colonia claviforme). A. gelatinosum (L.) (zoario cylindrico, lobulado ou circular com curto pedunculo), A papillatum O'Don. (zoécios providos de papillas). A pedunculatum Roberts. (zoario pyriforme, pedunculado; zoécios sem papillas), A rhomboidale O'Don. (colonia foliacea, bilaminada). A. (Paralcyonidium) vermiculare Okada (zoario filiforme), A verrilli Osb. (colonia lobulada, de consistencia mais firme que $A$. gelatinosum e A. hirsutum, ambos de crescimento semelhante). Talvez pertença o Alcyonidium duvidoso, mencionado por Prenant (1931, p. 3), ao A. verrilli ou, mais verosimilmente ainda, ao Alcyonidium topsenti (Roehrich 1910, p. CLXIV), tambem de crescimento erecto.

Continuando a resenha das especies conhecidas do genero Alcyonidium Lmx., para estabelecer a independencia do material presente, temos de separar A disjunctum Hcks. por causa do seu crescimento uniserial e duas especies espinhosas, a saber, A hirsutum (Flem.) e A parasiticum (Flem.).

Para ô ultimo grupo a ser discutido, adopto como criterio distinctivo o desenvolvimento de uma papilla ou tubulo orificial, ausente na nova especie. Pertencem a esse grupo: A albidum Ald., A cellarioides Calv., A columbianum O'Don., A disciforme Smitt, A. effusum Norm., A mamillatum Ald. E' claro, que A dupiex Prouho e A polyou.m (Hass.) poderiam ser incluidos aqui, mas, prefiro separa-los da nova especie por outros caracteres. Como se sabe, ás vezes é chata, muito pouco conspicua, a papilla em zoécios jovens de A pol you m tendo justamente tal caracter levado varios autores a manter para filmes tenues das colonias novas de $A$. polyoum a denominação especial de A. mytili Dal. Além disso, é de se lembrar que é phenomeno commum apparecerem nas especies de Alcyonidium cônes orificiaes simulados, 
quando não se acharem completamente retrahidos os polypidios dos zoécios respectivos (Prouho 1892, p. 569-570, nota), podendo acontecer isto em colonias inteiras. Quanto á variação do cône orificial conforme o estado physiologico do individuo, refiro-me ás minhas verificações recem-publicadas (Marcus 1937. p. 127).

Importando a longura media dos zoécios de A duplex em $880 \mu$ (Prouho 1892, p. 580), de A polyoum em 400-700 $\mu$ (Marcus 1937. p. 125) estas duas especies logo se distinguem da nova. Dedico-a ao Snr. Ivan Hauff, ao qual o Departamento de Zoologia deve varias peças muito interessantes.

\author{
Buskia repens (O’Don.) (Est. XIV - Fig. 27A-B). \\ Cylindroecium repens O'Donoghue 1923, p. 192 t. 4 f. 38. \\ Buskia nitens O'Donoghue 1926, p. 60.
}

As colonias transparentes, incolores ou amarelladas, crescem em algas e conchas, ás quaes adherem por meio de estolão rasteiro parcamente ramificado. Os zoécios inserem no estolão aos pares ou em grupos de tres; ás vezes, encontra-se um zoécio sózinho. $\bigcirc$ estolão é de grossura mediocre, medindo o seu diametro uniforme em toda a parte 70-80 $\mu$. Septos atravessados de póro communicante subdividem em certos intervallos o estolão, cujas ramificaçöes frequentemente se encontram quasi immediatamente depois, i.é, distalmente de um grupo de zoécios.

Os zoécios são grandes, de 800-1200 $\mu$ de comprimento, exclusive o collare bem desenvolvido e franzido. E' notavel a posição dos zoécios que divergem do estolão amplamente. A larga base dos zoécios arredondada e provida de um ou varios prolongamentos pontudos insere-se no estolão com que se communica por placas em roseta uniporosas (septulas). Cerca de um quarto do zoécio é decumbente, erguendo-se o resto do zoécio successivamente. O cystidio estreita-se consideravelmente para cima, sendo geralmente nos animaes conservados porção da duplicatura evaginada ou o collare, até mesmo os tentaculos, deitados para fóra. O comprimento do collare importa em $350 \mu$, o dos tentaculos em $500 \mu$, de modo que o individuo evaginado póde chegar ao comprimento total de ca. de $2 \mathrm{~mm}$. No polypidio nota-se proventriculo globoso. Apezar de não ter sido possivel contar exactamente os tentaculos, posso affirmar que, pelo menos, são 16, verosimilmente 16-18.

Tão pouco, como no material de B nitens descripto por Harmer (1915, p. 86), foi possivel verificar achatamento unilateral dos cystidios, o chamado campo de abertura, considerado como caracter generico (Hincks 
1880, p. 531). Occorrem por outro lado as duas series de musculos parietaes. sobrepostos, que formam duas faixas longitudinaes em Farrella repens (Marcus 1926a, fig. 2,44, P) e outros Ctenostomata (Marcus 1938b, p. 292 f. 2D, m). Penso que material fixado de zoécios tão volumosos e de ectocysta fracamente chitinisada, como se encontram na especie actual, não permitta juizo definitivo sobre a ausencia de um campo chato em lado determinado do cystidio dos animaes viventes.

Recife, barra de Serinhaem, em algas do mar raso.

O numero dos tentaculos de B repens differe de todas as indicações até agora publicadas sobre os 8 tentaculos de Buskia a saber Buskia nitens (Alder 1857 p. 66; Harmer 1915, p. 86; Marcus 1938, p. 59), B socialis (Waters 1910, p. 241; Marcus 1937, p. 143), Buskia setigera (Harmer 1915, p. 87 "apparently with 8 tentacles"; Marcus. 1937, p. 142). Sobre o numero dos tentaculos de B a $r m a t a$ nem Verrill (1873, p. 710), nem Osburn (1912, p. 256) dão informação no texto, mas. a figura de Osburn $(1912$, t. 29 f. 84b) mostra 8 tentaculos. Com os outros elementos da anatomia interna faltam em B pilos a (Harmer 1915, p. 89) ainda os tentaculos.

A inserção dos zoécios no estolão, porém ,é do typo commum do genero $B$ uskia representado, com respeito a este caracter, por $B$ nitens $B$ socialis e $B$ repens havendo em $B$ setigera $B$ a rmata $e_{1}$ evidentemente, tambem em $B$ pilos a pequeno kenozoécio entre o estolão e o autozoécio. Caracter do genero Buskia é tambem ser decumbente a porção inferior do cystidio, de modo que no estado actual do systema dos Ctenostomata Stolonifera não haveria outro genero mais adequado para abranger a especie actual.

Quanto á identificação do material actual com a especie citada de O'Donoghue, refiro-me primeiramente á re-examinação do proprio autor (O'Donoghue 1926, p. 60), que collocou o seu Cylindroecium repens. no genero Buskia identificando a éspecie com B nitens Alder. A descripção original (Alder 1857, p. 67) e a de Hincks (1880, p. 532) falam na pequenez de B. nitens, dando Harmer (1915, p. 86) 290-360 $\mu$ eu (Marcus 1938, p. 59) até $400 \mu$ de longura dos zoécios d'esta especie. Além disso, são os zoécios de B nitens deitados quasi parallelamente ao estolão, cobrindo-o, como se vê na admiravel estampa original (Alder I. c., t. 5 f. ( 2) e tambem na mais recente figura da especie (Dons 1939, f. 2). No material de O'Donoghue e no presente os zoécios divergem largámento para os dois lados do estolão. 
Tamanho e posição dos zoécios concordam nas colonias de O'Donoghue e nas presentes, ambas pertencentes ao genero Buskia e incompativeis com B nitens "Porisso, acho conveniente conservar o nome especial introduzido anteriormente por O'Donoghue e reunir o seu material com o de Recife, apezar de tratar-se de regiões faunisticas muito differentes. Criterios zoogeographicos, porém, nunca devem intervir em classificação morphologica de Bryozoarios, especialmente na determinação das pequenas colonias dos Ctenostomata Stolonifera, que tão facilmente escapam a quem separar as especies de uma colheita.

Distribuição geographica: Região de Vancouver, em 27-36,5m de protundidade.

\section{IV \\ Resumo zoogeographico.}

Accrescentando ao material do districto de Santos as poucas especies aqui ainda não encontradas, mas, provenientes do Rio de Janeiro $(37,114)$ ou da costa meridional do Brasil (84, 93), até a ilha de S. Francisco (no norte de S. Catharina), chegamos ás seguintes 120 especies e variedades denominadas do litoral superior entre Lat. $23^{\circ}$ e $26^{\circ}$ 15' S. da costa brasileira. Bem conhecida, porém, é unicamente a bryozoofauna da bahia de Santos e em segundo lugar a da itha de S. Sebastião la ca. de $100 \mathrm{~km}$. do norte de Santos); do Rio de Janeiro e da costa do Paraná e de S. Catharina tivemos sómente provas escassas em mão.

\section{Entoprocta:}

I Loxocalyx sawayai Marc.

2. Pedicellina cernua (Pall.)

3. Pedicellina nannoda Marc.

4. Loxosomatoides evelinae Marc.

5. Barentsia gracilis (Särs)

6. Barentsia discreta (Bsk.)

7 Barentsia laxa Kirkp.

\section{Ectoprocta:}

Stenostomata (Cyclostomata):

8. Crisia ramosa Harm.

9 Crisevia pseudosolena Marc.

10. Crisulipora occidentalis Roberts.

11. Tubulipora lunata Marc.

12. Entalophora delicatula (Bsk.)

\section{Cheilostomata:}

13. Aetea anguina (L.)

14. Aetea sica (Couch)

15. Aetea truncata (Landsb.)

16. Aetea ligulata Busk

17 Eucratea loricata (L.)

18. Membranipora tuberculata (Bosc)

19. Conopeum reticulum (L.)

20. Conopeum commensale Kirkp. \& Metz.

21 Electra bellula (Hcks.)

22. Electra tenella (Hcks.)

23. Electra hastingsae Marc.

24. Acanthodesia savartii (Aud.)

25. Acanthodesia tenuis (Des.)

26. Acanthodesia serrata (Hcks.) 
27 Acanthodesia paulensis Marc.

28. Crassimarginatella leucocypha Marc.

29 Copidozoum tenuirostre (Hcks.)

30. Membrendoecium minus (Hcks.)

31 Smittipora sawayai Marc.

32. Steganoporella buskii Harm.

33. Thalamoporella falcifera (Hcks.)

34. Thalamoporella gothica (Bsk.) var. prominens Lev.

35. Thalamoporella evelinae Marc.

36. Scrupocellaria scrupea Bsk.

37 Scrupocellaria cornigera (Pourt.)

38. Scrupocellaria bertholletii (Aud.)

39. Synnotum aegyptiacum (Aud.)

40. Beania mirabilis Johnst.

41. Beania intermedia (Hcks.)

42. Beania hirtissima (Hell:)

43. Beania australis Bsk.

44. Bicellariella ciliata (L.)

45. Bugula neritina (L.)

46. Bugula flabellata (J. V. Thomps.)

47 Bugula turrita (Des.)

48. Bugula ditrupae Bsk.

49. Bugula californica Roberts.

50. Bugula uniserialis Hcks.

51. Caulibugula armata (Verr.)

52. Colletosia radiata (Moll.)

53. Membraniporella aragoi (Aud.)

54. Catenicella contei (Aud.)

55. Savignyella lafontii (Aud.)

56. Euteleia evelinae Marc.

57 Hippothoa hyalina (L.)

58. Trypostega venusta (Norm.)

59. Pasythea tulipifera (Elı. Sol.)

60. Exochella longirostris Jull.

6) Escharoides costifera (Osb.)

62. Escharina krampi Marc.

63. Schizoporella unicornis (Johnst.)

64. Schizoporella pungens Can. \& Bassl.

65. Schizoporella horsti (Osb.)

66. Schizoporella carvalhoi Marc.

b7 Stylopoma informata (Lonsd.)

68. Arthropoma cecilii (Aud.)

69. Dakaria sertata Can. \& Bassl.

70. Hippoporina porcellana (Bsk.)

71. Perigastrella contracta (Wat.).

72. Màstigophora pes-anseris (Smitt)

73. Hippoporella gorgonensis Hast.

74. Hippodiplosia americana (Verr.)
75. Hippodiplosia otto-mülleriana (Moll) var. parva Marc.

76. Hippodiplosia pertusa (Esper)

77 Smittina trispinosa (Johnst.)

78. Smittina trispinosa (Johnst.) var. nitida (Verr.)

79 Smittina trispinosa (Johnst.) var. munita (Hcks.)

80. Smittina trispinosa (Johnst.) var. loxa Marc.

81. Smittina evelinae Marc.

82. Microporella ciliata (Pall.)

83. Microporella ciliata (Pall.) var. co. ronata (Aud.)

84. Adeona violacea (Johnst.)

85. Adeona tubulifera Can. \& Bassl.

86. Rhynchozoon verruculatum Smitt

87 Rhynchozoon phrynoglossum Marc.

88. Hippopodina feegeensis (Bsk.)

89. Watersipora cucullata (Bsk.)

90. Cellepora dichotoma Hcks.

91 Siniopelta costazii (Aud.)

92. Siniopelta diota Marc.

93. Siniopelta langei Marc.

94. Holoporella mordax Marc.

95. Holoporella carvalhoi Marc.

\section{Ctenostomata:}

96. Alcyonidium polyoum (Hass.)

97 Alcyonidium mamillatum Ald.

98. Alcyonidium hauffi Marc.

99 Victorella sibogae Harm.

100. Arachnidium fibrosum Hcks.

101. Arachnoidea evelinae Marc.

102. Nolella gigantea (Bsk.)

103. Nolella sawayai Mirc.

104. Nolella dilatata (Hcks.)

105. Nolella alta Kirkp.

106. Anguinella palmata Bened.

107 Amathia convoluta Lmx.

108. Amathia distans Bsk.

109. Bowerbankia gracilis Leidy

110. Bowerbankia caudata (Hcks.)

111. Zoobotryon pellucidum Ehrbg.

112. Mimosella verticillata (Hell.) var. firmata Marc.

113. Buskia nitens Ald.

114. Buskia socialis Hcks. 
115. Buskia setigera Hcks.

116. Terebripora ramosa d'Orb.

117 Terebripora orbignyana Fisch.
118. Terebripora fischeri Jull.

119. Spathipora sertum Fisch.

120. Spathipora ditrupae (Norm.)

Adoptando os grupos zoogeographicos, anteriormente estabelecidos (Marcus 1938, p. 60 e seg.), consideramos primeiramente as formas novas da nossa collecção e as especies até agora encontradas sómente no litoral atlantico da America tropical. Tendo verificado $\mathrm{Mimosella}$ verti cillata (Hell.) var. firmata Marc. no material de Recife, considero-a como elemento morphologico mais estavel do que pensei ao encontral-a pela primeira vez. Em virtude da difficuldade de separar ou unir especies fosseis e recentes, deixamos por emquanto de lado qualquer eventual occorrencia geologica das especies. Agrupando-as unicamente conforme a sua distribuição actual, chegamos a 29 formas que, provisoriamente, poderiam passar por autochthones no Atlantico tropical americano. Seriam as especies: 13 , $4,9,11,22,2728,31,35,37,51,56,59,61,64,65,66,75,81,87,92$, 93, 94, 95, 98, 101, 103, 112, ou 24,2\% do numero total. Especies atlanticas tropicaes e subtropicaes são $7(20,42,48,62,80,86,118)$ ou $5,8 \%$. Nas costas tropicaes atlantica e pacifica da America occorrem 4 especies $(69,73,85,116)$ ou $3,3 \%$.

Especies circum-subtropicaes e circum-tropicaes da nossa fauna são 16 $\{10,21,24,38,39,41,45,50,55,67,70,72,83,108,111\}$ ou $13,3 \%$. Distribuição igual, com excepção do Pacifico oriental, teem 14 especies $(7,12$, $30,32,33,34,53,54,84$ chega até 0 sul da Inglaterra, 88, 99, 105, 107. II5) ou $11,7 \%$.

Em consideração á delimitação algo larga do conceito subtropical" o numero de 70 especies (ou $\mathbf{5 8 , 3 \%}$ ) da nossa fauna restrictas ás regiões tropicaes e subtropicaes é pequena.

As outras especies são eurythermas, podendo II $(2,5,6,57.82,96$, 97. $104,110,113)$, ou $9,1 \%$ ser consideradas como cosmopolitas e outras $13(13,15,18,19,29,40,52,58,68,77,102,109)$ ou $10,8 \%$ como vastamente distribuidas, faltando apenas nas latitudes polares. $\bigcirc$ grupo seguinte é constituido pelas especies pacifico-atlanticas; tratando-se de formas nomeadamente do Pacifico oriental e ausentes no Indico, reflecte a sua distribuição o mar central-americano existente antes da elevação do isthmo; são 5 especies $(26,46,49,71,74)$ ou $4,2 \%$. Por outro lado ha 7 especies $\{8$, $14,36,44,63,78,100$ ) do Atlantico e Indo-Pacifico occidental; são 5,8\% do numero total. Como habitantes do Atlantico temperado da nossa fauna podemos contar 8 especies $(25,47,90,106,114$ até o canal de Suez, 117 $119,120)$ ou $6,7 \%$. E' pequeno o numero das especies antiboraes da nossa fauna, havendo apenas $2(43,60)$ ou $1,7 \%$. Uma especie (17) é verosimilmente elemento estranho á bryozoofauna de Santos, provavelmente foi impor- 
tada para aqui por um navio $10,8 \%$ da nossa fauna). 3 especies, cuja taxonomia ainda não está completamente esclarecida, não pódem ser analysadas $(16,23,79)$, seriam $2,5 \%$.

Do material de Recife composto de 18 especies (veja p. ||3-||4), || ou $61 \%$ se conhecem tambem do litoral paulista. Do litoral dos Estados do Paraná e de St. Catharina tivemos em mão as especies seguintes, todas em conchas da collecção do Snr. Lange de Morretes.

\section{Estado do Paraná:}

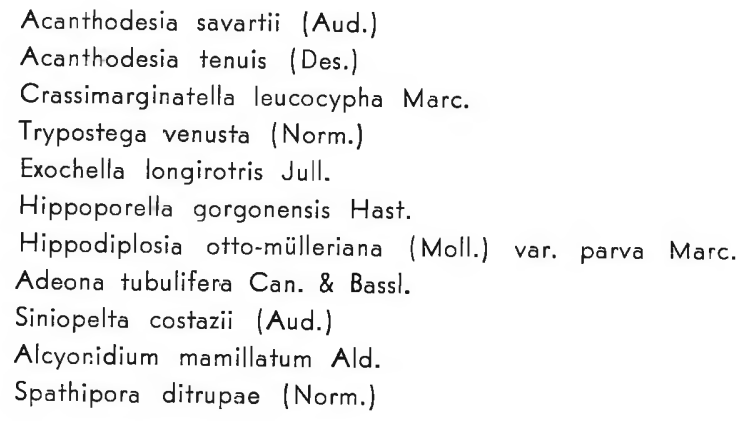

\section{Estado de Santa Catharina:}

Conopeum reticulum (L.)

Conopeum commensale Kirkp. \& Metz.

Acanthodesia tenuis (Des.)

Copidozoum tenuirostre (Hcks.)

Exochella longirostris Jull.

Mastigophora pes-anseris (Smitt)

Siniopelta langei Marc.

Das 18 especies classificadas, 16 , ou $88,9 \%$, occorrem tambem no litoral de São Paulo. Comparando a collecção do Sul com a de Recife e tomando em consideração que ambas são pequenas provas das bryozoofaunas sulina e nordestina respectivamente, de modo que são provisorias as conclusões zoogeographicas, o material paranaense e santacatharinense reflecte a vizinhança geographica e climatologica das zonas respectivas com o litoral paulista. 


\section{PARTE GERAL.}

\section{Introducção.}

Varios nomes relativos ao systema dos Bryozoa (Polyzoa) serào inevitaveis ncs capituios geraes, tanto no que se refere á myologia como á embryologia. Para facilitar aos leitores a compreensão rapida de taes termos, parece util o quadro synoptico seguinte. O nome da classe Polyzoa, allusivo (com erro linguistico) ao grande numero dos individuos reunidos em uma colonia foi publicado em dezembro de 1830 por John Vaughan Thompson. Os autores do imperio britannico, com excepção de Waters que publicou desde 1879 até 1926, e Jelly (1889) usam o termo Polyzoa, dando-se o mesmo com alguns autores (Leidy, Hyatt) dos Estados Unidos da America do Norte. Em outras publicações norte-americanas (Davenport, Robertson, Osburn) e na litteratura do continente europeu encontra-se o nome Bryozoa (Ehrenberg, março de 1831) que se refere á semelhança de certas colonias com musgos. Varios autores europeus (G. O. e M. Sars, Vigelius, Levinsen) e da America do Norte (Verrill) servem-se das duas denominações. A prioridade de "Polyzoa" é incontestavel, discutindo-se, porém, se Thompson definiu um genero ou uma unidade mais complexa. A discussão respectiva acha-se resumida por Hincks (1880, p. CXXXI, etc.) e Stebbing e outros (1911, p. 6I-72).

As sub-classes Entoprocta e Ectoprocta, quer dizer Bryozoa, cujo anus é situado dentro e fóra da corôa dos tentaculos, foram introduzidas por Nitsche (1869, p. 34)i a substituição do primeiro nome por Kamptozoa (animaes capazes de encurvamento; Cori 1929, p. 1-2) é inutil. Com excepção de Urnatella gracilis Leidy, especie norte-americana da agua doce, os Entoprocta habitam o mar, entrando varias especies tambem em agua salobra. Nos Ectoprocta distinguem-se duas super-ordens, os Phylactolaemata e os Gymnolaemata (Allman 1856, p. 10), quer dizer, respectivamente de bocca coberta (pelo epistôma) e núa. Os dois termos correspondentes, Lophopoda (tentaculos em tufo) e Stelmatopoda (tentaculos em cinto) embora mais antigos (Dumortier 1835, van der Hoeven 1827) usam-se hoje raramente, porque não foram introduzidos na forma e no sentido actuaes. Os Phylactolaemała vivem na agua doce. A divisão original (Busk 1852a, p. 346) dos 
Gymnolaemata em tres ordens Cheilostomata (de orificio provido de labio, i. é, do operculo) Ctenostomata (de orificio provido de pente, i.é, de dobras cuticulares) e Cyclostomata (de orificio circular) foi substituida por uma bi-partição (Borg 1926, p. 490). O nome da 1.a ordem Cyclostomata quasi homonymo com "Cyclostoma" (= Marsipobranchi, lampreias) foi substituido por Stenostomata, i.é, de orificio estreito (Marcus 1938, p. 116). Os Stenostomata são marinhos. A 2. ${ }^{a}$ ordem Eurystomata, i. é, de orificio largo (id. ibid.) abrange as 2 sub-ordens Cheilostomata e Ctenostomata. $\mathrm{Na}$ I. a sub-ordem, Cheilostomata, muito rica em especies, distinguem-se duas secções Anasca e Ascophora, i. é, sem sacco compensatorio e provido de tal (Levinsen 1909, p. 12, 88, 91). Com poucas excepções (fam. Membraniporidae) que entram na agua doce, todos os Cheilostomata são marinhos. Na 2. ${ }^{a}$ sub-ordem, Ctenostomata, é marinha a maioria das especies, havendo, porém, alguns generos da agua doce (p.e. Paludicella Victorella Hislopia Arachnoideal A denominação Ctenostomata, introduzida por Kahl para uma das sub-ordens dos $\mathrm{Ci}$ liata Spirotricha (Kahl 1932, p. 399, 401 518) e já recolhida na 5. edição do tratado conhecido da protozoologia de Doflein-Reichenow (1929), deveria ser mudada pelos protozoologos, porque nos registros dos tratados e das revistas tal homonymia dará origem a confusões.

\section{V.}

\section{Notas histo-myologicas.}

\section{Entoprocta.}

Os musculos dos Entoprocta são lisos. Adoptando a terminologia da Zoologia geral (Hesse 1935, p. 179 e seg.) não absolutamente identica com a da Histologia do homem e dos Mammalia (Maximow e Bloom 1938, p. 148 e seg.) distinguimos no tecido muscular as cellulas musculares uni-nucleadas (myocytos) e as fibras musculares pluri-nucleadas. Nos Entoprocta encontram-se sómente myocytos lisos, no pedunculo muito compridos. As differenciações contracteis dos myocytos, as myofibrillas, são sempre nitidas. As fibrillas acham-se situadas na peripheria do myocyto, o qual circumdam á maneira de um manto (Fig. 28). O nucleo encontra-se unilateralmente e dentro de uma saliencia do sarcoplasma, de maneira que o myocyto do pedunculo de Pedicellina lembra o typo conhecido da cellula muscular secundariamente epithelial das Ascaridae e outros Nematodes. Seja, porém, lembrado que tal semelhança não póde ser utilizada para approxi- 
mar os Entoprocta aos Aschelminthes, porque myocytos analogos occorrem tambem em Oligochaeta (Hesse 1894, p. 398 e seg. t. 24 f. 2) e Hirudinea (Scriban 1907. p. $402-403$ f. 2A, 2B; Autrum 1932, p. 470 f. 15). Ehlers (1890, p. 26,1/2) descreveu os pormenores dos myocytos de Ascopodaria macropus Ehl., ao meu vêr, identica á Barentsia discreta (Bsk.) (veja p. 210). As figuras dadas por Ehlers (p. e. t. I f. $12-14$, t. 2 f. 18) concordam nos șeus elementos essenciaes com as nossas de Pedicellina cernua (Pall.). A terminologia, porém, adoptada por Ehlers e repetida por Cori (1936, p. 50-5I) não me parece admissivel. Os dois autores chamam de "myoblasto' ou "corpo da cellula" (Ehlers) a saliencia sarcoplasmatica que contem o nucleo do myocyto. Myoblasto é um termo embryologico que significa cellula formadora de musculo. Usa-se especialmente como designação das cellula da lamella muscular do myotomo. dos Vertebrata. Póde naturalmente tambem applicar-se á qualquer cellula dos Evertebrata que dá origem a musculos. N'este sentido falla-se em myoblasto nos Platyhelminthes (Turbellaria: Jander 1897. p. 174 t. 13 f. 17-24; Böhmig 1906, p. 390 t. 12 f. 6; Prenant 1922, t. 2 f. 35. Trematodes: Bettendorf 1897, p. 313 f. 1-20. Cestodes: Zernecke 1895, p. 106 t. 15 f. 72). Em todos estes grupos originam-se varias faixas de fibrillas de uma cellula, de maneira que os elementos contracteis se tornam, morphologicamente de certo modo, independentes dos elementos nutritivos. Segundo Bartsch (1923, p. 29 †. 9 f. 66) appõem-se nas Planarias cellulas regeneradoras ás fibrillas musculares no tecido de animaes velhos. Taes cellulas são. naturalmente tambem myoblastos typicos.

\section{Ectoprocta.}

N'esta sub-classe que abrange ca. de 4.000 especies em opposição ás: ca. de 70 dos Entoprocta, o problema da histologia dos musculos é muito. mais complicado, denotando-se isto pela maneira, como tratados usuaes resumem as observações originaes. As cellulas musculares dos vermes são quasi sempre não estriadas, sómente os Rotatoria e Echinodera, quer dizer Kinorhyncha, como tambem alguns Bryozoa mostram em parte fibras bem estriadas transversalmente" (Bütschli 192I, p. 4II). O excellente artigo. relativo aos Bryozoa do diccionario das sciencias naturaes (2. ${ }^{\mathrm{a}}$ ed.) mostra que ainda não harmonizaram os varios pesquizadores da musculatura dos. Ectoprocta (v. Buddenbrock 1932, p. 268). Nota-se tal discordancia já muito cedo na litteratura bryozoologica. Foram especialmente discutidos os. grandes musculos retractores do polypidio que se contrahem rapidamente.

H. Milne Edwards (1836, p. 23) disse ser o musculo retractor do polypidio de Porella cervicornis (Pall.) (Cheilostomata Ascophora 
transversalmente estriado. Van Beneden (1845, p. 12) e Dumortier e van Beneden (1850, p. 48, 86) descreveram como sendo lisos os musculos em Gymnolaemata (Ctenostomata: Farrella, Paludicella) e Phylactolaemata. Busk (1854a, p. 27) referindo-se a uma sua publicação anterior ainda (1847) disse serem os musculos dos heterozoecios, avicularias e vibraculas dos Gymnolaemata Cheilostomata, estriados transversalmente, como se mostram nas figuras respectivas (t. $2 \mathrm{f}, 10,12$ etc.). O musculo retractor do polypidio dos Gymnolaemata (Paludicella) e Phylactolaemata foi, no estado de estensão descripto como estriado por Allman, na sua monographia dos Polyzoa da agua doce (1856, p. 30-31); em replica Smitt (1863, p. 25 , nota 2 da p. 24) asseverou nunca ter verificado estrias nos retractores dos Bryozoa marinhos (Gymnolaemata). Na mesma pagina (p. 25) refere-se aos musculos estriados das avicularias e vibraculas, dando dos musculos da vibracula alguns annos mais tarde a primeira figura da litteratura que mostra as estrias (Smitt 1867a, t. 17 f. 48). Nitsche (1868, p. 35-36) negou a occorrencia das estrias nos retractores dos Phylactolaemata pretendidas por Allman, mas verificou no esophago e ceco de Plumatella fungosa (Pall.) uma especie de estriação transversal" (p. 16-17 t. 2 f. 15), cuja natureza verdadeira deixou em suspenso. Pesquizando um representante dos Gymriolaemata marinhos, Membranipora membranacea (L.), Nitsche (187| p. 19) encontrou lisos os occlusores do operculo e os elementos da musculatura parietal, notando, porém, nos grandes retractores ás vezes, nem sempre, estrias transversaes, independentes da contracção ou do relaxamento. Disse que seriam condicionadas pela propria estructura das fibrillas, não por dobras do sarcolemma. Depois d'esta nota relativa a uma especie dos Cheilostomata houve outra acerca de Hypophorella expansa (Ehlers 1876, p. 53), pertencente aos Gymnolaemata Ctenostomata, cujo retractor Ehlers observou estriado no momento de se contrahir este musculo. Na introducção geral da monographia de Hincks (1880, p. XXXI) não são apresentados novos pontos de vista, sendo as figuras do retractor estriado e dos musculos estriados dos heterozoécios copiados de Nitsche (187I, t. 3 f. 11). Busk (1854a, t. 2 f. 10, 12) e Smitt (1867a, t. 17 f. 48).

Da época da bryozoologia moderna que póde ser datada desde a publicação da obra de Hincks (1880) cito apenas algumas passagens. Vigelius (1884, p. 35) descreveu no seu trabalho anatomico muito valioso acerca de Flustra membranaceo truncata (Smitt) (Gymnol. Cheilost.), nos musculos do operculo e no retractor, um typo de estrias transversaes, "de nenhum modo correspondente ao typo regular de taes estrias" Criticando a figura acima de Nitsche do retractor de Membranipora membran a cea (L.), accentuou a inconstancia do phenomeno. Kraepelin (1887. p. 
p. 67 68) viu estrias nos retractores estendidos dos Gymnolaemata (Paludicella) e Phylactolaemata da agua doce, confirmando assim a verificação de Allman. Freese $(1888$, p. 22, 28) notou ás vezes occlusores do operculo e retractores estriados. Sem allusão correspondente no texto, mostra-se entre os numerosos desenhos anatomicos de Jullien (1888), uma avicularia de musculos estriados (t. 9 f. 2), sendo todos os outros musculos de autozoécios e avicularias figurados como lisos. Davenport (1890, p. |4I) apontou musculatura estriada em redor do ceco de Cristatella mucedo Cuv. (Phylact.) sem, porém, demonstral-a na figura respectiva (t. 10 f. 85). Outro pesquizador contemporaneo dos Phylactolaemata (Pectinatella gelatinosa Oka 1890, p. III-1I2) disse: "os musculos nunca são estriados. Mesmo no retractor do polypidio, evidentemente de summa importancia physiologica, as fibras são lisas. Nos Polyzoa marinhos, porém, observei que são estriados os musculos das aviculariás e vibraculas" Do mesmo anno podemos ainda citar Braem (1890, p. 64) que se liga á opinião de Allman e Kraepelin quanto ás estrias presentes nos retractores estendidos. Na sua synopse dos Bryozoa da Dinamarca indicou Levinsen (1894, p. II) os retractores brevemente como estriados. Calvet $(1900$, p. $45,214,230)$ julgou provirem de pregas do manto sarcoplasmatico as estrias ás vezes visiveis nos musculos contrahidos, realmente todos lisos nos autozoécios dos Gymnolaemata. Nos musculos dos heterozoécios distinguiu (p. 53, 258) os adductores e abductores estriadis dos musculos parietaes lisos (abductores proximaes da terminologia applicada mais adiante). Tambem Ladewig (1900, p. 333) encontrou estriados os musculos da avicularia de Bugula avicularia (L.), desenhando estranhamente cada fibra provida de dois nucleos (t. 18 f. 26). Schulz (1901, p. 125-126) pôde verificar as estrias nos musculos dos autozoécios (t. 7 f. 26b) sómente com conservação especialmente favoravel; seja lembrado que o material de Schulz era Electra crustulenta (Pall.), não Membranipora membranacea (L.) (Borg 193I, p. 6). Na musculatura complicada da larva de Electra pilosa (L.) chamada Cyphonautes compressus Ehrbg., e em outras larvas do mesmo typo verificou Kupelwieser (1905, p. 28-30) musculos estriados, evidentemente quasi typicos. Silbermann (1906, p. 298) encontrou em Alcyonidium polyoum (Hass.) frequentemente elementos estriados, a saber nos tentaculos (p. 282) e no retractor. Braem (1908, p. 35 t. 4 f. 37) affirmou a occorrencia de estrias no retractor de Fredericella sultana (Blbch.), fallando Müller (1914, p. 35) sobre outros Phylactolaemata (gen. $\mathrm{P} \mid \mathrm{u} \mathrm{m}$ a tella) providos de retractor obliquamente estriado. Borg (1923, p. 5; 1926, p. 218, 225-226, 231-232) descreveu elementos estriados em varios musculos dos Gymnolaemata Stenostomata, a saber, nos tentaculos, no estomodeo, no "intestino jejuno" i. é, a 
cardia da litteratura bryozoologica anterior, nos dois retractores do polypidio e nos constrictores do canal annular. Pesquizados com auxilio do microscopio de polarisação (Marcus 1926b, p. 315 e seg.), todos os retractores examinados dos Gymnolaemata e Phylactolaemata mostraram-se lisos, permanecendo estriados sómente certos musculos dos heterozoécios dos Cheilostomata (f. 20 p. 3|7). Lophopus crystallinus (Phylactolaemata) possúe tambem unicamente musculos lisos, dando-se o mesmo com Fredericel! a (Marcus 1934, p. 554 564).

Tendo Becker (1937, p. 100, 113) novamente descripto musculatura annelar estriada no ceco de Cristatella mucedo Cuv. (Phylactolaemata), não visivel na fig. 31 (p. I|2) do córte transversal, onde deveria apparecer, re-examinámos essa especie com material de Berlin.

Verificamos as cellulas musculares annelares como sendo lisas. Como se vê na nossa figura topographica (Marcus 1934, f. 38 p. 563), é em Cristatella e Pectinatella especialmente forte a membrana sustentadora que se acha situada entre o epithelio intestinal e a musculatura. Becker (1937. p. I12) usa na explicação da sua figura 31 o termo "membrana basilar' ao meu vêr, pouco feliz para caracterisar essa membrana grossa. Em certas outras figuras do ceco de $\mathrm{Cristatella} \mathrm{dadas}$ por Becker (I. c., f. 25, 28, 29) faltam a membrana sustentadora e a musculatura intestinal, appondo-se o mesoderma immediatamente ao epithelio. Nota-se assim alguma incerteza do autor acerca das camadas extra-epitheliaes do intestino dos Phylactolaemata, e talvez tenha elle, na figura 3I, confundido certa porção da membrana sustentadora com a musculatura, por si mesma não tão larga em $\mathrm{Cr}$ istatella, como foi desenhada na figura citada. Seja repetido que não se mostra estriada a musculatura na illustração, em opposição ao texto (l. c., p. 100, I|3). Os presentes córtes tangenciaes do ceco de $\mathrm{Cr}$ istatella, corados ligeiramente com hematoxylina ferrica, permittem vêr na região da membrana sustentadora as dobras d'esta camada (Fig. 29). A substancia das dobras apresenta-se de densidade desigual, d'ahi resultando em algumas dobras estructura mais ou menos nitida de estrias irregulares, obliquamente dispostas. Outras dobras, porém, mostram-se homogeneas. Explicação plausivel do phenomeno offerece-se, se suppormos phases de contracção differentes nas varias cellulas musculares, adjacentes á membrana sustentadora. No ceco, onde os alimentos são amassados em rythmo e direcção determinados (Marcus 1934. p. 56I), tal differença da intensidade da contracção dos diversos elementos musculares é muito provavel. As dobras "estriadas" da membrana sustentadora seriam verosimilmente as adjacentes aos musculos mais fortemente contrahidos. Em todo o caso, as fracas differenciações obliquas na membrana sustentadora nada teem de vêr com isotropia e anisotropia; ccmo se 
manifestam em musculos estriados. Até 1938, foi, pelo que sei, publicada uma unica figura de musculos estriados em redor do intestino dos Bryozoa, a saber a musculatura do esophago de Plumatella fungosa (Pall.) (Nitsche 1868, t. 2 f. 15). Sem duvida, assemelha-se muito á nossa Fig. 29, mas não parece admissivel suppôr ter Nitsche tambem desenhado a membrana sustentadora com differenças de densidade. Levando em consideração a tenuidade da membrana sustentadora no esophago, prefiro deixar inexplicada a figura de Nitsche, em vez de interpretal-a de modo forçado.

No anno passado foram publicados novos desenhos de musculos estriados circum-intestinaes por Bronstein (1938, p. 258). Trabalhando com varios Eurystomata fixados em Bouin e corados com hematoxylina "incompletamente differenciada" Bronstein verificou estrias transversaes na musculatura circular do intestino e no retractor do polypidio, accrescentando (p. 258) que os retractores estriados, quando examinados á luz polarizada, se mostraram lisos. $O$ artefacto interessante foi de certo modo confirmado por nós em córtes de Acanthodesia tenuis (Des.) (Cheilostomata Anasca), fixada em alcohol e corados com hematoxylina ferrica-eosina. Como os córtes foram um pouco grandes demais, a differenciação não foi satisfactoria em toda a parte, verificando-se o phenomeno assignalado por Bronstein nas zonas insufficientemente differenciadas, tanto nas cellulas musculares do retractor (Fig. $30 \mathrm{r}$ ), como nos musculos annelares da pharynge (a). Ambos apresentam-se listrados, alternando discos pretos e descorados. Conforme á intensidade da differenciação varia a largura das porções pretas. Não occorre, porém, como na figura das cellulas correspondentes dada por Bronstein (1938, f. I, I) a separação dos myocommata muito regulares por membrana transversal (disco intermediario), ausente tambem no seu desenho do retractor (ibid., f. I, 2). A falta do disco intermediario e a irregularidade das estrias indicam que a "musculatura estriada" da nossa Fig. 30 não poderia ser confundida com musculos estriados verdadeiros. Musculos estriados dos Invertebrata, especialmente dos Arthropoda, mostram á luz polarizada o aspecto das boas microphotographias de musculos estriados de coleopteros (Schmidt 1924, f. 208, 210 ). As listras de Bronstein desapparecem completamente quando examinadas entre "Nicols" cruzados. (*) Córtes correctamente differenciados revelam os musculos do intestino e o retractor uniformemente claros e lisos. Por outro lado, não se precisa de manipulação especial para vêr dupla refracção verdadeira, permanente tambem no microscopio de polarisação (Marcus 1926b, f. 20 p. 317), nos

$\left({ }^{*}\right)$ Agradeço do meu collega Prof. Dr. E. Onorato por me ter proporcionado o microscopio de polarisação no Dept. de Mineralogia da Faculdade de Philosophia, Sciencias e Letras da nossa Univeŕsidade para este estudo. 
musculos das avicularias e vibraculas, não raras vezes nitida até nas colonias viventes.

Ao que parece, Bronstein viu e desenhou na pharynge de Electra pilos a (L.) estriação transversal, sem discuti-la no texto (ibid., f. II). Taes elementos estriados nas cellulas do epithelio do intestino anterior dos Bryozoa Ectoprocta foram pela primeira vez figurados por Davenport (189), t. 10 f. 85), mas não comprehendidos, como revela a explicação da figura e o texto correspondente (p. 63). A especie pesquizada por Davenport chamada por elle Escharella variabilis Leidy é Schizoporella unicornis (Johnst.), portanto um representante dos Cheilostomata Ascophora. As figuras de Calvet (1900, t. 2 f. 9, 10, 13; t. 6 f. 2, 6; t. 7 f. 4, 7. 15) mostram igualmente estructuras estriadas nas cellulas do intestino anterior de Cheilostomata Anasca e Ascophora, Ctenostomata e Stenostomata. Os pormenores d'esses desenhos e o texto (p. 4I, 220-22I) informam que Calvet considerou as zonas estriadas periphericas das cellulas como sendo os proprios limites cellulares: "as membranas das cellulas apresentam com intervallos regulares espessamentos e porções mais miúdas, dando isso ás membranas cellulares aspecto perfurado" Observação semelhante encontra-se no texto, não nas figuras, de Borg acerca dos Stenostomata (1926, p. 221): "como indicação da semelhança, - quer dizer entre os epithelios correspondentes dos Eurystomata e Stenostamata - podemos noticiar que as membranas cellulares na pharynge e no esophago mostram alternadamente zonas mais grossas e mais delgadas sendo, porém, esta estructura sempre parcamente desenvolvida e frequentemente até incognoscivel" Muito mais decidida é a descripção de Henneguy (1909, p. 134 e seg.) de fibrillas longitudinaes, estriadas transversalmente, nas cellulas do intestino anterior de Alcyonidium hirsutum (Flem.) (Ctenostomata) e de Bugula "alveolata" J. V. Thompson. Sendo "fla bellata" o unico nome valido ligado ao de John Vaughan Thompson no genero B u gul a, não figurando al ve ol a ta" nem sequer entre os synonymos, parece verosimil ter Henneguy trabalhado com B ugula flabella ta (J. V Thomps.). Com excepção da nota muito summaria de Calvet (1910, p. 20 nota) não conheço na litteratura bryozoologica outra referencia ás fibrillas em questão até 1934, quando tentámos em vão ver estes elementos em Kine toskias s m itti Dan. (Cheilost. Anasca) (Marcus 1934, p. 564-565). No rico material de Bryozoa marinhos convenientemente fixado (sublimado, Bouin etc.), actualmente disponivel, pudemos verificar zonas estriadas nas cellulas epitheliaes da pharynge das especies seguintes: Acanthodesia tenuis (Des.), Alcyonidium polyoum (Hass.), A. mamillatum Ald. Mimosella verticillata (Hell.) var. firmata Marc. e Crisevia pseudosolena Marc. As estrias estão longe de ser nitidas em 
todos os individuos examinados das especies citadas, e, ao que parece, não depende da fixação escolhida a possibilidade de observa-las, pois ás vezes se mostram bem em material da colleç̧ão geral do Departamento, fixado e conservado em alcohol, e em outros casos são imperceptiveis em polypidios de colonias fixadas para fins histologicos. Onde a estriação apparece (Fig. 31), apresenta-se uniformemente em cellulas contiguas. As cellulas pharyngeanas são prismaticas e providas de grandes vacuolos (v), restringindo-se o cytoplasma commum ás circumvizinhanças do nucleo $(u)$, situado no fundo da cellula e á peripheria cellular. Esta ultima zona acha-se listrada na sua totalidade, sem que tenha sido possivel, no material actual, discernir as proprias fibrillas longitudinaes descriptas e desenhadas por Henneguy. Tão pouco pudemos vêr o disco intermediario figurado por este ultimo autor. Não queremos negar a existencia de fibrillas longitudinaes estriadas transversalmente, mas devemos dizer que o augmento mais forte á nossa disposição (Zeiss Immersão (20) não possibilitou analysarmos fibrillas separadas na pellicula protoplasmatica muito tenue que envolve o vacuolo. Pensando talvez sejam mais favoraveis os polypidios jovens para vêr as fibrillas em cellulas pharyngeanas de vacuolos ainda menores, tal material tambem foi examinado, mas sem effeito differente. O nosso achado negativo em assumpto estudado por histologo tão competente, como Henneguy, não é decisivo, devemos portanto aguardar opportunidade futura para voltarmos ao problema. A occorrencia de cellulas myo-epitheliaes nos Bryozoa é, sem duvida, muito interessante sob ponto de vista da histologia comparativa. Systematicamente, porém, não convem exagerar a importancia do facto, porque ao lado dos Aschelminthes providos de cellulas myoepitheliaes na pharynge, a saber os Gastrotricha (Remane 1935, p. 63), os Rotifera (origem myo-epithelial, definitivamente syncycial, Remane 1932, p. 183, 193) e os Nematodes (pharynge semelhante á dos Rotatoria, Rauther 1930, p. 293) encontramos nos Kinorhyncha pharynge turbellarioide (Remane 1929a, p. (4) 219-220). Apezar d'isso merece a união dos Gastrotricha, Nematodes e Kinorhyncha proposta por Remane (1926, p. 749) no grupo dos Nematodaria approvação geral (Marcus 1938a, p. 79, 83).

São lisos tambem os musculos do estomago mastigador (moela, "gizzard") dos Ctenostomata, cuja contracção é rapida e contínua. Em Am athia distans Bsk. o estomago mastigador acha-se composto das camadas seguintes: esplanchnopleura pauci-cellular (Fig. 32, e), cellulas musculares circulares lisas $(\mathrm{m})$ e epithelio estomacal (s). Entre o epithelio e a camada muscular nota-se membrana sustentadora muito tenue que poderia ser chamada membrana basal do epithelio. As cellulas epitheliaes possuem nas suas pontas livres dentes chitinicos, como foram desenhados nos córtes transversaes do estomago mastigador de A mathia por Calvet (1900, 
t. 7 f. 8, ge) e Anna B. Hastings (1927 f. 88 D, p. 350). Distinguem-se dois grupos de dentes maiores dos restantes menores. Na Fig. 32 foi desenhado o lado do estomago mastigador voltado para o recto $(r)$ na vista offerecida pelo córte optico e o lado ab-anal (designo assim o lado opposto ao anus) na vista da face externa. Os nucleos das cellulas musculares, não vistos por Calvet (1900, p. 230), encontram-se no lado ab-anal. Como são mais grossos que as proprias cellulas filamentosas, os nucleos occupam lugares differentes na metade ab-anal do estomago mastigador. Não é tal disposição a regra seguida pelos nucleos das cellulas musculares dos Bryozoa Gymnolaemata. A litteratura contem varias figuras, em que estes nucleos na bainha tentacular e no intestino se acham situados no mesmo plano, seja transversal no caso de musculos longitudinaes, seja longitudinal, no caso de musculos circulares. Cito como exemplos apenas os musculos longitudinaes da bainha tentacular e do recto de Zoobotryon pellucidum (Gerwerzhagen 1913a, f. 4) e de Flustrella hispida (Graupner 1930, f. 28) e os musculos annelares do tracto intestinal de Bugula sabatieri (Calvet 1900, t. 2 f. I) e de Alcyonidium polyoum (Bronstein 1938, f. III). Das especies actualmente estudadas menciono Conopeum reticulum, Crassimarginatella leucocypha e Beania mirabilis, em que os nucleos das cellulas musculares longitudinaes se encontram no mesmo plano transversal da bainha tentacular e Aetea anguina, Electra bellula, Beania mirabilis, B. intermedia e Thalamoporella evelinae com nucleos da musculatura circular do intestino anterior dispostos no mesmo plano longitudinal. O tracto intestinal de $A$ ete a anguina (Fig. 33) mostra na pharynge $(p)$ e no esophago $(e)$ os nucleos em questão, todos no lado anal e sobrepostos em fila vertical. Na cardia (c) e no ceco (o) encontram-se no lado ab-anal, no pyloro $(y)$ e no recto $(r)$ continuam no mesmo lado que no intestino posterior convem chamar oral. A posição enfileirada e em um lado determinado do plano mediano assumida pelos nucleos das cellulas musculares circulares do tracto intestinal constitue um problema ainda não resolvido no estado actual dos nossos conhecimentos acerca do desenvolvimento do polypidio. Na ampla litteratura que versa sobre o desenvolvimento post-larval dos Gymnolaemata conheço sómente as figuras dos polypidios jovens de Hippodiplosia pallasiana (Davenport 1891, t. 10 f. 86) e de Bugula sabatieri (Calvet 1900, t. 5 f. 16 , t. 2 f. I) com os primordios dos musculos do estomago visiveis, notando Calvet I. c., p. 143) o apparecimento d'esses musculos, sem discutir o seu desenvolvimento ulterior.

Nos heterozoécios, nas avicularias e vibraculas dos Cheilostomata, encontram-se musculos estriados. Nas vibraculas ainda não é possivel esta- 
belecer uma regra fixa, quaes os musculos lisos e quaes os estriados. Em duas especies de $\mathrm{C}$ a berea, p. e., encontrámos anteriormente (Marcus 1926b, p. 315) musculatura estriada no exame pelo microscopio de polarisação e re-confirmámos agora este facto. Por outro lado, assignalámos como sendo lisos os musculos das vibraculas de Scrupocellaria cervicornis e S. diadema, verificando actualmente musculatura lisa na vibracula de Scrupocellaria cornigera (Fig. 34). Os musculos das avicularias da nossa lista anterior (l. c., p. 315) mostram varios casos de falta de estrias. Realmente o problema é muito complexo, por serem os occlusores estriados, os divaricadores (abductores) lisos. Além d'isso nem sempre é possivel, mesmo á luz polarisada, esclarecer a natureza dos musculos. Em Crassimarginatella leucocypha e Rhynchozoon phrynoglossum do material recentemente colhido em Santos as avicularias mostraram ás vezes occlusores estriados, ao passo que em outras avicularias da mesma serie de córtes não foi possivel descobrir estriação alguma. Tal phenomeno por enquanto não posso explicar. Silén diz (1938, p. 251-252) que os adductores (occlusores) da mandibula são estriados, "o que é especialmente nitido no estado relaxado Isto podemos confirmar e até accrescentar que nem sempre se mostram estriados os occlusores da mandibula de Synnotum aegyptiacum de Santos á luz polarizada, quando se examinar uma avicularia fechada, quer dizer de occlusores contrahidos. Avicularias abertas, porém, de musculos adductores relaxados fazem vêr estes musculos nitidamente estriados. Por outro lado, apparece o retractor do polypidio estriado na phase de contracção, quando o polypidio se acha invaginado. Tal estriação, porém, nunca resiste ao exame á luz polarisada, porque resulta do facto de se preguear o envoltorio de sarcoplasma não contractil do musculo. Sem excepção foi encontrado no material anterior e novamente examinado por nós o retractor do polypidio composto de cellulas musculares lisas.

\section{VI.}

\section{As vibraculas e avicularias.}

As pesquisas myologicas levaram-nos ao estudo dos heterozoécios já antes da publicação do trabalho de Silén (1938), cujos resultados em certos pontos divergentes dos nossos teremos de discutir nas passagens respectivas. Quanto aos 'musculos das vibraculas mantemos a nomenclatura introduzida por Calvet (1900, p. 335), fallando em m. abductor e m. adductor (Fig. 34). Ambos são de comprimento e volume iguaes correspondendo isso á amplitude e ao periodo iguaes dos dois movimentos executados pelo abductor e 
adductor respectivamente (Marcus 1926a, p. 56-57). O adductor (d) é o musculo que move a cerda (flagello, "saeta") (c) da vibracula para o lado do botão (*), o abductor (b) leva-a para o lado opposto. A vibracula pode ser chamada fechada, quando a cerda assume posição transversal na parede basal do autozoécio annexo, achando-se nesta phase os adductores contrahidos, os abductores relaxados. A vibracula abre-se, quando os abductores levantam a cerda até á posição perpendicular, parallela á direcção do crescimento da colonia. Contracção ulterior dos abductores faz então a cerda varrer sobre a parede frontal da colonia. Devido á elasticidade da chitina da cerda, ella curva-se durante o ultimo movimento, cuja phase final, a posição transversal da cerda sobre a parede frontal do autozoécio, significa o cume da phase aberta da vibracula. Acham-se então os abductores contrahidos no maximo, os adductores completamente relaxados. A seguir começa a actuação dos adductores, repetindo-se os movimentos descriptos no sentido contrario e dando-se agora a cúrvatura da cerda elastitica, quando ella passa da posição perpendicular para o lado basal da colonia. A cerda é implantada na camara da vibracula facilmente movel por meio de duas dilatações (Fig. 34B, i) que giram em torno de moentes chitinicos da camara $(\mathrm{m})$. A vista lateral mostra a terminação globular da cerda, e esta bola basal do flagello acha-se reforçada em dois lados oppostos por escleritos chitinicos (Fig. $34 \mathrm{~A}$, e), nos quaes os musculos adductor e abductor inserem.

As avicularias dos Cheilostomata possúem, sem excepção, dois grupos de musculos, physiologicamente antagonistas, a saber, os abductores e adductores da mandibula. Os adductores, tambem chamados occlusores, correspondem aos occlusores do operculo do autozoécio. Os ultimos, porém, são lisos. Na avicularia são os adductores os maiores musculos, e acham-se r.ompostos, como foi dito anteriormente, de cellulas, cujas myofibrillas são estriadas transversalmente. Ha geralmente um par de adductores, symetricamente situados, e cada musculo é provido de um tendão comprido. Os tendões inserem na região distal $\left({ }^{* *}\right)$ de um campo menos chitinisado da

$\left({ }^{*}\right)$ As circumstancias em que o material de Scrupocellaria cornigera foi colleccionado, não permittem confiar plenamente na fixação de todos os pormenores histologicos. Desde modo não convem discutir a ausencia de cilios no botão (p) desenhado, sendo estes sempre estructuras delicadas.

$\left({ }^{* *}\right)$ Para possibilitar a anatomia e physiologia comparativas da avicularia recommenda-se terminologia topographica uniforme, como foi usada tambem por Silén (1938). Seriam, portanto, applicadas aqui as denominações proximal e distal, frontal, basal e lateral no sentido que se conhece pelas descripções dos autozoécios. Em avicularias interzoeciares, p. e. das Membraniporidae, Flustridae etc., taes designações serão sem delongas comprehensiveis. Tambem nas avicularias lateraes das Scrupocellariidae não haverá difficuldades. Em avicularias adventicias brotadas na parede frontal, é verdade, a região 
mandibula. Em Hippodiplosia americana (Fig. 35) e Schizaparella horsti (Fig. 13) foi encontrado por nós um unico tendão; em Rhynchozoon phrynoglossum avicularias de typo igual pódem possuir um ou dois tendões (Fig. 36 A, B). Holoporella carvaI hoi mostra dois tendões nas avicularias vicarias (Fig. $23 C_{1}$ i), havendo um nas avicularias adventicias (zoeciaes) (Fig. 23 D). Quanto ás Adeonidae, segundo Busk (1884, p. 178) e Waters (1912, p. 496; 1913, p. 529) providas. de um unico musculo occlusor da avicularia, prefiro por emquanto fallar em tendão unico, como o mostram p. e. varias figuras de Levinsen (1909, t. 14 f. $2 e, 3 d, 4 f, 5 d)$, porque pode haver dois musculos com tendão commum, como se vê nas figuras de Rhynchozoon verruculatum (Fig. 20C) e Rh. phrynoglossum (Fig. 36 B).

Em opposição á uniformidade dos adductores nota-se diversidade dos. abductores que nem mesmo são identicos dentro do mesmo genero (veịa mais adiante: Flustira). Tal heterogeneidade dos abductores já se annuncia pela nomenclatura variada, fallando p. e. Calvet $(1900$, p. 52) em musculos parietaes na descripção de certos musculos que physiologicamente actuam como abductores. Nas Steganoporellidae, cujas avicularias providas de polypidios lembram muito os autozoécios, Harmer introduziu os termos. depressores e divaricadores (1902, p. 319; 1926, p. 272).

\section{Avicularias do typo autozoecial.}

A avicularia menos afastada do typo do autozoécio dos Malacostega. occore, pelo menos nas especies da bahia de Santos, em Crassimarginatella leucocypha (Marcus 1937. p. 46). As avicularias maximas desta especie (Fig. 37. 2) acham-se, como foi assignalado anteriormente (Marcus 1938, p. 20), providas de polypidios capazes de alimentar a avicularia. Este facto torna, sem duvida, precaria a definição de tal zoécio aberrante como avicularia. Na litteratura actual conheço sómente tres casos de heterozoécios providos de polypidios e considerados, embora não unan.memente, como avicularias. Occorrem em Acanthodesia serrata (Hastings 1930, p. 707-708), no genero Steganoporella (Harmer 1926, p. 268) e em Crepis decussata (ibid., p. 320). O primeiro caso passou desapercebido por Silén, o segundo é discutido por

distal da avicularia indicada pela ponta livre da mandibula muitas vezes (Scrupocellariidae, Ascophora de avicularias "descendentes", no sentido de Canu \& Bassler 1929, p. 341) achar-se-ha dirigida para o lado proximal do autozoécio. Não obstante, a homologia morphologica exige a applicação das mesmas indicações, como nas avicularias interzoeciaes. 
elle (1938, p. 342-347) e o terceiro collocado no seu quinto grupo de avicularias que abrange as duvidosas (ibid., p. 289).

Os criterios applicaveis na separação dos heterozoécios e autozoécios seriam a posição, muitas vezes, nem sempre, determinada dos heterozoécios na colonia, as medidas menores dos heterozoécios, o operculo aberrante e a ausencia de polypidio capaz de alimentação independente do individuo chamado heterozoécio. Foi assignalada por nós (Marcus 1926a, p. 38-40) a regra de apparecerem em Flustra foliacea as avicularias, que nesta especie são independentes (vicarias, zoariaes), em bifurcações das series longitudinaes formadas pelos zoécios communs (autozoécios). Nos pontos descriptos as avicularias são um dos dois novos botões (zoécios-filhas). As series zoeciaes de Flustra foliacea alternam, de maneira que os individuos se acham dispostos em quinconcio. Por isso torna-se o espaço disponivel para o individuo inferior dos dois iniciaes das duas series novas especialmente estreito. Sendo as avicularias em Flustra foliacea muito menores que os autozoécios é possivel considerar o apparecimento de todas as avicularias presentes como botões inferiores em bifurcações sob ponto de vista mechanico. Silén confirmou o facto $(1938$, p. 166) enumerando ainda numerosos exemplos que revelam ser muito commum a posição descripta nas avicularias dos Cheilostomata Anasca. Mas, no genero Cellaria, muito rico em especies, as avicularias de tamanho quasi igual ao dos autozoécios ou menores que estes, occorrem tanto em series indivisas (Marcus 1937a, p. 206: Cellaria punctata; Silén 1938, p. 289) como em bifurcadas (Silén 1938, p. 287). No terceiro e quarto grupo de avicularias de Silén ha outros exemplos ainda de avicularias dos Anasca desenvolvidas em series zoeciaes indivisas. As medidas tambem não fornecem caracter distincto que permittiria sempre distinguir autozoécios e avicularias. As avicularias de Membranipora triforia (Levinsen 1925, t. 3 f. 27a) são maiores que os autozoécios, as de Sarsiflustra abyssicola (Waters 1888, t. I f. 9. Hasenbank 1932, f. 23) de comprimento igual aos autozoécios. Em Acanthodesia nelliiformis, A. arctata (Harmer 1926, p. 218, 219), Antropora granulifera e A. marginella (ibid., p. 232, 234) os zoécios aberrantes, considerados por Harmer como avicularias, são um pouco maiores que os autozoécios ou de tamanho igual. Occorrem em series indivisas; a presença do polypidio alimentar ignora-se. Ao meu vêr, a grandeza e a posição dessas avicularias não dão direito a pôr em duvida a sua natureza de avicularias; o limite entre ellas e as avicularias vicarias restantes é indistincto. Quem quizer adoptar a posse de polypidio regular como criterio da systematisação dos heterozoécios, poderia, é claro, denominar as avicularias polypidiferas separadamente. 
Pesquisando a posição dos B-zoécios de Stega noporella ma $\mathrm{g}$ ilabris Silén (1938, p. 345) verificou que são sempre zoécios-mães de bifurcações e occorrem em todas as bifurcações. No material de S te ganoporella buskii da bahia de Santos, os B-zoécios presentes encontram-se igualmente todos como zoécios-mães em bifurcações, mas, além d'isso, ha muitas bifurcações, cujos tres componentes, I zoécio-mãe e 2 zoécios-filhas são A-zoécios (autozoécios communs). Será futuramente indispensavel tomar em consideração tambem as avicularias vicarias dos Ascophora (Adeona, Rhynchozoon, Cellepora, Holoporella etc.) para entender mais completamente os factores que determinam com certa regularidade a formação das avicularias vicarias. Verosimilmente esses factores são differentes nos varios generos ou familias. Por emquanto considero valida a comparação morphologica entre os B-zoécios de Steganoporella e as avicularias vicarias verdadeiras, desprovidas de polypidios em Thalamoporella (Harmer 1926, p. 291 t. 19 f. 5). No zoécio aberrante de Crrassimarginatella leucocypha considerado provisoriamente tambem como avicularia é o tamanho do polypidio (Fig. 37 p2) menor que nos autozoécios (pl) (Marcus 1938, p. 20), sendo tambem menos numerosos os seus tentaculos (9-10, em vez de $11-12$ nos autozoécios). Justamente tal reducção dá, ao meu vêr, o direito de considerar theoricamente o zoécio aberrante de Crassimarginatella leucocypha como 'avicularia incipiente" ("incipient avicularia" Harmer). Sem duvida, não seria esta a ultima palavra acerca dos zoécios aberrantes de Crassimarginatella, das especies de Antropora, de Acanthodesia nelliiformis, A. arctata e A. serrata (Hastings 1930, p. 707). A opinião de Silén (1938, p. 342 e seg.), contraria á incorporação dos B-zoécios do genero $\mathrm{S}$ teganoporella no grupo das avicularias, acha-se até de certo modo apoiada pelas nossas pesquizas acerca da musculatura á luz polarisada. Os occlusores dos operculos aberrantes (ou mandibulas) dos B-zoécios do nosso objecto, Steganoporella buskii, são lisos, como o são os musculos de quaesquer operculos verdadeiros de autozoécios. Dá-se, é verdade, o mesmo com os occlusores da "mandibula" do zoécio aberrante tido como avicularia de Crassimarginatella leucocypha, em opposição flagrante com os adductores das avicularias verdadeiras. Mas, mesmo se não fosse indicada certa reserva em frente dos resultados obtidos com o exame dos musculos á luz polarisada (veja p. 183), não acho que se pode basear a systematisação dos varios individuos da colonia dos Bryozoa na qualidade de ser estriada ou lisa a musculatura. $O$ confronto entre as vibraculas de $\mathrm{C}$ aberea (musculos estriados) e tres especies até agora examinadas de ScrupoceIa ria (musculos lisos) mostra ser impracticavel tal caminho. 
A base de reacção, i.é, a somma dos primordios e potencias é igual em todos os individuos que compõem a colonia de uma definida especie dos Bryozoa. Em muitos Cheilostomata a base de reacção implica potencias autozoecial e avicularial. Por via de regra os factores internos (geneticos) e presumivelmente tambem os externos, ambos, sem duvida, ainda não analysados, determinam a realisação dessas potencias em tempo e lugar differentes. Quanto ao tempo precedem na colonia inicial alguns autozoécios ás avicularias. Quanto ao lugar é a avicularia vicaria muitas vezes formada como botão inferior em uma bifurcação, apparecendo as avicularias adventicias frequentemente em pontos determinados dos autozoécios. Nem mesmo em Ste ganoporella parece faltar completamente a determinação especifica, sendo que verosimilmente são estereis os B-zoécios (Harmer 1926, p. 27I). Poder-se-ia talvez pensar em crescimento compensatorio, ao vêr o cystidio maior dos individuos estereis e os seus operculos mandibuliformes, mais fortes que nos A-zoécios. Em Crassimarginatella leucocypha (Fig. 37) a modificação da avicularia em confronto com o autozoécio não é consideravel, mas presente. O polypidio da avicularia é esteril e reduzido (veja acima), a configuração do operculo (m2) approxima-se mais á mandibula (m3) das avicularias typicas que ao operculo dos autozoécios (o). A agglomeração das avicularias polypidiferas no mesmo districto da colonia fala em favor de uma interferencia de factores externos que resultou nas colonias examinadas em formação de individuos de polypidios reduzidos e de operculos mandibuliformes, brevemente chamados avicularias"

Em uma avicularia d'este typo (Fig. 37,2) revela-se a homologia entre operculo e mandibula tanto pela anatomia como pela physiologia. Os musculos parietaes (mp2), quando se contrahem, approximam a membrana frontal á parede basal. Causando estes musculos uma depressão da membrana frontal actuam como depressores. Sendo que os liquidos não são comprimiveis, o polypidio tem de ser espremido pela contracção dos depressores. Os adductores da mandibula (d), relaxados permittem que o polypidio, ao sahir, abra a mandibula. Relaxamento dos depressores (mp2), contracção do retractor do polypidio da avicularia $(r)$ e finalmente contracção dos adductores da mandibula fazem voltar a avicularia á phase fechada. A avicularia abre e fecha-se, portanto, da mesma maneira como um autozoécio dos Malacostega se evagina e se invagina respectivamente.

Os occlusores do operculo (oc) são muito mais fracos que os adductores da mandibula (d). Os primeiros fecham sómente o operculo, ao passo que a contracção dos adductores mandibulae aperta Nematodes e outros animaes (Busk 1854a, t. 2 f. 13; Levinsen 1894, t. 4 f. 37; Harmer 1909, p. 720; id. 1931, p. 134; Marcus 1937a, f. 25A, n) que resistem com vivacidade. A Fig. 37 mostra alem d'isso differença entre os musculos parietaes do autozoé- 
cio (mpl) e os depressores da membrana frontal da avicularia (mp2). Esta differença, porém, nada tem que vêr com as funcções differentes dos dois typos de individuos.

As Membraniporidae mostram variabilidade consideravel e inesperada quanto á disposição dos musculos parietaes. O assumpto não se acha concluido pelas notas seguintes, mas requere um estudo de myologia comparativa dos generos e das especies d'essa familia enorme. Possúe p.e. Conopeum reticulum as fibras respectivas dispostas ao longo dos lados do campo de abertura, variando, porém, n'esta especie e em Conopeum commensale o numero dos feixes de 4-8, e assim a largura dos feixes. Trata-se de uma variação individual, porque se encontram typos differentes dentro da mesma colonia. Em opposição a outros phylos do reino animal, p. e. Vertebrata e Arthropoda, onde pontos definidos de origem e de inserção dos musculos condicionam o funccionamento d'elles, é nos Bryozoa evidentemente indifferente, em que ponto da parede e da membrana frontal os musculos que espremem o polypidio se originam e inserem respectivamente. Em Crassimarginatella leucocypha pudemos até verificar ao lado da origem ordinaria, a saber, na parede lateral, alguns autozoécios. cujos musculos parietaes se originam na parede basal. Silén pensou theoricamente (1938, p. 215) ser tal origem impossibilitada pela posição e actuação do polypidio. Como se vê, não é assim, embora seja, sem duvida, so excepcionalmente realisada tal origem morphologicamente simples e mecanicamente efficaz. Em Acanthodesia tenuis o typo mais frequente consiste em dois pares de tufos musculares symetricamente dispostos, um distal e um proximal, sómente em raros casos esses quatro feixes são dissolvidos em grupos menores. Acanthodesia paulensis possúe muitas vezes, nem sempre, as fibras concentradas na região proximal do campo de abertura, de modo que formam aqui um tufo denso. Ao que parece, os musculos do sacco compensatorio dos Ascophora que correspondem aos musculos parietaes dos Anasca, variam tambem, pelo menos são muito differentes em duas especies examinadas, Microporella ciliata e Watersipora cucullata. Na primeira especie veem-se tres pares symetricos de feixes; em Watersipora as fibras numerosas, não reunidas em feixes grossos, inserem no sacco compensatorio inteiro.

Embora mais complicados quanto ao esqueleto e á musculatura os B-zoécios de Steganoporella (Harmer 1902, p. 317-320; id. 1926, p. 272) poderiam ser comparados com a avicularia descripta de Crassimar. ginatella leucocypha, possuindo ambos polypidios completos. 


\section{Avicularias vicarias verdadeiras.}

O segundo typo de avicularias independentes abrange p. e. as avicularias das duas especies de FIustra descriptas por Silén (1938), as de Thala moporella la avicularia de Th li oticha foi tambem pesquizada por Silén, I. c., p. 233) e as de muitas Membraniporidae. Trata-se nos casos enumerados de avicularias vicarias ou zoeciformes, quer dizer, que occupam na colonia a mesma posição como os autozoécios, mas são desprovidas de polypidio propriamente dito. Todas essas avicularias zoariaes, vicarias, independentes (estes varios termos são synonymos), cujas paredes basaes se acham no nivel das paredes basaes dos autozoécios, poderiam ser reunidas no segundo typo, representado em Crassimarginatella leucocypha pelas avicularias interzoeciaes do typo medio (Fig. 37,3). Não obstante ser mutio menor a camara d'estas avicularias que a das avicularias polypidiferas, os musculos adductores (d) são de volume igual. Fecham tambem uma mandibula do mesmo tamanho, sendo assim individuos defensivos de efficiencia igual. Adoptando o principio de divisão de trabalho como criterio de especialisação poderiamos considerar essas avicularias, cuja alimentação depende dos autozoécios, como sendo mais altamente organisadas. Os abductores (b) inserem na membrana frontal perto do grosso esclerito basal da mandibula, portanto, do mesmo modo como os divaricadores da avicularia de Steganoporella (Harmer 1926, t. 17 f. 7. div.). N'este genero, porém, inserem os abductores por meio de um tendão, e em Crassimargina tella em parte immediatamente na membrana frontal. Os pormenores muito singulares da inserção dos depressores da avicularia de $\mathrm{C}$ ras si mar ginatella le ucocypha veem-se na Fig. 38. Algumas fibras $(x)$ inserem na propria cuticula, outras reunidas ás tres e mais $(y)$ inserem por meio de tendões collectivos, formados por cellulas epitheliaes, reconheciveis pelos seus nucleos $(\mathrm{n})$. O numero d'estes indica quantas cellulas epidermicas se prolongaram e se tornaram filiformes. A união entre a cuticula do campo de abertura e a chitina da mandibula encontra-sè no lado frontal da mandibula distalmente ao esclerito basal (s). Sendo que se acha apoiado o esclerito basal da mandibula nas paredes lateraes do cystidio (da camara da avicularia) compreende-se a funç̧ão dos abductores: a contracção d'elles approxima a membrana frontal á parede basal da avicularia ou em outras palavras, os musculos abductores retrahem a membrana frontal para dentro, funccionam d'este modo como abaixadores ou depressores da membrana frontal. Em torno do esclerito basal mandibular que funcciona como eixo de rotação, move-se a mandibula para fora, quer dizer, a base da mandibula 
segue ao movimento para baixo da membrana frontal. Assim, a ponta da mandibula é afastada da parede basal; a mandibula abre-se.

Em Flustra foliacea ha um unico feixe de abductores (Silén 1938, p. (76), cuja origem circular é situada entre os occlusores, e o mesmo typo pudemos verificar em $\mathrm{Flustra}$ barle e i Bsk. (material de Trondhjem, Noruega), ao passo que em Flustra membranaceo-truncata (Silén 1938, p. 221) e Thala moporella lioticha (ibid., p. 233) os dois feixes de abductores se originam symetricamente nas paredes lateraes. Em Crassimarginatella leucocypha originam-se os depressores nas paredes lateraes e nas paredes basal e proximal, variando individualmente o numero das fibras fixadas a estes varios lugares de origem.

Embora pertençam a um outro typo de avicularias as de Dendrobeania birostrata pesquizadas por Silén (1938, p. 246-247) e as de Dendrobeania murrayana (material dinamarquez, estudado por nós), de Beania intermedia (Fig. 44) e de Synnotum a egyptiacum (Fig. 45), da bahia de Santos, convem inserir aqui a descripção dos seus divaricadores (b). Na primeira especie ha dois feixes, cujas origens são dispostas na zona mediana-basal deixada livre pelos occlusores. Applicando a terminologia recommendada no precedente (veja nota na pagina (84) haveria em Dendrobeania birostrata duas origens de musculos abductores consecutivos em direcção proximo-distal da camara. Em Dendrobeania murrayana e nas especies de Beania e Sy n notu $m$ acima indicadas repete-se a occorrencia de um divaricador impar encontrado por Silén( l. c.) em Flustra foli a cea Nas especies pesquizadas aqui o musculo em questão tem posição differente de $F$ foliacea porque se origina proximalmente dos occlusores. Tambem a inserção é desigual, dando-se ella em B e a nia e Synnotum directamente na membrana frontal, em $F$ foli a cea mediante tendões filiformes como foram encontradas por nos igualmente em $D$ endrobe a n i a m ur rayan a

Voltando ao segundo typo de avicularias vicarias, formado pelas interzoeciaes, desprovidas de polypidios, devemos apontar que as tres especies estudadas por Silén, das quaes até duas do mesmo genero, não justificam generalisações. A avicularia de $\mathrm{Flustra}$ securifrons (material de Helgoland) examinada por nós (Fig. 40, 41), distingue-se por muitos caracteres daquellas de $F$ foliacea e $F$ membranaceo-truncata: tem, p.e., $F$ securifrons cryptocysta (Fig. $40 \mathrm{~A}, \mathrm{c}$ ) muito menor que F foliacea como ja resulta da estampa respectiva de Hincks (1880, t. 16 f. $|b, 3 a|$, ao passo que $F$ membranaceo truncata possúe uma gymnocysta (Silén 1938, p. 218). Alem d'isso é differente a disposição 
dos nucleos das cellulas epitheliaes que formam os tendões, tanto dos occlusores (Fig. $40 \mathrm{~A}$, nd) como dos divaricadores (Fig. 40, nb).

Para entender esses pormenores precisamos fazer rapida excursão sobre os tendões dos Bryozoa Cheilostomata. São tendões cuticulares ou epitheliaes na terminologia de um recente trabalho relativo a este assumpto (Korschelt 1938, p. 496). Os pontos de inserção conhecidos de muitos operculos isolados dos Cheilostomata Ascophora mostram que a inserção do tendão se dá na propria cuticula, não na epiderme *) que sempre é frouxa nos Cheilostomata. Isto ja foi observado por Davenport (1891, p. 29 t. 3 f. 26, 29) na inserção dos musculos parietaes na cuticula da parede do corpo de $\mathrm{P}$ aludicella Os tendões dos Bryozoa pesquizados aqui apresentam-se sob dois typos principaes, tendões singulares e tendões collectivos ("Sammelsehnen"), ambos presentes na avicularia de Flustra securifrons, a saber, no occlusor (Fig. $40 A_{1}$ d) e no divaricador (Fig. $40 \mathrm{~B}$, b) respectivamente. A origem dos dois tendões é epidermoidal, como se vê nos tendões singulares formados por cellulas da epiderme que cresceram para dentro e se tornaram filiformes. Uma boa figura d'esses tendões singulares foi dada por Waters (1921, t. 30 f. 29) em um desenho de fibras musculares da cerda da vibracula de Cupularia lowei Bsk. O desenvolvimento do tendão collectivo recommenda-se estudar em um outro objecto, p.e., na avicularia dependente (frontal) de Hippodiplosia americana (Fig. 35). Vê-se alli constar o tendão collectivo (t) proximalmente, onde se liga ás fibras musculares (d), de tendões singulares $(f)$, providos dos seus nucleos e assim manifestados como cellulas de origem epidermica. Os trechos distaes d'esses tendões singulares concorrem á formação do tendão collectivo. Aliás tal reunião nem sempre é completa, permanecendo ás vezes algumas fibras isoladas. A epiderme muito chata nos zoécios adultos torna difficil verificar os pormenores da inserção do tendão na cuticula. Os melhores objectos para tal estudo são mandibulas de grandes avicularias (Fig. 39) e operculos com escleritos chitinicos nos quaes os occlusores inserem. Taes objectos mostram ás vezes nitidamente o cône fibrillar ("Faserkegel" da litteratura entomologica allemã: Weber 1933, p. 25), i.é, a continuação das fibrillas do tendão na propria cuticula. A origem dos tendões collectivos por varias cellulas da epiderme que se prolongaram filiformemente para dentro revela-se occasionalmente tambem na região distal, onde ás vezes occorrem cônes chitinicos de inserção separados (Fig. 39, i). E' isto o typo commum de in-

$\left({ }^{*}\right)$ Sem embargo do muito respeito que tenho ao mestre infatigàvel, faço reserva ao termo "hypoderme", empregado por elle, porque é ambiguo e significa a membrana chitinogenea (a epiderme) des Arthropoda e o cório da pelle dos Vertebrata, portanto derivados de folhetos germinativos diversos. 
serção dos tendões singulares ou "fios epidermicos" da terminologia de Silén que estudou o seu desenvolvimento (1938, p. 206).

Recomeçando a descripção da avicularia de FIustra securifrons assignalamos a disposição dos nucleos dos tendões singulares (Fig. 40, nb) aos niveis differentes, não ao mesmo nivel como em Flustra foliacea e Dendrobeania birostrata pesquizadas por Silén (1938, p. 177, 246) e em Dendrobeania murrayana examinada aqui. No tendão collectivo do occlusor de Flustra securifrons dá-se certa concentração dos nucleos das cellulas formativas do tendão (Fig. $40 \mathrm{~A}, \mathrm{nd}$ ), por ser a zona das fibras isoladas muito curta. Occupam, porém, dentro d'esta zona, os nucleos posições differentes. Seja aliás repetido que occorrem musculos abductores da mandibula, de inserção directa e desprovidos de tendão, p.e., em Crassimarginatel! a le ucocypha (em parte, veja p. 190), Beania intermedia (Fig. 44, b) e Synnotum aegyptiacum (Fig. 45, b). A disposição dos musculos da avicularia de Flustra se curifrons é a seguinte: I) um par de occlusores (adductores, Fig. 40 $A, d)$ que inserem mediante tendões collectivos ( $t$ ) e se originam lateralmente na parede basal, elevando-se a origem de algumas fibras occasionalmente ás paredes lateraes e á distal; 2) um par de divaricadores (abductores, b) que inserem mediante tendões singulares (cellulas epitheliaes fibrilliformes) na parede frontal (membrana frontal, campo de abertura, f) e se originam nas regiões lateraes da parede basal (a). Em virtude da direcção das fibras dos occlusoires parece admissivel combinar o inicio da adducção com a contracção das fibras distaes e o fim com aquella das proximaes. As colonias do genero Flustra crescem erectamente, de modo que "o peso da propria mandibula" não poderia effectuar o ultimo passo do movimento dirigido para baixo como Silén pensa (1938, p. 185).

\section{O polypidio da avicularia.}

Quanto á anatomia do chamado polypidio da avicularia o material cie Silén evidentemente foi pequeno demais, tendo elle disposto somente de uma especie fixada para fins histologicos (1938, p. 151). Aliás o nosso material de Flustra securifrons tambem foi fixado sómente em alcool e mostra o polypidio tão bem como as especies fixadas com Bouin e varias misturas de sublimado. Silén tinha Flustra securifrons em mão (p. 279), não estudou, porém, as suas avicularias. Mas, mesmo se Silén não ti.vesse conseguido encontrar o orgão chamado ciliado por Calvet (1900, p. 50), o que pode resultar da sua ausencia real nas especies examinadas e não do estado de fixação, as quatro avicularias (2 de Flustra I de Tha 
moporella e I de Dendrobeania) estudadas pormenorizadamente por elle, não lhe davam o direito de generalizar a sua verificação negativa (Silén 1938, p. 255-256). Em 1884 Vigelius que estudou Flustra membranaceo-truncata Smitt, ja assignalou na avicularia d'esta especie ausencia de cerdas e continuidade do diaphragma, (p. 70), sem, porém, criticar os anteriores achados positivos que se referem a outras especies.

Em 1854, Busk publicou (1854, p. 104; 1854a, p. 29) os seus estudos sobre as avicularias vivas de Notamia bursaria thoje Epistomia bursaria Harmer 1923, p. 307. 314), e na introducção da sua monographia fundamental, Hincks (1880, p. LXXIV) deu observações ulteriores sobre a mesma especie. Alem d'isso, Busk pesquizou duas especies de B u gu la $(|854,1854 a$,$| . c.) e disse que não pôde descobrir o orgão respe-$ tivo em Scrupocellaria scruposa Verificou que os cilios são immoveis (1854a, p. 29) e por isso deveriam ser chamados cerdas os appendices. Considerou estas cerdas como orgão do sentido tactil e o corpo peculiar ("peculiar body") inteiro sendo de natureza nervosa. Das boas figuras que accompanham o trabalho de Busk (1854a) merece attenção especial a figura 13 da estampa 2 que mostra um vermezinho assegurado por uma avicularia.

Em Scrupocellaria scruposa desenhou Smitt (1865, p. 33 t. 7 f. 5-7) o polypidio da avicularia, sem duvida, não setoso, havendo do mesmo periodo da sciencia mais duas figuras de Nitsche $(187 \mathrm{la}$, p. 75,76$)$ do orgão setoso de Bugula flabellata ao qual denominou de botão sensorial ("Fühlknopf") homologando-o com o polypidio do autozoéció. Depois da introducção do microtomo, o orgão foi estudado por Calvet (1900, p. 49 e seguintes), Ladewig (1900, p. 332), Herwig (1915) e Forbes (1933, f. 2 e pg. 477) todos confirmando a occorrencia de cilios ou cerdas. O orgão setoso encontra-se, portanto, segundo o estado actual da litteratura nas especies seguintes: Epistomia bursaria (L.), Bugula plumosa (Pall.) B. avicularia (L.), Bं flabellata (J. V. Thomps.), B. sa batieri Calv. e B. turrita (Des.), i.é, em uma especie das Epistomiidae e em cinco das Bicellariellidae. Alem d'isso publicou Calvet $(1900$, f. 39 p. 252 t. 7 f. I) figuras do orgão setoso de Caberea boryi (Aud.) e Adeona violacea (Johnston), não descriptas no texto.

Os nossos estudos permittem agora ajuntar: Crassimargina tella leucocypha Marc. (Fam. Membraniporidae), Flustra securifrons (Pall.) de Helgoland (Fam. Flustridae), Synnotum a egyptia cum (Aud.) (Fam. Epistomiidae), Be ania intermedia (Hcks.), Bugula ditrupae Busk (Fam. Bicellariellidae) e como representantes dos Ascophora: Vittaticella elegans (Busk), das ilhas de Aru, Scuticella lorica (Busk), do estreito de Bass, ambas da Fam. Catenicelli- 
dae, Savignyella lafontii (Aud.) (Fam. Savignyellidae) e Siniopelt a costazii (Aud.) da Fam. Celleporidae.

A observação de Busk (1854, p. 105) acerca da occorrencia do orgão setoso em Bugula avicularia (L.) foi confirmada por Ladewig (1900, t. $18 \mathrm{f} .16,17)$ e por nós. Confirmamos tambem o orgão setosc das avicularias de Bugula turrita (Forbes 1933). O orgão correspondente da vibracula foi descoberto por Salensky (1874, p. 347) em Scrupocellaria scruposa (L.).

Para verificar o orgão setoso precisam-se avicularias vivas cu bem conservadas que devem ser estudadas depois da descalcificação e cr.loração em preparados totaes e, é claro, em córtes seriados. Essencialmente o orgão setoso consiste em dois componentes, um frontal, provido de cilios, e um basal. Este ultimo (Fig. 4I, 43, g) mostra nos dois casos especialnente estudados n'este particular por nós (Flustra securifrons $\in$ Bugula avicularial disposição de cellulas em redor de um centrc pontuado. Apresentando as figuras respectivas, deixamos aos leitores que conhecem o aspecto dos ganglios dos Bryozoa Ectoprocta nos córtes (p.e. Silbermann 1906, t. 19 f. 15; Gerwerzhagen 1913, f. 2, p. 318; 1913a, f. 5; Borg 1926, f. 6, 12, 13, 15; Graupner 1930, f. 1, 8-10; Marcus 1934, f. 20) decidir, se foi prematura a nossa interpretação da massa basal do orgão setosc como nervosa. Pesquisas histologicas ulteriores, sem duvida, pouco auskic osas em virtude das difficuldades notorias da impregnação do systema nervoso dos. Bryozoarios encontradas mesmo por um technico tão perfeito: como foi Retzius, e por todos os pesquisadores seguintes (Gerwerzhagen 19:3, p. 314; Graupner 1930, p. 40; Marcus 1934, p. 541-542), deveriam confirr ar a natureza de ganglio da massa basal do "polypidio" da avicularia. E' pequena esta massa, medindo, p.e., em Flustra securifrons $30 \mu$ na direcção frontal-basal e $40 \mu$ nas outras direcções. Sobre a presença ou ausencia de nervos que eventualmente poderiam ligar o ganglio directamente ao ganglio do autozoécio vizinho não pudemos apresentar factos, suppomos, forém, que não exista tal communicação. O resultado negativo da nossa busca de um nervo não influencia tanto sobre esta nossa opinião como a deliberação theorica que não se conhecem cordões nervosos connectivos entre os ganglios dos autozoécios. Alem d'isso, movimentam-se as avicularias em colonias desprovidas de polypidios activos (Waters 1904, p. 29). As experimentações iniciadas (Marcus 1926a, p. 56) que esperamos poder continuar, se houver opportunidade, igualmente não fallam em favor de uma ligação nervosa entre a avicularia e o autozoécio vizinho. As vibraculas, é verdade, reagem sobre estimulos applicados nas paredes frontal ou basal do autozoécio vizinho (Marcus 1926a, p. 56-60), de modo que deveria existir ligação nervosa, seja directa, seja talvez mais verosimil, indirecta, mediante dos plexos nervosos. 
dermaticos, quer dizer dos cystidios. A independencia do movimento das avicularias de taes plexos aliás quasi desconhecidos nos Gymnolaemata, evidencia-se pelas boas experiencias realizadas por Charles Darwin |1844, p. 253). Em avicularias amputadas da colonia as mandibulas moveram-se de maneira caracteristica, constituindo isso, ao meu vêr, plena prova da autonomia nervosa d'esses heterozoécios.

Conhecendo por practica a difficuldade de verificar as terminações das cellulas sensoriaes dos Bryozoarios, não hesitamos em considerar o polypidio da avicularia por emquanto como botão sensorial ("Fühlknopf" de Nitsche 1871 a , p. 75, 76), apezar de não termos verificado pellos ou cerdas em todas as avicularias examinadas, mas somente nas especies acima referidas (veja p. 194).

Silén nega a existencia de uma communicação entre o polypidio e o ambiente, dizendo ser contínuo o diaphragma nas quatro especies examinadas por elle e porisso sempre (1938, p. 197. 216, 254, 256). Apezar da "qualidade fragmentaria e confusa da exposição de Vigelius" (Silén 1938, p. 222) não se pode negar ter Vigelius $(1884$, p. 70$)$ que era, de facto, um observador consciencioso, ja assignalado o diaphragma contínuo em uma das quatro especies examinadas por Silén. Tambem quanto ás tres especies restantes fica por emquanto de pé a observação de Silén, ao passo que a sua generalisação nem mesmo vale para o genero $\mathrm{Flustra} A$ nossa Fig. $40 \mathrm{~B}$ mostra - diaphragma (i) de Flustra securifrons aberto, e assim se apresenta em 1-2 córtes de $10 \mu$ na grande maioria das 42 series disponiveis de avicularias isoladas desta especie. Em uma avicularia (serie 303) foi encontrada uma tampa no orificio do diaphragma. Embora formada por cellulas epitheliaes simples, não por sensoriaes, lembra essa tampa no seu aspecto geral o botão sensorial na papilla foliada da lingua do coelho. Nos córtes a tampa tem contorno approximadamente rectangular e consiste em cellulas altas. Assim não pode ser comparada com a pápilla digitiforme descripta como estructura normal no mesmo lugar em $\mathrm{Flustra}$ foli a cea (Silén 1938, p. 178). Em tres outros casos foi observado diaphragma contínuo, sem espessura especial. Revela-se pelo numero relativamente grande (ca. de $10 \%$ ) das excepções quão pouco se presta para generalisações morphologicas a anatomia microscopica das avicularias. Por via de regra, existe em Flustra securifrons um orificio no diaphragma, pelo qual alguns dos pellos finos se podem salientar para fóra. Aliás, mostram as duas avicularias desenhadas epithelio sensorial bastante differente, em Fig. 40 B vê-se um botão compacto, em Fig. 41 uma placa larga. Ao se abrir a mandibula e se achar estendida a membrana vestibular (Fig. 40 B, v) é levantado - polypidio e chega d'este modo a uma posição que faz comprehender a sua funç̧ão de orgão sensorial. Entre as lamellas epitheliaes do diaphragma 
(Fig. 4l, i) parece que ha um fino musculo annelar, tanto em FIustra securifrons como em Siniopelta costazii (Fig. 49, i). A presença d'este musculo é indicada pela viva coloração vermelha nos córtes corados segundo Mallory, distinguindo-se o tecido conjunctivo pela côr azul.

Composição do "polypidio" por ganglio proximal e cellulas setiferas distaes nota-se, como nas especies descriptas, tambem na avicularia de C r a s simarginatella leucocypha $O$ pincel formado pelas cerdas é delgado, porque consiste em sómente poucas cerdas. O diaphragma é contínuo, não possúe orificio central; ás vezes, nem sempre, é na região central especialmente fino. Para que possa o polypidio da avicularia perceber os movimentos de um verme ou de outro animal que entra no vestibulo, é indifferente, se tal verme attinge directamente as cerdas, ou se toca no diaphragma.

Fallando da membrana que liga o polypidio da avicularia ao vestibulo, Silén diz (1938, p. 187): " por causa da sua posição em relação ao polypidio e á parede do corpo, - quer dizer parede do corpo da avicularia, - a membrana pode com certeza ser interpretada como bainha tentacular, uma formação até agora não verificada no polypidio da avicularia. "Tal affirmação não é exacta, porque a homologação da bainha respectiva com a bainha tentacular do autozoécio encontra-se em tres publicações de Waters, a saber: 1892, p. 273; 1896, p. 16 (este trabalho figura na bibliographia de Silén) e 19/3, p. 487, nota. A bainha tentacular da avicularia de Flus tra foliacea foi descripta por Silén (1938, p. 187) com as palavras seguintes: "dos bordos da parte anterior do polypidio sahe uma membrana (ts) um pouco dilatada para diante que fixa o polypidio ao fundo do atrio á maneira de um sacco de papel cortado. Esta membrana é extremamente fina, achando-se os nucleos situados no lado externo do sacco de papel" As microphotographias correspondentes (Silén 1938, t. 3 f. 18, 19, 22, ts) não mostram os pormenores da bainha tentacular. O texto de Silén faz crêr, na minha opinião, que o autor encontrou nas avicularias de Flustra foliacea bainha tentacular uni-estratificada, cujos nucleos resaltam no lado da cavidade do corpo (celoma) da avicularia. Na fig. 24 da t. 4 de Silén seria talvez possivel identificar bainha tentacular bi-estratificada, mas não dispondo actualmente de: Flustra foliacea temos de deixar a questão aberta quanto a esta especie. Flustra securifrons em todo caso, possúe bainha tentacular composta de duas camadas, separadas por membrana sustentadora. Poderiam ser comparadas estas camadas ao ectoderma (Fig. 4I, e) e á somatopleura (s) do zoécio.

Descendo todos os individuos da colonia dos Bryozoa do primeiro individuo (ancestrula) que é a larva metamorphoseada, portanto de um ovo fe- 
cundado, permanece, é claro, a somma dos factores geneticos igual em autozoécios e quaesquer heterozoécios oriundos por gemmação. Em relação com este facto fundamental parecem banaes ou pelo menos pouco importantes as comparações entre as varias partes dos individuos, nos quaes se teem realizado essa ou aquella potencia prospectiva da base uniforme de reacção. A sciencia necessita mais de descripções exactas d'essas estructuras, da analyse da sua funcção e do seu desenvolvimento. Assim abstemo-nos de homologar os cordões musculares e os formados pelo frouxo tecido mesenchymatico, chamado funicular, com elementos dos autozoécios. Aliás seria tambem frustrada tal tentativa pela diversidade d'estes cordões nas varias especies, ja indicada por Silén (1938, p. 187.234, 254). Em Crassimargina tella leucocypha Flustra securifrons Beania inter. media Vittaticella elegans Scuticella lorica Rhynchozoon phrynoglossum, Siniopelta costazii e Holoporella mordax occorrem 2-4 fibras musculosas lisas que ligam o polypidio da avicularia á parede basal da camara (Fig. 40 B, 49, r). Foram por Calvet (1900, p. 55) verificadas em Bugula sabatieri e chamadas de musculo retractor do polypidio da avicularia. As figuras de Calvef (t. 3 f. 3, 4), é verdade, não convencem completamente, se se trata realmente de musculos, e nas nossas especies de Bugula não pudemos encontrar fibras musculares na região correspondente do orgão setifero. Pela comparação das avicularias aqui examinadas com o resultados obtidos por Silén, os outros cordões mais constantes são os seguintes: um que liga o orgão setifero á placa em roseta basal (o $4 .^{\circ}$ cordão de Silén 1938, p. 187 t. 3 f. 23 , styl encontrado por nós em as avicularias de Beania intermedia Bugula avicularia Bugula ditrupae Bugula turrita Synnotum aegyptiacum e Rhynchozoon phrynoglossum (Fig. 47, p). Dependendo a avicularia quanto á sua alimentação do autozoécio vizinho ou dos autozoécios vizinhos, é o cordão descripto o nutritivo por excellencia. Em Flustra securifrons e nas especies enumeradas de Beania Synnotum e Rhynchozoon nota-se tambem - $5 .^{\circ}$ cordão de Silén (l. c., stx) que liga a bainha tentacular ou o polypidio aos musculos divaricadores (Fig. 40 B $, 44,45,49$, o). Como já foi dito, não conseguimos verificar os nervos que deveriam sahir do ganglio innervando a musculatura da avicularia. Taes pesquisas ulteriores teriam de examinar, especialmente, eventuaes communicações entre o orgão setifero e os occlusores, porque a mandibula se fecha, quando fôr irritada a região do polypidio da avicularia (Marcus 1926a, p. 56). Deveria, naturalmente, existir, alem d'isso, connexão nervosa entre o ganglio e a musculatura que abre a mandibula. Em Flustra securifrons occorre do mesmo modo como em FIustra foliacea o cordão que liga a bainha tentacular da avicularia á 
parede distal (Fig. 40 B, e), ○ $1 .^{\circ}$ na descripção de Silén $(1938$, t. 3 f. 20, sty): em Beania intermedia foram verificados tambem os dois cordões lateraes que são mais fracos que os anteriormente descriptos.

\section{Avicularias dos Cellularina.}

Em 1755 John Ellis descobriu as avicularias de uma especie do genero Bugula chamada por elle "Bird's-Head Coralline" Esta é a Sertu laria avicularia de Linné (1758, p. 809). Na pesquisa das avicularias de Bugula participaram varios autores. Van Beneden (1845, p. 38 e seguintes), Nitsche (187la, p. 75) e Calvet (1900, p. 49-55) marcam os passos principaes do progresso dos conhecimentos relativos a essas avicularias. São avicularias adventicias, tambem chamadas zoeciaes ou dependentes. Os ultimos trabalhos dedicados ás avicularias do typo Bugula são os de Herwig (1915). Forbes (1933, estudos physiologicos) e Silén (1938). No curto trabalho de Herwig não faltam algumas observações certas e novas, mas as figuras não progridem além de Calvet. Bugula birostrata Yanagi \& Okada (1918, p. 420), cuja avicularia foi pesquizada por Silén (1938, p. 236-253), foi collocada por elle no genero Dendrobeania Este genero, criado por Levinsen (1909, p. 99, II3) para separar Bugula murrayan a (Johnston) das outras especies de Bugula por causa do operculo e das placas em roseta, é considerado por Harmer (1923, p. 306) como synonymo de Bugula Em notas preliminares sobre a bryozoofauna dinamarqueza como tambem na synopse dos Bryozoa da Dinamarca, trabalhos nossos que estão esperando o prelo, tenho mantido o genero Dendrobe a in i a em virtude dos caracteres indicados por Levinsen. A descripçãc seguinte vai revelar novos pormenores distinctivos quanto ás avicularias de Dendrobeania e Bugula Nas especies estudadas por nós, a saber Bugula ditrupae (Fig. 42), Bugula avicularia (material dinamarquez; Fig. 43) e Bugula turrita os musculos maiores são os adductores (occlusores), compostos por cellulas transversalmente estriadas (Fig. 42 d). Inserem com dois tendões compridos e largos, do typo do tendão collectivo (t) na região distal de um campo triangular arredondado da mandibula $(\mathrm{m})$ menos chitinisado que o resto d'ella. O epithelio vestibular reveste a face interna do bico e da mandibula, não somente em Bugula (Fig. 42, v), mas tambem nas outras avicularias pesquizadas por Silén e por nós (Fig. 35, 36, 40B, 44, v). Quanto á extensão muito variavel do epithelio vestibular indicam entre as especies examinadas aqui $R$ hynchozoon phrynoglossum e Siniopelta costazii o minimo e o maximo respectivamente. Como foi descripto por Ladewig (1900, p. 332) e Silén 
(1938, p. 184, 220,232, 249) os tendões são contiguos e soldados com a superficie do epithelio vestibular (Fig. $40 \mathrm{~A}$, iे, penetrando o tendão este epithelio no fundo do vestibulo, fóra do diaphragma. Quando aberta a mandibula acha-se, de certo modo, fixa. Dá-se isso pelos dois tuberculos basaes da mandibula embutidos na cavidade da articulação (Fig. 42 B, a) que, por sua vez, é segurada por cônes resaltados, em Bugula di itru p a e até gancheados, do bico ("rostrum"). Estes cônes fazem comprehender as duas phases na acção de se fechar a mandibula, descriptas por Nordgaard (1906, p. 77) em Scrupocellaria scruposa onde ha cônes correspondentes. Effectua-se alli o fechamento primeiramente pouco a pouco e na phase final de repente. Ao principio, os tuberculos basaes teem de ser tirados para cima dos cônes, tornando-se possivel acção rapida sómente, quando a mandibula se encontrar sobre a abobada dos cônes articulares. Colonias vivas de Bugula exhibem ordinariamente as mandibulas em estado aberto, notando-se a mesma posição, mecanicamente segurada, tambem na maioria das avicularias de material fixado.

Os musculos que abrem a mandibula da avicularia de Bugula os abductores ou divaricadores são não somente differentes dos abductores de Synnotum e Beania acima descriptos, mas tambem dos musculos correspondentes de Dendrobeainia embora seja um genero muito vizinho. Em Dendrobeania ha dois divaricadores impares medianos que inserem na membrana frontal (Silén 1938, p. 246-247), em Bu gula (Fig. 42) dois pares de divaricadores, um par proximal (posterior) (bl), que insere na membrana frontal, e um par distal (anterior) (b2), que insere no tuberculo mandibular anteriormente descripto. Acha-se assim liquidada a polemica em que Silén, apezar de não ter estudado avicularias de B u gu la tentou demonstrar (1938, p. 249-25I) a conformidade dos abductores em Dendrobeania birostrata e Bugula sabatieri (Calvet 1900, fig. 8 no texto e p. 53). Tal conformidade, porém, é indemonstravel, porque Calvet não errou, como pensa Silén. E' verdade, que a articulação da mandibula, como foi desenhada por Calvet, não faz comprehender a funcção dos seus "muscles abducteurs mandibulaires" mas, a quinta essencia da observação de Calvet fica de pé. Os "muscles pariétaux" (bl) são depressores typicos e assim abrem a mandibula (Silén 1938, fig. 6 no texto, p. 179), actuando os abductores (b2) immediata e efficazmente no mesmo sentido. O facto da inserção de um abductor na propria mandibula não se restringe ao genero Bugula como será mostrado a seguir (veja $\mathrm{Mi}$ croporella ciliata p. 208). Waters (1904, t. 8 f. 7a) tambem desenha tal inserção em Beania magellanica Nota-se assim, como em Flustra differença no tocante á musculatura que abre a mandibula, tambem no genero Beania porque o nosso objecto, Be ania inter- 
me dia, possúe sómente um abductor impar do typo parietal (Fig. 44, b). i.é, de inserção no campo de abertura.

Os "polypidios" das avicularias no genero Bugula e em Dendrobea nia birostrata (Silén 1938, t. 15, 16) são profundamente differentes. Em Bugula a "bainha tentacular" (Fig. 43, u) acha-se restricta a um vallado cylindrico em redor da base commum das cerdas cuticulares (c). Esta base forma um pedunculo do pincel comprido. Um diaphragma falta, de modo que as cerdas do orgão setifero lesta denominação parece muito mais adequada que "polypidio") se encontram em contacto immediato com o ambiente, quando se abrir a mandibula (Fig. 42 A). A gymnocysta (Fig. 43, y) apoia a membrana vestibular (v), ou, com palavras mais exactas, - bico ("rostrum") possúe a mesma calcificação como as paredes restantes, as lateraes e a basal, da camara da avicularia. A membrana vestibular consiste em cellulas altas na região entre o orgão setifero e a ponta do bico (Fig. 42, v). Herwig (1915, p. 157) que observou correctamente estes elementos falla em "epithelio sensorial" e realmente são providos de cilios. Ignorando-se, porém, a innervação e eventuaes reaç̧ões da avicularia sobre irritações tactis applicadas n'esse epithelio ciliado, é prematuro fallar em funcção sensorial d'estas cellulas. A região da membrana vestibular occupada pelas cellulas altas, visiveis tambem na avicularia de Beania in te rmedia (Fig. 44, v), dá em muitas avicularias, nomeadamente dos Ascophora, origem á glandula da avicularia (veja p. 204).

Silén descreve o pedunculo da avicularia de Dendrobeania birostrata como pertencente ao autozoécio (1938, p. 240). O mesmo typo foi encontrado por nós em as avicularias de Synnotum a egyptiacum e Beania intermedia. Em Synnotum a parede separadora (Fig. $45 \mathrm{~A}, \mathrm{~s}$ ), aliás perfurada por um póro (placa em roseta uniporosa, septula). é situada immediafamente na base da avicularia, de modo que o pedunculo realmente faz parte do autozoécio. Entre o pedunculo e o autozoécio restante encontra-se uma dobra externa (Fig. $45 \mathrm{~A}_{1}$ e) e justamente aqui as avicularias quebram-se muitas vezes. $E m$ Beania intermedia acha-se constringida a curta base da avicularia, separada por septo uniporoso (Fig. 44, s) do pedunculo autozoecial, igualmente curto. Em Syn notum aegyptiacum e Beania intermedia não foram verificados musculos no pedunculo que, segundo Silén (l. c.) faltam tambem em Dendrobeania birostrata As avicularias de Beania in termedia são verosimilmente immoveis, apresentando-se sempre na mesma posição, ao passo que as de Synnotum ás vezes parecem ser algo inclinadas. Em Bugula pertence o pedunculo á avicularia e consiste em um tubo relativamente estreito, separado por uma dobra do socco largo. Entre o socco e o autozoécio acha-se situada a parede uniporosa (Fig. $42 \mathrm{~A}$, 
s) que separa a avicularia do autozoécio. Segundo Silén (l. c.) os pedunculos das avicularias de Synnotum e de Bugula não seriam homologos. Convem, sem duvida, distinguir descriptivamente pedunculos autozoecial e avicularial, mas, o ponto, onde se forma na gemmação a parede transversal, é, ao meu vêr, menos importante que o desenvolvimento essencialmente concordante. As avicularias pedunculada e de forma de cabeça de ave começam embryologicamente sempre da mesma maneira. Prolonga-se o autozoécio mais ou menos tubiformemente e este tubo dilata-se vesicularmente na sua ponta distal (livre). Mais cedo ou mais tarde forma-se uma parede transversal no trecho tubular do primordio avicularial, cuja dilatação terminal representa a futura camara da avicularia. Depende do lugar, onde se forma a parede separadora descripta, se o trecho tubular, i.é, o futuro pedunculo da avicularia pertence ao autozoécio ou á avicularia.

movimento da avicularia anteriormente descripto (Marcus 1926a, p. 89-90) não se acha effectuado pelos elementos considerados por Calvet como musculos extensor e flexor (1900, f. 8 no fexto, $m$ u e, $m$ u f) e situados no trecho tubiforme do pedunculo. O tecido frouxo d'esta região (Fig. $42 \mathrm{~A}_{1}$ f) não é muscular, mas mesenchymatico, e os musculos se encontram no socco. A dobra (e) entre o tubo e o socco do pedunculo funcciona como articulação. Pela contracção das fibras basaes $(x)$ a avicularia é inclinada para o lado frontal do autozoécio-mãe, pela contracção das fibras frontaes (y) dá-se o movimento que resulta em approximação da ponta distal do bico á parede lateral do zoécio-mãe.

A avicularia de Beania intermedia (Fig. 44), cujo pedunculo já foi descripto, differe em varios respeitos da avicularia de Bugula. A differença mais notavel, talvez, consiste em formação completa de bainha tentacular (u), separada por diaphragma fino (i), mas completo, do vestibulo. Não foi verificado por nós um orificio diaphragmatico, mas, a ausencia de tal communicação, ao meu vêr, em nada tornaria inverosimil a funcção tactil das cerdas. Os pellos do orgão setifero em Beània intermedi a são compridos, formando um tufo ondulado. O epithelio vestibular (Fig. 44, v) no lado do bico é relativamente alto, mas não ciliado como em Bugula. Os tendões dos occlusores ( $t$ ) são especialmente largos na avicularia de Beania intermedia. As cellulas do abductor (b) impar mediano inserem immediatamente na cuticula do campo de abertura, sem tendões collectivos ou singulares.

Abductor distal não existe em Beania intermedia, occorre, porém, em Beania magellanica (Busk), onde foi desenhado por Jullien $(1888,+12$ f. 3), Waters $(1904$, t. 8 f. 7a) e Kluge $(1914$, f. 29a no texto p. 649). As figuras citadas não concordam entre si, sendo a de Jullien a melhor quanto aos abductores distaes. No material sul-africano de 
Beania magellanica (St. Sebastian Bay), aqui em mão, os abductores distaes são mais fortes que na figura de Waters e nitidamente separados dos abductores proximaes (depressores), o que não foi desenhado por Kluge. Inserem esses abductores distaes nas duas esquinas do esclerito bașal da mandibula. Provavelmente resulta da vista puramente lateral da avicularia figurada, ter Jullien, como aliás tambem Waters, desenhado o abductor distal de um lado só. Trata-se, com certeza, de um par de abductores distaes em Beania magellanica inseridos na propria mandibula, como em Bugula. O erro na figura citada de Jullien refere-se á inserção das fibras abductoras proximaes los seus "muscles em épaulette") e foi corrigido por Waters (1904, p. 28) que descreve tambem correctamente a funç̧ão d'estes depressores da membrana frontal comparando-os aos musculos do sacco compensatorio (por sua vez homologos aos musculos parietaes). A figura de Kluge concorda com a de Waters quanto aos abductores proximaes (depressores do campo de abertura) da avicularia de Beania magellanica, e o nosso material mostra-os tambem. São, é claro, homologos aos musculos párietaes laqui chamados abductores proximaes), descobertos em Bugula por Calvet (1900, f. 8 no texto, mup). A descripção e o desenho dos musculos de Be ania magellan i ca dados por Hasenbank (1932, p. 34। f. 14 C) não estão certos.

$E^{\prime}$ igualmente mistêr corrigir a minha figura anterior da avicularia de Caulibugula mortenseni (estreito de Sunda, Marcus 1925, f. 2). N'esta especie, cujo material original novamente foi estudado por nós, a musculatura da avicularia consiste em dois occlusores que inserem com tendões collectivos e em dois pares de abductores, a saber: um par distal (anterior) que insere na propria mandibula e um par proximal (posterior) que actua como depressor do campo de abertura. E' portanto, a musculatura identica com a da avicularia das especies do genero $B$ ugula, aqui examinadas. Dá-se o mesmo com a musculatura da avicularia de Caulibugula armata.

A avicularia de Bicellariella ciliata (L.) possúe, igualmente, abductores distaes que inserem na propria mandibula e além d'isso os depressores da membrana frontal (abductores proximaes).

Em Synnotum a egyptiacum occorrem dois typos de avicularias: pedunculadas (Fig. $45 \mathrm{~A}$ ), semelhantes a cabeças de passaros, e sesseis (Fig. 45 B) de forma de cône truncado. A organisação interna é igual nos dois typos, a mandibula (m) é fortemente denteada e movida por um par de occlusores e um divaricador impar. Os occlusores (adductores, d) mostram tendão collectivo longo e fino; o abductor (b) insere no campo de abertura, actuando assim como depressor. As fibras do abductor inserem sem tendões na cuticula do campo de abertura. O pincel do orgão seti- 
fero consiste em numerosas cerdas finas e é mais curto que em Bu gu la e Beania, notando-se massiça base commum das cerdas (c). Toda a região entre o orgão setifero e a ponta do bico acha-se occupada pela grande glandula da avicularia (g), trilobada na vista basal, por ser lateralmente constringida pelos musculos occlusores (d).

\section{Glandulas aviculariaes e avicularias dos Ascophora.}

Synnotum a egyptiacum representa o primeiro caso de uma glandula verificada na avicularia dos Anasca. Depois de terem sido assignaladas as glandulas oraes ou operculares pela primeira vez por Repiachoff (1876, p. 148), descobriu Waters as glandulas nas avicularias (1888, p. 27), dedicando-se tambem nos annos seguintes ao estudo especial d'estes orgãos (p. e. 1892, p. 272; 1900, p. 91-92; 1904, p. 21, 22, 85; 1909, p. 151,$153 ; 1925$, p. 533, 539). A "glandula de Biflustra a rmata Haswell é independente da avicularia (Waters 1913, p. 487; Harmer 1926, p. 247) e não pode ser comparada com a verdadeira glandula da avicularia. As estructuras em forma de cordão ou sacco comprido de Carbasea c a rbas e a (Ell. Sol.) desenhadas por Haddon (1883, t. 38 f. I2, I. c.) e descriptas em Flustra papyrea (Pall.) por Harmer (1892, p. 133) foram mencionadas por Waters (1909, p. 153, nota 5) na discussão das glandulas oràes, nada teem, porém, que vêr com estas. Os unicos representantes dos Anasca, providos, segundo a litteratura (Waters 1904, p. 21, 22) de glandulas oraes, seriam assim Bugula bicornis Busk e Bugula reticulata Bsk. var. spinosa Wat. Ao que parece, trata-se nas. estructuras descriptas de formações iguaes áquellas encontrádas nas Flustridae acima mencionadas, e não de glandulas oraes. Torna-se quasi certa esta opinião pelas observações de Waters sobre a occorrencia especial dos "corpos vermiformes" em zoécios degenerados, cujo polypidio se acha na phase do "corbo bruno" As glandulas oraes verdadeiras degeneram conjunctamente com o epithelio do vestibulo em que são situadas e se formam novamente, quando o botão regenerativo se acha em phase adiantada.

Tudo isto mostra que até agora não houve verificação certa da occorrencia de glandulas oraes nos. Cheilostomata Anasca, sendo a glandula das avicularias de Synnotum aegyptiacum o primeiro achado de semeihantes orgãos na secção alludida. A natureza glandular do orgão está, ao meu vêr, fora de duvida. Em Synnotum é composto por poucas cellulas volumosas, muitas vezes transparentes por se acharem cheias de grandes vacuolos (Fig. 46, c). A avicularia de Schizoporella carvalhoi possúe igualmente uma glandula, em relação á avicularia 
inteira, enorme, cujo sacco largo, bilobado (Fig. 46, f), situado no fundo da camara avicularial, circumda os musculos. O lumen da glandula contem uma massa grossa, ás vezes transparente, outras vezes fortemente tingivel. Em Perigastrella contracta (Fig. 46,g) e Microporella ciliata (Fig. 46, d) a glandula é ligada á bainha tentacular por um ducto nitido, em Microporella muito comprido e fino. Em varios casos essas glandulas volumosas dos Ascophora cobrem completamente o "polypidio" da avicularia. Em Perigastrella lembra a glandula avicularial impar muito as duas oraes, possuindo, como estas, fundo espherico formaclo por epithelio chato e cheio de conteudo homogeneo.

As descripções e figuras de Waters, acima citadas, fazem vêr ainda outros typos de glandulas aviculariaes nos Ascophora, concordando todos, porém, quanto ao aspecto glandular. Waters admitte tratar-se de orgãos excretorios tanto nas glandulas oraes como nas aviculariaes. A estructura e occorrencia das glandulas em autozoécios e heterozoécios provam que não pertencem aos systemas nervoso, nutritivo e reproductivo. Mas, cada passo ulterior leva-nos a hypotheses. Como o polypidio da avicularia não é analogo ao dos autozoécios, poderia tambem a glandula exercer funcções differentes nos differentes typos de individuos. A preponderancia ou quasí occorrencia exclusiva das glandulas nos Ascophora leva a crêr sejam relacionadas com o esqueleto. N'este sentido funcções de respiração, de excreção, de accumulação de cal, de adsorpção de $\mathrm{CO}_{2}$ e outras ainda poderiam scr tomadas em consideração, sem que seia por emquanto possivel assignalar observações ou argumentos theoricos em favor de uma ou outra possibilidade. Sendo a avicularia hoje considerada de funcção defensiva, a ideia de se tratar na glandula avicularial de uma glandula de secreção venenosa talvez mereça um exame physiologico.

Na sua descripção moderna e ampla de Synnotum aegyptiac u m Harmer (1926, p. 399) descreve a avicularia como provida de "deeply excavated palatal surface" Tal impressão é produzida nomeadamente, quando se applicar augmento fraco e a glandula se achar cheia de vacuolos de conteudo transparente. Em taes casos apparece como excavação o espaço realmente occupado pela glandula volumosa. Os autozoécios de Synnotum aegyptiacum não possúem orgão correspondente á glandula avicularial, de maneira que se apresentam difficuldades actualmente ainda insuperaveis tanto para a homologação morphologica como para a interpretação physiologica da glandula. As avicularias de Dendrobeania murrayana, embora mais fortemente calcificadas que as de Synnotum, carecem de glandulas.

Em Vittaticella elegans e Scuticella lorica, ambas pertencentes aos Ascophora bastante calcificados, falta tambem uma 
glandula da avicularia. Notam-se differenças inexplicaveis dentro das Celleporidae, possuindo a avicularia zoecial (dependente) de Holoporella mordax glaridula volumosa, emquarto que a de Siniopelta diota é muito pequena. Mesmo se entrar, segundo Levinsen (1909, p. 347): Holoporelia em familia especial, ficaria perto das Celleporidae. A glandula de Siniopelta diota (Fig. 46, e) acha-se representada por uma espessura do epithelio vestibular vizinho á bainha tentacular. $\bigcirc$ epithelic vestibular adjacente, i. é, situado entre o epithelio glandular e a ponta distal do bico, é composto por cellulas baixas semelhantes ás figuradas de Rhynchozoon phrynoglossum (Fig. 47, v). Em Siniopelta costazii, porém, falta uma glandula da avicularia dependente, e alli é alto o epithelio respectivo, lembrando o das especies de Bugula e de Beania intermedia (Fig. 44, v). Nota-se assim uma correlação entre o epithelio vestibular baso-distal e a glandula da avicularia. Talvez substitua este epithelio nas especies desprovidas de glandula avi-: cularial a funcção d'esta.

Em Schizoporella horsti (Fig. 13) e Hippodiplosia a mericana (Fig. 35) os dois occlusores da mandibula inserem por meio de um unico tendão collectivo. Occorre o mesmo em Schizomavella a uriculata (Hass.) var. inordinata Canu \& Bassler (material de Catania, Sicilial e nas avicularias dependentes de Holojporella carvalhoi (Fig. 23). Em Rhynchozoon phrynoglossum, como já foi dito anteriormente, algumas avicularias mostram cada um dos occlusores provido de tendão especial (Fig. 36 B), outras com um tendão commum para os dois occlusores (Fig. $36 \mathrm{~A}$ ). Quanto aos nucleos dos tendões dos occlusores (Fig. 47. nd) e abductores (nb) respectivamente, nota-se distribuição differente: os primeiros dispostos em varios niveis occupam toda a zona dos tendões singulares que perfazem a zona basal do tendão collectivo, ao passo que os nucleos dos tendões filiformes, singulares dos abductores se encontram todos no mesmo nivel, a saber, na base dos tendões, onde estes se unem com as cellulas musculares. Alli insere tambem o cordão (o) que liga a bainha tentacular (u) aos abductores (b). Veem-se no córte densenhado além d'isso o cordão (p) que vai do polypidio á placa em roseta basal e as fibras do retractor $(r)$ do polypidio. $O$ proprio polypidio acha-se composto, como sempre, de duas porções, uma basal, por nós considerada como nervosa (g) e outra frontal, côniforme, aqui desprovida de cerdas, incluida na bainha tentacular. A glandula (n) é volumosa, sendo formada, talvez em correlação com isto, a parede do vestibulo em toda a parte por epithelio baixo (v). O diaphragma é contínuo, de modo que não ha communicação entre o vestibulo e o cône do polypidio. 
Muito singular é o mecanismo que abre a mandibula (Fig. 48, m). campo de abertura, commummente formado por membrana fina, acha-se em Rhynchozoon phrynoglossum fortemente chitinisado á maneira de se apresentar como placa solida (s). Não poderia em Rhynchozoon phrynoglossum a contracção dos abductores tornar concava a face frontal do campo de abertura, mas sim, terá de puxar a placa inteira para dentro. Quando deprimida, ella bate na base da mandibula unida á placa frontal por membrana elastica (e). Assim a mandibula abre-se subitainente. sahindo tanto em direcção proximal, quanto os tendões (ou o tendão) dos occlusores permittem. Convem notar que os modelíos e os desenhos respectivos (Fig. 48 A, B) foram construidos por nós na base de córtes seriados, portanto, na base de material descalcificado. Por isso, ignoramos o papel da vara basal calcarea ("calcareous bar") na base da mandibula que provavelmente serve como eixo de rotação.

O córte da avicularia vicaria (zoarial) de Siniopelta costazii (Fig. 49) prova que occorre tambem nos Ascophora polypidia da avicularia em forma de orgão setifero, dando-se o mesmo em Vittaticel! a elegans, Scuticella lorica e Savignyella lafontii. O tufo de cerdas (c) communica-se com a cavidade do vestibulo (v), por ser aberto o diaphragma (i) que separa a bainha tentacular (u) do vestibulo. As fibras lisas do retractor $(r)$ do orgão setifero e dos musculos abductores (b) da mandibula contrastam com as transversalmente estriadas dos adductores. (occlusores, d). Nota-se no córte figurado tambem um dos dois tendões collectivos $(t)$, cujas fibras singulares, filiformes se veem entre $\circ$ tendão collectivo e as fibras dos occlusores.

A avicularia de Microporella ciliata (Fig. 50) destaca-se pelas. condições singulares do seu systema musculo-tendinoso. Os occlusores (d) apresentam tendão collectivo $(\dagger)$ quee, porém, reune sómente uma parte dos. elementos de inserção d'esse musculo. As cellulas epitheliaes transformadas em fibras tendinosas formam uma rede $(r)$ com anastomoses na região, onde se ligam ás cellulas musculares. Esta rede lembra a descripta por Silén (1938, p. 246 f. 9, epf 3) do musculo occlusor da avicularia de Dendrobeania birostrata. Fazem parte da rede tendinosa tanto - tendão collectivo ( $t$ ) como tambem as fibras (i) que se manteem isoladas distalmente da rede até a sua inserção na mandibula. Nem na litteratura, nem nas numerosas especies aqui examinadas foi até agora encontrado caso semelhante de fibras tendinosas separadas no adductor da avicularia. Os occlusores da mandibula de Microporella ciliata occorrem aos pares, possuindo cada musculo um tendão collectivo e uma porção de fibras tendinosas isoladas. Dos abductores apparecem, como em Bugula e Caulibugula, dois grupos, um anterior (distal) e outro posterior (pro- 
ximall. O proximal ( $\left.b^{1}\right)$ insere do mesmo modo como em Rhy nchozoon phrynoglossum na membrana (s) fortemente chitinisada do campo de abertura; os nucleos são situados na zona basal dos tendões, onde estes se unem ás cellulas musculares. As cellulas mais proximaes $(y)$, porém, inserem por um tendão muito curto no campo de abertura. Tal modo de inserção foi acima descripto dos abductores da avicularia de Crassim a rginatella leucocypha (Fig. 38, y). Os abductores distaes $\left(b^{2}\right)$ realizam typo de inserção ainda não observado nos divaricadores. Inserem no bordo proximal da propria mandibula, como em Bugula, mas, por meio de tendão collectivo (c), o que é excepcional nos abductores. Evidencia a avicularia de Microporella ciliata novamente a multiplicidade das estructuras occorrentes nas avicularias, das quaes certamente ainda muitas poderiam ser descobertas.

VII.

\section{Sobre os orgãos generativos dos Entoprocta.}

Quem procurar informação rapida sobre as condições sexuaes dos Entoprocta, p. e., na ultima edição do "Brehm" (1918, p. 324), fonte geralmente muito recommendavel para taes fins, encontra a indicação de gonochorismo (separação dos sexos) em Urnatella gracilis Leidy e no genero Pedicellina, e a de hermaphroditismo em Loxosoma singulare Kefcrst. e L. neapolitanum Kow. A litteratura original, porém, mostra ser muito mais complicado o problema. De Urnatella gracilis conhecem-se até agora sómente individuos masculinos (Davenport 1893, p. 15), de modo que é prematuro designa-la como gonochoristica. As duas familias Loxosomatidae e Pedicellinidae serão aqui objecto de discussão.

\section{a) Loxosomatidae.}

Originalmente foram consideradas como gonochoristicas (Claparède 1863, p. 106; 1867. p. 30; Kowalewsky 1866, p. 5), logo depois como hermaphroditas (O. Schmidt 1876, p. 7 t. I f. I t. 2 f. 8; Nitsche 1876. p. I57; O. Schmidt 1878, p. 74-75), mas por Vogt (1876, p. 322) e nomeadamente por Harmer (1885, p. 280) encontradas no momento da observação ou com gonada masculina ou com gonada feminina. Por isso são tidas desde Harmer como gonochoristicas. Das especies mencionadas no "Brehm" L. singulare Keferst. faz parte do material de Harmer e a segunda, 
Loxocalyx neapolitanus (Kow.), continua até hoje ser especie pouco conhecida (Harmer 1915, p. 8), cuja diagnose originai, porém, mostra separação dos sexos, observada por Kowalewsky (1886, p. 5).

Exame da litteratura faz ver que não ha segura verificação moderna de Loxosoma especies providas de orgãos generativos masculinos e femininos desenvolvidos simultaneamente. Dá-se o mesmo com os outros generos dos Entoprocta solitarios ou Loxosomatidae, a saber Loxoc al y x Mort. e Loxosomella Mort. (Mortensen 19ll p. 40I). A separação de Loxosomella e Loxosom a aliás é discutivel (Harmer 1915, p. 6). No ultimo trabalho Harmer descreveu numerosas especies de Loxosom a, todas providas sómente de testiculos ou de ovarios, tanto quanto eram visiveis os orgãos generativos. Mas isso ainda não justificaria a denominação gonochoristicos" para os Loxosomas. Já no seu primeiro trabalho bryozoologico o grande mestre Harmer (1885) tinha accentuado o facto de lançarem botões tanto os machos como as femeas de Loxosom a (p. 280) e encontrado um macho de L. te thy a e Sal. de testiculos evidentemente atrophiados, persistindo a vesicula seminal (t. 20 f. 16). Por isso Harmer considerou possivel realizarem-se as maturações masculina e feminina successivamente em estações differentes. Esta opinião reencontra-se no tratado excellente de Parker e Haswell (1930, p. 347), alli referente aos Entoprocta em geral. Tal procedimento, porém, é antecipado.

Certas observações de Daphne Atkins (1932, p. 35 f. 9 no texto) apoiam de certo modo a existencia da successão alludida em uma especie do genero Loxosoma. Originam-se em um individuo feminino tres botões, um masculino, um feminino e um de gonada ainda não classificavel. Não se trata de um caso isolado (1. c., p. 353), mas, por outro lado, de uma unica população composta por ca. de 16 individuos de classificação duvidosa, talvez bastardos entre Loxosoma singulare Keferst. e L. claviforme Hcks. Por conseguinte o achado, tão importante que seja, não permitte generalisações. Prova em todo o caso que uma larva de Loxosom a póde dar origem a individuos masculinos e femininos. Em Loxosom a phascolosom a tum Vogt tal evidentemente não se dá, sendo em geral todos os individuos de uma população do mesmo sexo (Daphne Atkins 1927. p. 751). O hermaphroditismo verdadeiro de Loxosoma loxalinum (Assheton 1912, p. 122-123) é muito duvidoso. Segundo Daphne Atkins (1932, p. 380) foi observado um caso de substituição das cellulas germinativas femininas por masculinas dentro da mesma gonada em Loxosoma davenporti por Nickerson, admittindo este autor por isso alternação de varios periodos de actividade sexual masculina e feminina durante a vida de um individuo da especie mencionada (Nickerson 1901, p. 367). O methodo de medir dentro de uma população de Loxosomatidae os exemplares masculi- 
nos, femininos e sexualmente indeterminaveis até agora não deu resultados positivos acerca do problema da sexualidade (Daphne Atkins 1932, p. $384-$ 385). A observação mais importante, ao meu vêr, sobre a sexualidade dos Loxosomas é a daquella autora, (1932, p. 333-334), cujo material de L. crassicauda Sal. mantido nos tanques do laboratorio de Plymouth durante quasi um anno se achava composto unicamente por machos $e$ individuos sexualmente indeterminaveis. Deve-se isso verosimilmente ou à proterandria da especie ou á determinação phenotypica do sexo.

No amplo material aqui em mão de Loxocalyx sawayai (veja p. 116$)$ os varios, mas não numerosos, individuos, que permittem classificação da gonada, sẽo femeas.

\section{b) Pedicellinidae.}

Nas Pedicellinidae os nossos conhecimentos são mais escassos ainda. Os tratados dão figuras de Pedicellina cernua (Pall.) como hermaphrodita (Lameere 1931 p. 323 f. 358 no texto: Claus-Grobben-Kühn 1932, p. 528 fig. 508 no texto), e Cori (1930, p. 25) escreve: "Por via de regra os Kamptozoa" (quanto a este nome superfluo, veja Marcus 1938, p. 5 nota)" são de sexos separados. Na mesma colonia e no mesmo estolão respectivamente" (sómente as formas providas de estolão, as Pedicellinidae e Urnatellidae formam colonias, as Loxosomatidae constituem populações) "originam-se individuos masculinos e femininos, sendo porém algumas poucas especies hermaphroditas, entre ellas Pedicellina cernua (Pall.)" Segundo Cori, haveria portanto nos Entoprocta: a) hermaphroditismo colonial combinado com gonochorismo individual e b) hermaphroditismo dos. individuos e consequentemente da colonia. O typo al acha-se representado na lifteratura por Ascopodaria (hoje Barentsia) macropus do porto de Cartagena (Ehlers 1890, p. 83,197), cuja descripção muito pormenorisada nada deixa a desejar. Existe portanto em Ba rentsia o mesmo phenomeno como em Loxosoma, a saber uma larva poder dar origem a individuos masculinos e femininos. Hermaphroditismo colonial combinado com gonochorismo individual, quer dizer machos e femeas dentro da mesma colonia, foi verificado tambem em Myosoma spinosa (Robertson 1900a, p. 330).

O genero Ascopodaria Busk 1886 não pode ser mantido e cahe na synonymia de Barentsia Hincks 1880 (Harmer 19/5, p. 27). A especie A. macropus, ao meu vêr, é synonyma com B. discreta (Bsk.). Ehlers indicou como caracteres distinctivos: "pedunculo 3 vezes mais comprido que o socco (macropus), 5 vezes (discreta)i o calice insere em porção subglobosa do pedunculo ( $m$ a cropus), em porção an- 
nelada (discreta) O numero de tentaculos de macropus, 20 , não offerece signal distinctivo, em virtude da variabilidade deste numero em discreta (Marcus 1937 p. 16). O comprimento do pedunculo de discreta varia tambem (Harmer 1915, p. 31) e quanto á inserção do calice de discreta diz Osburn (1912, p. 214): calice atado ao pedunculo por uma porção annulada, flexivel e carnosa, que frequentemente é mais ou menos bulbosa" O gráo de annelação no material de Waters (discreta da região magelanica; 1904, t. 8 f. 17b) e no presente de Santos é o mesmo e não differe de certas figuras de Ehlers 11890, †. 3 f. 41, t. 4 f. 59). Waters (1904, p. 100) falla sobre a variabilidade da região alludida. E verdade que os especimes da nossa collecção da ilha de Campbell (Marcus 1921, p. !20) correspondem aos dois caracteres acima mencionados de discreta, sendo nas colonias de Santos o pedunculo do comprimento do de discreta, mas indistincta a annelação. Por isso julgo inevitavel considerar B. ma cropus (Ehlers) como synonymo de B. discreta (Bsk.). Depois de ter achado Zirpolo a ultima especie no golfo de Napoles (Marcus 1937. p. 16), a occorrencia de ma cropus ao sudeste da costa espanhola não é mais um facto isolado na distribuição total de discreta.

Os typos sexuaes enumerados por Cori (veja p. 210 ) não esgotam todas as possibilidades realizadas nos Entoprocta, nem mesmo nas Pedicellinidae. A propria Barentsia discreta foi encontrada no Japão com individuos gonochoristicos e colonias unisexuaes, isto é, masculinas ou femininas (Harmer 1915, p. 32). O material da mesma especie da ilha de Campbell (Marcus 1921, p. 120), tanto que mostram as laminas á minha disposição, é composto por individuos gonochoristicos. A colonia de B. discreta da bahia de Santos contem unicamente individuos femininos. Existe assim nas Pedicellinidae, ao lado dos typos reproductivos enumerados, tambem unisexualidade das colonias e gonochorismo dos individuos, ou pelo menos foi observada inexistencia de maturidade simultanea individual e colonial de ovos e espermatozoides. A este typo que por emquanto poderia ser denominado gonochorismo colonial e individual pertencem, segundo Foettingcr (1887, p. 312), tambem Barentsia benedeni (Foett.) e B. belgica (van Ben.), sendo a ultima hoje considerada (Harmer 1915, p. 26) como synonymo de B. gracilis (M. Sars). Andersson (1902, p. 556) assignala B. maior Hcks. como sendo de sexos separados, mas nada diz em relação ás condições sexuaes da colonia total. Loxosomatoides colonialis (Annandale 1908, p. 18), apezar do nome pertencente ás Pcdicellinidae, possúe colonias unisexuaes, masculinas ou femininas, "havendo, porém, certos indicios nas femeas de se ter effectuado nellas proterandria Nem o texto, nem as figuras fazem ver quaes eram esses indicios. A maior das 
colonias de Loxosomatoides evelinae de Santos (v. p. 120) compõe-se por femeas sem vestigios de proterandria.

Barentsia laxa Kirkp. do mar malayo é considerada por Harmer (1915, p. 33) como especie hermaphrodita, cujos orgãos generativos são situados inversamente aos descriptos originalmente em $\mathrm{Pedicell}$ ina cernu a (Nitsche 1869, t. 2 f. 2D, t. 3 f. 5). Tal não se dá com o material de B. I a a de Santos, anteriormente descripto (Marcus 1938, p. 10). Pesquizámos, a minha senhora e eu, 28 exemplares. Entre estes ha 14 femeas com ovarios e até 8 embryões dispostos em uma profunda bolsa incubadora de epithelio chato e não lobada como em Barentsia macropus Ehl. (= discreta Bsk.); 7 individuos são jovens e outros 7 se acham no estado de regeneração do calice que ainda não mostra orgãos generativos. Como se evidencia pela Fig. 5I, é muito volumoso e provido de lumen in-

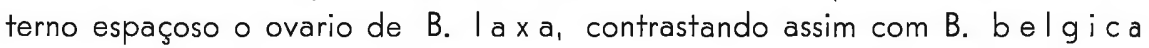
(= gracilis M. Sars), B. benedeni (Foettinger 1887, t. 7 f. 18, 23) e B. macropus (= discreta Bsk.) (Ehlers 1890, t. 4 f. 68-73). Os ovocytos em crescimento são muito mais numerosos que em $\mathrm{Pedicellina}$ cernua (Pall.). Segundo as observações de Harmer e as nossas, haveria portanto em B. I a xa tanto individuos de orgãos reproductivos masculino e feminino simultaneamente desenvolvidos como tambem exemplares gonochoristicos, seja durante certo tempo, seja permanentemente.

\section{Hermaphroditismo em Pedicellina cermua (Pall.).}

Temos, segundo o estado actual da litteratura, de admittir o mesmo no caso de Pedicellina cernua (Pall.), o prototypo dos Entoprocta em muitos tratados. Leitores que talvez acompanhassem a resenha seguinte com a litteratura original, alli encontrariam as denominações: Pedicellina cernua (Pall.), P. e chinata M. Sars, P glabra Hcks. e P. hirsuta Jull. Como já foi mencionado anteriormente (Marcus 1938, p. 6-7), não se trata de especies differentes. Na descripção original (Pallas 1774, p. 57) são mencionados "pellos" no pedunculo, não visiveis na figura correspondente (t. 4 f. 10). A forma ou variedade e chin ata (M. Sars 1835, p. 5 t. I f. $\mid b$, Ic) possúe espinhos no calice e no pedunculo, cahindo consequentemente hirsuta (Jullien 1888, p. 13) na synonymia de echinata. Exemplares completamente desprovidos de espinhos foram denominados var. gla bra (Hincks 1880, p. 565 t. 81 f. I). Completando as indicações anteriores (Marcus 1938, p. 6), podemos agora com muitas series de cortes em mão accrescentar que no nosso material podem occorrer 8-24 tentaculos 
em Pedicellina cernua (Pâll.); o maximo 24 iá foi observado por M. Sars (1835, p. 5).

Deixando de lado os trabalhos anteriores, encontramos nas publicações de Nitsche (1869, p. 26-28; 1876, p. 161) a descripção do apparelho generativo hermaphrodita. As figuras respectivas (1869, t. 2 f. $2 D$, t. 3 f. 5 ) eram desenhadas com sómente poucos exemplares conservados em alcool" disponiveis (ibid., p. 14); no segundo trabalho, desprovido de figuras, Nitsche já cortava ou fendia os seus objectos por meio de um escalpello (1876, p. 133). E' sabido que Nitsche não interpretou certamente os protonephridios de Pedicellin a (1869, p. 29 t. 3 f. 4, m), mas, quem ler as exposições circumspectas da interpretação alludida e admirar sempre de novo as numerosas descobertas exactamente descriptas d'este trabalhador excellente, apenas porá em duvida ter elle encontrado individuos hermaphroditas em Pedicellina cernua. Entretanto seja frizado que as duas exposições de Nitsche são contradictorias relativamente á situação dos testiculos e ovarios. Originalmente (1869) descreveu e desenhou (l. c.) os testiculos em posição anal e os ovarios oralmente situados; no segundo lugar (1876) indica posição inversa sem figura correspondente e sem reterencia á descripção anterior. Concordaria a situação dos orgãos hermaphroditas encontrados por Harmer (1915, p. 33) em Barentsia laxa (veja p. 212) com a ultima observação de Nitsche. Sem allusão á contradicção assignalada; publíca Cori $(1929,1930,1936)$ uma descripção e figuras que correspondem exactamente ás que acompanham a primeira exposição de Nitsche.

Nos individuos gonochoristicos, aqui em mão, não existem orgãos pares vesiculares no lado anal dos ovarios, de modo que nenhuma outra interpretação se offerece para os testiculos desenhados por Nitsche. Por outro lado, não posso supprimir as minhas duvidas quanto ao testiculo, assim designado por Hatschek (1877 p. 523 t. 30 f. 47. 48, †). Tratando-se de um botão, não se veem espermatozoides, mas um epithelio interpretado por Hatschek como sendo composto por espermatogonias. As cellulas germinativas femininas já podem ser identificadas, ao passo que o pretendido epithelio germinativo masculino lembra muito o da glandula de casca a ser descripta em seguida. E' verdade que Hatschek falla em duas vesiculas testiculares, o que justificaria plenamente sua opinião. A vista lateral dos seus desenhos impossibilita naturalmente vêr que duas vesiculas se acham presentes, de modo que fica, ao meu vêr, indecisa a interpretação do orgão respectivo.

Ehlers, com o auxilio do microtomo, encontrou Pedicellina cernua de Cartagena em estado hermaphrodita (1890, p. 96) e a forma glabra do Mar do Norte como sendo gonochoristica (ibid., p. 97). Infelizmente Ehlers não dá figuras dos orgãos generativos de Pedicellina 
e a sua descripção dos gonoductos não concorda com a de Nitsche (1869, p. 27), sem que Ehlers tivesse indicado essa differença. A prova mais importante do hermaphroditismo realmente existente em Pedicellina c e rn u a apresenta-se no corte horizontal publicado por Stiasny $(1904, t .13$ f. 2). O tamanho dos testiculos e os pormenores da glandula de casca mostram ter Stiasny desenhado o seu proprio material e não apenas completado o seu corte que visa unicamente o protonephridio, com auxilio de figuras anteriores. Nitsche e Stiasny são assim os principaes fiadores do hermaphroditismo em Pedicellina cernua. Lebedinsky (1905, p. 543544) interpretou no seu estudo embryologico, sem duvida com muita reserva, - $2 .^{\circ}$ e $\circ 3 .^{\circ}$ sacco celomatico do embryão como ovario e testiculo respectivamente (f. I p. 54I), não havendo, porém, outros autores que tivessem: encontrado orgãos reproductivos em phase tão jovem (Seeliger 1906, t. 1 f. 14; Czwiklitzer 1908, f. I p. 162). Nos seus textos, Cori (1929, p. 25; 1930, p. 25; 1930a, p. 4; 1936, p. 62) affirma que Pedicellina cernua é individualmente hermaphrodita. Uma das figuras de Cori (1929. f. 17), eschematica e resultante da combinação de varios cortes, evidentemente foi influenciada pelo desenho original de Stiasny, acima citado; outra figura de Cori $(1929$, f. 9), igualmente eschematizada, repeteos pormenores do apparelho genital da f. 17. de maneira que sómente a vista lateral de um animal vivo e desenhado, como se fosse transparente (1929, f. 5), contribue para a documentação do hermaphroditismo de Pedicellina cernua sendo aliás justamente esta figura a menos nitida. Repetindo-se as tres figuras nos trabalhos seguintes de Cori (1930, 1936), podemos resumir que o corte publicado por Stiasny é o unico da litteratura que mostra o estado hermaphrodita nas Pedicellinidae e nos Entoprocta em geral.

Nós tambem não podemos fornecer tal figura, visto que é gonochoristico todo o material de Pedicellina, tanto da especie cernua (Pall.), como de nannoda Marc. Dá-se o mesmo com as Pedicellinidae. restantes aqui em mão, a saber Barentsia gracilis (M. Sars). Barentsia laxa Kirkp., Barentsia discreta (Busk), Loxosomatoides evelinae sp. n. (veja p. 120) e com a unica Loxosomatida actualmente disponivel Loxocalyx sawayai sp. n. (veja p. 116). hermaphrodita que descreverei mais adeante (veja p. 225) representa um caso de hermaphroditismo transitorio ou talvez accidental na nomenclatura de Eggert (1929, p. 565-566) e nada tem que vêr com as observações de: Nitsche, Stiasny e Cori, cujas figuras e descripções se referem ao typo da "ambogonia germinal vera bilateral e simultanea" 


\section{Gonochorismo em Pedicellina cerma (Pail.).}

Pedicellina nannoda Marc. e P. cernua (Pall.) da bahia de Santos são individual e colonialmente de sexos separados, dando-se o mesmo com o material de P cernua das ilhas de Auckland (Marcus 192I, p. II8) e uma colonia (f. gla bra Hcks.) da nossa collecção da bahia de Kiel (mar Baltico occidental). Correspondem assim á verificação de Harmer (1885, p. 280-28 |\} que não encontrou, em nenhum caso, ovarios e testiculos maduros no mesmo individuo. "Vê-se façilmente" diz Harmer, "que individuos providos de embryões em desenvolvimento no vestibulo se acham desprovidos de testiculos nas especies de Loxosoma e Pedicellina examinadas por mim A sua figura dos orgãos generativos femininos de $\mathrm{Pe}$ dicellina cernua (1. c., t. 20 f. 12) é a unica do estado gonochoristico de Pedicellina que se apresenta na litteratura. Certas differenças existentes entre esta figura e as nossas observações serão notadas em seguida. O segundo autor, cujos achados concordam com os nossos acerca do gonochorismo de Pedicellina é Foettinger (1887. p. 313) que diz: "quanto á Pedicellina echinata" portanto $P$ cernua lveja p. 212), "pude somente examinar femeas, mas estou quasi certo de que aqui os dois sexos se acham repartidos tambem lquer dizer como em Barentsia benedeni e B gracilis pesquizadas por Foettinger)" sobre individuos differentes e que as colonias são masculinas ou femininas" Já foi dito que Ehlers $(1890$, p. 96, 97) tem encontrado hermaphroditismo individual e gonochorismo individual e colonial em $\mathrm{Pedicel}$ lina do mar Mediterraneo e mar do Norte respectivamente.

Nem a litteratura, nem o nosso material amplo de Pedicellina contem indicios de hermaphroditismo colonial, i. é, de maturação simultanea dos orgãos generativos masculino e feminino; as nossas colonias compõem-se ora por machos, ora por femeas. Nas colonias masculinas e femininas occorrem botões novos no estolão commum, individuos adultos em funcção reproductiva e calices em regeneração, e em todos os casos, onde os orgãos generativos se acham reconheciveis, são colonialmente uniformes. Os dados sobre a duração da vida das colonias de Pedicellina são escassos e vagos (Cori 1930, p. 53). Se verdadeiramente a colonia vivesse somente "poucas semanas (I. c.), seria inverosimil que houvesse alternação sexual nas colonias de Santos. Entre estas colonias ha algumas quasi unicamente compostas por individuos estereis (janeiro de 1938), outras do mesmo luḡar e da mesma dała quasi sem excepção formadas por individuos providos de orgãos generativos. Estes são dentro de uma colonia ou masculinos ou fe- 
mininos em phases differentes de desenvolvimento. Botões jovens e regenerações occorrem nas colonias estereis e nas ferteis.

As gonadas de Pedicellina cernua (Pall.) acham-se situadas no parenchyma do corpo, entre o tecto do estomago ou mesodeo e as paredes do corpo, a saber as paredes direita e esquerda do calice e o fundo do atrio.

O termo "estomago" em vez de "mesodeo" póde ser applicado no sentido topographico. Quando se trata de animaes oriundos por gemmação, nos quaes o tracto intestinal total deriva do ectoderma (Seeliger 1889, p. 182 e seguintes), o termo mesodeo" parece até inconveniente, porque significa o trecho medio endodermico do intestino dos Protostomia. A denominação de "região hepatica" (Cori 1936, p. 56, 63, 92, f. 42) é impropria para o tecto do estomago (Becker 1937, p. 78).

\section{2a. Orgãos generativos masculinos de Pedicellina cernua.}

Em concordancia com as observações sobre outros Entoprocta gonochoristicos, a saber Loxosoma obesum (Daphne Atkins 1932, p. 370), Barentsia benedeni (Foettinger 1887. p. 312) e B. gracilis (= macropus, Ehlers 1890, p. 90) tambem os testiculos de Pedicellina cernu a (Pall.) no nosso material de sexos separados são mais volu. mosos que os ovarios (veja Fig. 52, t. e Fig. 53, o). Nos exemplares hermaphroditas de Pedicellina cernua tal differença não existe (Nitsche 1869, t. 3, f. 5; Cori 1936, f. 45). Poder-se-ia pensar na necessidade de maior quantidade de cellulas germinativas masculinas para garantir a fecundação entre os individuos gonochoristicos de colonias differentes, em opposição ás colonias constituidas por individuos hermaphroditas. Mas não convem ligar muita importancia á correlação assignalada, possuindo muitas vezes taes interpretações apparentemente plausiveis validade bastante restricta. Crescem frequentemente colonias de sexos separados mescladas umas com as outras (Ehlers 1890, p. 97), de modo que o caminho dos espermatozoides entre individuos gonochoristicos poderia ser tão curto como o entre hermaphroditas, a menos que nestes haija autogamia.

Pelos testiculos enormes, tornam-se salientes os lados direito e esquerdo do calice (Fig. 54, 55), achando-se restringido o atrio. Quando esvaziados os testiculos, a sua intumescencia diminue, ás vezes consideravelmente. Na Figura 52 da topographia geral, vê-se que os testiculos desembocam na 
metade actinal $\left({ }^{*}\right)$ e no terço oral de uma vesicula seminal espaçosa. Esta é um sacco (Fig. 56, s) approximadamente piriforme, cujo fundo é situado para o lado neural (Fig. 56, g), i. é, oral. Em machos jovens a vesicula seminal ainda não se demarca, mas nos adultos o gráo de enchimento não influe sensivelmente sobre o volume dessa vesicula, cuja parede se acha formada por um epithelio chato. As paredes da vesicula esvaziada são ligeira.mente enrugadas. Tal vesicula seminal falta na nossa $P$ edicellina $n$ a nnoda (Marcus 1937. p. 14) gonochoristica e nos hermaphroditas de Pedicellina cernua estudados por Nitsche $(1869,1876)$ e Cori (1929. 1930, 1936). E' tambem ausente em Barentsia macropus (=discreta) gonochoristica, pesquizada por Ehlers (1890, p. 90 e seguintes) e em B gracilis (M. Sars), cujos cortes, aqui em mão, revelam concordancia com as figuras correspondentes de B discreta (Ehlers 1890, t. 4 f. 58-61). Neste typo de orgãos generativos masculinos os testiculos desembocam por curtos ductos efferentes infundibuliformes para dentro de um ducto ejaculatorio ciliado, tambem curto. $\bigcirc$ ducto ejaculatorio dirige-se em direcção actinal e anal, sendo porem inconsideravel a sua extenção em direcção anal. Desemboca sem papilla quasi no centro do chão do atrio. Em machos gonochoristicos de Pedicellina cernua faltam os ductos efferentes verdadeiros. A parede do testiculo é membranosa com escassos nucleos appostos, pertencentes verosimilmente ao parenchyma do corpo. Essa parede é contigua com o epithelio da vesicula seminal, assignalando-se a presença de um exiguo póro efferente principalmente pelo facto de passarem. espermatozoides maduros do testiculo para a vesicula (Fig. 55) em pontos symetricamente sifuados. Na vesicula ennovelam-se e são eliminados por um. comprido ducto ejaculatorio, provido de fortes cilios (Fig. 55, d.). O ducto encurva-se para o lado oral e desemboca perto do cône anal (Fig. 56, c). 0 epithelio do ducto é chato, embora um pouco mais alto do que o da vesicula.

$\left({ }^{*}\right)$ Recommendam-se as denominações "actinal" e "abactinal" conhecidas pela litteratura sobre os Echinodermata para distinguir nos Entoprocta as direcções dos tentaculos e do pedunculo respectivamente. Coincidindo o lado apical da larva e o lado oral do adulto, a applicação dos termos "apical" e "oral" é precaria, nomeadamente porque nas descripções do calice o lado "oral" mais recto, é geralmente comparado com o lado anal, mais convexo. Poderiamos, é claro, distinguir os lados oral e anal tambem como lados anterior e posterior, mas com isso perde-se o rexo com a topographia da larva. Apezar de ser recommendavel, ao meu vêr, evitar os termos "dorsal" e "ventral" no adulto, não se pode fugir á necessidade de definir os lados direito e esquerdo. Para isso convem adoptarmos um criterio da embryologia das phases iniciaes, considerando o lado actinal como dorsal, cujo ponto mais anterior seria representado na larva pela placa apical, situada no polo animal do ovo. N'este sentido são indicados os lados direito e esquerdo nas explicações das nossas Fig. 52 e 53, sem preten-são de supprimir com isso interpretações contrarias. 
seminal (s): distingue-se do epithelio do atrio (a) o do ducto ejaculatorio pela altura menor e os nucleos menos numerosos, de modo que as vias eliminatorias dos productos generativos masculinos diminuem de fóra para dentro relativamente á altura das cellulas e ao numero dos nucleos.

E' estranho verificar a cada passo differenças anatomicas entre os orgãos generativos das varias especies dos Entoprocta. Assim, desemboca o ducto ejaculatorio dos nossos machos de Pe dic ell in a cernua immediatamente diante do cône anal. Em Barentsia be ne den i (Foettinger 1887. p. 315 t. 10 f. 2), B discreta (Ehlers 1890, p. 90) e B gracilis pesquizada por nós o gonoporo masculino é situado approximadamente no centro do atrio, em todo o caso distante do anus. Nas Loxosomatidae ignora-se ainda a posição do ducto ou mais verosimilmente póro eliminatorio dos espermatozoides (Vogt 1876, p. 324; Harmer 1885, p. 281).

Não ha concordancia completa entre a idade dos botões dePedicellina cernua e o estado da gonada masculina ou feminina. Observámos, p. ex., machos jovens com parcas espermatogonias, cujos nucleos quasi todns ainda se manteem em estado vegetativo e outros machos, menores ainda, com espermatogenese em andamento, desprovidos, porém, ainda de espermatozoides maduros na vesicula seminal. Nos animaes adultos, cuja vesicula contem espermatozoides, o testiculo acha-se repleto pelas varias phases das cellulas germinativas muito numerosas. Estão misturadas sem nenhuma ordem, havendo, porém, sempre accumulações de phases congeneres (Fig. 54). Evidenciam taes grupos que as divisões successivas procedem rhytmicamente.

As espermatogonias do testiculo maduro são situadas na membrana testicular não estructurada ou perto della. Possuem um ou dois nucleolos arredondados (Fig. 58, A). As divisões das espermatogonias não foram encontradas nos testiculos maduros, mas sómente nos jovens, realizando-se, portanto, a divisão e a maturação das cellulas germinativas masculinas em epocas differentes. O nucleo da espermatogonia desenhada na Fig. 57 acha-se no inicio da anaphase, onde começa a separação dos chromosomas. Voltando á descripção do testiculo adulto, notamos nos espermatocytos de $1 .{ }^{a}$ ordem, a phase leptotena (Fig. 58, B) e pachytena (C), observando-se no ultimo grupo uma phase provavelmente diplotena (d). Na diakinese que precede á formação do fuso da l. ${ }^{a}$ divisão de maturação desapparece a membrana nuclear, mostrando-se os geminos (chromosomas bivalentes), cujas fendas longitudinaes, que justificariam o termo "tetrades" só excepcionalmente se acham visiveis. Depois da l.a divisão de maturação (Fig. 58, D), cujos pormenores se subtraem á observação, entram os espermatocytos de $2 .^{a}$ ordem na phase da interkinese (Fig. 58, E). Os espermatocytos de 2.a ordem, caracterisados pela sua pequenez, começam a seguir com a 2. a divisão de małuração, cuja 
prophase se vê na Fig. 58, F. Os chromosomas do nosso material fixado coin - liquido de Bouin são nas phases seguintes $(G)$ da 2. divisão de maturação de tal maneira agglomerados que não podem ser individualisados. As metaphases e anaphases das duas divisões de maturação devem ser percorridas rapidamente, porque são raras.

A transformação das espermatides em espermatozoides (Fig. 58, H-N) dá-se pelo alongamento do protoplasma quasi incolor e do nucleo compacto e homogeneo. As duas extremidades do nucleo differenciam-se na phase $L$, tornando-se a futura ponta da cabeça do espermatozoide ponteaguda, ficando obtuso o lado opposto. Na mesma phase começa o crescimento do fio axial da cauda e apparece uma differenciação cytoplasmatica. E' um aggregado de mitochondrios (Fig. 58, $L, m$ ) que escondem evidentemente, como na phase correspondente de Lophopus (Marcus 1934, Fig. 40, L) os centrosomas, não observados em Pedicellina. Um cytophoro, como occorre nos Ectoprocta Gymnolaemata (Bonnevie 1907. p. 573; Borg 1926, p. 339-340: globulo alimenticio) e Phylactolaemata (Braem 1897, p. 10; Marcus 1934, p. 568, e outros autores), falta no representante dos Entoprocta aqui estudado. A propria cauda do espermatozoide forma-se tarde, desapparecendo o cytoplasma em redor da cabeça simultaneamente com a phase de excrescencia da cauda (M). Tanto as cabeças compridas como as caudas enormes formam novelos intricados nos cortes, de modo que não se prestam para o estudo das minusculas estructuras na peça media, que deveriam ser pesquizadas em esfregaços testiculares de animaes vivos. Uma coisa, porém, podemos affirmar: as cabeças dos espermatozoides do nosso material gonochoristico são muito mais compridas e estreitas que no espermatozoide do hermaphrodita figurado por Cori (1936, p. 65). Alli a cabeça tem forma de fotha de salgueiro, no material presente é anguilliforme. Differem tambem as proporções da peça media, na figura de Cori, menor que a cabeça, no material aqui em mão, de comprimento igual (Fig. $58 \mathrm{~N}, \mathrm{p}$ ). A peça media tinge-se mais intensamente com eosina que a cauda e se distingue além disso, tanto nos novelos na vesicula como em outros lugares, da cauda por se manter mais direita que esta; evidentemente é mais rigida.

Os espermatozoides maduros esvaziados pela acção do musculo depressor do atrio (Cori 1936, p. 87), que comprime a vesicula seminal, ou pelo movimento ciliar no ducto ejaculatorio devem, no material presente, atravessar a agua procurando uma colonia feminina. Quasi sempre encontramos espermatozoides nos ovarios das femeas jovens e adultas entre os ovocytos e muitas vezes no atrios femininos e nos oviductos. Pela vagina passam os espermatozoides, ao que parece, com rapidez, porque alli foram sómente raras vezes verificados. A accumulação dos espermatozoides no atrio das femeas implica ás vezes serem esses comidos pelos embryões ainda 
fixos no embryophoro a ser descripto em seguida. Veem-se então no intestino dessas larvas como tambem raramente apparecem no tracto digestivo de machos e femeas adultos.

\section{2b. Orgãos generativos femininos de Pedicellina cernua.}

A figura de uma femea jovem (Fig. 59) mostra todos os orgãos presentes no plano horizontal que passa pelos ovarios: bocca (b), orgãos de excreção $(x)$, ganglio $(g)$, gonada $(0)$, atrio $(a)$, intestino $(n)$. Quanto ao orgão excretor convem notar que nem sempre se acha nitido em femeas maduras. Já Joliet (1880, p. 500) disse que sómente em femeas de gonadas e bolsa incubadora vazias esse orgão póde ser estudado no estado vivo. Embora jovem, a femea figurada já se mostra provida de todos os elementos existentes no apparelho reproductivo feminino, a saber: ovarios e oviductos bilateral-symetricos e vagina impar $(v)$. O desenvolvimento dos orgãos generativos nem sempre concorda com o crescimento dos botões, notando-se no nosso material femeas bem maiores que a figurada, mas com o apparelho reproductor no mesmo estado. Depende evidentemente o progresso do desenvolvimento das cellulas germinativas, e, com isso, dos orgãos de multiplicação sexual do affluxo mais ou menos rico de alimentos e se acha, como nos Ectoprocta, subordinado ao desenvolvimento somatico. Garantindo o individuo mesmo esteril, pela sua capacidade gemmipara, a existencia da colonia e o povoamento intenso de um substrato apropriado, passa para o segundo plano a multiplicação por cellulas germinativas e larvas. Em Pedicellina, onde os embryões situados perto da bocca da mãe entram em concorrencia alimenticia com ella, a propagação sexual será realizavel sómente sob boas condições nutritivas. Serve tal propagação mais como instrumento de distribuição extensa do que como meio de conservação da especie.

De mesmo modo como os testiculos, são tambem os ovarios dos Entoprocta gonadas sacculiformes, fundamentalmente differentes das gonadas planiformes dos Ectoprocta. Como muitas vezes em ovar.os tubuliformes é tambem nos muito jovens de Pedicellina impossivel distinguir exactamente entre ovario e oviducto, visto se acharem ambos delimitados pelo mesmo epithelio chato. Como em Barentsia macropus $1=d i s$ creta) (Ehlers 1890, p. 87) os ovocytos mais jovens são tambem em $\mathrm{Pe}$ dicellina cernua situados no limite entre o oviducto e o proprio ovario. Fig. 60 mostra um ovocyto no primeiro periodo de crescimento (op), com o nucleo no estado pachyteno. Os ovocytos mais adiantados e os ovos promptos para a ovipostura encontram-se no fundo do ovario, na parede. 
opposta ao orificio do oviducto. O trecho mediano do ovario tubular continua, permanentemente sem differenciação especial do seu epithelio, e porisso póde ser denominado de "oviducto" apezar de não se achar topographicamente separado do "ovario" Na phase jovem desenhada (Fig. 59) caracterisa-se a vagina ( $v$ ) por epithelio de nucleos altos.

Possuimos nas nossas series algumas femeas um pouco mais velhas que a da Fig. 59, cujos ovocytos, porém, ainda basi-chromaticos (veja no paragrapho seguinte), se acham no inicio da $2 .^{a}$ phase de crescimento. Não obstante, já se encontra certo numero de espermatozoides no atrio, accumutando-se algumas vezes diante do orificio externo da vagina.

Não ha elementos do epithelio ovarial que formem folliculo em redor do ovocyto, nem que auxiliem de outra maneira ou sejam incorporados pelo ovocyto como alimento. Encontra-se portanto ovogenesis solitaria em $\mathrm{Pe}$ dicellina cernua, certamente não na mais restricta accepção do te:mo (Korschelt \& Heider 1902, p. 308), de se isolarem cedo os ovocytos da parede ovarial. Pelo contrario. permanecem durante todo o periodo de crescimento contiguos com a parede, dando-se esta connexão com grande parte da superficie do ovocyto, não por um pedunculo. Nucleos vitellinos, tão communs em Phylactolaemata e Gymnolaemata, não foram encontrados nos ovocytos de Pedicellina cernu a estudados por nós. Como em muitos outros casos de ovogenesis (Ankel 1933, p. 18) modifica-se tambem em P cernua o comportamento chromatico dos ovocytos no decorrer do periodo de crescimento. Ovocytos jovens são basichromaticos, os quasi adultos oxychromaticos, dando-se essa mudança tarde e bastante repentinamente.

Antes do termo do periodo de crescimento o ovocyto é seminado por um unico espermatozoide, cuja cauda se desprega e fica fóra do ovocyto. Não concordam as nossas observações com os achados de Lebedinsky (1905, p. 537). . qual descreveu seminação polysperma na metaphase da 1. ${ }^{a}$ mitose de maturação e 8 chromosomas curtos, bacilliformes na placa equatorial do fuso. No material aqui em mão sómente encontramos mónospermia, realizada na ultima phase do $2 .^{\circ}$ periodo de crescimento, importando o numero diploide dos chromosomas em 30. A Fig. 6I representa uma diakinesis na terminologia de Belar (1928, p. 169) e Wilson (1934, p. 545), i. é, a phase precedente á formação do fuso da $1 .^{a}$ mitose de maturação. Os chromosomas bivalentes (geminos) já são quadripartidos de modo que apparecem 15 tetrades, nem todas de tamanho igual. Ha 6 tetrades maiores, 4 menores e 5 de tamanho intermediario. Na placa equatorial (Fig. 6I C) os geminos formam um annel tão denso que não pódem ser individualisados. Faltam ainda pormenores da $2 .^{\mathrm{a}}$ mitose de maturação que foi observada por nós em um ovocyto de $2 .^{a}$ ordem durante a sua passagem pela vagina (Fig. 62). No caso figurado o ovo já tinha passado pelo trecho inicial do. 
gonoducto feminino e porisso acha-se provido de casca (c). A feição approximadamente lenticular do ovo é plasmada pela configuração do lumen da vagina $(v)$. Veem-se no ovo o pronucleo masculino (s), o nucleo do ovo na 2. a divisão de maturação (2) e o primeiro polocyto (1), perto do lugar, onde - $2 .^{\circ}$ se forma. A divisão typica do $1 .^{\circ}$ polocyto realiza-se só raramente em Pedicellina cernua (Fig. 66), de modo que apparecem geralmente dois polocytos de tamanho differente nos embryões (Fig. 67). Com certeza confirma-se a observação de Hatschek (1877 p. 504) que os polocytos adherem ao ovo deposto, achando Ehlers (1890, p. 89-90) possivel que permaneçam em Barentsia no ovario.

O parenchyma do corpo circumda o ovario, como foi desenhado por Harmer em Pedicellina e Loxosoma (Harmer 1885, t. 20 f. I2, 14), havendo além d'isso uma membrana sem estructura em redor dos testiculos e ovarios, que se vê na Fig. 65. Tal membrana foi notada por Daphne Atkins (1932, p. 370) em Loxo so m a obes um. Cori (1936, p. 64) fala de uma tunica propria que envolve o ovario, seguindo assim a Ehlers (1890, p. 87). Entendendo-se por "tunica propria" um envoltorio formado por tecido conjunctivo, o termo não parece adequado; faltando tambem no envoltorio ovarial de Barentsia, figurado por Ehlers (I. c., t. 4 f. 69-7I, 80-82) e Foettinger (1887, t. 10 f. 10, 23) os nucleos cellulares que justificariam a denominação "tunica propria

No trecho interno da vaginá, i. é, ao nivel da desembocadura vaginal dos oviductos (Fig. 60, 61 i) o epithelio vaginal torna-se alto em femeas adultas. As cellulas de protoplasma granuloso e acidophilo são secretorias como indica o lumen do respectivo trecho vaginal, parcialmente repleto por floccos não estructurados. O termo "glandula de casca" introduzido em Pedicellina por Ulianin (1869; veja Nitsche 1876, p. 161) e em Barentsia por Foettinger (1887 p. 319) é empregado para estructuras bilateralsymetricas (Daphne Atkins 1932, p. 372) e impares (Assheton 1912, p. 122 t. 7 f. 3-5) semelhantes das Loxosomatidae. Trata-se, ao meu vêr, em todos os Entoprocta de orgãos homologos. Quanto ás figuras já existentes na litteratura, a glandula de casca da Pedicellina cernua gonochoristica aqui presente, concorda melhor com os orgãos homologos de $\mathrm{B} \mathrm{a}$ rentsia (Foettinger 1887, t. 10 f. 21-23; Ehlers 1890, t. 3 f. 49) que com as cellulas pedunculadas e claviformes que perfazem a glandula de casca nos exemplares hermaphroditas de $P$ cernua (Cori 1936, p. 41, 45, 49). Em virtude dos fios de secreção não foi possivel verificar, nos cortes, com certeza, cilios eventualmente presentes nas cellulas da glandula de casca, onde foram encontrados em Barentsia (Ehlers 1890, p. 87). O epithelio do trecho externo da vagina sem duvida é um epithelio ciliado (Fig. 63, v).

Entrando n esta parte da vagina, os ovos acham-se envolvidos por uma casca viscosa que se alonga pedunculadamente. $O$ pedunculo adhere ao 
bordo superior do orificio vaginal, como o mostra o embryão III da Fig. 64. Emquanto o epithelio cubico, ciliado do fundo da vagina se continúa quasi inalteradamente como cubico epithelio, não ciliado, no fundo da bolsa incubadora, o epithelio cubico, ciliado do tecto da vagina acaba no orificio vaginal. As cellulas da zona central adjacente do epithelio atrial tornam-se mais altas na femea madura. O crescimento geral da zona respectiva resulta na formação do embryophoro, como foi apropriadamente denominado por Ehlers (1890, p. 95). Em individuos estereis e femeas jovens o epithelio chato e de superficie lisa forma um assoalho uniforme do atrio pouco distante do tecto do estomago. Em femeas de actividade propagativa, porém, o epithelio da zona desenhada nas Fig. 63, 64,e cresce de tal maneira que faz pregas, assumindo a superficie um aspecto gibboso. Augmenta tambem o mesenchyma do corpo desenvolvendo-se uma massa sustentadora, gelatinosa e paucicellular. Assume, quando tratada com a coloração de Mallory, a mesma côr azul brilhante como a membrana sustentadora dos Ectoprocta. Esta ultima, porém, que é um producto da epiderme e do epithelio intestinal, acha-se desprovida de cellulas. As dobras epitheliaes fixam os pedunculos pegajosos da casca dos ovos e embryões e sẹgregam prolongamentos d'estes pedunculos dirigidos para dentro do parenchyma. Veem-se na Fig. 63 esses grossos pedunculos $(p)$, que se tingem fortemente com as côres communs do plasma (eosina, orange $G$ etc.) e chegam á parede do calice onde se ligam ao epithelio. Originalmente designou Cori (1929, f. 26; 1930, f. 27) as fibras encontradas por elle no parenchyma do embryophoro como "retractor do atrio" mais tarde como " retractor do embryophoro" (Cori 1936, f. 50). A descripção (ibid., p. 75-76) d'essas "fibras musculares corresponde quanto á origem e inserção, aos pedunculos cuticulares da nośsa Fig. 63. Em virtude de se tratar na Pedicellina cernua estudada por Cori de material hermaphrodita e no nosso de gonochoristico não me sinto competente para negar simpiesmente a existencia de um depressor do embryophoro em $\mathrm{P}$ cernua. Ha tantas differenças nos dois materiaes que por emquanto importa pouco mais uma imcompatibilidade. Todavia, insere o depressor vestibuli (ou retractor do atrio) nos especimens gonochoristicos, aqui pesquizados, no assoalho do atrio na região da bocca e do póro excretor e fibras musculares faltam no embryophoro. Becker (1937. p. 97) deixa aberta a questão se o pedunculo da casca eventualmente funcciona conduzindo substancias alimenticias do individuo-mãe aos embryões, mas tal funcção é muito inverosimil, visto que se trata no pedunculo de formação puramente cuticular.

O epithelio alto do embryophoro leva comisigo os peduncuios da casca dos ovos e se estende durante o periodo de reproducção por cres. 
cimento contínuo em direcção oral. D'este modo os embryões mais desenvolvidos chegam a occupar os pontos mais afastados do gonoporo, perto do qual os ovos recem-depositados se acham ancorados. No material presente não ha mais de 15 embryões e ovos simultaneamente fixados no embryophoro. Nos exemplares hermaphroditas foram encontrados 20 e mais (Hatschek 1877. p. 503) e 40 até 50 (Cori 1930, p. 27). Na ultima compilação (Cori 1936) faltam os algarismos respectivos, discordando com os dados anteriores a segunda das duas phrases seguintes, entre si contradictorias: "sendo que os ovos são depositados ás fornadas, os agglomerados de ovos conteem diversas phases embryologicas" (Cori 1936, p. 26) e: "em correlação com o cuidado á prole, os ovos madurecem successivamente em pequena quantidade, sendo sempre depositados os ovos um a um em intervallos" (ibid., p. 64). E' sómente o ultimo typo que se acha realizado no material presente.

Os embryões mais adiantados que frequentemente são denominados de larvas ainda em estado fixo provocam dilatações nos lados direito e esquerdo do calice. Vê-se na Fig. 63 que as zonas dilatadas do epithelio atrial se acham situadas entre a fenda ciliada (f) do atrio e a inserção dos tentaculos. Differe portanto a bolsa que abriga nos nossos exemplares os ovos e embryões das bolsas dobradas, encontradas nas Pedicellina cernua gonochoristicas de Harmer (1885, t. 20 f. 12) e Foettinger (1887. p. 320-32I), nas hermaphroditas de Nitsche (1869, p. 26 t. 2 f. I, 2 B-D) e Cori (1929, f. 25; 1936, p. 66) e em Barentsia benedeni (Foettinger 1887 p. 320) e B discreta (Ehlers 1890, p. 92-95). Topographicamente differe a bolsa incubadora do nosso material pela sua posição superior, anatomicamente distingue-se pela ausencia de diverticulos lobados e histologicamente pelo epithelio pavimentoso, não differenciado do epithelio atrial restante. Todos os autores citados descrevem especialisação do epithelio da bolsa incubadora, falando no seu aspecto prismatico cylindrico e glandular. No nosso material ha alguns calices, cujos embryões mais desenvolvidos embora ainda ligados pelos pedunculos com o embryophoro resaltam de tal maneira que no animal conservado e de tentaculos encurvados se apresentam fóra do atrio. Sem observações de material vivo não podemos dizer, se tal proeminencia dos embryões provem da pequenez da bolsa incubadora dos nossos exemplares, ou se foi fixado por acaso o momento transitorio em que as larvas se desligam do pedunculo. Ao que parece a bolsa incubadora dos especimens de Santos é realmente pequena demais em correlação com os embryões alli abrigados; uma femea de calice sem duvida muito pequeno continha um unico embryão e era por elle unilateralmente deformada, por assim dizer de face inchada. 


\section{2c. Hermaphroditismo lateral em Pedicellina cernua.}

Nas especies de Barentsia estudadas por Foettinger (be nede $\left.n i_{1}\right)$ Ehlers (discreta) e nós (gracilis) e na Pedicellina cernua gonochoristica o gonoducto masculino encurva-se em direcção actinal, ao passo que na Pedicellina cernua hermaphrodita o ducto eliminatorio commum dạs cellulas germinativas masculinas e femininas é direito como a vagina do material gonochoristico. Os elementos glandulares do ducto hermaphrodita concordam histologicamente muito melhor com a glandula de casca da femea gonochoristica do que com a vesicula seminal do macho. Mostra-se assim o typo hermaphrodita em Pedicellina cernua (Pall.) como sendo somaticamente feminino. Dá-se o mesmo com o hermaphrodita lateral (Fig. 65), descoberto no nosso copioso material uma vez por minha Senhora. As vias efferentes, oviductos (i), glandula de casca (g) e va jana são topographica e histologicamente femininas, mas o ovario direito é substituido por um testiculo em que se encontram espermatozoides maduros e varias phases da espermatogenese. Ignora-se, é claro, se os espermatozoides no ovario do lado esquerdo e na glandula de casca proveem do mesmo animal. Como outra pequena parte do nosso material o hermaphrodita unilateral é infestado por um Microsporidio $(\mathrm{m})$ semelhante ao $\mathrm{No-}$ sema bryozoides (Kor.) (Marcus 1934, p. 584-589), cujo estudo exacto precisaria de material maior.

\section{VIII. \\ O desenvolvimento de Pedicellina cernua (Pall.).}

Entre os principaes trabalhos sobre a embryologia dos Entoprocta sejam mencionados aqui os de Vogt (1876, p. 327), Barrois (1877. p. 10-24) e Harmer (1885, p. 285-304) sobre varias especies do genero Loxosoma e os de Barrois (1877. p. 27-43), Hatschek (1877. p. 503-5/3) e Lebedinsky (1905, p. 536-547) sobre Pedicellina cernua Harmer foi o primeiro que aplicou o microtomo no estudo do desenvolvimento dos Entoprocta. O trabalho de Lebedinsky dedica á segmentação e gastrulação sómente uma pagina (p. 538) sem figuras. A publicação de Hatschek baseada em observação dos ovos vivos alcançou repercussão geral, apparecendo as figuras respectivas em varios tratados como prototypo do desenvolvimento dos Entoprocta (Korschelt-Heider 1893, p. 1255; MacBride 1914, p. 399; Dawydoff 1928, p. 341; Cori 1929, p. 31; 1930, p. 45; 1936, p. 27). Muito melhor que a embryologia conhece-se a larva e a metamorphose (Barrois 1886, p. 54-64: 
Harmer 1887; Seeliger 1906; Czwiklitzer 1909; Cori 1929, p. 36-37; 1936. p. 34-35) assim como o desenvolvimento vegetativo, não tratado aqui.

Nos trabathos de Cori (1929, p. 31; 1936, p. 27) encontra-se a phrase seguinte: A segmentação é total e desigual. E' possivel nas figuras de Hatschek ver certos indicios que poderiam fallar em favor do modo da segmentação em espiral" N'este sentido a primeira figura de Barrois (1877. t. 2 f. I) merece, ao meu vêr, citação ainda mais accentuada. Realmente a segmentação de Pedicellina cernua realiza-se conforme o typo espiral, mas tanto as generalidades como as particularidades das nossas figuras teem muito pouca semelhança com as de Hatschek. Por isso não redundaria em proveito dõ leitor confronto pormenorizado de cada phase com a correspondente de Hatschek. Este autor dilacerou os calices libertando assim os embryões que estudou vivos. Não conseguiu, porém, accompanhar o desenvolvimento em ovos determinados (Hatschek 1877. p. 505, nota 2) mas desenhou as phases, conforme se apresentavam. A ordem mais tarde estabelecida nem sempre está certa, como se verifica, mesmo sem conhécimentos especiaes sobre o desenvolvimento de Pedicellina, pela contagem dos. blastomeros em medianos cortes opticos successivos. Acha-se p.e. composta por 12 ectomeros e 7 entomeros a gastrula da fig. 12 e por 10 ectomeros e 5 entomeros, a phase mais adiantada da fig. 14 B, sem que haja indicação de confluencia ou consumpção de blastomeros. E' portanto indispensavel coloração dos nucleos para as preparações totaes das phases iniciaes e reconstrucção de córtes seriados das phases adiantadas.

Como foi dito anteriormente (v.p. 224) o numero de embryões que se desenvolveu simultaneamente no material de Santos é muito menor que nos exemplares dos mares europeus. Além d'isso perdemos certa percentagem do nosso material fixado em Bouin pelo pegamento mutuo dos embryões, sendo assim difficil separa-los intactos no oleo de cravo. Nomeadamente as phases mais jovens são bastante frageis. Anesthesia antes da fixação teria talvez evitado a constricção do atrio e com isso possivelmente a deformação reciproca dos embryões que inutilizou uma parte d'elles. Para poder isolar os embryões vivos e fazer passa-los pelos varios liquidos de fixação. coloração etc. até o oleo, precisar-se-ia um lugar de trabalho proximo ao. mar e material abundante, porque perdas serão inevitaveis. Excepto a inconveniencia alludida o nosso methodo proporcionou ao material a protecção mecanica natural, até começaram os proprios estudos, mostrando-se assim os polocytos em posição normal. Representam estes nos primeiros passos de segmentação a unica marca de orientação e possibilitaram inclusão ajustada. As preparações totaes incluidas em oleo de cravo receberam nos dois lados da lamina supportes (fios de vidro) e ao lado do embryão um cabello, resaltatado fóra da laminula. Puxando no cabello consegue-se agitar o oleo e 
rolar o embryão, assim observavel por todos os lados. A coloração applicada nas preparações totaes foi hematoxylina de Ehrlich e Eosina-Orange. Para os cortes serviram calices gravidos, corados anteriormente para verificar, se continham embryões e depois reunidos por 20-30 em uma gotta de oleo de cravo (I parte) celloidina $8 \%$ ( 1 parte). Endurecida no chloroformio a gotta foi incluida na parafina; os cortes foram corados com hematoxylina ferrica de Heidenhain, hematoxylina de Ehrlich e as côres communs de plasma.

ovo, quando entra no atrio, e se fixa pelo pedunculo da casca no embryophoro, é approximadamente lenticular. Por via de regra são os embryões na sua casca situados com a calotta animal voltada para o pedunculo fixador, o que se torna nitido nomeadamente nas phases organogeneticas. O eixo primario do ovo que liga os polos animal e vegetativo mede cerca de $40 \mu_{1}$ o eixo maior ca. de $60 \mu$ e o terceiro ca. de $50 \mu$. Persistindo os polocytos frequentemente até o inicio da gastrulação póde ser definido o eixo primario do ovo como eixo apico-atrial, ou se adoptarmos a nomenclatura da Trochophora (Heider 1909, p. 58, 72) eixo antero-posterior. Nos Polychaeta, onde a placa apical da larva indica o ganglio supraesophageano presumptivo do verme e o anus larval a ponta terminal do adulto. as denominações "anterior" e "posterior" parecem mais convenientes que nos Entoprocta, onde na phase adulta a bocca e $\circ$ anus se encontram no mesmo lado do corpo, cuja denominação mais adequada, ao meu vêr, seria "actinal" Dos dois eixos restantes corresponde provavelmente o de ca. de $60 \mu$ ao eixo dorso-ventral preșumptivo da larva e o de ca. $50 \mu$ ao dextrosinistrali pelo menos são estas approximadamente as relações dos eixos correspondentes da larva. O eixo primario, porém torna-se, quando se apresenta como eixo apico-atrial, maior eixo da larva.

\section{a. As duas primeiras clivagens (phases de 2 a 4 blastomeros).}

As duas primeiras divisões do ovo são meridionaes, i.é, os planos de divisão conteem o eixo primario do ovo. Observa-se a regra da perpendicularidade por serem situados os segundos fusos perpendicularmente sobre a direç̧ão do primeiro. A primeira fenda (Fig. 66) separa dois blastomeros iguaes. Theoricamente poder-se-ia fallar em plano de divisão transversal e consequentemente distinguir um blastomero ventral ( $A B)$ de um dorsal (CD). Tal denominação topographica seria baseada no confronto sem duvida admissivel entre a larva' de Pedicellina e a Trochophora (Seeliger 1906, p. 68, f. 4). Falta, porém, em Pedicellina a predominancia de um primeiro somatoblasto $(2 \mathrm{~d})$, cujos descendentes componentes da placa somatica crescem nos Polychaeta de tal maneira, que o prostoma (blastóporo) 
se approxima á placa apical. Porisso o blastóporo não se desloca tão consideravelmente na larva de $\mathrm{Pedi}$ cellina e não se desenvolve um lado ventral extenso, caracterisado na Trochophora pela "migração" do blastóporo. Em metades ventral e dorsal do corpo da larva de Pedicellina podemos fallar, sem que seria possivel verificar, se as letras indicativas da nossa Figura 66 realmente correspondem ás respectivas posições presumptivas. Em Loxosoma leptoclini (Harmer 1885, t. 21 f. 26) os dois primeiros blastomeros são iguaes, notando-se uma pequena differença das 2 cellulas na figura correspondente de Pedic ellin a (Hatschek 1877, t. 28 f. 2). O texto (p. 505, 508) diz: "Pela primeira divisão o ovo divide-se em dois blastomeros de tamanho muito pouco differente. mostrando-se no proximo passo da divisão que a differença pequena, mas sempre verificavel não era sem significação, visto que se divide em seguida sómente o maior dos dois primeiros blastomeros. A phase de duas cellulas tornou-se um corpo bilateraí-symetrico pela direcção do plano de segmentação. como tambem pela desigualdade dos dois primeiros blastomeros" Embora a symetria bilateral não tenha sido verificada por Hatschek além da phase de 6 cellulas, a des.gualdade inicial por elle alludida parece tão significativa que dedicámos attenção especial a todas as phases de 2 blastomeros do nosso material. Não pudemos, porém, verificar desigualdade constante, ao maximo houve de vez em quando pequenas variações, communs no typo igual da segmentação, que porisso na maioria dos casos mais correctamente deveria ser chamado subigual (quasi igual). No desenvolvimento de Lineus ruber (Nemertini) occorre nos dois primeiros passos da clivagem a mesma variação do volume dos blastomeros (Nusbaum e Oxner 1913, p. 96-97) como resultaria das observações de Hatschek e das nossas em Pedicellina cernua.

O segundo plano de segmentação é meridional como foi o primeiro, e se acha situado perpendicularmente sobre o primeiro; corresponde theoricamente ao plano mediano presumptivo. A phase de quatro blastomeros (Fig. 68) mostra, porém, que os dois planos iniciaes formam um angulo de ca. de 45 gráos com os planos transversal e mediano. A Figura 67 em que se veem as 2 segundas mitoses de divisão dá um embryão de tal maneira comprimido que o eixo primario do ovo, normalmente o mais curto, se tornou o mais comprido. Os nucleos da phase de duas cellulas manteem antes do inicio do $2 .^{\circ}$ passo da clivagem ainda uma posição algo obliqua nos blastomeros, porque já a l. ${ }^{a}$ divisão era de certo modo obliqua. A situação dos dois fusos da 2. ${ }^{a}$ clivagem corresponde perfeitamente ao typo espiral: acham-se no mesmo nivel mas invertidos em 90 gráos. O plano de divisão é quasi parallelo ao plano do desenho (Fig. 67 A) e assim são tambem as placas equatoriaes quasi parallelas a este plano. Os fuscs formam angulos de 45 gráos com o plano de divisão. Um observador ninus- 
culo de pé dentro do ovo com as solas sobre o pólo vegetativo e a cabeça dirigida para o pólo animal (Heider 1909, p. 56) veria os fusos estendidos obliquamente de ba.xo á direita, para cima á esquerda. A divisão é portanto laiotropica ou sinistral, realiza-se no sentido contrario do ponteiro ("anticlockwise").

Apezar da inclinação dos fusos no inicio da phase de 4 blastomeros, todos os productos da $2 .^{a}$ clivagem tocam nos polos animal e vegetativo (Fig. 68), sem duvida com formação de fendas polares ou fendas de contacto ("polar furrows" "cross-furrows" "Brechungsfurchen"). Mais tarde, porém, dá-se a posição mecanicamente estavel em que dois blastomeros contiguos, os tradicionalmente denominados por $A$ e $C$ assumem posição um pouco mais alta, i.é, mais animal que $B$ e $D$. Os 4 blastomeros não mostram no nosso material differença qualitativa ou quantitativa, de modo que é arbitrario quaes os designados por $A, C$ e $B, D$ respectivamente. Existe evidentemente nos Annelida uma correlação entre o desenvolvimento especial do blastomero D e a apparencia precoce do esboço do tronco. Heider (1909. p. 74) menciona varios vermes, cujo tronco se forma tarde na Trochophora, compondo-se nos embryões respectivos a phase de 4 cellulas por blastomeros iguaes. Em Pedicellina o animal permanece na phase da larva que se torna sessil e capaz de cytogonia e gemmação. Um tronco vermiforme nunca se desenvolve. O pedunculo que se origina approximadamente na zona em que brota o tronco na Trochophora, carece de todos os attributos considerados geralmente como typicos de um tronco dos Annelida, embora nem todos sejam sempre encontrados: origem entre metatrochio e telotrochio (paratrochio), segmentação, crescimento teloblastico, systema nervoso, intestino etc. No sentido da correlação alludida de Heider é interessante notar que em $\mathrm{Pedicellina}$ sómente no $5 .^{\circ}$ passo de clivagem o macromero D se torna notavel pelo seu volume.

\section{b. A terceira e quarta clivagem (phases de 8 e 16 blastomeros).}

A phase de 4 cellulas foi descripta por Hatschek (1877. p. 505) como composta por dois blastomeros maiores no pólo vegetativo e dois menores no pólo animal. Por consegunte seria na figura correspondente (t. 28 f. 4), desprovida de polocytos, o polo vegetativo situado por cima. As analyses seguintes referem-se á formação de embryões constituidos por 6 e 7 ce!lulas; fallando Hatschek d'ahi por diante sómente em phase ulterior ("wciteres Stadium"). O texto que acompanha a fig. 5 contem o equivoco: "jeje der kleinen Zellen am vegetativen Pole hat sich getheilt" evidenciando-se pelo sentido que se trata do polo animal. Mesmo depois d'esta correcção é 
impossivel unir a figura 5 de Hatschek com as nossas; quanto á sua figura 6 poder-se-ia suppôr que se trata de um embryão de 7 blastomeros, visto do polo animal. Permanece, porém, inconciliavel a desigualdade entre os 3 blastomeros animaes e os 4 vegetativos na figura de Hatschek e a igualdade das duas corôas nos nossos embryões. Não obstante podemos distinguir "macromeros" e "micromeros" termos estes que em descripções do typo espiral sómente possuem significação topographica (Heider 1909, p. 71).

A terceira clivagem de $\mathrm{Pe}$ dicellina é equatorial e nitidamente dexiotropica. As duas figuras da phase de 7 blastomeros, vistas do pólo animal (Fig. 69 A) e do lado (Fig. 69 B) mostram ser a posição obliqua do fuso de divisão a causa primordial da dexiotropia, não a tensão superficial que sómente póde actuar sobre a disposição definitiva dos blastomeros quando já separados. A dexiotropia da 3. ${ }^{\text {a }}$ divisão encontrada nos Entoprocta é condicionada pela posição dos fusos das mitoses correspondentes e assim revela uma qualidade inherente do ovo, mecanicamente inexplicavel (Surface 1907. p. 525, 549; Wilson 1934, p. 993). Como o desenvolvimento é um processo epigenetico, a sciencia terá de esclarecer quaes os factores, no sentido mais largo da palavra, i. é, quaes as forças e condições na ovogenese e fecundação que determinam a posição alludida dos fusos da clivagem. Reapparecem esses factores em phylos, cujos representantes são providos de ovos que differem muito quanto ao conteudo de vitello, quanto á relação entre o polo animal presumptivo e o polo livre da ovogonia na phase ainda epithelial, e differem ainda quanto á nutrição e á postura. Por isso é inverosimil que se trate de uma d'essas adaptações estructuraes, como são lembradas por Snodgrass (1938, p. 149), independentemente apparecidas, e, por serem vantajosas, fixadas pela selecção. E' muito mais provavel constituir esse caracter genetico verificado em Annelida (Polychaeta, Echiuroidea, Sipunculoidea), Platyhelminthes (Nemertini, Polyclada) e Mollusca um indicio de um plano commum de estructura em estes phylos, em muitos caracteres profundamente differentes. O termo "Spiralia" exprime esta communidade perfeitamente e liga os phylos alludidos uns com os outros.

Quanto á nomenclatura do embryão de 8 blastomeros podemos distinguir 4 cellulas pela sua posição em redor do pólo animal, das outras que circumdam $\circ$ pólo vegetativo. Designamos as primeiras que perfazem o I. quarteto por la-ld e as ultimas, os macromeros, no sentido topographico acima explicado, por IA-ID. A igualdade dos componentes das metades animal e vegetativa deixa todos os 4 quadrantes sem marca especial, de modo que a collocação das letras é arbitraria, com excepção da distincção entre letras minusculas e maiusculas. Não ha blastocela n'esta phase. As fendas de contacto no polo animal e vegetativo formam uma com a outra um angulo de ca. de 45 gráos. A vista do pólo animal da phase de 
8 blastomeros (Fig. 70) lembra muito á correspondente de Polygordius (Wilson 1934, Fig. 462 B).

Em conformidade com a regra da alternancia a clivagem seguinte é. laiotropica. Tanto na metade animal como na vegetativa as divisões sãc desiguaes. No 1.० quarteto os productos de divisão superiores são maiores, dando-se o contrario no pólo vegetativo. D'ahi resulta aspecto muito regular da phase de 16 blastomeros com 4 cellulas maiores em redor dos pólos animal e vegetativo respectivamente e 8 blastomeros menores no equador do embryão. Segundo a situação das cellulas e o tamanho d'ellas pódemos distinguir do pólo animal para baixo: as 4 cellulas maiores do 1. quarteto $(|a|-|d|)$, as 4 cellulas menores do $1 .{ }^{\circ}$ quarteto $\left(\left|a^{2}-\right| d^{2}\right)$, as 4 cellulas do $2 .^{\circ}$ quarteto $(2 \mathrm{a}-2 \mathrm{~d})$ e os 4 macromeros $(2 \mathrm{~A}-2 \mathrm{D})$. Os dois embryões figurados, na vista dos pólos animal (Fig. 7| A,D) e vegetativo (Fig. $7 \mid B, E)$ differem de certo modo quanto á configuração geral, verosimilmente por causa da pressão acima mencionada, mas concordam essencialmente no tocante ao processo da clivagem. Como o embryão visto do pólo vegetativo mostra tambem a vista lateral (Fig. $7 \mid \mathrm{C}$ ) a intercalação do blastomero inferior $\left(\mathrm{Id}^{2}\right)$ do $1 .{ }^{\circ}$ quarteto entre os elementos do $2 .^{\circ}$ quarteto, offerecendo assim a phase inteira um aspecto de uma clivagem espiral perfeita.

\section{c. A $5 .^{a}$ e $6 .^{a}$ clivagem (embryões de $32-56$ blastomeros).}

A formação do $3 .^{\circ}$ quarteto e as divisões simultaneas do $1 .^{\circ}$ e $2 .^{\circ}$ quarteto realizam-se por divisões dexiotropicas (Fig. 72). Na metade animal nota-se certa desigualdade entre os productos que resultam da 5. clivagem tornando-se as cellulas apicaes lall-Idll algo maiores que as cellulas intermediarias $\mid a^{12}-I d^{12}$. E' muitas vezes desigual no typo espiral essa divisão, podendo os Polyclada Discocelis tigrina (Heider 1909, p. 66), Planocera (hoje Hoploplana) inquilina (Surface 1907, p. 527) e Cycloporus papillosus (Bresslau 1933, f. 154, 7) servir como exemplos, onde a proporção entre lall e lal2 é igual ao nosso objecto, an passo que em Arenicola cristata (Polychaeta) (Heider 1909, f. 41 A, p. 77) e Trochus magus (Gastropoda, Prosobranchia) (Robert 1902, t. 14 f. 32) as cellulas apicaes são menores. As cellulas intermediarias intercalam-se nos descendentes de $\left|a_{2}-\right| d 2$, a saber, $\left|a^{2}\right|-|d 2|$ e $\mid$ a22- $\mid$ d22. Sem discutir por emquanto a sua significação presumptiva, podemos chamar os 8 blastomeros descendentes. da divisão de $1 a^{2}-1 d^{2}$ os trochoblastos. Sendo que la22-Id22 são situados mais posteriormente, i.é, para a metade vegetativa que $\left|a^{2}\right|-|d 2|$ não é possivel ve-los inteiramente na vista do pólo animal, porisso parecem um pouco menores. Dá-se o mesmo na vista do pólo

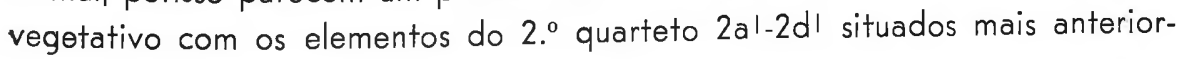


mente ou para o pólo animal, que em consequencia d'esta posição parecem menores que os blastomeros $2 a^{2}-2 d^{2}$, situados em horizonte mais approximado ao polo vegetativo.

Desde a $5 .^{a}$ clivagem o embryão torna-se bilateralsymetrico em virtude de se manter o macromero de um quadrante maior que os tres restantes. A designação do macromero respectivo com $3 \mathrm{D}$ justifica-se pelo comportamento do blastomero correspondente do $4 .^{\circ}$ quarteto. Em Pedicellina cernua, cujos blastomeros são mutuamente achatados não é facil. formar juizo certo acerca do volume de cada blastomero. Evidentemente é $3 \mathrm{~d}$ um pouco menor que as outras cellulas do $3 .^{\circ}$ quarteto, mas provavelmente não se acha aqui a unica causa da preponderancia de 3D. Póde bem ser que já houve no 4. passo da clivagem certa. desigualdade entre os blastomeros do 2. ${ }^{\circ}$ quarteto e que agora pela repetição de tal phenomeno a differença entre $3 D$ e $3 A-3 C$ se torna patente. Conforme a posição que o quadrante d assume na gastrula, 3D indicaria no embryão de 32 blastomeros o lado dorsal, 3B o lado ventral, ambos naturalmente na metade do futuro atrio da larva. A analyse da phase de 32 cellulas (Fig. 72) faz ver a serie typica da segmentação espiral, a saber:

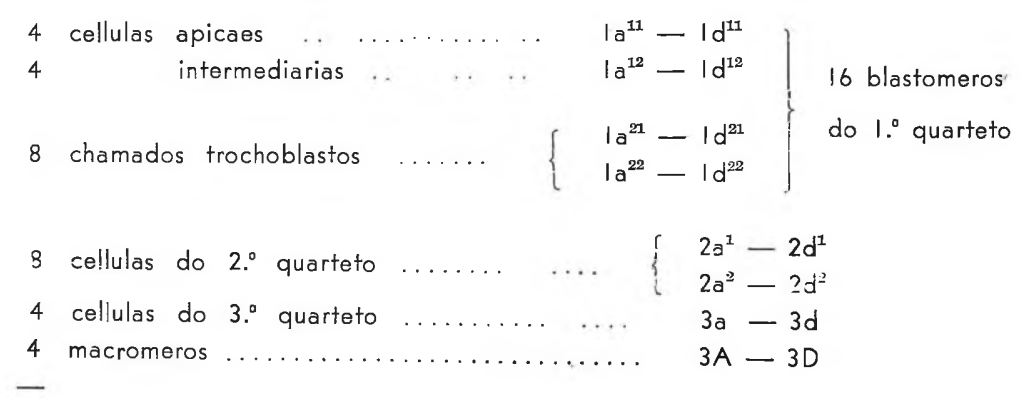

32

Um blastocela falta completamente; achando-se os blastomeros prolongados para o centro, onde se tocam, não é possivel nem pelos cortes, nem pelas preparações totaes chegar a uma harmonia entre as figuras de Hatschek e o material presente.

Do mesmo modo como foi descripto de Hoploplana inquilina (Surface 1907, p. 528), tornam-se tambem em Pedicellina cernua as divisões mais ou menos irregulares; certas cellulas dividem-se varias vezes, emquanto em outras ainda não se realiza clivagem alguma. Confirma-se em Pedicellina a regra de Kofoid do typo da segmentação espiral que as cellulas tanto mais cedo se dividem, quanto maiores são. A sexta clivagem que é laiotropica realiza-se primeiramente nos macromeros (Fig. 73) e 
depois nas grandes cellulas $1 a^{11}$ - Id ${ }^{11}$ cuja divisão resulta em $1 a^{111}$ $I d^{111}$ e $I^{112}$ - Id ${ }^{112}$ (Fig. 74).

Os blastomeros situados em redor do pólo animal fornecem as pequenas celluias apicaes em roseta $I a^{111}-1 d^{111}$ e as consideravelmente maiores $1 a^{112}$ - I d $d^{112}$ (cellulas da cruz dos Annelida, cellulas periphericas em roseta dos Mollusca). Não havendo formação da cruz em Pe dic ellin a talvez pudesse recommendar-se para o nosso objecto applicar a denominação usada na descripção da clivagem dos Mollusca. A desigualdade entre as cellulas apicaes em roseta e as periphericas é, porém, nos Mollusca menos accentuada (veja p. e. Patella, Trochus, Crepidula e Dreissensia; MacBride 1914, f. 227 B; Robert 1902 f. 15 f. 41; Heider 1909, f. 62 Bi Meisenheimer 1901, t. 3 f. 28; $d^{1}$ e $d^{13}$ na nomenclatura d'elle), que nos Polychaeta (veja p. e. Polygordius e Arenicola; Mac Bride 1914, f. 102: Heider 1909, f. 41 B). D'este modo a differença notavel entre as ceilulas apicaes e as da cruz approxima $P$ edicellina mais aos Annelida que aos Mollusca. Nos Turbellaria, cujas larvas (a "Protrochula" Bresslau 1933, p. (1) 165) não possúem placa apical tão differenciada como os Polychaeta, as cellulas apicaes em roseta pódem ser pequeninas (Polyclada: Hoploplana, Surface 1907, p. 530; Cycloporus, Bresslau 1933, f. 154, 8) ou de tamanho médio (Acoela: Convoluta, Bresslau 1933, f. 153, 15), sempre porém são menores que I a $a^{112}-1 d^{112}$. Phenomeno commum no typo espiral (Polyclada: Hoplopla na; Polychaeta: Aren icola) constitue tambem o facto de se dividirem $1 a^{12}-1 d^{12}$ mais tarde que $I a^{11}$ - I $d^{11}$, mostrando a nossa Figura $74 \mathrm{~A}$ os fusos das mitoses em $1 a^{12}-1 d^{12}$ e a sexta clivagem já acabada nas cellulas apicaes. Nos Mollusca, porém, onde $\mid a^{12}$ - $\mid d^{12}$ são maiores que $\mid a^{11}-1 d^{11}$ e formam a cruz, dividem-se geralmente mais cedo (Prosobranchia: Patella, Trochus, Crepidula). Já foi dito que no typo espiral os blastomeros se dividem tanto mais cedo quanto maiores são. A differença do tamanho dos blastomeros anteriores do $1 . .^{\circ}$ quarteto e consequentemente das phases da sua clivagem approximam $\mathrm{P}$ edicellin a mais aos "Vermes que aos Mollusca. As figuras de Dre is sensia (Lamellibranchiata) pelo outro lado não mostram formação de uma cruz, mas disposição concentrica dos descendentes do $1 .{ }^{\circ}$ quarteto (Meisenheimer 1901, t. 3 f. 27. 28, t. 4 f. 37) e, em correlação com tal ausencia da cruz, os blastomeros I $a^{12}$ $1 d^{12}$, de Dreissensia dividem-se mais tarde que $1 a^{\mathbf{1 1}}$ - I $d^{11}$, como se vê na figura 37 de Meisenheimer, modernisada quanto 'á nomenclatura por MacBride (1914, f. 264 B, p. 334). O heterochronismo entre as divisões dos blastomeros indicados em Dreissensia concorda assim com o dos Polychaeta. 
Resulta d'esta discussão que os blastomeros $1 a^{112}$ - I d $d^{112}$ de Pedicellina cernua devem ser denominados cellulas da cruz lou cellulas da cruz dos Annelida na terminologia de MacBride 1914, p. 133). Correspondentemente $1 \mathrm{a}^{12}$ - $\mathrm{Id}^{12}$ deveriam ser chamados cellulas intermediarias ("intermediate girdle cells"), sendo estas as cellulas da cruz dos Mollusca. Sem embargo das desigualdades entre os blastomeros correspondentes dos varios quadrantes que se encontram em $\mathrm{Ph}$ ascolosoma, a figura $C$ de Gerould (1907. p. 98) parece-se bastante com a phase da 6. ${ }^{a}$ clivagem em Pedicellina. Vejo, porém, n'isso nada mais do que uma approximação geral dos Entoprocta aos Annelida e não uma ligação aos Sipunculoidea talvez no sentido dos Podaxonia mantidos por MacBride (1914, p. 372) e relacionados por elle com os Ectoprocta (ibid., p. 406).

Até a phase de 44 blastomeros (Fig. 74), realizada logo que as cellulas intermediarias se teem dividido, os oito trochoblastos formados pela $5 .^{\mathrm{a}}$ clivagem permanecem não divididos. Tão pouco dividem-se os 8 descendentes do $2 .^{\circ}$ quarteto e os 4 componentes do $3 .^{\circ}$. Os quatro macromeros, porém, dão origem a um novo quarteto de micromeros volumosos.

A vista lateral (Fig. 73) que foi desenhada para mostrar ao lado das figuras restantes simplificadas, o aspecto natural da segmentação do ovo de Pedicellina, mostra que a formação do $4 .^{\circ}$ quarteto é o primeiro passo divisorio no embryão de 32 cellulas. Corresponde isso tanto á regra de se dividirem muitas vezes no typo espiral os blastomeros maiores com antecedencia como á observação de Lillie, que a celeridade da clivagem tem relação com o momento em que começam a funccionar os productos das divisões correspondentes (Dautert 1929, p. 460). Na phase fixa da larva - seu intestino já funcciona, de modo que a intensidade divisionaria do complexo endodermico poderia ser interpretada no sentido de Lillie. O termo "travail évolutif" de Lacaze-Duthiers caracteriza de um modo, ao meu vêr, muito feliz a actividade morphogenetica e ao mesmo tempo physiologica do embryão. Pela separação precoce do endomesoderma presumptivo contido no endomesoblasto $4 \mathrm{~d}$ na phase de 36 blastomeros o endoderma especializa-se, tornando-se enteroderma, i. é, a porção do germe presumptivamente de funç̧ão digestiva. Seja lembrado que em outras formas dos Spiralia $4 d$ se isola mais cedo ainda, p. e. em Crepidula fornicata, onde aliás mais que a metade d'este teloblasto contribue para a constituição do enteroderma.

Olhando no $1 .^{\circ}$ quarteto seria difficil vêr na divisão prematura dos blastomeros volumosos $I a^{11}$ - I $d^{11}$ mais que uma confirmação da regra de Kofoid. E' verdade que a placa apical se forma muito cedo, mas uma funcção d'ella eventualmente já presente no estado fixo do germe ignora-se. 
Durante a phase livre a placa apical provida de cirros e cellulas ganglionares funcciona muito provavelmente como orgão sensorial, mas então trabalha tambem o orgão locomotor que se forma muito tarde.

As ultimas phases que pudemos analysar são as de 48 e 56 cellulas. Originam-se pela continuação da sexta clivagem, laiotropica, nos ectomeros do $1 .^{\circ}$ e $2 .^{\circ}$ quarteto e pela realização da septima divisão na região vegetativa. A clivagem das cellulas intermediarias $\left(\mid a^{12}-\left(d^{12}\right)\right.$, já iniciada na phase de 40 blastomeros (Fig. 74) dá origem aos blastomeros anteriores I $a^{121}$ - I $d^{121}$ e aos posteriores $I a^{122}-I d^{122}$. Mostra a Fig. 75 a intercalação dos primeiros entre as 4 cellulas da cruz $\left(1 a^{112}-I^{112}\right)$ e dos segundos entre os oito trochoblastos que ainda permanecem indivisos. Os descendentes do $1 .^{\circ}$ quarteto formam d'esta maneira tres corôas sobrepostas uma á outra, constituidas por 4, 8 e 12 blastomeros respectivamente. A separação dos 4 quadrantes revela-se muito regularmente n'esta phase e nas seguintes.

Um pouco depois da divisão das cellulas intermediarias clivam-se os macromeros novamente. Esta divisão é dexiotropica na orientação acima estabelecida (veja p. 228), de modo que se manifesta como laiotropica na vista do pólo vegetativo (Fig. $75 \mathrm{~B}$ ). A clivagem é bem desigual, tornando-se as cellulas do novo quarteto $(5 \mathrm{a}-5 \mathrm{~d})$ os elementos minimos do embryão, ao passo que os macromeros (5 A-5 D) se conservam como os maximos. Mantem-se tambem a differença entre os macromeros, dos quaes $5 \mathrm{D}$ é um pouco maior que os restantes.

Na phase de 48 blastomeros a cellula 4 d ainda indivisa, começa a desapparecer da superficie do embryão. Intercala-se entre os ectomeros do 1..$^{\circ}$ e 2..$^{\circ}$ quarteto do quadrante d e é parcialmente coberta por $5 \mathrm{c}$. O mecanismo de tal deslocação poderia talvez ser deduzido da forma arredondada de $4 \mathrm{~d}$. Tal configuração poderia provir de uma tensão superficial maior em $4 \mathrm{~d}$ do que nos blastomeros vizinhos e faria comprehender que as cellulas de tensão superficial menor, crescem por cima de $4 \mathrm{~d}$. Um blastocela (cavidade de segmentação) ainda não existe. Os macromeros 5 A-5 D encurvam-se um pouco em direcção anterior (animal), de maneira que os micromeros do quinto quarteto indicam os infimos elementos do germe visto do pólo animal. A encurvadura dos macromeros annuncia a gastrulação, que se realiza sómente muito mais tarde, quando o embryão se compõe de ca. de 100 cellulas. O ultimo embryão, cuja constituição pudemos analysar foi o composto por 56 cellulas (Fig. 76). Distingue-se da phase anterior, formada por 48 blastomeros pela realização de uma clivagem das cellulas do $20^{\circ}$ quarteto. Trata-se de uma divisão laiotropica que perfence ao sexto passo divisionario do germe. 
O embryão agora acha-se composto pelos 56 blastomeros seguintes:

24 ectomeros do. 1. quarteto

16 ectomeros do $20^{\circ}$ quarteto

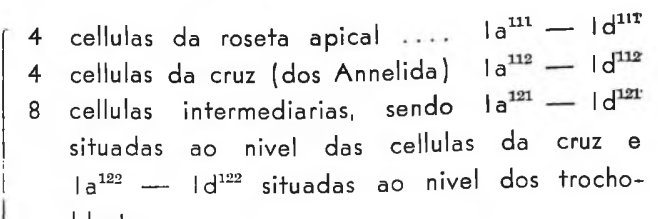

$$
\begin{aligned}
& \text { blastos. } \\
& 8 \text { trochoblastos }\left\{\begin{array}{l}
1 a^{21}-1 d^{21} \\
1 a^{22}-1 d^{22}
\end{array}\right. \\
& \text { fatando ainda a ba. clivagem dos trocho- }
\end{aligned}
$$

$$
\begin{aligned}
& 2 a^{11}-2 d^{11} \\
& 2 a^{12}-2 d^{12} \\
& 2 a^{21}-2 d^{21} \\
& 2 a^{22}-2 d^{22}
\end{aligned}
$$

4 ectomeros do $3 .^{\circ}$ quarteto $\left\{\begin{array}{l}3 a-3 d, \text { falta } \\ 3 .^{\circ} \text { quarteto. }\end{array}\right.$

I teloblasto $=4 \mathrm{~d}$ cellula matriz do endo-mesenchyma, i. é, do folheto germinativa. médio, oriundo do endoderma e apparecendo como tecido mesenchymatico.

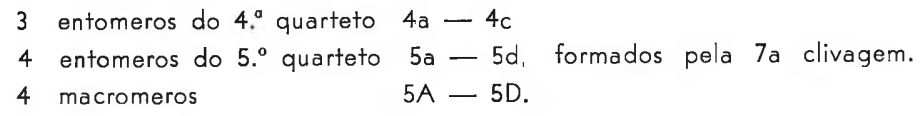

56

\section{d. Blastula e gastrula.}

Os côrtes medianos opticos da gastrula em formação e acabada de Hatschek (1877, t. 28 f. 12, 14 B) conteem 20 e 15-16 cellulas respectivamente, que parece muito pouco em comparação com os côrtes de $10 \mu$ das. phases de gastrulação figuradas aqui (Fig. 78, 28 cellulas; Fig. 79, 33 cellulas; Fig. 80, 28 cellulas). Por isso não se póde esperar resultado concreto. de um confronto entre a segmentação descripta por Hatschek e a linhagem das cellulas aqui observada. As phases seguintes, porém, parecem-se de certo modo e por isso mesmo precisa-se accentuar o seguinte: Em Pedicellina cernua não ha até a gastrulação outros elementos dentro do embryão além da cellula $4 d$ que se divide no inicio da gastrulação. $4 d$ pertence com certeza ao quarteto formado pela divisão dos macromeros depois da phase de 32 cellulas, portanto ao quarto quarteto. Segundo os trabalhos de Hatschek (1877) e Lebedinsky (1905) sobre Pedicellina cernua e o de Harmer (1885) sobre Loxosoma 
leptoclini e tethyae, cellulas internas faltam absolutamente nas. phases correspondentes e se mostram sómente depois da gastrulação (Hatschek 1877 t. 28 f. 14 B - 17. m; Harmer 1885, t. 21 f. 32, 61, pm; Lebedinsky 1905, p. 538).

As Figuras $77 \mathrm{~A}, \mathrm{~B}$ apresentam dois côrtes $(10 \mu)$ dos seis que perfazem. uma blastula de 67 cellulas, sendo a Fig. 77 A o côrte mediano, Fig. 77 B o precedente da serie. Nota-se um pequeno blastocela, cuja extensão principal coincide com a direcção dorso-ventral, indicando a posição de $4 d$ o. lado dorsal. A direcção do eixo primario do ovo é definida pelos polocytos (c), as cellulas estreitas (a) do futuro orgão apical e o pedunculo (p). fixador do embryão no embryophoro, indicando todas estas estructuras a calota animal, ao passo que cellulas vclumosas, provavelmente os macromeros, caracterisam a calota ventral, um tanto achatada. A blastula lembra a do Nemertineo Lineus ruber (Nusbaum \& Oxner 1913, p. 111). comparada pelos autores a una placula. A cellula $4 d$ é a unica da blastula de Pedicellina que não faz parte do blastoderma superficial mantendo-se 4d ainda indivisa. Referindo-me ás exposições anteriores acerca da' nomenclatura (Marcius 1938, p. 101-102) chamo 4d endomesoblasto, i. ér cellula matriz do endomesoderma. Onde se origina o mesoderma por diverticulos do archenteron, como nos Echinode:mata e outros, o termo. "endomesoderma" i. é, mesoderma crıundo do endoderma, comprehende-se sem delongas. Para entender tal denominação em casos de deslocação. precoce de $4 d$, como se realiza no embryão de Pedicellina cernua composto por 48 blastomeros (Fig. 75), devemos lembrar a presumptiva significação endodermica das cellulas-irmãs de $4 d$ e os casos numerosos, onde 4d participa na formação do mesodeo (mesenteron), fornecendo alguns enteroblastos (Wilson 1898, p. 6-9; Heider 1909, p. 275; Dawydoff 1928 , p. 138, 631). Antecipadamente podemos frisar aqui que em Pedicellina $4 d$, pelo que pudemos verificar, é cellula mesoblastica especialisada que não contribue com os seus descendentes para a constituição do intestino medio. A ausencia de enteroblastos rudimentares no blastomero 4d de Pedicellina é de certa importancia sob ponto de vista phylogenetico. Wilson (1898, I. c. e p. 12, 24 efc.) julga taes enteroblastos como reminescencias ancestraes e quem considerar o celoma um derivado do intestino no sentido da theoria do enterocela dos Hertwigs (Heider 1914, p. 484-486) será da mesma opinião. Se a segregação precoce do endomesoderma fôr de tal maneira especializada ou determinada (Conklin), que 4d. não mais contem potencias enterodermicas, mas sim sómente mesodermicas, o desenvolvimento revela-se abreviado e secundariamente simplificado. Quanto á differenciação do mesoderma (endomesoderma) Pedicellina não representa um typo primitivo. 
Sómente em embryões constituidos por 90 cellulas e mais notam-se certos phenomenos que iniciam a gastrulação. Os macromeros situados no centro da placa dos entomeros e até agora as maiores cellulas do embryão dividem-se verosimilmente mais que uma vez, tornando-se muito estreitos. Em Fig. 78 e 79 acham-se marcados por pontinhos densos. A extensão da zona que em seguida se vai invaginar foi marcada com pontinhos escassos, mas, como não ha indicios histologicos dos entomeros, a marcação na Fig. 78 que foi baseada na phase da Fig. 79, é sómente uma avaliação approximativa. A cellula $n$ salienta-se pelo seu volume consideravel, indicando isto que não se dividia desde a sua formação. Participa na invaginação, pertence portanto aos entomeros. Entre estes, $\circ$ 5. quarteto consiste em blastomeros pequenos e os macromeros occupam posição central, de modo que a cellula $n$ deveria pertencer ao $4 .^{\circ}$ quarteto. Como no côrte visinho se encontra uma cellula semelhante quanto ao volume e á côr, são evidentemente dois componentes do $4 .^{\circ}$ quarteto que se manteem indivisos. Reencontrando-se durante a organogenese e histogenese na região apical do mesodeo da larva tornam-se indistinguiveis com a differenciação histologica do tracto intestinal.

Entre uma das cellulas $n$ e os macromeros clivados mostram-se as duas cellulas indicadas por 3, não marcadas por pontinhos. São elementos que, ao nosso vêr, não participam na invaginação e por isso não pódem ser considerados como entomeros. A Figura 79 da phase seguinte faz vêr as cellulas $3 \mathrm{em}$ posição superficial e situadas no mesmo plano transversal em que a invaginação do endoderma é a mais profunda. Verosimilmente as cellulas aqui indicadas por 3 são as cellulas consideradas por Hatschek (1877. p. 507) e Lebedinsky (1905, p. 538) como cellulas mesodermicas primordiaes ("Urmesodermzellen"). Harmer (1885, p. 288) diz: uma das duas cellulas polares do mesoblasto vê-se na vizinhança do blastóporo, ainda que a relação entre esta cellula e as duas camadas germinativas não pudesse ser verificada distinctamente" A figura 34 (t. 21) de Harmer representa uma das cellulas aqui indicadas por 3 na mesma posição como se vê na nossa Fig. 78. Harmer explica a figura 34 da seguinte maneira (p. 335): "A invaginação avançou muito achando-se obliterado o blastocela. O blastóporo, apparentemente é preenchido por uma das cellulas polares mesoblasticas, que, porém, realmente é situada em um plano algo mais profundo do corte" Quanto ao endoderma, a gastrulação da fig. 34 de Harmer é nitidamente mais adiantada que a representada na fig. 32, onde a cellula polar do mesoblasto é situada bem mais interiormente. Assim acho possivel harmonizar os achados de Harmer que cortou embryões de Loxosoma com os apresentados aqui acerca de Pedicellina. A gastrula da fig. 32 de Loxosoma contem a cellula $4 d$, a fig. 34 um 
dos ectomeros designados aqui pelo algarismo 3, por se tratar possivelmente de elementos do quarteto adjacente que deveria ser o terceiro.

Segundo a posição originalmente anterior parece inadmissivel considerar as cellulas marcadas por 3 como sendo descendentes de 4d. Taes elementos chamados enteroblastos posteriores são conhecidos de varios Spiralia, p. e. dos Polyclada (Surface 1907. p. 537. 548), dos Nemertini (Coe 1899, p. 245-246, t. 33 f. 3, explicação p. 259). Polychaeta e Mollusca (Heider 1909, p. 1|4-1|5, 275), mas sempre mostram relação topographica com os endomesoblastos. Do mesmo modo é inverosimil que as cellulas aqui designadas por 3 façam parte do $5 .^{\circ}$ quarteto que nas ultimas. phases aqui analysadas da clivagem se acha disposto no infimo nivel, i. ér no mais vegetativo. Sem duvida não satisfará a muitos leitores a nossa descripção de ectomeros (3) interpostos entre os entomeros, mas não podendo verificar participação destes elementos na invaginação tivemos de deixa-los sem pontinhos ou risquinhos usados para marcar enteroderma $e$ endomesoderma respectivamente.

$\mathrm{Na}$ phase de 90-100 blastomeros em que o embryão representa uma sterroblastula (stereoblastula) realiza-se a divisão da cellula $4 d$, correspondendo o plano da clivagem ao plano mediano do germe. Sendo o espaço entre os entomeros e ectomeros muito estreito, collocam-se os dois descendentes de $4 d$ algum tanto um atráz do outro. Os embryões apertados no atrio materno mostram configuração bem diversa, de modo que não poderia interessar descripção das varias transformações por acaso representadas no nosso material. Mesmo o prolongamento dos ectomeros da presumptiva placa apical (Fig. 78, a) verosimilmente não deveria ser attribuido a um processo morphogenetico mas á pressão externa, á qual se adapta o embryão plastico na sua fina casca de chitina elastica.

$\mathrm{Na}$ phase seguinte, p. e. as cellulas respectivas (Fig. 79. a) são no corte escolhido para o desenho da gastrulação muito menos longas, accentuando-se isso ainda mais na gastrula adiantada (Fig. 80, a). A gastrula de invaginação da Fig. 79 possúe no total ca. de 120 cellulas. As cellulas $\mathrm{n}$ fornecem marcas que possibilitam analysar o procedimento da invaginação.

Esta realiza-se mais intensamente pelo lado da frente, de modo que as duas cellulas $n$ veem occupar o apice do archenteron, onde mais tarde se collocam nos dois lados do plano mediano. As cellulas 3 bloqueiam o blastóporo. Tambem os cortes precedente e seguinte ao desenhado não conteem blastóporo aberto, mas entomeros que participam na invaginação e por isso situados menos periphericamente que os ectomeros 3 . O corte transversal da gastrula de ca. de 120 cellulas, que separaria as metades 
anterior e posterior do embryão, conteria as duas cellulas $n$ e uma unica cellula 3 confinante nos dois lados com entomeros, faltando, é claro, no corte respectivo as duas cellulas descendentes de $4 \mathrm{~d}$.

No germe composto por ca. de 130 cellulas o blastóporo apparece como orificio muito pequeno, visivel sómente no quarto corte da serie que consta de 7 cortes no total. As cellulas da placa apical (Fig. 80, a) assumem aspecto muito caracteristico para as phases da gastrula adiantada e da formação do intestino larval. Abstrahindo dos cilios ainda ausentes, lembram a papilla digitaliforme no apice do Pilidium de Cerebratulus (Wilson 1900, p. 155-156 t. II f. 69-73). O blastocela (cavidade primaria do corpo) torna-se visivel antes e atrás do archenteron, porque o embryão da phase alludida possúe extensão antero-posterior maior que dorso-ventral (animal-vegetativa). Como foi dito, corresponde a descripção da formação dos folhetos germinativos dada por Harmer de varias especies de Loxoso ma (1885, p. 288-289), approximadamente á presente de Pedicellina c ernua, com excepção da origem do endomesoblasto (4d) e de certos pormenores evidentemente relacionados com as differenças da configuração geral e das proporções. A fig. 61 de Harmer, p. e., que apresenta uma gastrula jovem de Loxosoma te thy a e Sal. concorda muito bem com a phase de blastóporo aberto do nosso material. Além das cellulas que derivam de $4 d$, concordantes topographicamente com os elementos correspondentes de Pedicellina, veem-se na figura citada dois entomeros volumosos no apice do archenteron. Talvez sejam homologos ás cellulas $n$ de Pedicellina.

Hatschek (1877 p. 506 e seg.) e Lebedinsky (1905, p. 538) descrevem gastrulação por invaginação em $\mathrm{Pedicelli}$ a cernua, mas os resultados d'esses dois autores, differem dos aqui publicados quanto á origem do folheto médio. Os dois autores consideram duas cellulas periphericamente dispostas como endomesoblastos primordiaes. A figura correspondente de Hatschek (t. 28 f. 13B) poderia ser harmonizada com as observações actuaes, se fossem interpretadas as cellulas $m$ de Hatschek como identicas com as cellulas 3 da descripção presente. A exposição de Lebedinsky, desprovida de illustração, não concorda com a de Hatschek e ainda menos com a nossa, porque Lebedinsky pretende ter visto os dois endomesoblastos na blastula, situados no limite entre o ectoderma e endoderma presumptivos.

Tendencia do crescimento semelhante á notada na gastrulação observa-se na formação do estomodeo, aqui illustrada pelas Figuras 81 e 82. D'estas pertencem Fig. 8। A e 81 B á mesma serie de cortes, sendo o corte da Fig. 81 A o mediano da serie respectiva, o da Fig. 81 B um dos dois cortes paramedianos, confinantes com o mediano. As duas figuras mostram que o estomodeo se origina pelo crescimento especialmente intenso da 
região antero-ventral. A nossa observação de uma massa compacta cellular que se projecta para dentro e para traz, concorda um pouco melhor com a figura correspondente de Harmer (1885, t. 21 f. 35) do que com as de Hatschek (1877, t. 28 f. 15, 16 e 18), onde se vê invaginação de esophago tubular desde o seu primeiro apparecimento. $O$ primordio do estomodeo cresce em forma de semicirculo ou melhor de ferradura, porque é mais grosso no centro anterior que nos dois lados. $O$ blastóporo acha-se fechado pelos ectomeros designados por 3, os quaes depois da formação do estomodeo não se distinguem mais, porque provavelmente são incorporados neste trecho ectodermico do intestino. Quanto á transformação geral do embryão na phase da formação do estomodeo concordo com Hałschek (1877. p. 5,9). Os cortes medianos da gastrulação adiantada e do inicio do desenvolvimento do estomodeo são transversalmente ovaes, sendo o embryão inteiro approximadamente lenticular. Ao se tornar tubuliforme o estomodeo e se ligar ao mesodeo, a configuração do embryão approxima-se mais á globular. Diminue a extensão do eixo antero-posterior e augmenta a da direcção apico-oral. $\bigcirc$ confronto das figuras que illustram a formação do estomodeo e do proctodeo (Fig. 81 e 84) revela diminuição do vitello (deuteroplasma) no ectoderma da parede do corpo. Evidencia-se assim tratar-se no alongamento descripto, não sómente de translocação do material, mas de crescimento verdadeiro, custeado pelo consumo do deuteroplasma. O sulco annular, já observado por Hatschek (1877. p. 509), separador das metades apical e orail do embryão, apparece no nosso material, quando o corte transversal mostra supremacia consideravel da direcção apico-oral sobre a dextro-sinistral (Fig. 83). Depois de se ter completado o tracto intestinal accentua-se a preponderancia da direcção apico-oral tambem sobre a antero-posterior. $O$ estomodeo reveste-se muito cedo de cilios, embora não sejam, como Hatschek (l. c.) disse, os primeiros do embryão, visto que simultaneamente pequenos apparecem no presumptivo orgão apical. Estreitando-se o estomodeo na sua extremidade interna forma-se muito nitida porta pharyngeana equivalente ao blastóporo.

São embryões compostos por 180-200 cellulas em que se nota na região antero-ventral o primeiro espessamento ectodermico do estomodeo inicial. Dividem-se nesta phase e nas seguintes os endomesoblastos, dando assim origem ao endomesenchyma, escasso durante a phase larval. A divisão dos endomesoblastos póde resultar em disposição mais ou menos claramente linear dos seus descendentes (Fig. 84, d). As figuras correspondentes de Hatschek (1877. t. 28 f. 16, t. 29 f. 21, m) e de Harmer (1885, t. 21, f. 40,4I, mes), que estudaram Pedicellina e Loxosom a respectivamente, mostram o mesmo; os textos relativos ao mesoderma são: "as cellulas mesodermicas dos dois lados forneceram productos 
de divisão, que se adiantam para o lado oral" (Hatschek 1877, p. 510) e: "a faixa mesoblastica consiste de uma serie de cellulas ramificadas" (Harmer 1885, p. 290). Na figura principal (f. 40) são aliás bem compactas, epitheliaes e não ramificadas. Seja como fôr, as exposições seguintes de Harmer são univocas; não viu somato- e esplanchnopleura, mas sim logo. em seguida dissolução da faixa mesodermica.

Fundamentalmente differentes são os dados de Lebedinsky (1905, p. 542 e seguintes) que distingue ectomesenchyma e celothelio (endomesoderma), o ultimo procedente das faixas formadas pelos endomesoblastos ou cellulas mesodermicas primordiaes ("Urmesodermzellen") da terminologia de Lebedinsky. Tri-metamerisação da faixa (estria) mesodermica resultaria em tres vesiculas de paredes uni-estratificadas, os somitos ou saccos celomaticos, cujo destino, nephridios, ovarios, testiculos, o autor descreve com certa reserva. Verosimilmente por causa de concordar a descripção dada por Lebedinsky com o desenvolvimento typico dos Protostomia mesenchymaticos cujas gonadas e emunctorios representam o celoma e os celomoductos, esta exposição do desenvolvimento de $\mathrm{Pedicellina}$ influenciou o capitulo sobre os Entoprocta no tratado de MacBride (1914, p. 401, 405). Dawydoff (1928, p. 342, nota) recusa categoricamente os pretendidos saccos. celomaticos, dizendo ter Lebedinsky assim interpretado certas estructuras ectodermicas oriundas do atrio. Seja qual fôr a causa do erro de Lebedinsky, a tri-metamerisação das faixas mesodèrmicas não existe, e não havendo dissoluçãa de paredes de um celoma, o mesenchyma de Pedicellina permanece mesenchyma primario ou coelenchyma na terminologia de Dawydoff (1928, p. 382).

Parece até muito duvidosa a homologia das series quasi incoherentes de. cellulas endomesenchymaticas de Pedicellin a com os tractos compactos. e desde o inicio da sua formação bem definidos do endomesoderma dos Annelida e Mollusca. Além de serem ephemeras as series endomesenchymaticas de Pedicellina, distinguem-se tambem topographicamente das faixas endomesodermicas, p. e. dos Annelida, que nunca entram na região. da episphera. Como a hyposphera falta na larva de Pedicellina, a sua serie endomesenchymatica disposta dorsalmente do proctodeo (Fig. 84, d) occupa posição atypica. Comtanto que se considerem homologos os descendentes de $4 d$ nos Polyclada e nos Annelida e Mollusca, embora os primeiros só occasionalmente sejam agrupados em forma de fita, poder-se-ia reclamar homologia igual para as series frouxas de Pedicellina. Ao lado do facto importante da origem concordante do endomesenchyma e endomesothelio dos Spiralia mesenchymaticos e celomaticos respectivamente, a questão da homologia entre as phases morphologicas mais ou menos transitorias, percorridas pelos descendentes de $4 d$, parece menos significativa. 
Tal identidade da origem ainda não foi possivel estabelecer para os elementos interpretaveis como endomesodermaticos nos Ectoprocta, onde os Ctenostomata são o unico grupo, em que ha indicações acerca do folheto germinativo medio (veja Marcus 1938, p. 103). As faixas evidentemente endomesodermicas de Flustrella (Pace 1906, p. 464, 468, t. 25 f. 63b, 65c) apparecem tão tarde que seria impossivel averiguar a sua linhagem cellular. Quanto á coherencia dos seus componentes as faixas de Flustrella hispida (Fabr.) ultrapassam grandemente as series de cellulas conhecidas dos Entoprocta. Seria prematura a tentativa de coordenar o endomesoderma nas duas sub-classes dos Bryozoa.

Outra differença ainda nota-se entre Ectoprocta e Endoprocta pela ausencia de ectomesenchyma nos Ectoprocta ou ao menos pela falta de verificação correspondente com excepção do cordão neuro-muscular (Marcus 1938, p. 105). Deixando de lado a separação secundaria entre o desenvolvimento da chorda e do mesoderma por um lado e do enteroderma pelo outro, realizada nos Amniota, podemos ainda hoje, como na época em que Heider discutiu clarissimamente os typos da formação do mesoderma (1909, p. 262-309) manter o seguinte: nos Deuṭerostomia são escassas as indicações sobre a occorrencia do ectomesoderma, nos Protostomia são numerosas, trazendo o termo "mesoblasto larval" synonymo de ectomesoderma (histologicamente sempre de caracter mesenchymatico), a sua origem do apparecimento do ectomesenchyma em phases larvaes dos Protostomia. Discutindo os poucos casos, onde o mesoblasto larval falta nos Spiralia, Shearer (1911, p. 553) mantem unicamente Apl ysia punctata, representante dos Opisthobranchia, onde a ausencia do ectomesoderma foi affirmada insistentemente (Saunders \& Poole 1910, p. 50I). Os Tentaculata (Bryozoa ectoprocta, Phoronidea, Brachiopodal evidenciam-se de certo modo apartados dos Protostomia restantes tambem pelo facto de ser insignificante o seu ectomesoderma, representado apenas pelo cordão neuromuscular entre os orgãos apical e pyriforme nos Ectoprocta. Não obstante, a larva de todos os grupos reunidos nos Tentaculata é trochophoroide. Refere-se o ultimo tambem aos Entoprocta, cujo ectomesoderma se enquadra bem aos elementos correspondentes nos outros Spiralia.

Embora não possa eu confirmar a modalidade da origem do ectomesoderma, como foi indicada por Harmer (1885, p. 289) e Lebedinsky (1905, p. 542, 545), tenho de assignalar como estes autores a existencia d'essa formação. Harmer disse apenas o seguinte: "Pela consideração dos cortes de Loxosoma tethyae torna-se provavel originar-se o mesoderma em parte de qualquer porção do embryão de modo inteiramente independente das cellulas polares" chamando Harmer assim os endomesoblastos. Lebedinsky que pesquizou Pedicellina cernua enuncia a opinião 
precisa: "O mesenchyma forma-se á custa do ectoderma; o lugar do qual se origina o mesoderma, apresenta-se como espessura ectodermica bisymetrica, situada na face posterior do embryão no mesmo nivel como o orgão pre-oral" Possivelmente interpretou Lebedinsky o primordio do proctodeo como sendo espessura do ectomesoderma presumptivo. O proctodeo, porém, origina-se como invaginação tubuliforme, como foi indicado por Lebedinsky (l. c., p. 540), se bem que não "quasi simultaneamente com o primordio do estomodeo e atrio" como pretendeu. Havendo no trabalho de Lebedinsky apenas duas figuras esquematicas, é muito difficil coordenar com os factos as affirmações d'esse autor perito na theoria, mas insufficiente na pratica. O ectomesenchyma de Pedicellina forma-se no bordo do estomodeo, como se vê na Fig. 83. N'esta phase ainda é possivel distinguir os descendentes de $4 d$, o endomesenchyma $(\mathrm{m})$ do ectomesenchyma ainda parcialmente coherente com o ectoderma na dobra formada pelo estomodeo (s) e a parede do corpo. Mais tarde não conseguimos mais differenciar os componentes do mesenchyma larval, de maneira que não podemos definir a origem endo- ou ectomesenchymatica das celluias musculares ou de caracter de tecido conjunctivo na larva adulta. Abstrahindo da configuração differente do mesodeo (mesenteron, e) e do facto da escassez dos elementos mesenchymaticos, o corte transversal do embryão de Pedicellina (Fig. 83) lembra muito o da mesma phase de Hoploplana inquilina (Surface 1907. p. 543, fig. 4 no texto). A nossa verificação da origem do ectomesenchyma de Pedicellina em redor da bocca enquadra-se perfeitamente com a conhecida relação entre os estomatoblastos e o mesoblasto larval em outros Spiralia e talvez até em outros Protostomia (Nematodes; Heider 1909, p. 268).

Corresponde ao crescimento da região antero-ventral, pelo qual se realiza a formação do estomodeo, o augmento das cellulas ectodermicas da zona postero-ventral do embryão. Dá origem esta proliferação ao lado ventral, situado futuramente entre bocca e anus e ao proctodeo, cujo orificio externo marca mais tarde a extremidade posterior do curto lado ventral da larva. Apresentando phases approximadamente coetaneos a do corte transversal, que passa pelo estomodeo completo (Fig. 83) e a outra do corte mediano, em que a invaginação do proctodeo ainda não chegou ao contacto com o mesodeo (Fig. 84), evidencia-se certo atraso do crescimento na zona postero-ventral. O orgão pre-oral (o) já se acha esboçado no lado anterior, emquanto posteriormente não se formou lumen continuo do tracto intestinal.

Um traço caracteristico da organogenese da Trochophora falta na larva de Pedicellina, a saber, a formação da raphe gastrular (suturạ prostomial) que resulta do successivo fechamento do blastóporo de tráz para 
diante e se mantem na Trochophora completa como sulco neuro-trochoide. E' sabido que a caminhada do blastóporo caracteriza o presumptivo lado ventral ou em outras palavras: torna-se lado ventral aquelle lado do corpo. em que diminuiu a distancia entre a placa apical e o bordo do blastóporo. Tal approximação dá-se em certos embryões de Molluscos tambem pela translocação do orgão apical em direcção ventral e poder-se-ia considerar - orgão pre-oral como semelhante elemento derivado da placa apical. Esta homologia será discutida mais adiante (veja p. 259), mas não mantida, em virtude de se originar o orgão pre-oral independentemente da placa apical e, maiș ainda, por ser orgão transitorio, puramente larval nos Entoprocta. Voltando á approximação entre placa apical e blastóporo realizada pela concrescencia dos bordos d'este ultimo, devemos accrescentar que ella causa a flexão do eixo primario dos Triploblastica (Bilateria) Protostomia, tornando-os heteraxonos. Na larva de Pedicellina, porém, em que falta a migração alludida, o eixo primario do ovo, que vai do pólo animal ao vegetativo, coincide quasi, não completamente, com o eixo longitudinal (antero-posterior) da larva. A capacidade da evaginação do atrio e com isso a remoção da bocca para diante e do anus para tráz, póde resultar em ligeira flexão do eixo principal do corpo em relação ao eixo da gastrula. Essa deliberação theorica reveste-se, ao meu vêr, de certa importancia, porque fornece novo criterio para as relações entre os Enteropneusta e os Tentaculata.

No grupo dos Deuterostomia é Ba la noglossus o unico representante dos Protaxonia, i. é, dos Bilateria, cujo eixo longitudinal coincide com - eixo da gastrula. Encontramos agora nos Entoprocta novamente Protaxonia, d'esta vez no grupo dos Protostomia. No Cyphonautes dos Ectoprocta Gymnolaemata, a topographia é a mesma dos Protaxonia e nos Phylactolaemata a coincidencia é até mesmo total. Sabemos que os estudos da promorphologia, nomeadamente quando se absteem da construcção de "formas primitivas" permanecem abstractos, mas quanto menos esperamos descobrir elementos concretos que poderiam unir phylos distantes, tanto mais devemos ponderar os traços fundamentaes dos planos de estructura differentes.

A natureza dos Entoprocta como Protostomia é indubitavel, a opinião contraria de Harmer $(1885$, p. 288, 289) de se originar o anus no lugar de blastóporo ou este persistir como anus, explica-se facilmente pela pequena extensão do lado ventral. No embryão de Loxosoma tal extensão parece miais curta ainda (Harmer 1885, t. 21 f. 52) que em Pedicellin a, onde pelo menos no momento do primeiro apparecimento do proctodeo o anus se mostra como sendo a neo-formação typica dos Protostomia. 


\section{e. Organogenese e Histogenese.}

As phases seguintes da organogenese e histogenese foram estudadas por nós sómente nos seus traços principaes, porque os orgãos nervosos e sensoriaes, assim como o atrio e os seus annexos já foram pesquizados por Prouho (1892, p. 692 e seg., t. 30 f. 91, 93, 96, 99) e pormenorizadamente por Seeliger (1906). O intestino foi sufficientemente descripto por Cori (1936, p. 31). Larvas livres que constituiram o objecto do trabalho de Czwiklitzer (1908) não tivemos em mão; a publicação alludida provida de figuras muito boas, serviu como base para os respectivos capitulos nas. obras de MacBride (1914, p. 401-402) e Cori (1929, p. 32-33; 1936, p. 30-31). Os trabalhos anteriores e o nosso fazem que, com a unica excepção do desenvolvimento do protonephridio, a embryogenese de Pedicellina cernua, ao nosso vêr, agora se acha esclarecida nos pontos mais essenciaes.

Nos embryões, em que o intestino se forma, as cellulas do ectoderma assumem feição muito singular, tornando-se rectangulos estreitos e compridos com nucleo alongado e disposto parallelamente á extensão maior das. cellulas. Á maneira de um muro de tijolos o ectoderma circumda o embryão nas phases finaes da gastrulação e durante a organogenese do intestino. Tal disposição, porém, não persiste. No seguinte realiza-se divisão cellular especialmente intensa no estomodeo e de modo geral na face ectodermica ventral. Este processo, em que o ectoderma lateral não participa com intensidade igual, resulta em augmento da extensão apico-oral do embryão $e$, ao mesmo tempo, em dissociação do conjuncto estreito, anteriormente presente, dos ectomeros lateraes. Agora não se poderia mais: fallar em muro de tijolos formado pelo ectoderma na circumferencia do embryão inteiro. Pelo contrario, acham-se os componentes da pelle embryonaria necessitados pelo crescimento intenso dos bordos buccaes de accompanhar o alongamento resultante do crescimento alludido e assim são estirados. Compõe-se d'este modo, por poucas cellulas compridas e chatas a epiderme embryonaria na phase da histogenese intestinal e da organogenese dos orgãos ectodarmicos a serem descriptos a seguir.

Outra consequencia do alongamento notado dá-se pelo facto de o embryão preencher completamente desde agora a casca ovular, até aqui distante do embryão e ligeiramente dobrada. Ao se differenciar o intestino histologicamente, a casca torna-se caduca, persistindo sómente em redor do manubrio caliciforme, oriundo pela invaginação da placa apical (Fig. 85, 87. a). Neste ponto acha-se atado o pedunculo que liga o embryão ao 
embryophoro. O ectoderma desprovido da casca secerna envolucro evidentemente pegajoso que se reveste com incrustações alheias, p. e., particulas de limo e restos das fezes do animal-mãe (Fig. 87, x). Permanece isento de tal camada todo o ectoderma ventral (zona do metatrochio, Fig. 85, 87. m), assim como a região do prototrochio (Fig. 85, $87 \mathrm{p}$ ) enrolado para dentro nos embryões ainda fixos no embryophoro materno, mas, como se sabe, voltado para fóra na phase de locomoção livre, i. é, na larva. A dissolução da casca ovular possibilita os embryões alimentarem-se por si mesmos. Evidencia-se pelo conteúdo do intestino dos embryões a efficiencia dos cilios do prototrochio e do estomodeo como orgãos, cujo turbilhão traz particulas nutritivas á bocca. Não assumindo o epithelio do atrio no material aqui em mão caracter especial de bolsa incubadora (Cori 1936, p. 66-67; Becker 1937. p. 96), faltam tambem no tracto intestinal da larva as cellulas cheias de albumina, gordura, etc., oriundas do epithelio materno, que contribúem para a alimentação da larva. No nosso material - conteúdo do intestino larval é o mesmo como nos adultos.

O consumo do vitello e a differenciação histologica do intestino são processos evidentemente muito rapidos, visto que são rarissimas as phases respectivas. Além do alongamento já alludido realiza-se n este periodo. a invaginação da placa apical (Fig. 85, 87, a) e do orgão pre-oral (o) como tambem a formação do cordão neuro-muscular (c), que liga estes dois orgãos neuro-sensoriaes. Tendo Seeliger (1906, p. 7-23) descripto no capitulo dedicado ao apparelho nervoso a organogenese e histogenese d'esses elementos, cujas phases iniciaes se acham desenhadas nas nossas Fig. 81 e 84, aqui não foram estudadas pormenorizadamente.

Como já foi dito por Hatschek (1877, p. 513), concorda o intestino do embryão, quando differenciado, nos traços principaes com o tracto digestivo do animal metamorphoseado. Aliás acha-se bem descripto o appareTho nutritivo por Hatschek (I. c., p. 511-513), Cori (1936, p. 31) e Becker (1937. p. 93-97), de modo que unicamente os nossos desenhos (Fig. 85, 87) se apresentam como accrescimo dos conhecimentos. $O$ estomodeo abrange dois trechos differentes, a saber a pharynge (Fig. 85, h) infundibuliforme, provida de longos cilios e o esophago (e) igualmente revestido por cilios compridos, mas mais estreito que o trecho precedente. $O$ mesodeo compõe-se do estomago (s) espaçoso, cujo epithelio possúe ciliáção escassa, formada por cilios curtos, e pelo intestino (i) ovoide, dotado de uma orla densa: constituida por numerosos cilios curtos e fortes. $O$ proctodeo ( $r$ ), approximadamente fusiforme, mostra poucos cilios curtos do typo encontrado no estomago. Com a differenciação das varias partes do tracto digestivo as cellulas $n$ tornam-se indistinguiveis. 
Os elementos mesenchymaticos, fibras musculares, cellulas ramificadas de caracter de tecido conjunctivo e cellulas do typo de amebocytos são pouco numerosos nas phases estudadas aqui, de modo que se apresenta cavidade do corpo primaria (blastocela) ampla. Sómente nas regiões perto do fundo do atrio o mesenchyma é mais ricamente desenvolvido (Fig. 89). Ainda hoje pouco conhecido é o emunctorio larval (Cori 1936, p. 31), descoberto por Hatschek (1877 p. 515). Quanto á situação d'este orgão concordam os autores sómente de um modo geral, dizendo que se encontra na região atrial, post-esophageana. Tão perto, porém, da pharynge, como foi desenhado por Seeliger (1906, f. I A no texto, p. 27), não se encontra no nosso material. Menos ainda posso concordar com a descripção d'este autor (l. c., p. 34) quanto á situação do nephróporo immediatamente atrás do esophago, ainda antes do tufo ciliado, quer dizer do chamadc labio inferior. A topographia do protonephridio no respectivo desenho de Hatschek (1877, t. 29 f. 26 E) tambem não concorda com os nossos achados (Fig. 89, n). Tal discrepancia, porém, talvez seja menos importante, porque Hatschek estudou o emunctorio sómente na larva livre, cuja capacidade de contracção, evaginação e retracção, nomeadamente da região da hyposphera, possivelmente poderia causar deslocação do orgão excretor. A figura de Czwiklitzer (1908, fig. I, p. 162) mostra o protonephridio ou mais exactamente, o canal ciliado evacuador commum dos dois protonephridios em vista lateral. Trata-se de um esquema combinado de dois cortes sobrepostos, tencionando o autor ao mesmo tempo illustrar orgãos do plano mediano e outros do lado esquerdo.

Visto que os dois protonephridios da larva começam perto do epithelio dermico e ao nivel da região superior (apical) do orgão advestibular esophageano (veja a seguir, p. 250), são córtes ou em direcção horizontal ou em transversal mais indicados para estudar os emunctorios (Fig. 89, n). O texto de Czwiklitzer (1908, p. 176) acerca da origem do protonephridio abaixo da parede do estomago corresponde á nossa Fig. 89, n. Apezar da differença topographica já mencionada, que existe entre a observação de Seeliger e a nossa, concordam os pormenores histologicos. O protonephridio larval possúe estructura identica com o emunctorio do animal metamorphoseado, conhecido especialmente pelos trabalhos de Foettinger (1887. p. 308-309) e Stiasny (1905, p. 5 e seguintes). Acha-se composto por um solenocyto com tufo de cilios compridos (chamma de cilios) e duas cellulas que formam o ducto, cujos nucleos se acham situados alternadamente nos dois lados do lumen. No nucleo do solenocyto ha um ou dois nucleolos. O canal evacuador não se mostrou sufficientemente nitido nas nossas laminas para estudos exactos, parece que é formado por numerosas cellulas e revestido por cilios. A figura 46 de Cori $(1936$, p. 61) tem aliás legenda 
erronea, porque não se trata dos protonephridios de Pedicellina cernua (Pall.) mas sim de Loxosoma crassicauda Sal. Naturalmente é impossivel decidir pela figuração do orgão completo, se o ducto do emunctorio é intercellular ou intracellular. $O$ canal evacuador é nitidamente intercellular. $O$ ducto excretor que termina com o solenocyto é verosimilmente intracellular, em virtude da excellente figura de Harmer (1887. t. 20 f. 17) que mostra um solenocyto e mais para fóra 3 cellulas șuccessivas cylindricas perfuradas (ibid., p. 278) no emunctorio de Loxosoma crassicauda Sal. A tentativa de Lebedirisky (1905, p. 543, 546). de derivar o emunctorio do 1.0 par de somitos, como elle disse, e de provar assim a natureza intercellular do ducto excretor devemos considerar como falha. Novas pesquizas sobre o desenvolvimento do emunctorio seriam muito desejavéis, mas o material actualmente á nossa disposição não revelou phases da formação do orgão excretor. A grande importancia attribuida anteriormente (p. e. Meisenheimer 1910, p. 308) e hoje (Cori 1936, p. 62) á natureza intracellular do ducto, provem da antiga separação profunda entre protonephridios e nephridios (metanephridios) como caracteres dos Scolecida e Annelida respectivamente. Aliás é estranho que Cori, apezar de accentuar o caracter protonephridial do orgão excretor dos Entoprocta, constantemente falla no "nephridio delles. Pelas pesquizas de Goodrich (1900, p. 736 e outras) sabemos que em certos Annelida os canaliculos excretores mostram caracter perfeito de protonephridios (Heider 1928, p. 237-238), de modo que em nossos dias a solução do problema da natureza intercellular ou intracellular do ducto nos Entoprocta não seria mais tão significativa para o systema. Como foi dito, verosimilmente, é intracellular o lumen alludido, mas não se póde acceitar a phrase de Cori (1936, p. 62): "devemos considerar como estabelecido, especialmente ainda confirmado por Stiasny, o facto de ser intracellular o lumen do canal renal"

Já foi dito por Seeliger (1906, p. 23), que o atrio se forma muito tarde no embryão de Pedicellin a cernu a em opposição aos botões d'esta especie, e, podemos accrescentar, aos embryões do genero Loxosoma (Harmer 1885, p. 293). A região indicada por Seeliger com ponto de interrogação com at, quer dizer atrio (1906, t. I f. I), não discutida no seu texto, com certeza não é o primordio do atrio. As proprias palavras de Seeliger (1906, p. 23) contradizem a tão prematuro apparecimento do atrio: "o vestibulo ou atrio apparece no decorrer do desenvolvimento embryonario sómente muito tarde e independentemente do canal intestinal" Seeliger (1906, p. 23) continuando refere-se á exposição de Hatschek (1877. p. 513), onde, porém, a formação do atrio se acha descripta de uma maneira não. absolutamente correcta: em consequencia de crescimento consideravel da massa que compõe o fundo do calice, esse fundo forma immediatamente 
atraz do orificio buccal uma profunda dobra transversal, em cuja parede posterior o anus se encontra A nossa Fig. 85, † mostra, porém, a independencia do primordio do atrio e do anus. Approximadamente corresponde esta Fig. 85 ao corte optico mediano do embryão vivo desenhado por Seeliger (1906, + I f. 5). O córte horizontal (Fig. 86) que contem a parede ventral do estomago (s) mostra o atrio bilobado $(t)$ i em um plano mais ventral seriam confluentes os dois lobulos. Além do atrio nota-se differença entre os dois córtes medianos (Fig. 85, 87) sómente com respeito ao chamado epistoma (Fig. 87. z) ou labio inferior, ainda não desenvolvido na phase da formação do atrio. Aliás os embryões são muito semelhantes quanto ás dimensões e á differenciação histologica. Mostram-se asșim o atrio e as estructuras especiaes oriundas do atrio atrasadas, entrando na phase da organogenese, quando o intestino já tem passado pela histogenese e começou a funccionar. Lateralmente á invaginação do atrio o ectoderma ventral aprofunda-se formando a fenda atrial, (Fig. 88, a) que circumda o proctodeo (r).

Dos orgãos que Seeliger chamou de orgãos advestibulares (1906 p. 26) foram reencontrados os tres observados por este autor. Seguem-se do lado oral para ○ anal o orgão advestibular esophageano (Fig. 88, 89, d) ○ orgão advestibular basal (Fig. 87-89, g) e o orgão advestibular rectal (Fig. 87-89, v). Visto que todos esłes orgãos apparecem sómente depois de se ter formado o atrio e se manteem em contacto com elle, considero-os de origem ectodermica. As duvidas de Seeliger (1906, p. 30, 31) sobre a procedencia do $1 .^{\circ}$ e $3 .^{\circ}$ desses orgãos proveem, ao meu vêr, do facto de ter elle estudado essas differenciações principalmente na larva livre, não como nós, no embryão. Poucas cellulas do epistoma, desprovidas de cilios formariam, segundo Czwiklitzer (1908, p. 175) um quarto grupo de glandulas da hyposphera. Estas "glandulas do epistoma" ainda não se achavam differenciadas no nosso material, na sua totalidade mais jovem que as larvas livres do trabalho de Czwiklitzer. Se considerarmos com Dawydoff (1928, p. 342, nota) os tres somitos descriptos por Lebedinsky (1905, f. I, p. 54I) identicos com os tres grupos de orgãos advestibulares, seria estabelecida a continuidade das respectivas observações desde 1905 até hoje.

O epistoma (Fig. 87, z) é formado por cellulas altas, providas de cilios, e, segundo Czwiklitzer (1908, p. 171), ligadas ao orgão pre-oral por dois cordões nervosos que cercam o estomodeo. A existencia desses cordões pudemos confirmar, mas como se acham dispostos lateralmente, não poderiam ser desenhados no córte mediano. Concordando com Cori (1936, p. 31) consideramos o epistoma (ou labio inferior) como orgão tactil, porque foi observado por Cori que os cilios apalpam o substrato como o fazem os do orgão pre-oral. As denominações de ganglio pharyngeano superior e inferior applicadas ao orgão pre-oral e epistoma respectivamente, teem causado 
varias interpretações systematicas, ao meu vêr, inadmissiveis. Caracter de ganglio não se vê nas cellulas do epistôma dos nossos embryões, nem nas larvas livres estudadas por Czwiklitzer (1908, p. 17| f. 14, UG). Embryologicamente os cilios do epistoma, situados atrás da bocca, pertencem ao metatrochio (Fig. 85, 87. m), do qual constituem os unicos elementos notaveis, sendo curtos os cilios restantes do metatrochio. Histologicamente são bem differentes o atrio (Fig. 89, a) a fenda atrial (Fig. 88, a) e a sua parede anterior, o chamado labio inferior (Fig. 88, u) inclusive o epistoma de um lado e os orgãos advestibulares do outro lado. Os primeiros componentes do atrio conservam o caracter multinuclear que ainda mais se nota no primordio do atrio (Fig. 85, 87, †). Nos orgãos advestibulares predomina o cytoplasma sobre os nucleos, perdendo-se o caracter epithelial especialmente no orgão central (Fig. 88, g).

O orgão advestibular esophageano da terminologia. de Seeliger (1906, p. 31) é paucicellular (Fig. 88, 89, d) e composto por dois lobulos racimosos, bilateralmente situados. O caracter syncytial, descripto por Seeliger (p. 32) não foi reencontrado no material aqui em mão, onde as cellulas são bem distinctas. Explica-se tal divergencia sem delongas pela comparação das figuras de Seeliger (1906, t. 2, f. 23-25) com as nossas, revelando-se então ter Seeliger considerado o labio inferior (Fig. 88, u) como pertencente ao orgão advestibular esophageano. Por isso, confina o orgão nas figuras de Seeliger directamente com o esophago pertencendo, porém, os nucleos centraes das suas figuras, tão bem como nas nossas, ao labio inferior. Em córtes frontaes que passam pela dobra formada pelo fundo do atrio e o labio inferior o caracter epithelial, muito claro nos córtes sagittaes, não se mantem porque tal córte encontra as cellulas atriaes tangencialmente. No estado de differenciação que o orgão advestibular esophageano apresenta nas phases aqui disponiveis, sem duvida mais jovens que aquellas estudadas por Seeliger, não se encontram elementos que insinuassem tratar-se de um orgão nervoso. Certamente a allusão em tal sentido feifa por Seeliger é muito reservada, as suas figuras tambem não favorecem opinião semelhante. $\bigcirc$ aspecto das cellulas do orgão advestibular esophageano dos embryões estudados aqui é glandular. A descripção de Czwiklitzer (1908, p. 175) das glandulas esophageanas e a boa figura 17 (O e D) correspondem bem ás nossas verificações.

O orgão advestibular basal (Fig. 88, g) é mais volumoso que o precedente e o seguinte. Apresenta-se como massa approximadamente reniforme e solida, notando-se constricção annular no plano mediano. Na Fig. 89 que passa pelo atrio, veem-se sómente os lobulos externos d'este orgão, no córte da Fig. 88 situado na respectiva região mais apicalmente, apparece tambem a massa central. $O$ aspecto histologico concorda com as descripções de Seeliger (1906, p. 29) e Czwiklitzer (1908, p. 174), a saber, disposição peri- 
pherica dos nucleos e protoplasma homogeneo, claro, atravessado por linhas que se tingem mais intensamente. Nos nossos embryões estas linhas, ao que parece, ainda coincidem mais ou menos com os limites das cellulas, nas larvas de vida livre estudadas por Seeliger e Czwiklitzer tal relação não se dá mais, confluindo e parcialmente desapparecendo as linhas interpretadas. por Seeliger como fibras sustentadoras. O orgão advestibular basal apresenta caracter glandular mais nitidamente que os dois outros orgãos advestibulares.

O orgão advestibular rectal (Fig. 87-89, v) compõe-se tambem de uma massa central (Fig. 87, v) e dois lobulos lateraes. $\bigcirc$ aspecto histologico lembra de certo modo o orgão advestibular esophageano, mas as cellulas são algo mais volumosas e se tingem muito mais intensamente. Seeliger diz (1906, p. 30): "ás vezes notei na escura massa protoplasmatica, homogenea, alguns nucleos especialmente grandes, claros e vesiculares, lembrando então. o aspecto do orgão de certo modo um primordio juvenil do apparelho genital" Tal aspecto, é verdade, dá-se nas nossas figuras ainda muito mais nitidamente que nos desenhos de Seeliger (1906, t. I f. 20, + 2 f. 22-24, 27. gs). Lembrando as observaçães sobre a incorporação das cellulas germinativas no endoderma de Oligochaeta marinhos (Penners 1929, p. 332, etc.; 1930, p. 106 etc., 115) tomámos em consideração a entrada das cellulas $n$, não mais visiveis depois da differenciação do tracto digestivo, no orgão advestibular rectal. As nossas laminas porém, não documentam a continuidade entre a ultima phase, em que as cellulas $n$ se veem e a primeira, em que o orgão advestibular rectal se forma. Tão pouco contem a litteratura quaesquer indicios de se manter o orgão alludido até o momento tardio, em que a gonada apparece (Seeliger 1889, p. 175 t. 9 f. 3). Finalmente, referir-se-ia a semelhança entre o orgão advestibular rectal e a gonada sómente a um ovario de ovocytos volumosos, mas não ao ovario jovem de Pedicellin a, cujas cellulas germinativas são muito menores que as cellulas do orgão larval em questão, sem duvida de funcção glandular como os outros orgãos advestibulares. Nas figuras de Czwiklitzer (1908, t. I f. 2, 3, 16, 17, RD) ○ caracter glandular do orgão advestibular rectal na larva de vida livre é indubitavel, mostrando-se que o aspecto do orgão mudou bastante desde o seu primeiro apparecimento nos embryões estudados aqui.

$E^{\prime}$ de se notar que os espermatozoides á procura dos ovos do individuomãe entrados no atrio materno penetram tambem no atrio dos embryões (Fig. 89, a) e d'ahi o turbilhão dos cilios faz evidentemente entrar os espermios na bocca, porque ás vezes foram verificados no tracto intestinal do embryão. 


\section{f) Conclusões geraes.}

Tendo comparado os pormenores do desenvolvimento de Pedicelli na na descripção precedente com phases correspondentes de alguns outros representantes dos Spiralia, posso restringir as conclusões geraes aos pontos principaes, a saber, á relação dos Entoprocta com os Ectoprocta e á posição dos Entoprocta no systema zoologico. Cori (1936, p. 101) confrontou os caracteres dos Entoprocta e Ectoprocta da maneira seguinte:

\section{A. Entoprocta.}

1) O desenvolvimento do embryão é determinado.

2) A embryogenese resulta em Trochophora modificada.

3) $\mathrm{Na}$ metamorphose, passam a parede do corpo, o intestino e o rim da larva á phase da imago.

4) O resultado da metamorphose é um plano de estructura igual ao da larva.

5) O animal adulto é um Acelomato.

6) A cavidade primaria do corpo achase repleta de mesenchyma.

7) Os rins são protonephridios.

8) As gonadas são sacculiformes.

9) A parede do corpo consiste sómente no epithelio ectodermico do corpo.

10) Sob o ponto de vista da anatomia comparativa é o lado ventral que se dirige como face activa para a agua.

11) A corôa tentacular origina-se da região pré-oral do corpo, i.é, da região da episphera larval.

12) $O$ ganglio é um ganglio sub-pharyngeano.

13) A concavidade do intestino volta-se para o lado ventral do corpo.

14) Para entrarem em posição de protecção os tentaculos encurvam-se simplesmente para dentro.

15) Ao lado da propagação sexual existe a asexual por gemmação.

\section{B. Ectoprocta.}

1) O desenvolvimento é modificado, sendo o typo indistincto.

2) A embryogenese resulta em Trochophora modificada.

3) Na metamorphose, conserva-se sómente a parede do corpo da larva, todos os orgãos (restantes) formam-se novamente por um processo igual á gemmação.

4) O resultado da metamorphose é um plano de estructura mais alto que - da larva.

5) $O$ animal adulto é um Celomato.

6) Uma cavidado secundaria do corpo é presente.

7) A occorrencia dos rins é posta em duvida.

8) As gonadas sãa planiformes.

9) A parede do corpo consiste em epithelio ectodermico e em mesothelio.

10) Sob o ponto de vista da anatomia comparativa é o ládo dorsal que se dirige como face activa para a agua.

11) A corôa tentacular origina-se por territorios da região post-oral do corpo.

12) O ganglio é um ganglio supra-pharyngeano.

13) A concavidade do intestino volta-se para o lado dorsal do corpo.

14) Para entrarem am posição de protecção os tentaculos são retrahidos no celoma.

15) Ao lado da propagação sexual exis. te a asexual por gemmação. 
Em consequencia do seu confronto, Cori (I. c., p. 102) separa com Hatschek os dois grupos. Reconhece sómente como ponto de concordancia a occorrencia de uma Trochophora. Rejeita a gemmiparidade como insignificante para o problema do parentesco, por ser frequentemente correlata com a sessilidade. Resumindo diz que os pontos discordantes perfazem typos de feição completamente differente e representam dois degráos estructuraes de idade diversa dentro do ambito dos animaes bilateraes. Aqui o plano de estructura dos Scolecida, alli o dos Coelomata.

Considerando primeiramente esta ultima synthese de Cori, lembramos aqui que a gemmação em si mesma poderia ser eliminada das discussões systematicas, mas que o modo identico, como se processa em Entoprocta e Ectoprocta, é impressionante. (Harmer 1930, p. 110). A formulação do segundo ponto de Cori é insustentavel, porque o termo Coelomata é um synonymo do termos Bilateria ou Triploblastica que abrangem, entre outras unidades, tambem os Scolecida. A definição dos Scolecida: "Protostomia vermiformes, não segmentados, cujo celoma está restricto ás cavidades das gonadas e talvez aos emunctorios" (Marcus, 1938a, p. 79) mostra ser esse grupo uma unidade sómente theorica, caracterizada principalmente por elementos negativos. Cori deixa aberta a questão sobre em que phylo dos Scolecida os Entoprocta deveriam entrar, nos Platyhelminthes ou nos Aschelminthes.

E' sabido, que esse problema foi resolvido pela escola de Hatschek no sentido da incorporação dos Entoprocta nos Asche!minthes (Claus-Grobben Kühn 1932, p. 528). Sendo eliminados os Nemertini do phylo Aschelminthes, como é, ao meu vêr, indicadissimo para estes vermes parenchymaticos, e incorporados nos Platyhelminthes, os Aschelminthes tornam-se com o seu conteudo anteriormente delimitado por mim (Marcus 1938a, p. 78, 83), uma unidade taxonomica bastante homogenea. Tal homogeneidade, porém, seria diminuida pela incorporação dos Entoprocta que são Spiralia parenchymaticos. Por outro lado, a classificação dos Entoprocta nos Aschelminthes não destruiria directamente a unidade do phylo, visto que este não carece de allusões ao typo espiral de segmentação (Heider 1909, p. 268-269; tambem nos Acanthocephala) e de formas com parenchyma bastante desenvolvido (Nematomorpha e certos Nematodes). Em todo o caso, a incorporação dos Entoprocta com a sua larva trochophoroide nos Aschelminthes não se offerece immediatamente, porque nas outras classes do phylo faltam taes larvas. Seja mencionado que a Trochosphaera, este Rotifero espherico, hoje não se considera mais como élo especialmente trochophoroide entre Annelida e Rotatoria (Remane 1929, p. 82-88). Não. precisamos discutir, melhor fôra classificar os Entoprocta no outro phylo dos Scolecida, nos Platyhelminthes, porque se apresenta uma solução muito melhor, a saber, a união dos Entopro- 
cta com os Ectoprocta. Examinemos de perto o confronto acima traduzido, segundo Cori opposto á tal união.

ad 1). O desenvolvimento dos Entoprocta é determinado, embora não se distingam os planos da larva antes do fim da $5 .^{a}$ clivagem, onde se apresenta o futuro quadrante posterior caracterizado pelo macromero 3D, maior que os restantes. Nos ovos quasi ellipsoides de certos Ectoprocta /Cheilostomata ascophora) é igualmente possivel esboçar uma geographia geral do germe composto por 32 blastomeros, ainda destituido, certamente, de signaes distinctivos anterior ou posterior (Marcus 1938, p. 95-96). A segmentação dos Entoprocta pertence ao typo espiral, a dos Ectoprocta é irregular (Phylactolaemata, Stenostomata $=$ Cyclostomata) ou relativamente semelhante ao typo disymetrico nos Eurystomata (Gymnolaemata cheilostomata e ctenostomata). Lembra a configuração geral do embryão dos Cheilostomata ascophora nas phases de 48 blastomeros e mais (Marcus 1938, t. 24), onde se compõe de 4 quadrantes que perfazem verdadeira symetria tetra-radial, o aspecto do germe dos Entoprocta. Considerando o total da segmentação, esta não favoreceria a união de Entoprocta e Ectoprocta. A formação dos folhetos germinativos não offerece concordancia maior. A separação precoce dos entomeros em endomesoderma e enteroderma nos Entoprocta caracteristica do typo determinado do desenvolvimento, não encontraria parallelo nos Ectoprocta de desenvolvimento indeterminado. Certamente são incompletos os nossos conhecimentos actuaes quanto a tal separação nos Ectoprocta (Marcus 1938, p. 102-103). Seja lembrado que nos. Brachiopoda, outra classe do phylo Molluscoidea (Tentaculata), occorrem allusões á segmentação espiral (Conklin 1902, p. 45).

ad 2). As larvas dos Entoprocta e Ectoprocta são muito semelhantes, até homologas quanto á placa apical, ao prototrochio (corôa) e ao intestino tripartido, assim, sem duvida, dentro dos Ectoprocta sómente representado. pelo Cyphonautes. Os orgãos restantes nem todos permittem estabelecer homologias rigorosas, embora Seeliger (1906, p. 64 e seguintes) tenha diligenciado em homologar o orgão pre-oral dos Entoprocta e o orgão pyriforme da larva dos Ectoprocta. Ambos são orgãos sensoriaes que apalpam o substrato antes da fixação e assim são analogos. Mas o orgão pre-oral dos Entoprocta pertence á episphera da Trochophora, i.é., ao campo entre orgão apical e prototrochio $\theta$ o orgão pyriforme dos Ectoprocta á hyposphera, por ser situado atras da corôa ciliada. O orgão tactil post-oral dos Entoprocta, impropriamente chamado ganglio sub-esophageano por Czwiklitzer (1908, p. |71), não possúe formação homologa nos Ectoprocta; a sua situação, quanto ao prototrochio, corresponde, é verdade, á do orgão pyriforme, mas este tem posição pre-oral. Os orgãos advestibulares, nomeadamente o basal, podem sem difficuldade ser homologados com o sacco interno, de origem 
e posição identicas e de funç̧ão semelhante. O protonephridio da larva dos Entoprocta falta nos Ectoprocta. O blastocela das larvas dos Entoprocta e dos Ectoprocta (Cyphonautes de Flustrella Pace 1906, p. 467), contém endomesenchyma e, além d'isso, nos Ectoprocta pelo menos no cordão neuromuscular que liga os orgãos apical e pyriforme (Marcus 1938, p. 105), ectomesenchyma. Em summa, são as larvas dos dois grupos não simplesmente "Trochophoras modificadas" mas sim Trochophoras com hyposphera exigua e concordancia nos pontos mais essenciaes da sua organisação.

ad 3). Fundamentalmente o contraste é indubitavel. Quanto aos pormenores não devemos esquecer que o pedunculo dos Entoprocta adultos com os seus elementos internos inclusive um apparelho complicado na base do calice, e além d'isso o ganglio, os tentaculos e certos musculos do adulto são novas formações da phase sessil dos Entoprocta.

ad 4-6). O organismo adulto dos Entoprocta é em pontos essenciaes igual a uma larva fixada com o seu polo embryologicamente vegetativo, ou, em outras palavras, com o campo oral da larva. Do mesmo modo fixa-se a larva dos Ectoprocta Gymnolaemata. A chamada larva dos Ectoprocta Phylactolaemata, porém, fixa-se com o polo animal do embryão ou, se considerarmos o polo, onde o endoderma primario immigra, como homologo ao campo oral, com o campo aboral da phase livre. Em concordancia topographica com o brotamento do pedunculo dos Entoprocta formam-se estolões em certos Ectoprocta (Ctenostomata Stolonifera). O chamado plano de estructura mais alto" do individuo metamorphoseado dos Ectoprocta consiste unicamente no facto de se appôr o mesenchyma dos Ectoprocta ao ectoderma do adulto. Digo de proposito ao ectoderma, porque nos Gymnolaemata adultos ou nas "larvas" dos Phylactolaemata não ha intestino medio endodermico, brotando o intestino totalmente do ectoderma. Fala-se sempre em celoma nos Ectoprocta, revestido por somatopleura e esplanchnopleura e, é verdade, a cavidade do corpo parece um celoma. Mas, se pesquizarmos a origem d'esses folhetos parietal e visceral, chegamos ao resultado de que não é mesoderma typico. No maximo é reconduzivel ao endoderma primario, faltando até a prova da continuidade entre este endoderma primario e o revestimento do chamado celoma (Marcus 1938, p. 108-109). E' prematuro designar a cavidade do corpo dos Ectoprocta cavidade secundaria do corpo ou celoma verdadeiro. E' subjectivismo, verosimilmente erroneo, considerar a presença de um celoma nos Triploblastica como prova de estructura mais alta, mais tarde apparecida na phylogenia. Em geral tal graduação é sempre precaria por causa da mistura de caracteres "adiantados" e "atrazados" em quasi todos os phylos. Se, porém, admittirmos excepcionalmente os termos "primario" e "secundario" o exemplo dos Arthropoda e Mollusca, ambos providos de endomesenchyma, não de 
endomesothelio celomatico, presente nos Chaetopoda, faria vêr que ausencia de celoma pode apresentar-se como phenomeno secundario. Seja mesmo a cavidade do corpo dos Ectoprocta um celoma verdadeiro, a segregação da cellula matriz do endomesenchyma nos Entoprocta entende-se sómente como especialisação.

ad 7). Os emunctorios dos Ectoprocta são póros da cavidade do corpo, ás vezes ciliados, os dos Entoprocta são protonephridios e os dos Molluscoidea restantes (Phoronidea, Brachiopoda) metanephridios. Os nephridios da Actinotrocha são providos de solenocytos typicos (Goodrich, 1904, p. 114). Desde que foram descobertos protonephridios nos Annelida, o contraste entre protonephridios e metanephridios perdeu o seu valor para o systema. A differença entre nephridios e póros da cavidade do corpo é innegavel, embora não seja um argumento novo em favor da separação dos Entoprocta e Ectoprocta. Encontram-se póros da cavidade do corpo sómente em animaes de ampla cavidade do corpo, protonephridios geralmente em animaes mesenchymaticos. Como excepção d'esta regra menciono a combinação da espaçosa cavidade do corpo e protonephridios nos Rotatoria. O protonephridio dos Entoprocta é um caracter typicamente larval.

ad 8). Essa differença refere-se tambem á estructura acelomatica e pur assim dizer celomatica, possuindo os Chaetopoda celomaticos gonadas planiformes, os Hirudinea, Scolecida, Mollusca e Arthropoda de celoma reduzido ou transitorio respectivamente gonadas sacculiformes.

ad 9). Nada tenho a oppôr contra isso, além da qualidade extra-ordinaria do "mesothelio" dos Ectoprocta que está longe de um mesoderma typico, e muitas vezes (Stenostomata p. e.) quasi não apresenta caracter epithelial.

ad (0). Em uma das super-ordens dos Ectoprocta a face do animal adulto, a qual Cori chama a activa, deve necessariamente coincidir com a face activa dos Entoprocta. Não póde deixar de ser assim, porque os respectivos lados são diametralmente oppostos em Phylactolaemata e Gymnolaemata. Nos Phylactolaemata realiza-se por immigração polar a gastrulação. Embora não haja blastóporo verdadeiro em uma gastrula formada d'este modo, o pólo, onde os entomeros immigram, deve ser considerado como pólo vegetativo. O lugar do pólo vegetativo caracteriza o lado oral ou ventral. Brotando os tentaculos, o intestino e o ganglio, brevemente o polypidio, no mesmo lado em que houve immigração do endoderma, a face activa dos Phylactolaemata adultos encontra-se indubitavelmente no lado ventral. A phase livre fixa-se com o pólo opposto ao vegetativo, portanto com o pólo animal que caracteriza o lado dorsal. Desde que Braem (1897 p. 83) discutiu essa topographia, não foi mais, pelo que sei, posta em duvida. 
Nos Gymnolaemata e Entoprocta a phase livre é uma larva trochophoroide, cuja configuração externa se transforma consideravelmente durante a metamorphose, tornando assim difficil a homologação dos lados dorsal e ventral entre larvas e adultos.

Nos Gymnolaemata encontram-se o blastóporo, a bocca e o anus da larva no mesmo lado, portanto no pólo vegetativo e lado ventral respectivamente. A larva fixa-se com este lado, brotando o polypidio do adulto no lado opposto. E' este lado na larva caracterizado pela placa apical e devemos assim designar a posição da face activa do Gymnolaemato adulto como antero-dorsal ou simplesmente dorsal. Como ás vezes (Kupelwieser 1905, p. 39) a placa apical contribue para a formação do polypidio adulto e assim implicitamente para o ganglio, podemos theoricamente chamar o ganglio dos Gymnolaemata adultos ganglio supra-esophageano. Em outros casos a placa apical succumbe a uma histolyse completa (Zschiesche 1909, p. 26), mostrando-se assim theorica a interpretação do ganglio dos Ectoprocta Gymnolaemata como supra-esophageano ou dorsal. Realmente não é dorsal, mas. anterior a posição da placa apical, tanto na Trochophora (Fig. 90, 9), quanto na larva dos Gymnolaemata. Sómente porque esta placa dá origem ao ganglio supra-esophageano nos Annelida, Mollusca e outros Spiralia, chegamos á conclusão theorica de que se acha situado o ganglio dos Gymnolaemata adultos dorsalmente á bocca. Parece admissivel continuar na nossa interpretação, dizendo que $\circ$ anus dos Gymnolaemata adultos tem posição dorsal em relação á bocca. $\bigcirc$ unico criterio existente para justificar tal opinião, acha-se dado pela posição do ganglio, já por si mesmo não observado, mas sómente interpretado como sendo situado dorsalmente á bocca. Além da topographia do anus não se póde determinar nenhuma região do corpo do individuo adulto dos Gymnolaemata. Durante o brotamento do polypidio não é possivel estabelecer relação topographica com as faces da larva além da mencionada origem apical do polypidio. $O$ corpo (cystidio) da larva acha-se sujeito a taes transformações do seu aspecto externo e é tão plastico que resultaria em méra especulação a designação das paredes. do corpo do animal metamorphoseado (ancestrula). Por isso não póde haver continuidade entre a terminologia applicada ás faces da larva e ás paredes dos individuos adultos (zoécios). Tomando isso em conta usamos ra morphologia dos Gymnolaemata denominação differente, fallando em paredes basal e frontal, paredes lateraes e terminaes (proximal e distal, segundo a direcção do crescimento colonial). Convem accrescentar que a formação do polypidio do $1.0^{\circ}$ individuo colonial, da ancestrula, se mostra como sendo regeneração e não gemmação (litteratura veja Marcus 1938, p. 66), tambem pelo facto da incorporação do "corpo bruno" do polypidio larval no intestino do botão regenerador (Repiachoff |876, p. 148-149). 
Nos Entoprocta as relações entre blastóporo, bocca e anus são das mais nitidas, porque se forma a gastrula por invaginação e assim apparece blastóporo verdadeiro. Fechando-se o blastóporo e invaginando-se o estomodeo que leva o blastóporo para dentro, onde se torna porta pharyngeana no limite entre o estomodeo e o mesodeo (mesenteron), ao passo que o anus se origina como orificio externo do proctodeo formado secundariamente, a larva dos Entoprocta é uma Trochophora quasi typica. Falta-lhe, é verdade nitida região posterior, mas é possivel sem eschematisação exagerada indicar todas as regiões da Trochophora no sentido da Fig. 90, 4 e 7 . A hyposphera seria na larva dos Entoprocta representada pelo atrio de contorno externo concavo em opposição á hyposphera convexa da Trochophora.

Fixando-se a larva dos Entoprocta por meio da hyposphera, que é o lado ventral e apparecendo a face activa do adulto no lado opposto, seria de crer que os zoologos considerassem tudo isso identico e homologo em Ectoprocta e Entoprocta. Tal, porém, em geral, não se dá. Emquanto os primeiros autores (p. e. Barrois 1877, p. 22 t. I 2; Hatschek 1877 etc.) acreditavam que a larva se fixasse com a placa apical, deram a este orgão denominações como glandula pedal, ventosa, glandula argamassadora e semeIhantes. Harmer (1887) descobriu a fixação da larva com a face ventral. Não obstante, considerou a face activa do adulto, opposta á face da fixação, como sendo ventral. Na argumentação de Harmer (1887. p. 25। etc.) desempenha o orgão pré-oral papel dominante. Sem ignorar que este orgão é um orgão larval, que não entra na formação do ganglio adulto, homologa-o com o ganglio cerebral ou supra-pharyngeano e considera como dorsal o. lado em que se acha situado. Chega assim á determinação seguinte dos lados do animal adulto: o lado dorsal estende-se do ponto mais anal do calice até o ponto correspondente do pedunculo, ao passo que perfariam o. lado ventral as regiões séguintes: a base do pedunculo, fixa ao substrato, o. lado oral do peduncúlo e do calice e a face activa, atrial ou tentacular. Acha-se mantida com isso a continuidade da denominação do lado com que a larva se fixa e a base do pedunculo, fixadora do estado adulto. Seriam além disso o ganglio do adulto e o anus situados dorsalmente á bocca, de modo que se poderia fallar em ganglio supra-pharyngeano no Entoprocto adulto, embora não seja oriundo da placa apical histolysada durante a metamorphose.

A homologação do orgão pré-oral com o ganglio cerebral é mantida por MacBride (19/4, p. 405) e, se bem que indistinctamente, por Cori (1936, p. 33). Tanto em Loxosoma (Harmer 1885, p. 291 t. 31 f. 37) como em Pedicellina (veja Fig. 81) os primordios da placa apical (a) e do orgão pré-oral (o) apparecem independentemente, formando-se sómente mais. tarde o cordão neuro-muscular que liga os dois orgãos. Em Annelida e 
Mollusca a placa apical dá origem ao ganglio cerebral que sómente mais tarde se afasta della, nomeadamente nos Mollusca (veja p.e. MacBride 1914, f. 239, 281, phases iniciaes; Meisenheimer 1901, p. 80 e seg., t. 8-9, desenvolvimento ulterior). Estes pormenores, sem duvida, são de importancia sómente secundaria, para distinguir entre o ganglio cerebral dos Mollusca e - orgão pré-oral da larva dos Entoprocta. Para entendermos a bipartição dos orgãos dos sentidos ou nervosos na episphera da larva dos Entoprocta vale até bem o exemplo dos Mollusca, indicado por Harmer, e mais ainda, porque o orgão pré-oral da larva de Loxosoma é vestigialmente bilobado (Harmer 1885, p. 294, 297). De nenhum modo, porém, este orgão merece a denominação de "orgão dorsal" (Harmer, MacBride), seja qual fôr a sua significação prospectiva. No Veliger, na Trochophora e na larva dos Entoprocta a placa apical é situada anterior e não dorsalmente. O orgão pré-oral deveria antes que dorsalmente ser considerado como situado ventralmente, a menos que se perca a homologia com a Trochophora. A posição do ganglio supra-pharyngeano no Veliger que entra em metamorphose e no Mollusco adulto não poderia, ao meu vêr, definir o lado do orgão préoral na larva dos Entoprocta como sendo dorsal, porque esta larva deve ser orientada pelo Veliger jovem ou pela Trochophora antes da formação do verme.

Ao lado da orientação simples da parede do corpo dos Entoprocta (Fig. 90, 5, 6) que concordaria com a dos Ectoprocta Gymnolaemata ha outra estabelecida por Hatschek e reivindicada por Cori. Em virtude de passarem a bocca, o tracto intestinal (em parte), o anus, o atrio (em parte) e provavelmente o emunctorio á phase adulta por uma rotação de $180^{\circ}$, effectuada pelo crescimento desigual da parede do corpo e do mesenchyma (Cori 1936, p. 36), considera-se a phase adulta como permanecida em estado larval. Seria então o trecho curto entre bocca e anus o lado ventral do animal, e - ganglio, que se forma depois da metamorphose, seria um ganglio sub-esophageano. A argumentação é logica e inexpugnavel, quanto aos orgãos alludidos. Ao se considerar o animal inteiro com o seu calice e pedunculo, cujos lados oral e anal então deveriam ser considerados como perfazendo o dorso, revela-se a artificialidade da opinião de Hatschek. Justamente o pedunculo, em que entra a divisão ventral do atrio (Harmer 1887. p. 245) e que se encontra indubitavelmente no centro do lado ventral da larva (veja Cori 1936, f. 9-10 e a nossa Fig. 90, 5-6) tornar-se-ia na interpretação de Hatschek o centro do dorso.

$\mathrm{Na}$ A ntedon a larva fixa-se com a região pre-oral e o intestjno faz uma rotação de $90^{\circ}$ do lado ventral para o lado posterior. Mas com excepção talvez de certas denominações de placas do esqueleto (p.e. placa centrodorsal) não apparecem na terminologia dos Crinoidea os termos "dorsal" e 
"ventral" mas sómente actinal (oral) e abactinal (apical, aboral). De certo interesse theorico é a hypothese de MacBride (1914, p. 405) e outros (Balfour, veja Ehlers 1890, p. I6I) que admittem a ascendencia dos Entoprocta de animaes que se fixaram com a região pre-oral. Onde tal se dá /Cirripedia, Crinoidea), nota-se crescimento especial da região pre-oral. Nos Entoprocła, porém, é mais intenso, depois da fixação, o crescimento da região postoral, exactamente do lado larvalmente dorsal (Fig. 90, 4-6). Seja notado que occorre fixação post-oral em Brachiopoda e Phoronidea.

Em resumo podemos dizer que os Entoprocta dirigem a face dorsal como face activa para a agua, se considerarmos a topographia do corpo larval de primeira importancia. Concordariam então com os Ectoprocta Gymnolaemata. Se adoptarmos a theoria de Hatschek, diriamos que os Entoprocta se dirigem com a face ventral para a agua. N'este caso parecer-se-iam com os Ectoprocta Phylactolaemata.

Pelos methodos da anatomia comparativa foi estabelecida uma relação entre os Phoronidea e os Bryozoa, não excluindo, mas sim pondo em evidencia os Entoprocta (Caldwell 1883; Lankester 1885). Esta relação foi posta em duvida por autores muito competentes (Harmer 1885, p. 306 e seguintes; 1901, p. 512; 1930, p. 110; v. Buddenbrock 1932, p. 274) em virtude da differença profunda entre o desenvolvimento dos Bryozoa e dos Phoronidea. Como já disse (Marcus 1934, p. 590), não posso decidir-me a considerar as semelhanças anatomicas entre a Phoronis adulta, p. e. Phoronis ova lis (Harmer 1917, t. 9 f. 4I), e os Bryozoa, nomeadamente os Phylactolaemata, como coincidencias provindas de uma ascendencia originalmente differente, mas successivamente convergente e me sinto apoiado não sómente por embryologos afamados (Heider 1928, p. 290; MacBride 1914, p. 385), mas tambem por um especialista moderno dos Bryozoa, Borg (1926, p. 490), que tem estudado a fundo as relações dos Bryozoa com outros grupos. Em todo o caso, porém, o parentesco entre Phoronidea e Bryozoa permanece sempre uma hypothese que nunca deveria intervir em discussões sobre a topographia dos orgãos dos Bryozoa, como ainda hoje acontece.

Na Actinotrocha, i.é, a larva dos Phoronidea, encontramos um lobo preoral (episphera) com a placa apical, uma bocca ventral e um anus terminal, um prototrochio, tentaculos post-oraes que poderiam corresponder ao metatrochio e um paratrochio (telotrochio) pre-anal (Fig. 90, 1). Mostra-se assim a Actinotrocha como larva trochophoroide, pela hyposphera estirada habitualmente bem differente das larvas dos Bryozoa. A Actinotrocha fixa-se, como a larva dos Bryozoa Ectoprocta Gymnolaemata e dos Entoprocta, por meio da sua face ventral. Ahi evagina-se tubiformemente o primordio do tronco do animal adulto. $O$ intestino da Actinotrocha entra na Phoronis adulta como o da larva de Pedicellina no $1 .^{\circ}$ individuo da colonia. 
Fixado pelos mesenterios á ponta interna do tubo evaginado, o intestino tem de acompanhar o movimento do tubo em cujo lumen entra. Diminuindo a turgescencia das partes restantes da larva, a bocca e o anus approximam-se um ao outro. O lobo pre-oral inclusive a placa apical, os tentaculos larvaes e o prototrochio perdem o seu nexo com o corpo; são engulidos e digeridos. A perda da placa apical, que é o centro nervoso da Actinotrocha, lembra a degeneração do mesmo orgão na larva dos Entoprocta e de certos Gymnolaemata. A corôa tentacular da $\mathrm{Ph}$ or on is metamorphoseada, homologa á larval (veja mais adiante, ad II), designa assim a extremidade anterior do corpo, o anus a ponta posterior, de modo que o trecho curto entre bocca e anus é o dorso. O ganglio situado entre bocca e anus é nitidamente supraesophageano. Os dois lados do tubo evaginado, inclusive a base do animal, perfazem a sua face ventral. Dirige-se portanto nos Phoronidea a face dorsal como face activa para a agua, o que concorda com os Ectoprocta Gymnolaemata e contrasta com os Phylactolaemata. A topographia embryologicamente univoca dos Phoronidea e a semelhança anatomica incontestavel entre Phoronis e um individuo adulto dos Phylactolaemata induziu Hatschek e sua escola a negligenciar a topographia embryologica dos Phylactolaemata. Dizem que em Phoronidea e Ectoprocta é o lado dorsal a face activa dirigida para a agua, em opposição aos Entoprocta, onde é o ventral. Vimos agora que a posição respectiva nos Entoprocta é interpretavel de dois modos contradictorios, mas que os Phylactolaemata dirigem o campo prostomial na linguagem embryologica, o lado ventral na linguagem anatomica, como lado activo para a agua.

ad 11). Em todos os Bryozoa os tentaculos são pre-oraes. Assim acho seria descripto do modo mais simples e univoco a topographia dos tentaculos que se formam em todos os Bryozoa da mesma maneira. Na parede do corpo origina-se um sacculo ectodermico revestido por uma camada epithelial do chamado mesoderma parietal (somatopleura, Ectoprocta) ou circumdado por cellulas mesenchymaticas diffusas (Entoprocta). Por uma dobra da parede do sacculo separa-se um compartimento anterior, o atrio presumptivo, de um posterior, o futuro intestino. Na parede do atrio brotam os tentaculos no inicio bilateralmente dispostos. O primordio sacculiforme do intestino torna-se tubuliforme crescendo em forma de $U$ até novamente attingir o atrio (Fig. 90, II) Dá-se assim uma phase em todos os Bryozoa que corresponde ao estado adulto dos Entoprocta (Nitsche 187I. p. 44 t. 3 f. 26 ; Seeliger 1890 , p. 586 +. 26 f. 3), sendo a bocca e o anus em communicação com um atrio, em cuja parede longitudinal crescem os tentaculos. Tambem Davenport pôz em relevo que os botões dos Ectoprocta fassam por uma phase entoproctoide, ou como seria talvez melhor dizer, por uma tase ainda não nitidamente ectoproctoide $(1890$, p. 127.132 t. 3 f. 18; 189| p. 
102-103 t. 3 f. 25 t. 9 f. 77). As figuras de Davenport sem duvida são instructivas, mas o facto alludido se reduz, ao meu ver, parcialmente ao phenomeno commum da simplicidade das phases evolutivas anteriores em comparação com os estados adiantados. Taes primordios incomplexos de orgãos futuramente complicados lembram os esboços de desenhos que carecendo dos pormenores permittem ao observador interpretação de certa largueza. De modo nenhum posso acompanhar Davenport em considerar a semelhança alludida, como prova da posição ancestral dos Entoprocta, no sentido da recapitulação ontogenetica da phylogenia. Ha differenças de segunda importancia quanto á precedencia da formação dos orificios do intestino. Nos Entoprocta o primeiro diverticulo do sacculo inferior do botão representa a bocca e o intestino anterior (Seeliger 1889, p. 183, 184 t. 9 f. 8), sendo nos Ectoprocta a primeira communicação entre os compartimentos superior latrio presumptivo) e inferior (intestino presumptivo) ora o futuro anus (Stenostomata, Borg 1926, p. 330; Phylactolaemata em geral, Braem 1890, p. 46 t. 9 etc.; Eurystomata, em parte, Agatz 1912, p. 14), ora a futura bocca (Phylactolaemata: Pectinatella Oka 1890, p. 134, 14l t. 20 f. 49-52Bi Braem 1912, p. 20). Aliás não parece completamente esclarecida a antecedencia da formação do intestino anterior no botão de Pectina.tella (Davenport 1891, p. 104). Em varios Eurystomata (Agatz, 1. c.) originam-se os primordios de bocca e anus ao mesmo tempo, apparecendo dois diverticulos na base do sacculo atrial. Esses factos foram referidos, de certo modo pormenorizadamente, para eliminar da discussão sobre a posição dos tentaculos qualquer tentativa subtilizada, de relacionar o apparecimento dos primordios tentaculares com particularidades da formação de bocca e anus.

Do mesmo modo não seria possivel a argumentação seguinte: nos Phylactolaemata os tentaculos originam-se com relação ao eixo principal da gastrula em situação mais vegetativa que a bocca, por isso seriam post-oraes. Nos Gymnolaemata originam-se, por assim dizer dorsalmente á bocca, em situação mais animal que a bocca, portanto pre-oralmente. Nos Entoprocta - juizo sobre a posição dos tentaculos dependeria do nosso conceito sobre - lado para que os adultos voltam a sua face activa. Nos Phylactolaemata talvez seja possivel definir como post-oraes os tentaculos, mas tal dito não tem sentido algum. Quando os botões dos polypidios se formam no lado ventral da larva os tentaculos situados antes da bocca neccessariamente teem de se originar mais ventralmente ainda (Fig. 90, 8). A metamorphose dos Gymnolaemata combina-se com destruição tão profunda que não é possivel comparar directamente as relações topographicas da larva e do animal adulto (Heider 1893, p. 1229). Cori quer evidentemente preencher essa lacuna pela consideração da metamorphose da Actinotrocha. Nos Phoronidea são os tentaculos incontestavelmente post-oraes, porque já apparecem 
na larva na base dos transitorios tentaculos larvaes post-oralmente situados. As nossas figuras simplificadas (Fig. 90, 1-3) conteem por isso sómente uma serie de tentaculos. Na larva dos Ectoprocta faltam, porém, taes tentaculos larvaes; a corôa ciliada predominante tem posição pre-oral. Para não sermos levados a um circulo vicioso, devemos abster-nos de interpretar a posição dos tentaculos dos Gymnolaemata por meio da comparação com os da Phoronis.

O melhor methodo seria, ao meu vêr, tomar como unico criterio para definir a situação dos tentaculos dos Bryozoa, que sómente occorrem na phase adulta, a relação ontogenetica d'elles com a bocca definitiva, supprimindo quaesquer interpretações que se referem ás phases larvaes. Considerando assim de modo immediato e primitivo os tentaculos de todos os Bryozoa como pre-oraes, não pretendo ter descoberto uma nova homologia entre Entoprocta e Ectoprocta. Penso sómente que a posição dos tentaculos nos dois grupos não envolve uma opposição.

ad 121. O problema do ganglio acha-se intimamente ligado á inter. pretação ou verificação da posição da face activa. Assim não é possivel definir univocamente a situação do ganglio dos Entoprocta. Certamente não participa a placa apical na sua formação, de modo que uma definição ontogeneticamente exacta é completamente impossivel. Na interpretação de Fatschek seria o ganglio sub-pharyngeano, mas n'este caso chegariamos a denominar o centro do pedunculo como meio do dorso. Ao meu ver, seria esta consequencia tão contraria aos proprios acontecimentos evolutivos que prefiro abandonar a hypothese de Hatschek. Por outro lado, não posso fugir á necessidade de definir as regiões anterior e posterior, quando se trata de interpretar a posição do ganglio. Vê-se então que a conservação da topographia larval levaria ao resultado singular, embora realizado em certas Appendiculariae (Lohmann 1933, p. 98 f. 77) e Crinoidea fosseis (Bather 1900, p. 136) de ser o anus disposto mais para diante e a bocca mais para traz. $O$ ganglio seria por conseguinte pre-oral e se continuarmos n'essas deducções abstractas, seria um ganglio cerebral ou super-pharyngeano. O resumo concreto, porém, das nossas deliberações é claramente negativo: quem não mais adoptar a theoria de Hatschek, porque dá ao pedunculo uma denominação topographica contrastante com os factos, tem de renunciar aos termos "ganglion pharyngeum superius" e "inferius" nos Entoprocta adultos. Adoptando uma terminologia descriptiva, que não admitte exploração phylogenetica, poderiamos chamar o ganglio "post-oral" por ser situado atraz da bocca em relação á ponta physiologicamente posterior, i.é, o anus. Quem adherir á opinião de Hatschek falaria em ganglio sub-pharyngeano e ganglio post-oral, attribuindo a ambas estas denominações o sentido embryologico de uma homologia entre o ganglio do animal adulto e o orgão sen- 
sorio, verosimilmente tactil, situado no labio inferior alongado (epistomal da larva, atraz da bocca.

O ganglio dos Phylactolaemata é univocamente post-oral e sub-pharyngeano. Para verificar isto, basta lembrar que a bocca e o anus definitivos se originam sobre o campo prostomial e o ganglio entre elles, adjacente á pharynge (Fig. 90, 8). Não se comprehende, como foi possivel ter Cori abstrahido da ontogenese muito clara dos Phylactolaemata, declarando simplesmente ser ganglio supra-pharyngeano o ganglio dos Ectoprocta. Talvez Cori tenha sido influenciado pela comparação anatomica entre $\mathrm{P}$ ho ro n is e um individuo dos Phylactolaemata que resulta em semelhanças sem duvida demonstrativas.

Nos Phoronidea, porém, era sómente a embryọlogia que fazia reconhecer o trecho entre a bocca e anus como sendo dorsal. Não seria logico aproveitarmo-nos dos conhecimentos ganhos pelo estudo do desenvolvimento em um certo grupo para interpretar arbitrariamente um orgão de outros animaes, embora este se origine differentemente. Os Phoronidea, como já foi dito, perdem durante a sua metamorphose com o lobo pre-oral a sua placa apical, de modo que carecem de uma continuidade entre a placa apical e o ganglio definitivo. A este respeito os Phoronidea lembram os Entoprocta e certos Gymnolaemata (veja mais adiante). A alludida descontinuação evolutiva, porém, não altera o caracter post-oral e supra-esopha-: geano do ganglio da $\mathrm{Ph}$ or on is situado no lado dorsal e atraz da bocca. Seja como fôr a nosssa opinião acerca do ganglio dos Entoprocta, este tem de concordar topographicamente ou com o ganglio dos Phylactolaemata ou com o ganglio dos Phoronidea e assim com o ganglio dos Gymnolaemata.

Realmente a homologia entre o ganglio dos Phoronidea e Gymnolaemata não se revela pela observação do desenvolvimento. Nos Phoronidea a extremidade posterior da larva permanece marcada durante a metamorphose, pelo anus (Fig. 90, I-3, p), ao passo que nos Gymnolaemata adultos as pontas anterior e posterior precisam, depois da metamorphose, de novas definições (Fig. 90, 10-11). A transformação da larva torna impossivel qualquer homologação entre os lados anterior e posterior larvaes e adultos. Por isso é mistér adoptarmos criterios topographicos do botão polypidial considerando a bocca e o anus como situados anterior e posteriormente. Seria então o ganglio dos Gymnolaemata um ganglio post-oral e supra-pharyngeano, homologo ao ganglio dos Phoronidea. Nos casos em que a placa apical da larva fornece o material para o primeiro botão e o seu ganglio, a nossa definição estaria em accordo com a ontogenese, e nas larvas cuja placa apical degenera, sentimo-nos autorizados a suppôr identica relação topographica do ganglio. 
ad 13). A opposição pretendida coincide com o ponto 10 e por isso prescinde de uma discussão especial. Nos Entoprocta o lado actinal, para - qual a concavidade do intestino adulto se acha voltada, é o lado dorsal, se conservarmos a topographia do corpo larval, e é o lado ventral se adoptarmos a hypothese de Hatschek. Nos Phylactolaemata a concavidade dirigese para o lado ventral e nos Gymnolaemata e Phoronidae para o lado dorsal.

ad 14). A differença descripta existe de facto e foi correlata por Harmer (1901, p. 488) com a existencia e ausencia de uma espaçosa cavidade do corpo em Ectoprocta e Entoprocta respectivamente. Permitte esta aos primeiros retracção dos tentaculos, ao passo que os Entoprocta sómente os encurvam. Em todo o caso acham-se tambem nos Entoprocta os tentaculos, quando em posição de protecção, dentro das paredes do corpo, cuja continuação actinal, a saber a membrana do calice provida de fibras musculares circulares, cobre os tentaculos encurvados.

ad 15). A gemmação realiza-se nos dois grupos de um modo muito semelhante, como foi descripto anteriormente (veja p. 262). Os individuos novos brotam nos Entoprocta e nos Ectoprocta Phylactolaemata no lado oral do individuo precedente (Fig. 90, 6, 9, b), nos Ectoprocta Gymnolaemata geralmente no lado anal (Fig. 90, 11, b), excepcionalmente no lado oral (Zschiesche 1909, p. 64). Os processos de degeneração e regeneração revelam igualmente uma semelhança consideravel (Heider 1909, p. 686), embora os pormenores mostrem comprehensivelmente algumas differenças.

O resultado final da nossa discussão sobre as relações entre Entoprocia e Ectoprocta seria a conservação da unidade da classe Bryozoa. As distincções principaes são: os typos de segmentação differentes, a permanencia do estado larval, mesenchymatico nos. Entoprocta adultos, a situação do anus dos Entoprocta dentro da corôa dos tentaculos, assim disposto sómente nos botões dos Ectoprocta e os emunctorios differentes. Convem lembrar que a differença da cavidade do corpo é, como foi dito por Davenport 11893, p. 31), antes gradual que fundamental. Nomeadamente nos Gymnolaemata os chamados cordões funiculares pódem preencher uma parte consideravel da cavidade do corpo. Evidencia-se o entrelaçamento dos caracteres morphologicos dos Entoprocta e Ectoprocta pelo facto de representarem justamente os Phylactolaemata o extremo de cavidade do corpo vazia, p.e. Lophopus (Marcus 1934, f. 4 I p. 57l). Por outro lado correspondem em esta super-ordem dos Ectoprocta a topographia da face activa e do ganglio completamente aos Entoprocta na interpretação de Hatschek. Tão pouco cọmo as differenças da cavidade do corpo separam fundamentalmente Oligochaeta e Hirudinea (Ehlers 1890, p. 154), hoje considerados como ordens de uma classe (Clitellata), justificariam separa şão profunda de Ectoprocta e Ento- 
procta. Os Tunicata parenchymaticos e os Acrania excessivamente celo. naticos são ćsis phylos, cujo parentesco ninguem contesta.

Contraste ulterior entre Entoprocta e Ectoprocta dá-se pelo facto da ausencia de chitina no sentido chimico da palavra nos Entoprocta, ao passo que os Ectoprocta possúem chitina (Schulze 1924, p. 653 654). A importancia d'esta differença, porém, não é de pr meira ordem, visto que é chitinica a casca do ovo nas Ascaridae e os espiculos do macho não o são (ibid., p. 653). Os Onychophora molles teem cuticula chitinica (ibid., p. 654) e os Tardigrada, em parte cobertos por cuticula muito forte (Scutechiniscidae), são desprovidos de chitina (Marcus 1927, p. 353-355). No trabalho de Becker (1937) que demonstra distincções h.stologicas no intestino dos dois grupos, encontra-se a phrase (p. 122): o recto forma-se nos Kamptozoa, i.é, Entoprocta, ectodermicamente, nos Bryozoa (quer dizer Ectoprocta) origina-se do mesmo folheto como o intestino medio (do endomesoderma)" Como o autor escreve esta phrase accessoriamente em um trabalho não embryologico, só póde ser attribuida a um erro na comprehensão de uma passagem da litteratura. De facto derivam nas larvas dos Entoprocta e Ectoprocta Gymnolaemata o estomodeo e proctodeo do ectoderma, sendo aliás escassas as observações relativas aos Ectoprocta (Prouho 1892, p. 611-615; Pace 1906, p. 462 sómente estomodeo; Marcus 1926a, p. 34 estomodeo e primordios do proctodeo). O mesodeo das larvas dos Enioprocta e Ectoprocta Gymnolaemata é formado pelo folheto interno que nos Entoprocta é um enteroderma, nos Gymnolaemata um endoderma primario, talvez em certos casos (Prouho 1892, p. 611, t. 28 f. 62, 63) um enteroderma. $\mathrm{Na}$ phase sessil dos Entoprocta o intenstino é identico com o larval, ao passo que o tubo digestivo inteiro da phase larval dos Phylactolaemata e da phase fixa d'elles e dos Gymnolaemata é ectodermico. Rigorosamente homologos em Ectoprocta e Entoprocta seriam portanto sómente o intestino anterior e posterior, mas a doutrina dos folhetos germinativos não abrange os processos gemmiparos e regenerativos (Heider 1897. p. 733 e seg.).

Reassumindo o problema da união ou separação dos Entoprocta e Ectoprocta e considerando ao lado das differenças acima enumeradas tambem a diversidade manifestada pela organogenese do intestino achamo-nos impossibilitados de adoptar a opinião de Goette (1921, p. 280-28I): "a organisação dos Ectoprocta e Entoprocta constrõe-se de maneira completamente homologa sobre um campo prostomial; os dois grupos andam intimamente juntos. Emquanto se ignorava a segmentação dos Entoprocta, a opinião de Goette talvez tivesse sido correcta. No estado actual dos nossos conhecimentos, porém, não é mais possivel dizer que os dois grupos se acham intimamente unidos. Não deveriam ser collocados em phylos differentes como Hatschek e sua escola viennense suppuzeram. Concordo assim 
com a opinião de Lameere (1931, p. 319) e v. Buddenbrock (1932, p. 274), pensando até que as relações entre Dipnoi e Amphibia citadas pelo ultimo como exemplo para o modo, como se deva imaginar o parentesco entre Entoprocta e Ectoprocta, são mais distantes que as dos dois grupos dos Bryozoa. A categoria systematica é naturalmente subjectiva e o taxonomista mais cuidadoso preferiria talvez coordenar varios phylos pequenos (Borradaile-Potts 1932, p. 530 e seg.). Facilita, porém, uma certa subordinação das unidades taxonomicas a tarefa da systematisação, e asssim o systema dos Bryozoa alcança o seu fim, quando considera Entoprocta e Ectobrocta duas sub-classes da classe Bryozoa ou Polyzoa. Na diagnose da classe seria mistér alludir na organisação da larva dos Ectoprocta oviparos, i. é, do Cyphonautes, e notar que os Entoprocta adultos conservam traços essenciaes de taes larvas. Sómente como retrospecto litterario, não como argumento, seja frișado que desde Nitsche todos os autores, cujas publicações contribuiram para o progresso dos nossos conhecimentos sobre anatomia e embryologia dos dois grupos, quer dizer, que publicaram sobre os Entoprocta e sobre os Ectoprocta, a saber, Harmer, Ehlers, Davenport e Seeliger teem conservado os dois grupos na mesma unidade systematica. 


\section{IX.}

\section{Larvas viventes de Ectoprocta marinhos.}

Em janeiro de 1939, pudemos observar na ilha das Palmas (entrada da bahia de Santos) as larvas ainda não descriptas dé sete especies, dos Cheilostomata anasca, ascophora e Ctenostomata (est. XXXI). Apezar de se iratar em todas as especies examinadas daquelle typo, cujos embryões não crescem durante a sua estancia na colonia materna, é possivel reconhecer as larvas maduras. Taes larvas promptas para a eclosão e não alimentadas no oécio ou no corpo do individuo-mãe ( $\mathrm{N} \circ$ lella) tornam-se pelo consumo do vitello mais claras que as phases antecedentes (Marcus 1938, p. 109). Abrindo-se os oécios respectivos ou a parede do corpo do individuo que contem embryões adultos ( $\mathrm{Nolella}$ ) por meio de uma fina agulha, conseguem-se larvas que nadam livremente.

A larva de Crassimarginatella leucocypha (ca. de $100 \times(20 \mu)$ é, depois da larva de Tendra zostericola (Repiachoff 1875, p. |33-|35|, a primeira estudada da familia Membraniporidae que se desenvolve dentro da colonia. O ovo de Tendra zostericola é transportado pelo orgão intertentacular no gonozoécio sobreposto ao individuo fertil (Paltschikowa-Ostroumowa 1925, p. 100) e desenvolve-se na Crassimarginatella no endo-oécio formado pelo proprio individuomãe. A larva de Tendra zostericola seria especialmente interessante, porque se conhece outra especie do genero, a saber, Tendra repiachowi, que é ovipara e cuja larva é um Cyphonautes (Ostroumoff 1885, p. 219). Infelizmente a descripção e ainda mais as figuras da larva de Tendra zostericola permittem, ao meu vêr, sómente uma conclusão certa que não se trata de um Cyphonautes, dando-se o mesmo com a larva de Crassimarginatella. Mesmo se fosse correcta a interpretação dada por Repiachoff (l. c.), qual a de possuir a larva de Ten dra zostericola um intestino ou vestigios de um tal, como as figuras 1 e 2 da est. 8 o tornam provavel, ella ainda estaria longe da larva de Flu strella, citada n'esse conjuncto por Harmer (1926, p. 20I) e provida de concha bi-valvada. A larva de Crassimarginatella ainda não foi microtomizada, de modo que se ignora a sua anatomia interna. Quanto á externa, lembra entre as larvas até agora descriptas, sem duvida muito pouco numerosas (Harmer 1931, p. 157), mais as larvas das duas especies 
de Cellaria figuradas por Calvet (1900, t. II f. 10-12). Agora, no inicio do estudo comparativo das larvas dos Bryozóa, tal semelhança externa entre as phases livres de divisões differentes, a saber, Malacostega ( $\mathrm{C}$ r a s s imarginatella) e Pseudostega (Cellaria), não abre perspectivas auspiciosas para a nova systematisação das familias conforme as larvas, visada por Canu \& Bassler (1920, p. 71). Este principio systematico seria, como Harmer (1931, p. 156) disse, "singularmente infeliz" Além das inconveniencias mencionadas por Harmer (I. c.), a difficuldade technica de obter todas essas larvas ephemeras em estado maduro e corta-las tornaria quasi impracticavel o methodo proposto. O eixo antero-dorsal da larva de Crassimarginatella leucocypha é algo mais comprido que - apico-ventral. Em cada lado, possúe quatro manchas oculares. A larva de Thalamoporella evelinae (ca. de $150 \times 180 \mu$ ) é a primeira larva que se conhece da divisão dos Cheilostomata Coilostega. O typo é differente de todas as outras larvas conhecidas, com excepção talvez da larva de Scruparia chelata (Barrois 1877 p. 194 t. 15 f. 10), pertencente a outra divisão (Malacostega), cujas proporções e orgão apical excentrico, sem duvida, são bastante differentes. A larva da Thal a moporella presente, cujos varios aspectos se veem na Fig. 91, mostra heteromorphismo extraordinario, estendendo e contrahindo a corôa ciliada mais que outras larvas, de maneira que resultam feições tão differentes como reproduzidas nos esboços 6 e 8 . Os cilios do orgão apical são rigidos e immoveis, a episphera amarella e gibbosa, de modo que o contorno de perfil se apresenta como recortado. Quem conhece o aspecto de varias larvas marinhas quando observadas vivas no vidro de relogio, com temperatura elevada, poderia pensar que se trata no aspecto da larva de Thal a moporella da forma enrugada assumida por taes larvas ao se tornar a agua do mar hypertonica pela evaporação. Subindo a temperatura na localidade das observações até $42^{\circ} \mathrm{C}$. na sombra, a possibilidade alludida foi tomada em consideração e continuamente renovada a agua em que as larvas nadaram. A existencia de uma superficie papillar na larva de Thalamoporella evelinae deve assim ser considerada como normal. $O$ orgão pyriforme é um grosso botão branco densamente ciliado e provido de um tufo grosso de cilios agglutinados. Durante a natação o orgão pyriforme adianta-se e é rapidamente retrahido, apalpando todos os objectos attingidos pela larva. A hyposphera branca é muito pouco convexa, approximadamente plana, de modo que se percebem na vista lateral quasi sómente os cilios da hyposphera.

Além das 2 larvas dos Anasca, foram encontradas 4 dos Ascophora, representantes de 3 familias. A larva de Catenicella contei (ca. de $(00 \mu)$ é a primeira estudada da familia respectiva, cujos zoécios com as 
suas camaras complicadas pertencem ás estructuras que da melhor maneira são conhecidas. Apezar da posição systematica singular occupada pelas Catenicellidae, a configuração da larva é do typo lepralioide tão commum nos Cheilostomata ascophora. A corôa é larga, se bem que nitidamente restricta á zona equatorial. Ao mesmo typo pertence a larva de Savignyella lafontii (ca. de $120 \mu$ ), a mais diversicolor de todas as larvas até agora descriptas. O centro do orgão apical é carminado, a zona circumjacente mais clara e como empoada com ouro em pó, o silhão pallial provido de manchas pretas, a episphera côr de rosa, a corôa é vermelha pompeana sem limites das cellulas e a hyposphera amarella clara com estrias pretas. Na episphera notam-se duas manchas oculares pretas na metade anterior e duas outras indicadas por ovaes rubros. Tudo isto produz com os cilios brancos dos orgãos apical e pyriforme e da corôa um effeito que mesmo a melhor illustração não póde reproduzir. As larvas de Schizoporella carvalhoi e Hippoporella gorgonensis $(75 \times 100 \mu)$, que pertencem á mesma familia (Escharellidae), são bastante semelhantes e ambas providas de corôa larga. Os limites das cellulas notam-se na larva de Schizoporella mais, porque o seu conteúdo é mais claro. Além d'isso, caracterisa-se a larva de Hippoporella gorgonensis pelas 4 manchas oculares estiradas, carminadas, situadas nos dois lados das regiões anterior e posterior.

Em relação ao numero das especies dos Ctenostomata, conhecemos relativamente muitas larvas d'esta sub-ordem. A unica larva conhecida, dos Paludicellea (Harmer 1915, p. 43), grupo que abrange a especie presente, Volella gigantea, pertence a outra familia. Segundo a unica descripção rapida, acompanhada sómente por figuras de cortes (Braem 1896, p. 54), aquella larva (Paludicella articulata) é completamente diversa da larva de Nolella Seja frisado que Paludicella articula ta é ovipara, em opposição aos outros Bryozoa da agua doce (Phylactolaematal e a tantos outros Invertebrados com larvas no mar e com viviparidade dos representantes correspondentes na agua doce (Hesse 1924, p. 36, 312). No grupo dos Vesicularina encontramos larvas talvez comparaveis á de Nolella gigantea, p. e., a de Bowerbankia pustulos a (Calvet 1900, t. II f. 18-19). Esta ultima, porém, possúe o orgão pyriforme muito mais frontal, approximado ao orgão apical que a larva de $\mathrm{Nolell}$ a. A pequenez do orgão apical, que se nota tambem em outra larva dos Vesicularina, a saber, de Amathia lendigera (Barrois 1877. t. II f. 16-19), ligaria de certo modo as larvas de Amathia e Bowerbankia á de Nolella. A larva de Alcyonidium polyoum (Borg 1930, p. 137), porém, mostra ser tal caracter de modo nenhum typico para as larvas dos Ctenostomata. 


\section{C. \\ SUMMARY}

A I. Including the 5 species of Terebriporidae (Marcus 1938b) the author has now seen 110 species from the shallow waters of the district of Santos, the varieties, to which the typical forms also were found, not counted. The present material comes from the coast of São Paulo, Paraná and Santa Catharina (p. 172) and a collection of 18 species from Recife de Pernambuco (p. 113).

11.-III. The 24 species discussed include 7 new ones: Loxocalyx sawayai (Fig. I) is related with L. pes. Loxosomatoides evelinae (Fig. 2) has spines on the peduncle. The opesiulae of Thala moporella evelinae (Fig. 8) form a continuous line on the basal wall. Siniopelta langei (Fig. 21) differs from S. costazii (Fig. 22) and $S$ diota by the characters compared on the table p. 157. Holoporella carvalhoi (Fig. 23) has independent avicularia with pointed mandibles. H. schubarti (Fig. 24) is confronted with the related species of Hoporella p. 160. Alcyonidium hauffi (Fig. 26) covers stems of hydroids and gorgonids with a thick and knobby layer. The rather confoundable species Membranipora tuberculata(Fig. 4), Conopeum commensale (Fig. 5, 6) and C. reticulum (Fig. 7) are separated, especially by the proportion of height to length of the zooecia. Escharina krampi has a single oral gland (Fig. 12 B). Growth and regeneration were observed in Alcyonidium mamillatum (Fig. 25). Buskia repens (O'Donoghue) was found in Recife; it belongs to Buskia but differs from B. nitens.

IV $58,3 \%$ of the Bryozoa of the litoral of Santos may now be consicuered as approximately stenothermic warm water-forms, but this count is based upon the very wide limits of what is regarded as subtropical region.

B. Introduction. Nomenclature of the chief higher systematic units of the class or phylum Bryozoa (Polyzoa). Cyclostomata is nearly homonymous with Cyclostoma (lampreys and hags) and should be substituted by Stenostomata (better than Stenolaemata Borg 1926, criticized by Harmer 1930) Cheilostomata and Ctenostomata united as Eurystomata could be opposed to the Stenostomata. Kamptozoa (Cori 1929) instead of Entoprocta Nitsche 
1869 is useless. Ctenostomata lately introduced for a suborder of spirotrichous Ciliata (Kahl 1932) should be changed by protozoologists in order to avoid confusion in indices.

V. I. In Entoprocta all muscles are smooth; those of the stalk liken the muscle-cells of Nematodes and other worms owing to the position of their rucleus in a lateral sarcoplasmatic swelling (Fig. 28).

2. In the Ectoprocta the nature of the fibrils of the muscle-cells has been much discussed. The retractor of all Phylactolaemata and eurystomatous Gymnolaemata examined in polarized light appeared smooth. Contraction folds in the structureless supporting membrane between the epithelium and the circular muscles of the gut in Phylactolaemata can illude the presence of striated intestinal muscles (Fig. 29). Also the staining effect obtained by Bronstein (1938) has nothing to do with true striated structure (Fig. 30). On the other hand the thin layer of protoplasma which surrounds the large vacuole of the pharyngeal cells in various Eurystomata is striated (Fig. 31), though we did not succeed to see the single fibrils observed by Henneguy (1909). The muscles of the gizzard are smooth (Fig. 32), their nuclei are all on the abanal side, but, as the cells are narrower than the nuclei, these lie at different levels. In other cases the nuclei of the musclecells frequently form a single row (Fig. 33); we see no explanation for the change of their position in the figured gut of Aetea. In the vibracula occur striated ( $\mathrm{Caberea}$ ) and smooth muscles (Fig. 34). In the avicularia the abductors (divaricators) are smooth, the adductors (occlusors) striated, but it must be noted, that even with the polarization microscope the striae of the occlusors can not always be observed, especially when these are contracted. The striae in the contracted retractor come from folds of their noncontractible sheath, they always disappear in polarized light.

VI. The vibracularian abductor, that draws the seta towards the frontal side of the colony, and the adductor, that pulls it backwards, are of equal size (Fig. 34), corresponding to the uniform amplitude and rhythm of the two movements. In the avicularia generally 2 occlusor muscles occur with 2 tendons, but some species have only one occlusor tendon (Fig. 35, 36). The position and number of the abductors varies more than in the occlusors.

1. Polypidiferous avicularia (Fig. 37, 2), not included in Silén's groups of true avicularia, are indeed difficult to judge. The occlusors of the mandible' in the respective avicularium of Crassimarginatella le ucocypha and in the B-zooecia of Steganoporella buskii are smooth, but the reduction of the polypide and the shape of the opercula 
(Fig. $37 \mathrm{~m}^{2}, \mathrm{~m}^{3}$ ) can in the actual state of our knowledge only be understood with Harmer's conception of incipient avicularia. The parietal muscles are very different in various Membraniporidae. In Crassimarginatella leucocypha beside such with the common origin on the lateral walls occur parietal muscles originating on the basal wall.

2. Crassimarginatella l. has also true vicarious avicularia; the insertion of their depressors is shown in Fig. 38. In Flustra barleei (Norway) we met the circular origin, of the abductor described by Silen in F. foliacea. In Crassimarginatella the depressors originate on the lateral, basal and proximal walls; in Dendrobeania murrayana (Denmark), Beania intermedia and Synnotum aegyptiac u $m$ the divaricator is unpaired and originates proximally to the occlusors. In Dendrobeania m. the insertion is like that of Fl. folliacea, in the two other species they insert directly at the frontal membrane. The collective tendon (Fig. 35, +) and its nuclei (Fig. $40 \mathrm{~A}$, nd) and the single epithelial cells transformed into tendinous fibres (Fig. $40 \mathrm{~A}, \mathrm{nb}$ ) as well as the fibrillar insertion-cone (Fig. 39) are understood easiest with the mentioned figures.

3. The polypide of the avicularium bears in some cases setae or cilia that may project into the vestibule through an orifice in the diaphragma (Fig. $40 \mathrm{~B}$ ). Also where the diaphragma is continuous (Fig. 44), the polypide's cilia can of course exercise their sensoria! function. That is made likely by the authors earlier experiments $(1926 a$, p. 56) and by the histological aspect of the polypide's basal mass, that likens a ganglion (Fig. 4I). 43, g).

4. Fig. 42 interprets the function of the abductors and adductors. The latter must draw the mandible over two basal knobs of the beak; they close the mandible in 2 phases, as Nordgaard has described it. These knobs seem to fix the mandible in its open position. The distal pair of abductors inserts directly at the mandible (see also Fig. 50). The peduncle belongs to the avicularium ( $B$ ugula) or to the zoecium ( $B$ e a nia Fig. 44; $S$ ynnotum Fig. $45 \mathrm{~A}$ ), the muscles moving the avicularium of $B$ u gula (Fig. $42 A, x, y)$ lie in its socle. The tentacle-sheath in the avicularium of Beania (Fig. 44, u) is very different from that of Bugula (Fig. 43, u) and is separated from the vestibule (Fig. 44, v) by a continuous diaphragma (i). The occlusor-tendon $(t)$ is very broad, the unpaired abductor $(b)$ inserts at the frontal membrane. In B. magellanica (South Africa) also a distal abductor occurs, that inserts at the mandible's basal sclerite. My figure of the avicularian muscles in Caulibugula mortenseni 
$(1925, f .2)$ is wrong: the muscles are identical in number, origin and insertion with those in Bugula.

5. In the two types of avicularia of Synnotum a egyptiacum occurs a big gland (Fig. 45, g), seen for the first time in avicularia of Anasca. The autozooecia of this species have no oral glands. Various forms of avicularian glands or corresponding thickenings of the vestibular epithelium in front of the polypide are shown in Fig. 46. These glands can neither belong to the nervous, nor to the nutritive, or reproductive system and might perhaps have something to do with the stronger skeleton of the Ascophora. But as rather calcified Catenicellidae (Vittaticella elegans, Aru-Islands, and Scuticella lorica, Bass' Strait) have no avicularian glands, Holoporella mordax a big and Siniopelta costazii a very small one, the function of the organs still remains unknown; they might be poisonous. In the dependent avicularia of R hynchozoon phrynoglossum the frontal membrane (Fig. 47 48, s) is thickly chitinized, and, if depressed by contraction of the abductor (b), hits the mandible's base and opens the mandible suddenly. Like in the above mentioned C.atenicellidae the polypide of the vicarious avicularium of $\mathrm{S}$ i $\mathrm{n}$ i opelta costazii bears setae (Fig. 49. c); the diaphragma is incomplete. The occlusors of the avicularium in Microporella ciliata (Fig. 50) insert by means of a collective tendon and some single fibres, basally joined in a tendinous net; the distal abductor has a collective tendon inserting at the base of the mandible; the proximal abductor's muscle-cells insert partly with long, partly with very short tendinous fibres at the strongly chitinized frontal membrane.

B VIla. As far as the observations hitherto published are univocal, the individuals of Loxosomatidae contain either testes or ovaries, not both at the same time. Moreover there are few facts that favor a succession of the two sexes in the same individual. The present material of Loxocalyx s a wayai contained females only.

b. For Pedicellinidae the literature cites a) individuals of different sexes united in the same colony; b) hermaphrodite individuals; c) colonies of only one sex. All the colonies we have seen of Barentsia discreta, gracilis, laxa and Loxosomatoides evelinae are unisexual. Ascopodaria macropus Ehlers is considered synonymous with Barentsia discreta (Bsk.) (p. 2lo).

I. The indications of hermaphroditism in Pedicellina cernua are partly criticized, for instance Nitsche's descriptions (1869, p. 26-28; 1876, p. 161) contradict each other with respect to the arrangement of the gonads. Nevertheless Ehlers' description (p. 96) and Stiasny's section (t. 13 
f. 2) as well as Cori's picture of a living animal (1936, f. 25) prove the occurrence of individual and simultaneous hermaphroditism.

2. All the colonies of $P$ c. from the Baltic, Auckland Islands and Santos and $P$. nannoda that we have seen, are unisexual.

2a. The testes of the males of P. c. are much bigger than the ovaries of the females. The testes open - without ductus efferentes - into a large vesicula seminalis, that is missing in $P$ na nnoda and $B$ arentsia gracilis. The ductus ejaculatorius is long and ciliated and ends close below the anus. The spermatogenesis is described (Fig. 58).

2b. The bag-shaped ovaries are hardly limited against the oviducts: the biggest ova lie in the bottom of the bags with.n the layer of ovarian cells but without special alimentary cells around them. One sperm enters the ovum at the end of the second growing period. The diploid number of chromosomes seems to be 30. The first maturation division (Fig. 61) takes place in the ovary. The upper part of the vagina is formed by high, acidophile gland cells, that enclose the ovum with a soft shell with a long stalk. These stalks are fastened between the folds of the embryophore and reach the side-walls of the calyx (Fig. 63). The brood chamber in our material is formed by the walls of the vestibule between the tentacles and the vestibular groove. It is not lobed and its epithelium consists of the common flat vestibular cells.

2c. The hermaphrodites of $P$ c. mentioned in the literature agree with our unisexual females with respect to the strait course of their gonoduct and the presence of a shell gland; they are somatically females. From a colony infested by Microsporidia a lateral hermaphrodite is described (Fig. 65).

VIII. The colonies were stained in total and either eggs were isolated in the oil of cloves, or the individuals containing embryos enclosed in paraffine for sections. The ripe eggs measure $40 \times 50 \times 60 \mu$. The polocytes generally persist up to gastrulation; the primary axis of the egg $(40 \mu)$ lies apico-vestibularly.

a. The first furrow is meridional, the 2 blastomeres are equal in size. The second plane of division is also meridional and perpendicular to the first, the spindles are inclined laeotropically $=$ anticlockwise. The 4 blastomeres are of equal size.

b. The third segmentation is equatorial and dexiotropic, the fourth laeotropic. The 16 now formed blastomeres are of different size; the upper four in the animal half and the lower four in the vegetative half are bigger than the 8 equatorial ones. The aspect is typically that of a spiral cleavage, though the 4 quadrants are of the same size. 
c. The dexiotropic fifth segmentation gives apical cells bigger than the intermediate girdle-cells; one of the macromeres is bigger than the others, thus the embryo becomes bilaterally symmetrical. The following division justifies the denomination $3 \mathrm{D}$ of the bigger macromere. In the laeotropic sixth segmentation the macromeres divide before the apical cells (rule of Kofoid). The micromeres of the fourth quartette are large. The difference in the size of the anterior blastomeres of the first quartette and therefor the rhythm of cleavage is in Pedicellima more worm (Annelida Turbellaria) - than mollusc-like. $1 a^{112}$ etc. are the cells corresponding to the annelidan cross. In the 48 cell-embryo the undivided cell $4 \mathrm{~d}$ begins to disappear (Fig. 75). The last analyzable stage had 56 cells (p. 236).

d. In the blastula of 67 cells the endomesoblast is still undivided. As in Pedicellina $4 d$ is purely mesoblastic (in the meaning of Surface 1907. p. 548), this must be considered as a precocious segregation, and in the light of Wilson's theory of ancestral reminiscence as a secondary simplification. Gastrulation begins in embryos of 90 cells. Two especially big cells (Fig. $78, \mathrm{n}$ ) probably belonging to the fourth quartette are recognizable from the beginning of the invagination till to the histological differenciation of the mid-gut. Up to the formation of the stomodaeum two ectomeres (Fig. 78,3) are visible, probably the "Urmesodermzellen" of Hatschek and "pole-cells" of Harmer. Embryos of 90-100 cells show 4d divided in the median plane. The invagination of the entoderm is more intense in the front part, the same is the case, when the stomodaeum forms. During this the apico-oral axis grows longer. The mesodermic bands budded from the two descendants of $4 \mathrm{~d}$ are loose and transitory; later on the endomesenchymatous elements are no longer discernible from the ectomesenchymatous cells, that grow inwards from the border of the mouth (Fig. 83).

The primordial of the pre-oral organ and the invagination of the ectodermal proctodaeum are found in the same stage. As the very short ventral side (between mouth and anus) in the larva of Pedicellina is so to say an additional formation, that does not remove the blastopore nearer to the apical plate as in true Trochophora, the axis of the gastrula coincides approximately with the apico-oral one in the adult larva. The same is the case in Cyphonautes and the Phylactolaemata. Balanoglossus was considered the only representant of the Protaxonia among the Bilateria. Now there appear beside this deuterostome form further Protaxonia among the Protostomia. This fact is certainly rather important, although the two phyla must of course be maintained distinctly separated.

e. During the outgrowth of the stomodaeum and the histogeny of the gut the cells of the integument do not increase in number, but the few 
existing ones stretch. The apical plate and the pre-oral organ invaginate. At the same time the egg shell vanishes with exception of the stalk that is fastened around the apical pit. The skin then incrusts with small particles of mud and broken diatoms. After the disappearance of the shell the embryo begins to feed. First then the vestibule is developed, and gives rise to the 3 advestibular glandular organs. The lower lip has high cells with long cilia and is connected with the pre-oral organ by two nerve-strands that surround the oesophagus. The larval protonephridia liken those of the adult animal. They lie between the oesophageal and the basal advestibular organ.

f. Since Hatschek, the Vienna school of Zoologists /Claus-Grobben, Cori and others) consider it necessary to separate Ectoprocta and Entoprocta distinctly. Also Cori's confrontation in his recent monograph (1936, p. 101) defends this point of view. In the present paper the critical examination, especially of his points 5, 6 and 10-13 in the cited confrontation, leads to maintain the Polyzoa (Bryozoa) as a taxonomic unit, as already Harmer, Davenport, Prouho, Seeliger and others did. As the face, that Cori calls the active one, is opposite in Phylactolaemata and Gymnolaemata, it must in one of these be the same as in Entoprocta. Anatomically the Phoronidea liken the Polyzoa, especially Phylactolaemata, but embryologically both classes are different. Wether Phoronidea and Polyzoa are united in the same phylum (by the author) or separated (by Harmer), the topographic orientation of Phoronis, derived from its development, may not be applied to determine what is dorsal and ventral in adult Polyzoa. Cleavage, protonephridia, the origin of the gut in the adult and the position of the anus are the principal facts, that make it impossible to consider Entoprocta and Ectoprocta so closely related as Goette did; but they ought to be united in the same taxonomic group. 
D.

\section{BIBLIOGRAPHIA.}

AGATZ, J. 1912, Knospung und Regeneration bei den Bryozoen. Inaug. Dissert. math. - naturwissenschaftl. Fakult. Strassburg i. E. 30 pg. 4 tab. Bamberg.

ALDER, J. 1857, A catalogue of the Zoophytes of Northumberland and Durham. Transact. Tyneside natural. Field club, v. 3, p. 1-72 t. 1-8 (da separata). Newcastle-uponTyne.

ALLMAN, G. J. 1856, A monograph of the fresh-water Polyzoa, etc. London.

ANDERSSON, K. A. 1902, Bryozoen. der schwedischen Expeditionen 1898 und etc. Zool. Jahrb. Syst. v. 16, p. 537-560 t. 30. Jena.

ANKEL, W. E. 1933, Ei und Eibildung. Handwoerterb. Naturwissensch. 2.a ed. v. 3, p. 7-36. Jena.

ANNANDALE, N. 1908, The fauna of brackish ponds at Port Canning, Lower Bengal; pars 7. Further observations on the Polyzoa etc. Rec. Ind. Mus. v. 2, p. 11-19. Calcutta.

- 1915, Fauna of the Chilka lake. The Polyzoa of the lake and of brackish water in the Gangetic delta. Mem. Ind. Mus. v. 5, p. 127-132 (Unnatellidae \& Loxosomatoides). Calcutta.

- 1916, Zoological results of a tour in the far east. Polyzoa Entoprocta and Ctenostomata. Mem. Asiat. Soc. Bengal v. 6, p. 13-37 t. 1-2. Calcutta.

ASSHETON, R. 1912, Loxosoma loxalina and Loxosoma saltans. Quart. Journ. micr. Sci. v. 58, p. 117-143 t. 6-7. London.

ATKINS, D. 1927, A new habitat for Loxosoma phascolosomatum Vogt. Journ. Mar. Biol. Assoc. Unifed Kingdom v. 14, p. 749-752. London.

- 1932, The Loxosomatidae of the Plymouth area, including L. obesum sp. nor. Quart. Journ. micr. Sci. v. 75, p. 321-391. London.

AUTRUM, H. 1932, Die Erregbarkeit und ihre Beziehung zur Struktur der Muskelzellen bei .. Hirudo etc. Zool. Jahrb. Phys. v. 50, p. 447-478. Jena.

BARROIS, J. 1877, Mémoire sur l'Embryologie des Bryozoaires. Thèses etc. Lille.

- 1886, Mémoire sur la métamorphose de quelques Bryozoaires. Ann. Sci. nat. Zool. Paléont. sér. 7 v. 1 n. ${ }^{\circ}$ I, p. 1-94 t. 1-4. Paris.

BARRoso, M. G. 19/2, Briozoos... de Santander. Trab. Museo Cienc. Nat. n.: 5, p. I-63. Madrid.

- 1915, Contribución al conocimiento de los Briozoos marinos de España. Bol. R. Soc. españ. Hist. nat. v. 15, p. 413-420. Madrid. 
- 1917,Notas sobre Briozoos. Bol. R. Soc. esp. Hist. nat. v. 17, p. 494-499. Madrid.

- 1919, Notas sobre Briozoos españoles. Bol. R. Soc. esp. Hist. nat. v. 19, p. 340-347. Madrid.

- 1920, Notas sobre Briozoos españoles. Bol. R. Soc. esp. Hist. nat. v. 20. p. 353-362. Madrid.

- 1921. Notas sobre algunas especies de Briozoos de España. Bol. R. Soc. esp. Hist. nat. (v. 50 aniversar.), p. 68-78. Madrid.

- 1922, Notas sobre Briozoos marinos esp. Bol. R. Soc. esp. Hist. nat. v. 22, p. 88-101. Madrid.

BARTSCH, O. 1923, Die Histiogenese der Planarienregenerate. Arch. mikr. Anat. \& Entw. Mech. v .99, p. $1-35$ (sep.j t. 6-9. Bellin.

BASSLER, R. S. 1922, The Bryozoa, or Moss Animals. Smithson. Rep. for 1920, p. 339-380 t. 1-4. Washington.

- 1935, Fossilium Cafalogus I. Animalia, pars 67 Bryozoa, p. 1-229. s'Gravenhage.

- 1936, Nomenclatorial notes on fossil and recent Bryozoa. Journ. Wash. Ac. Sci. v. 26, p. 156-162. Washington.

BATHER, F. A. 1900, The Echinoderma. E. Ray Lankester, A Treatise on Zoology. pars 3. London.

BECKER, G. 1937, Untersuchungen über den Darm und die Verdauung von Kamptozoen. Bryozoen etc. Zeitschr. Morph. Oekol. v. 33, p. 72-127. Berlin.

BELAR, K. 1928, Die cytologischen Grundlagen der Vererbung. Handb. Vererbungswissensch. v. I B, p. 1-4/2 t. 1-2. Berlin.

BENEDEN, P J. van 1845, Recherches sur l'organisation des Laguncula, etc. Nouv. Mém. Ac. Roy. Bruxelles v. 18, p. 1-29 t. I-3. Bruxelles.

BETTENDORF, H. 1897, Ueber Muskulatur und Sinneszellen der Trematoden. Zool. Jahrb. Anat. v. 10, p. 307-358 t. 28-32. Jena.

BLAINVILLE, H. M. de 1834, Manuel d'Actinologie ou de Zoophytologie. Paris.

BOEHMIG, L. 1906, Tricladenstudien. Zeitschr. wiss. Zool. v. 81, p. 344-504 t. 12-19. Leipzig.

BONNEVIE, K. 1907, Untersuchungen über Keimzellen. 2. Physiologische Polyspermie bei Bryozoen. Jen. Zeitschr. Naturwissensch. v. 42 (n. F. v. 35), p. 567-598 t. 32-35. Jena.

BORG, F. 1923. On the structure of Cyclostomatous Bryozoa, prel. note. Ark. Zool. v. 15, nr. 11, p. I-17. Stockholm.

- 1926,Studies on recent Cyclostomatous Bryozoa. Zool. Bidr. Upps. v. 10 p. 181507 t. 1-14. Uppsala.

- 1926a, On the Body-wall in Bryozoa. Quart. Journ. micr. Sci. v. 70, p. 583-598. London.

- 1930, Moostierchen oder Bryozoen (Ectoprocten). Dahl, Tierwelt Deutschl. pars 17. p. 25-142. Jena.

1931, On some species of Membranipora. Ark. Zool. v. 22 A, n. 4, p. I-35 t. 1-3. Stockholm. 
- 1933. Die Bryozoen, 3. Die marinen Bryozoen .. des arktischen Gebietes. Fauna arctica v. 6, p. 5|6-55|. Jena.

BORRADAILE - POTTS etc. 1932, The Invertebrata. A manual for the use of students. Cambridge (University Press).

BRAEM, F. 1890, Untersuchungen über die Bryozoen des süssen Wassers. Bibl. zool. fasc. 6. Cassel.

- 1896, Die geschlechtliche Entwicklung von Paludicella Ehrenbergii. Zool. Anz. v. 19, p. 54-57. Leipzig.

- 1897. Die geschlechtliche Entwicklung von Plumatella fungosa. Zoologica, fasc. 23. Stuttgart.

- 1908. Die geschlechtliche Entwicklung von Fredericella sultana. Zoologica, fasc. 52. Stuttgart.

BRAEM, F. 1912, Die Keimung der Statoblasten von Pectinatella und Cristatella. Zoologica, fasc. 67. Stuttgart.

BREHM, A. E. 1918, Tierleben, 4." ed., v. I. Bryozoa: p. 319-324. Leipzig \& Wien. BRESSLAU, E. 1933. Turbellaria. Kükenthal-Krumbach, Handb. Zool. v. 2 fasc. I, p. (1) 52 - (1) 304. Berlin \& Leipzig.

BRONSTEIN, G. 1938, Sur la présence de muscles striés chez les Bryozoaires. Bull. soc. zool. France v. 63, p. 257-259. Paris.

BUCHNER, P 1918, Ueber totale Regeneration bei chilostomen Bryozoen. Biol. Centralbl. v. 38, p. $457-461$. Leipzig.

- 1924. Studien über den Polymorphismus der Bryozoen. Zool. Jahrb. Syst. v. 48, p. 155-216 t. 15-17. Jena.

BUDDENBROCK, W. von 1932, Bryozoa ectoprocta. Handwörterb. Naturwissensch. 2." ed., v. 2, p. 264-280. Jena.

BUSK, G. 1852a, An account of the Polyzoa etc. App. de J. MacGillivray, Voyage of H. M. S. "Rattlesnake", v. I, p. 343-385, 402 t. I. London.

- 1852, Catalogue of Marine Polyzoa etc. pars I (Cheilostomata part.). London.

- 1854. Catalogue of Marine Polyzoa etc. pars 2 (Cheilostomata part.). London.

- 1854a, Remarks on the structure and function of the avicularian and vibracular organs of the Polyzoa etc. Quart. Journ. micr. Sci. v. 2, Transact. p. 26-33 t. 2. London.

- 1855, Zoophytology. Quart. Journ. micr. Sci. v. 3, p. 253-256, 320-322 t. 1-4. London.

- 1856, Zoophytology. Quart. Journ. micr. Sci. v. 4, p. 176-180, 308-312 t. 7-12. London.

- 1859, A Monograph of the fossil Polyzoa of the Crag. London.

- 1875, Catalogue of Marine Polyzoa etc. pars 3 (Cyclostomata). London.

- 1884, Report on the Polyzaa collected by H. M. S. "Challenger" etc. Pars I. The Cheilostomata. Rep. Voy. Chall. v. 10, pars. 30. London.

BOTSCHLI, O. 1921, Vorlesungen über Vergleichende Anatomie (em parte re-impresšo de 1910 e 19/2). Berlin. 
CALDWELL, W. H. 1883, Preliminary note on the structure, development and affinities of Phoronis. Pr. R. Soc. London v. 34, p. 37I-383 (7. XII, 1882). London.

CALVET, L. 1896, Résult. scient. de la campagne du "Caudan" etc. Bryozoaires. Ann. Univ. Lyon v. 26, p. 25I-27| t. 7. Paris.

- 1900, Contribution à I'histoire naturelle des Bryozoaires ectoproctes marins. Trav. Inst. Zool. Montpellier, n. sér. Mém. 8, p. 1-488 t. 1-13. Montpellier \& Paris.

- 1902, Bryozoaires marins de la région de Cette. Trav. Inst. Zool. Montpellier, sér. 2. Mém. I.I, p. 1-103 t. I-3. Montpellier.

- 1902a. Bryozoaires marins des côtes de Corse. Trav. Inst. Zool. Montpellier, sér. 2. Mém. 12, p. I-52 t. 1-2. Montpellier.

- 1903, Description d'une nouvelle espèce de Bryozoaire cténostome etc. Bull. soc. zool. France v. 28, p. 33-36 f. I-4. Paris.

- 1907. Bryozoaires. Exp. scient. "Travailleur" et "Talisman" v. 8, p. 355-495 t. 26-30. Paris.

- 1910, Titres et travaux scientifiques. 48 p. Montpellier.

- 1927. Bryozoaires de Monaco et environs. Bull. Inst. Océan. n. ${ }^{\circ}$ 503, p. 1-46. Monaco.

- 1927a, Nouvelle contribution .. Bryozoaires de la Méditerranée occidentale. Arch. Zool. exp. v. 66 Notes n. 1, p. 1-6. Paris

- 1928. Documents faunistiques sur les Bryozoaires etc Bull. Inst. Océan. n. ${ }^{0}$ 530, p. 1-7. Monaco.

- 1931, Bryozoaires .. Campagnes scient. Albert !. de Monaco. Rés. Camp. s.ii. Albert I. fasc. 83, p. I-83 t. I-2. Monaco.

CANU, F 1904, Bryozoaires tertiaires ... sud de la Tunisie etc. 37 p. (Explor. scier.t. Tunisiel t. 33-35. Paris.

- 1931. Notes biologiques sur la croissance de quelques grands Bryozoaires libres. Bull. Inst. Océan. n. ${ }^{\circ} 585$, p. I-8. Monaco.

CANU, F. \& BASSLER, R. S. 1917, A Synopsis of early tertiary Cheilostome Bryozoa. Smithson. Inst. U. S. Nat. Mus. Bull. n.a 96, p. 1-87 t. 1-6. Washington, D. C.

- 1920, North American early tertiary Bryozoa. Smithson. Inst. U. S. Nat. Mus. Bull. n. 106, p. 1-879 t. 1-162. Washington, D. C.

- 1923, North American later tertiary and quarternary Bryozoa. Smithson. Inst. U. S. Nat. Mus. Bull. n. ${ }^{\circ}$ 125, p. 1-302 t. 1-47. Washington, D. C.

- 1925, Les Bryozoaires du Maroc etc. Mém. I. Mém. Soc. sci. nat. Maroc n.10, p. 1-79 t. 1-9. Rabat, Paris, Londres.

- 1927, Bryozoaires de îles Hawaii. Bull. Soc. sci. Seine-et-Oise fasc. 7 suppl. 1927 \& fasc. 7 suppl. 1928, p. 1-66 t. 1-11. Thiers.

- 1928, Fossil and recent Bryozoa of the gulf of Mexico region. Próc. U. S. Nat. Mus. n. 271.0 v. 72 art. 14, p. 1-199 t. 1-34. Washington, D. C.

- 1928a, Bryozoaires du Brésil. Bull. Soc. sci. Seine-et-Oise v. 9 fasc. 5 p. 58-119 t. 1-9. Thiers.

- 1928b, Les Bryozóaires du Maroc etc. Mém. 2. Mém. Soc. sci. nat. Maroc n.0 18, p. 1-85 t. 1-12. Rabat, Paris, Londres. 
- 1929, Bryozoa of the Philippine region. Smithson. Inst. U. S. Nat. Mus. Bull. 100, v. 9, p. 1-685 t. 1-94. Washington, D., C.

- 1930, The Bryozoan fauna of the Galapagos islands. Proc. U. S. Nat. Mus. n. 2810 , v. 76, art. 13, p. 1-78 t. 1-14. Washington, D. C.

- 1930a, Bryozoaires marins de Tunisie. Stat. Océanogr. Salammbô, ann. n. 5 , p. 1-91 t. 1-13. Paris.

CIPOLLA, F. 1921, I Briozoi pliocenici di Altavilla etc. Pubbl. ist. geol. R. Univ. Palermo, Giorn. soc. sci. nat. Palermo, v. 32, p. 1-185 t. 1-8. Palermo.

CLAPAREDE, E. 1863, Ueber eine wahrscheinlich zu den Baryozoen gehörige Thierform. Beob. wirbelloser Thiere etc. Loxosoma p. 105-107 t. 2 f. 6-10. Leipzig.

- 1867, Miscellanées zoologiques. Ann. sci. nat. Zool. sér. 5 v. 8, p. 5-36 t. 3-6 (Lo xosoma Kefersteinii, p. 28-30 t. 6 f. (-3). Paris.

- 1870, Beiträge zur Anatomie und Entwickelungsgeschichte der Seebryozoen. Zeitschr. wissensch. Zool. v. 21 (|87|), p. |37-174 t. 8-10. Leipz:g [p. I-38 da separata].

CLAUS-GROBBEN-KÜHN 1932, Lehrbuch der Zoologie. Entoprocta p. 528-529. Ectoprocta p. 809-814. Berlin \& Wien.

$\mathrm{COE}_{1}$ W. R. 1899, On the development of certain Nemerteans. Trans. Connect. Ac. v. 10 (1897-1900) no. 5 p. 235-262 t. 31-35. New Haven.

CONKLIN, E. G. 1902, The embryology of a Brachiopod etc. Pr. Americ. Philos. Soc. v. 41, no. 168, p. 41-76 t. I-10. Philadelphia.

CORI, C. I. 1929, Kamptozoa (Entoprocta). Kükenthal-Krumbach, Handb. Zool. v. 2, p. (5) 1-(5)64. Berlin \& Leipzig.

- 1930 Kamptozoa (Entoprocta). Grimpe-Wagler, Tierwelt Nord \& Ostsee, v. 4 a. p. 1-68. Leipzig.

- 1930a, Kamptozoa und Phoronidea. Dahl-Bischoff, Tierwelt Deutschlands, pars 17, p. I-24. Jena.

- 1936, Kamptozoa. Bronn, Klassen \& Ordn. Tierreichs v. 4, 2. ${ }^{a}$ parte, 4. I-I19. Leipzig.

COUCH, R. Q. 1844, A Cornish Fauna etc. pars 3 (containing the Zoophytes) XVII + 164 p. 23 tab. Truro.

CZWIKLITZER, R. 1908, Die Anatomie der Larve von Pedicellina echinata. Arb. zool. Inst. Wien v. 17, p. 157-186 t. 1. Wien.

DARWIN, Ch. 1844, Naturwissensch. Reisen, tradução allemã e com notas de E. Dieffenbach, I.d parte. Braunschweig.

DAUTERT, E. 1929, Die Bildung der Keimblätter bei Paludina vivipara. Zool. Jahrb. Anat. v. 50, p. 433-496. Jena.

DAVENPORT, C. B. 1890, Cristatella, the origin and development etc. Bull. Mus. comp. Zool. Harvard Coll. v. 20, p. 101-151 t. 1-11. Cambridge, U. S. A.

- 1891. Observations on Budding in Paludicella efc. Bull. Mus. comp. Zool. Harvard Coll. v. 22, p. I-I/4 t. 1-12. Cambridge, U. S. A.

- 1893, On Urnatella gracilis. Bull. Mus. comp. Zool. Harvard Coll. v. 24, p. 1-44 t. 1-6. Cambridge, U. S. A.

DAWYDOFF, C. 1928, Traité d'Embryologie comparée des Invertébrés. Paris. 
DONS, 1939, Norges Strandfauna 22, Bryozoer I. K. Norsk. Vidensk. Selsk. Forh. v. 12 no 4, p. II-14. Trondheim.

DUMORTIER, B. C. \& VAN BENEDEN, P. J. 1850, Histoire naturelle des Polypes composés d'eau douce. 2 partes. Mém. Ac. Roy. Bruxelles v. 16. Bruxelles.

EGGERT, B. 1929, Der Hermaphroditismus der Tiere. Zeitschr. wissenschaftl. Zool. v. 133, p. 563-585. Leipzig.

EHLERS, E. 1876, Hypophorella expansa. Abhandl. physik. Klasse Ges. Wiss. Göttingen v. 21 . p. I-156 t. I-5. Göttingen.

- 1890, Zur Kenntnis der Pedicellineen. Abhandl. physik. Klasse Ges. Wiss. Göttingen v. 36, p. I-200 t. 1-5. Göttingen.

EKMAN, S. 1935, Tiergeographie des Meeres. Leipzig.

ELLIS, J. \& SOLANDER, D. 1786, The natural history of many curious and uncommon Zoophytes. London.

FISCHER, P. 1870, Bryozoaires marins du Dépt. Gironde. Actes Soc. Linn. Bordeaux v. 27 (sér. 3 v. 7), p. 329-357. Bordeaux.

FOETTINGER, A. 1887, Sur l'anatomie des Pedicellines etc. Archives de Biologie v. 7. p. 299-329 t. 10. Gand.

FORBES, A. 1933, Conditions affecting the responses of the avicularia of Bugula. Biol. Bull., v. 65 no. 3, p. 469-479. Lancaster, PA.

FRATTARELLI, A. 1929, Primo contributo alla conoscenza dei Briozoi del Mediterraneo. Arch Zool. ital. v. 13, p. 373-401. Torino.

FREESE, W. 1888, Anatomisch-histologische Untersuchung von Membranipora pilosa L. Arch. Naturgesch. 54 Jahrgang v. I, p. 1-42 t. 1-2. Berlin.

FRIEDL, H. 1917, Bryozoen der Adria. Zool. Anz. v. 49 no. 9, p. 225-240. Leipzig.

GEROULD, J. H. 1907, The development of Phascolosoma. Zool. Jahrb. Anat. v. 23, p. 77-162 t. 4-11. Jena

GERWERZHAGEN, A. 1913, Beiträge zur Kenntnis der Bryozoen etc. Zeitschr. wissensch. Zool. v. 107, p. 309-345 t. 12-14. Leipzig.

- 1913a, Untersuchungen an Bryozoen. Vorläufige Mitteilung. S. Ber. Heidelberg Akad. Wissensch. mathem. naturwissensch. Klasse Abtlg. B, biolog. Wissensch. Jahrgang 1913, 9. Abhandl. 16 p. Heidelberg.

GLIESCH R. 1925, A fauna de Torres (Rio Grande do Sul). 75 p. Porto Alegre (Offic. graphic. Escola Engenharia).

GOETTE, A. 1921. Die Entwicklungsgeschichte der Tiere. Berlin \& Leipzig.

GOODRICH E. S. 1900, On the nephridia of the Polychaeta, part 3. Wuart. Journ. micr. Sci. n. s. v. 43, p. 699-748 t. 37-42. London.

- 1904, Nephridia of the Actinotrocha larva. Quart. Journ. micr. Sci. n. s. v. 47, p. 103-121 t. 8-9. London.

GRAUPNER, H. 1930, Zur Kenntnis der feineren Anatomie der Bryozoen etc. Zeitschr. wissensch. Zool. v. 136, p. 38-77. Leipzig.

GRAVElY, H. D. 1927, Polyzoa. Bull. Madras Gouv. Mus. n. s. Nat. Hist. sect. v. I, p. 89-94 t. II. Madras. 
HADDON, A. C. 1883, On budding in Polyzoa. Quart. Journ. micr. Sci. n. s. v. 23, p. 516-555 t. 37-38. London.

HAMILTON, A. 1898, A list of recent and fossil Bryozoa of New Zealand. Transact. Proc. New Zealand Inst. v. 30, p. 192-199. Wellington.

HARMER, S. F. 1885, On the structure and development of Loxosoma. Quart. Journ. micr. Sci. n. s. v. 25, p. 261-337 t. 19-21. London.

- 1887. On the life-history of Pedicellina. Quart. Journ. micr. Sci. n. s. v. 27, p. 239-263 t. 21-22. London.

- 1892, On the nature of excretory processes in marine Polyzoa. Quart. Journ. micr. Sci. n. s. v. 33, p. 123-167 t. 2-3. London.

- 1900, A revision of the genus Steganoporella. Quart. Journ. micr. Sci. n. s. v. 43, p. 225-297 t. 12-13. London.

- 1901, Polyzoa. Cambridge Natur. Hist. v. 2, p. 463-533. London.

- 1902, On the morphology of the Cheilostomata. Quart. Journ. micr. Sci. n. s. v. 46, p. 263-350 t. 15-18. London.

- 1909, Address to the zoological section. Brit. Ass. Rep. 78th meeting (1908 Dublin) p. $7|5-73|$.

- 1915, The Polyzoa of the Siboga Exped. part I (Entoprocta etc.). Siboga Exped. v. 28 a, p. 1-180 t. 1-12. Leyden.

- 1917, On Phoronis ovalis. Quart. Journ. micr. Sci. n. s. v. 62, p. 115-148 t. 7-9 London.

- 1923, On Cellularine and other Polyzoa. Journ. Linn. Soc. Zool. v. 35, p. 293-36I t. 16-19. London.

- 1926, The Polyzoa of the Siboga Exped. part 2 (Cheilostomata Anasca). Siboga Exped. v. 28b. p. 18|-50| t. 13-34. Leiden.

- 1930, Polyzoa. President. Address Proc. Linn. Soc. London 1928-1929, sess. 141, p. 68-118 t. 1. London.

- 1931, Recent work on Polyzoa, President. Address Proc. Linn. Soc. London 1930-1931, sess. 143, p. 1!3-168. London.

- 1934, The Po'yzoa of the Siboga Exped. part 3 (Cheilostomata Ascophora 1). Siboga Exped. v. 28c, p. 503-640 t. 35-4l. Leiden.

HASTINGS, A. B. 1927, Report on the Polyzoa of the Suez Canal. Transact. Zool. Soc. v. 22 part 3 no. 8, p. 331-354. London.

- 1930, Cheilostomatous Polyzoa from the... Panama Canal etc. Proc. Zool. Soc. London 1929, p. 697-740 t. 1-17. London.

- 1932, Polyzoa etc. Great Barrier Reef Exped. sci. Rep. v. 4 no. 12, p. 399-458 t. 1. London.

HATSCHEK, B. 1877, Embryonalentwicklung und Knospung der Pedicellina echinata. Zeitschr. wissensch. Zool. v. 29, p. 502-548 t. 28-30. Leipzig.

HEIDER, K. 1893, Bryozoa ectoprocta \& entoprocta. Korschelt \& Heider, Lehrb, vergl. Entwicklungsgesch. wirbellos. Thiere, Spec. Theil, v. 3, p. 1187-1265. Jena.

- 1897. Ist die Keimblätterlehre erschüttert? Zool. Centralblatt 4. Jahrg. 1897, p. 1-13 (no volume: p. 725-737). Leipzig. 
- 1909, Furchung und Keimblätterbildung: Ungeschlechtiche Fortpflanzung und Regeneration. Korschelt \& Heider, Lehrb. vergl. Entwicklungsgsch. wirbelloser Thiere, 1. \& 2. ${ }^{a}$ ed. Allgemeiner Theil $3 .^{\circ}$ fasc. p. 1-470; 47I-896. Jena.

- 1914, Phylogenie der Wirbellosen. Kultur der Gegenwart. 3. Teil 4. Abtlg. v. 4. p. 453-529. Leipzig \& Berlin.

- 1928, Entwicklungsgeschichte und Morphologie der Wirbellosen. Separ. de Kultur der Gegenwart 3. Teil 4. Abtlg. v. 2, 2. Hälfte 19/3, p. I-IV + 175-332. Leipzig \& Berlin.

HELLER, C. 1867, Die Bryozoen des Adriatischen Meeres. Verhandl. zool. bot. Ges. Wien v. 17, p. 77-136 t. 1-6. Wien.

HENNEGUY, F 1909, Sur un épithélium à fibres musculaires striées. C. R. Ac. Sci. v. 148, p. 134-138. Paris.

HERWIG, E. 1913, Beiträge zur Kenntnis der Knospung bei den Bryozoen. Arch. Naturgesch. 79. Jahrgang, Abtlg. A, fasc. 12, p. 1-24. Berlin.

- 1915, Die Avicularien von Bugula flabellata. Arch. Naturgesch. 81. Jährgang, Abtlg. A, fasc. 7, p. 156-159 I tab. Berlin.

HESSE, R. 1894, Zur vergleichenden Anatomie der Oligochaeten. Zeitschr. wissenschaftl. Zool. v. 58, p. $394-439$ t. 24-25. Leipzig.

- 1924, Tiergeographie auf oekologischer Grundlage. Jena.

- 1935, Tierbau und Tierleben etc. $2 .^{a}$ ed. de Hesse \& Doflein, Tierbau und Tierleben, v. I. Jena.

HINCKS, Th. 1880, A History of the British Marine Polyzoa. v. 1 (texto) v. 2 (estmp.) London.

- 1880a, Contributions towards a general History of the marine Polyzoa. Ann. Mag. Nat. Hist. ser. 5 v. 6, p. 376-384 t. 16-17. London.

- 1881. Contr. gen. Hist. Polyzoa. Ann. Mag. Nat. Hist. ser. 5 v. 7, p. $147-16 \mid$ t. 8-10. London.

- 1883, Report on the Polyzoa of the Queen Charlotte islands. Ann. Mag. Nat. Hist. ser. 5 v. II, p. $442-451$ t. 17-18. London.

- 1884, Rep. Polyzoa Queen Charlotte isl. Ann. Mag. Nat. Hist. ser. 5 v. 13, p. 49-58 t. 3-4; p. 203-215 t. 9. London.

- 1887, On the Polyzoa etc. of the Mergui Archipelago. Journ. Linn. Soc. London v. 21 . p. $121-135$ t. 12. London.

JANDER, R. 1897, Die Epithelverhältnisse im Tricladenpharynx. Zool. Jahrb. Anat. v. 10. p. 157-204 t. 13-15. Jena.

JELLY, E. C. 1889, A synonymic Catalogue of the recent marine Bryozoa. London.

JOHNSTON, G. 1847, A History of the British Zoophytes 2. ${ }^{a}$ ed. v. 1 (texto) v. 2 (est.). London.

JOLIET, L. 1877. Contributions à l'histoire des Bryozoaires des côtes c's France. Arch. zool, expér. v. 6. p. 193-304 (na separata: p. 1-112) t. 6-13. Paris.

- 1880, Organe segmentaire des Bryozoaires endoproctes. Arch. zool. expér. v. 8, p. 497-512 t. 39. Paris.

JULLIEN, J. 1888, Bryozoaires. Mission du Cap Horn v. 6, p. 1,1-1,92 t. 1-15. Paris. 
JULLIEN, J. \& CALVET, L. 1903, Bryozoaires... de I'Hirondelle. Rés. Camp. sci. Albert I. fasc. 23, p. 1-188 t. 1-18. Monaco.

KAHL, A. 1932, Ciliata (Infusoria). 3. Spirotricha. Dahl, Tierwelt Deutschlands, pars 25, p. 399-650. Jena.

KEFERSTEIN, W. 1862, Ueber Loxosoma singulare gen. ef sp. n., den Schmarotzer einer Annelide. Untersuchungen ueber niedere Seethiere. (copia de Zeitschr. wissensch. Zool. v. 12, fasc. 1) VI + 147 p. II tab. (Loxosoma p. 131-|32 t. II f. 29). Leipzig.

KIRKPATRICK, R. 1888, Polyzoa from Port Phillip. Ann. Mag. Nat. Hist. ser. 6 v. 2, p. $|2-2|$ t. 2. London.

- 1888a, Polyzoa. Zoology of Fernando Noronha. Journ. Linn. Soc. London v. 20, p. 504-506. London.

- 1888b, Polyzoa of Mauritius. Ann. Mag. Nat. Hist. ser. 6 v. I, p. 72-85 t. 7-10 London.

KIRKPATRICK, R. 1890, Report upon the Hydrozoa and Polyzoa... in the China sea. Ann. Mag. Nat. Hist. ser. 6 v. 5, p. 1I-24 t. 3-5. London.

KIRKPATRICK, R. \& METZELAAR, J. 1922, On an instance of commensalism between a hermit crab and a Polyzoon. Proc. Zool. London 1922, p. $983-990$ t. 1-2. London.

KLUGE, H. 1906, Ergänzungsbericht über die von der "Olga" - Expedition gesammelten Bryozoen. Wiss. Meeresunters. D. Meere v. \& Abtlg. Helgoland fasc. I, p. 31-55. Oldenburg.

- 1914, Die Bryozoen der deutsch. Südpolarexpedition, pars I. D. Südpolarexped. v. 15 (Zool. v. 7), p. 60I-678 t. 27-34. Berlin.

KORSCHELT. E. 1938, Cuticularsehne und Bindegewebssehne. Zeitschr. wissensch. Zool. v. 150, p. 494-526. Leipzig.

KORSCHELT, E. \& HEIDER, K. 1902-1903, Lehrb. vergl. Entwicklungsgesch. wirbell. Thiere. I.2 \& 2. ${ }^{n}$ ed. Allgem. Theil fasc. I \& 2, X +750p. Jena.

KOWALEWSKY, A. 1866, Beiträge zur Anatomie und Entwickelungsgeschichte des Loxosoma Neapolitanum sp. n. Mém. Ac. Impér. Sciences St. Pétersbourg 7. sér. v. 10 no. 2, p. 1-10 f. 1-11. St. Petersburg.

KRAEPELIN, K. 1887, Die deutschen Süsswasser-Bryozoen. I. Anat. system. Theil Abhandl.

Geb. Naturwissensch. (Naturw. Verein Hamburg) v. 10, p. 1-168 t. 1-7 Hamburg. KRUMBACH, Th. 1932, Kamptozoa und Branchiotremata des arktischen Gebietes. Fauna arct. v. 6, p. 81-92. Jena.

KUPELWIESER, H. 1905, Untersuchungen über den feineren Bau und die Metamorphose des Cyphonautes. Zoologica v. 19 fasc. 46, p. $1-50$ t. 1-5. Stuttgart.

LADEWIG, F. 1900, Über die Knospung der ektoprokten Bryozoen. Zeitschr. wissensch. Zool. v. 67, p. 323-339 t. 18. Leipzig.

LAMARCK, J. B. P A. de 1816, Histoire naturelle des animaux sans viertèbres. I." ed. v. 2. Paris.

LAMEERE, A. 1931, Bryozoaires. Précis de Zoologie v. 2, p. 295-324. Pâris.

LAMOUROUX, J. V. F 1816, Histoire des Polypiers coralligènes flexibles, vulgairement nommés Zoophytes. Caen. 
- 1821, Exposition méthodique des genres de l'ordre des Polypiers, etc. Paris.

- 1824, Corallina; or, a classical arrangement of flexible coralline Polypidoms. etc. London.

LANKESTER, E. R. 1885, Polyzoa. Encyclópaedia Britannica 9." ed. pars 73, p. 429-441. London.

LEBEDINSKY, J. 1905, Die Embryonalentwicklung der Pedicellina echinata Sars. Biol. Centralbl. v. 25, p. 536-548. Leipzig.

LEUNIS, J. 1886, Synopsis der Thierkunde $3 .^{\mathrm{a}}$ ed. (H. Ludwig) v. 2. Hannover.

LEVINSEN, G. M. R. 1894, Mosdyr. Zool. Danica v. 4 avdel. I, p. 1-105 t. 1-9. Köbenhavn.

- 1907, Sur la régéneration totale des Bryozoaires. Oversigt K. Danske Vidensk. Selsk. Forh. 1907 no. 4, p. I5I-|59 | tab. Käbenhavn.

- 1909, Morphological and systematic Studies on the Cheilostomatous Bryozoa. Copenhagen.

- 1916, Bryozoa, Endoprocta etc. Conspect. Faun. Groenlandiae. Medd. om Grönland v. 23, p. 547-634. Köbenhavn.

- 1925, Undersögelser over Bryozoerne i den Danske Kridtformation. Mém. Ac. K. Sci. Lettr. Danmark, sect. sciences, sér. 8 v. 7. p. 283-445 t. 1-8. Köbenhavn.

LINNE' C. 1758, Systema naturae, ed. 10 v. I. Holmiae.

LINNE' C. \& GMELIN, J. G. 1791, Systema nafurae, ed. 13 v. 1, pars 6. Lipsiae.

LIVINGSTONE, A. 1927, Studies on Australian Bryozoa, no. 5. Rec. Austr. Mus. v. 16 no. I, p. 50-69. Sydney.

LOHMANN, H. 1933, Appendiculariae. Kükenthal \& Krumbach, Handb. Zool. v. 5, pars 2. p. 1-202. Berlin \& Leipzig.

LOMAS, J. 1886, Report on the Polyzoa of the L. M. B. C. district. Liverpool mar. biol. Comm. Rep. n.' I. Proc. Lit. Phil. Soc. Liverp. v. 40 Appendix, p. 161-200 t. 3 Liverpool.

MACBRIDE, E. W. 1914, Text-Book of Embryology. v. I. Invertebrata. London.

MACGILlivRAY, P. H. 1880, Polyzoa. McCoy, Prodr. Zool. Victoria v. I dec. 5, p. 27-52 t. 45-49. Melbourne \& London.

- 1887, A Catalogue of the Marine Polyzoa of Victoria. Tr. Proc. R. Soc. Vict. v. 23, p. 187.224. Melbourne.

- 1887a, Polyzoa. Mc Coy, Prodr. Zool. Victoria v. 2 dec. 15, p. 173-188 t. 146-148. Melbourne.

- 1888, Polyzoa. Mc Coy, Prodr. Zool. Victoria v. 2 dec. 17, p, 241-253 t. 165-168. Melbourne.

- 1889, Polyzoa. Mc Coy, Prodr. Zool. Victoria v. 2 dec. 19, p. 307-323 t. 185-187. Melbourne \& London.

- 1895, A Monograph of the Tertiary Polyzoa of Victoiia. Tr. R. Soc. Victoria, v. 4. p. 1-166 t. 1-22. Melbourne.

MARCUS, E. 1921, Bryozoen von den Auckland- und Campbell-Inseln. Videnskäbei. Meddel. Dansk Naturhistor. Foren. v. 73, p. 85-121 t. 5. Köbenhavn.

-. 1922, Bryozoen von den Aru-Inseln. Abhandl. Senckerib. naturf. Ges. v. 35, p. 421-446 t. 24-25. Frankfurt. 
- 1925, Ueber Stirpariella mortenseni und das Genus Stirpariella. Videnskabel. Meddel. Dansk Naturhistor. Foren. v. 81, p. 37-55. Köbenhavn.

- 1926, Bryozoa. Grimpe \& Wagler, Tierwelt Nord- und Ostsee pars 7c, p. 1-100. Leipzig.

- 1926a, Beobachtungen und Versuche an lebenden Meeresbryozoen. Zool. Jahrb. Syst. v. 52, p. 1-102 †. 1-2. Jena.

- 1926b, Beobachtungen und Versuche an lebenden Süsswasserbryozoen. Zool. Jahrb. Syst. v. 52, p. 279-350 t. 6. Jena.

- 1927, Zur Oekologie und Physiologie der Tardigraden. Zool. Jahrb. Phys. v. 44. p. 323-370. Jena.

- 1934, Ueber Lophopus crystallinus (Pall.). Zool. Jahrb. Anat. v. 58, p. 50I-606. Jena.

- 1937. Bryozoarios marinhos brasileiros 1. Bol. Fac. Phil. Sc. Letr. Univ. S. Paulo v. I Zool. I, p. I-224 t. I-29. São Paulo.

- 1937a, Bryozoen von St. Helena. Videnskabel. Meddel. Dansk Naturhistor. Foren. v. 101, p. 183-252. Köbenhavn.

- 1938, Bryozoarios marinhos brasileiros II. Bol. Fac. Phil. Sc. Letr. Univ. S. Paulo v. 4, Zool. no. 2, p. 1-196 †. 1-29. S. Paulo.

- 1938a, Sobre o systema zoologico. Filosof., Ciências e Letras, ano 3 no. 6. p. 55-84. São Paulo.

- 1938b, Bryozoarios perfuradores de conchas. Arch. Inst. Biol. v. 9, p. 273-296. São Paulo.

MAXIMOW, A \& BLOOM, W. 1938, A textbook of Histology. 3. a ed. Philadelphia \& London. MEISENHEIMER, J. 1901, Entwicklungsgeschichte von Dreissensia polymorpha Pall. Zeitschr. wissenschaft. Zool. v. 69, p. 1-137 t. 1-13. Leipzig.

- 1910, Die Exkretionsorgane der wirbellosen Tiere. Ergebn. \& Fortschr. Zool. v. 2, p. 275-366. Jena.

MILNE EDWARDS, H. 1836, Recherches anatomiques, physiologiques et zoologiques sur les Eschares. Ann. sci. nat. sér. 2 v. 6 (Zool.). p. 5-53 t. I-5. Paris.

MORTENSEN, Th. 1911, A new speciẹs of Entoprocta, Loxosomella antedonis from $\mathrm{N}$. -E-Greenland. Meddel. Grönl. v. 45 no. 7 (Danm.-Eksped. Grönl. 1906-1908 v. 5 no. 8), p. $399-406$ t. 26 . Köbenhavn.

MOLLER, A. 19/4, Histologie des Darmtraktes und Spermatogenese der Plumatella polymorpha Krpl. Festschr. Siebenbürg. Ver. Naturw. Hermannstadt v. 65, p. 34-48 t. 1-2. Hermannstadt.

NEVIANI, A. 1939, I Briozoi Adriatici del Museo Civico di Storia Naturale di Venezia. Mem. R. Ist. Venet. Sci. Let. Art. v. 30 no. 4 p. |-|3| t. |-5. Venezia.

NICHOLS, A. R. 1911, Polyzoa from the coasts of Ireland. Fish. Ireland Sci. Invest. 1910 no. I, p. I-37 t. I. Dublin.

NICKERSON, W. S. 1901, On Loxosoma davenporti (sp. nov.). Journ. Morphol. v. 17, p. 351-380 (citado segundo Atkins 1932, p. 391).

NICKLES, J. M. \& BASSLER, R. S. 1900, A Synopsis of American Fossil Bryozoa, etc. Bull. U. S. Geol. Survey no. 173, p. 1-663. Washington. 
NITSCHE, H. 1868, Beiträge zur Anatomie und Entwickelungsgeschichte der Phylactolaemen Süsswasserbryozoen etc. Inaugur. Dissert. p. 1-57 t. 1-4. Berlin.

- 1869, Beiträge zur Kenntniss der Bryozoen. 1-2. Zeitschr. wissenschaftl. Zool. v. 20, p. 1 -36 t. 1-3. Leipzig.

- 1871. Beiträge zur Kenntniss der Bryozoen. 3. Zeitschr. wissenschaftl. Zool. v. 21 , p. 416-470 (p. $1-55$ da separata) t. 25-27 (t. 1-3 da separata). Leipzig.

- 1871a, Beiträge zur Kenntniss der Bryozoen. 4. Zeitschr. wissenschaftl. Zool. v. 2I، p. $471-498$ (p. 56-83 da separata). Leipzig.

- 1876, Beiträge zur Kenntniss der Bryozoen. 5. Zeitschr. wissenschaftl. Zool. v. 25, Suppl. (Festschr. J. F. v. Brandt), p. 343-402 (p. |2|-180 da separata) t. 24-26. Leipzig.

NORDGAARD, O. 1896, Systematisk Fortegnelse over de i Norge hidtil observerede Arter af marine Polyzoa. II. Cyclostomata. Berg. Mus. Aarbog for 1896 no. 2, p. I-6. Bergen.

- 1905, Bryozoa or Polyzoa. Hydr. \& Biol. Inv. Norweg. Fjords, p. 164-174 t. 3-5. Bergen.

- 1906, Die Bryozoen des westlichen Norwegens. Appellöf, Meeresfauna Bergen fasc. 2. p. 73-112 t. 1-2. Bergen.

- 1906a, Bryozoa from the second "Fram" Expedition. Rep. 2. Norw. Arct. Exped, v. 2 no. 8, p. 1-44 t. I-4. Christiania.

- 912, Revision av Universitetsmuseets Samling av norske Bryozoer. K. Norsk. Vidensk. Selsk. Skrift. 1911 no. 3, p. 1-27. Trondhjem.

- 1918, Bryozoa from the arctic negions. Tromsö Mus. Aarsh. v. 40 (1917) n.o 1. p. 1-99. Trondhiem.

- 1927, Bryozoa. Grönlie, O. T. \& Soot-Ryen, T., The Folden Ficrd. Tromsä Mus. Skrift. v. I pars 9, p. I-10. Tromsö.

NORMAN, A. M. 1903, Notes on the natural history of East Finmark. Ann. Mag. Nat, Hist. ser. 7 v. 11, p. 567-598 t. 13; ibid. v. 12, p. 87-128 t. 8-9. London.

- 1906. Greenlandic Polyzoa. Ann. Mag. Nat. Hist ser. 7 v. 17, p. 90-93. London.

- 1909, The Polyzoa of Madeira etc. Journ. Linn. Soc. London, Zocl. v. 30 p. 275314 t. 33-42. London.

NUSBAUM. J. \& OXNER. M. 1913, Die Embryonalentwicklung des Lineus ruber. Zeitschr. wissenschaftl. Zool. v. 107, p. 78-197 t. 1-8. Leipzig.

O'DONOGHUE, C. H. \& E. 1923, A preliminary list of Bryozoa (Polyzoa) from the Vancouver island region. Contr. Canad. Biol. Fish. n. s. v. I, p. 143-201 t. I-4. Toronto.

- 1924, The Bryozoa (Polyzoa) collected by the S S. "Pickle" Un. South Afr. Fish. mar. Survey Rep. no. 3 (1922) no. 10, p. 1-63 t. 1-4. Capetown.

- 1925, List of Bryozoa from the vicinity of Puget Sound. Publ. Puget Sound mar. Biol. Stat. v. 5, p. 91-108. Washington.

- 1926, A second list of Bryozoa (Polyzoa) from the Vancouver island region. Contr. Canad. Biol. Fish. n. s. v. 3 no. 3, p. 49-131 t. I-5. Toronto.

O'DONOGHUE, C. H. \& DE WATTEVILLE, D. 1935, A collection of Bryozoa from South. Africa. Journ. Linn. Soc. London, Zool. v. 39, p. 203-218 t. 5-6. London.

OKA, A. |891, Observations on Fresh-Water Polyzoa. Journ. Coll. Sci. Univ. Japan v. 4 part. I, p. 89-150 t. 17-20. Tokyo. 
OKADA, Y. 1925, Alcyonidium (Paralcyonidium) vermiculare etc. Annot. Zool. Jap. v. 10, p. 28I-284. Tokyo.

OSBURN, R. C. 1912, The Bryozoa of the Woods Hole region. Bull. Bur. Fish. v. $30(1910)$. p. 203-266 t. 18-31. Washington, D. C.

OSBURN, R. C. 1914, The Bryozoa of the Tortugas islands, Florida. Publ. Carnegie Inst. Washingt. no. 182, p. 181-222. Washington, D. C.

- 1927, The Bryozoa of Curaçao. Bijdr. Dierkunde v. 25, p. 123-132. Amsterdam.

OSTROOUMOFF, A. 1885, Note sur la métamorphose du Cyphonautes. Zool. Anz. v. 8. p. 219. Leipzig.

PACE, R. M. 1906, On the early stages in the development of Flustrella hispida (Fabr.) etc. Quart. Journ. micr. Sci. n. ser. v. 50, p. 435-478 t. 23-25. London.

PALLAS, P S. 1774, Spicilegia zoologica, quibus novae imprimis et obscurae animalium species iconibus descript. atque commentariis illustrantur. v. I fasc. 1-10 t. 1-43 (1767-1774). Berlin.

PALTSCHIKOWA-OSTROUMOWA, M. W. 1925, Kurze Bemerkung über den Ovidukt bei Bryozoen. Zool. Anz. v. 65, p. 100-102. Leipzig.

PARKER, T .J. \& HASWELL, W. A. 1930, A Text-Book of Zoology. 5. a ed. v. I. London.

PENNERS, A. 1929, Entwicklungsgeschichtliche Untersuchungen an marinen Oligochaeten I. Zeitschr. wissenschaftl. Zool. v. 134, p. 307-344. Leipzig.

- 1930, Entwicklungsgeschichtliche Untersuchungen an marinen Oligochaeten II. Zeitschr. wissenschaftl. Zool. v. 137, p. 55-119. Leipzig.

PERGENS, E. 1889, Untersuchungen an Seebryozoen. Zool. Anz. v. 12, p. 504-510, 526-533. Leipzig.

PHILIPPS, E. G. 1900, Report on the Polyzoa... Loyalty islands, New Guinea and New Britain. Willey, Zool. Res. v. 4, p. 439-450 t. 42-43. Cambridge.

PRENANT, M. 1922, Recherches sur le parenchyme des Plathelminthes. Arch. Morph. gén. expér. v. 5, p. 1-175 t. 1-8 (separata). Paris.

- 1931, Sur une collection de Bryozoaires de la mer du Nord. etc. Bull. Mus. Hist. Nat. Belgique v. 7, no. 17, p. 1-6. Bruxelles.

PRENANT, M. \& TEISSIER, G. 1924, Notes éthologiques sur la faune marine sessile etc. Trav. Stat. Biol. Roscoff fasc. 2, p. 1-49. Paris.

PROUHO, H. 189I, Contribution à I'histoire des Loxosomes etc. Arch. Z̈ool. ex. sér. 2 v. 9. p. 91-116 t. 5. Paris.

- 1892, Contribution à I'histoire des Bryozoaires. Arch. Zool. exp. sér. 2 v. 10, p. 557-656 t. 23-30. Paris.

RAUTHER, M. 1930, Nematodes. Kükenthal-Krumbach, Handb. Zool. v. 2 pars 1 fasc. 8, p. (4) 249-(4) 402. Berlin \& Leipzig.

REMANE, A. 1926, Morphologie... der aberranten Gastrotrichen I. Zeitschr. Morphol. Oek. v. 5, p. 625-754. Berlin.

- 1929, Rotatoria. Grimpe \& Wagler, Tierwelt Nord \& Ostsee pars 7e, p. 1-156. Leipzig.

- 1929a, Kinorhyncha (Echinodera). Kükenthal-Krumbach. Handb. Zool. v. 2 pars ! fasc. 6, p. (4) 187-(4) 248. Berlin \& Leipzig. 
- 1932, Rotatoria. Bronn, Klassen \& Ordn. Tierreichs v. 4 pars 2, 1.: livro fasc. 2. p. 161-288. Leipzig.

- 1935, Gastrotricha. Bronn, Klassen \& Ordn. Tierreichs v. 4 pars 2, 1. livro 2." sec. fasc. 1, p. 1-160. Leipzig.

REPIACHOFF, W. 1875, Zur Entwicklungsgeschichte der Tendra zostericola. Zeitschr. wissenschaftl. Zool. v. 25, p. 129-142 †. 7-9. Leipzig.

- 1876, Zur Naturgeschichte der Chilostomen Seebryozoen. Zeitschr. wissenschaftl. Zool. v. 26, p. 139-160 t. 6-9. Leipzig.

RETZrUS, G. 1905, Das sensible Nervensystem der Bryozoen. Biol. Unters. neue Folge v. 12, p. 49-54 t. I. Stockholm.

ROBERT, A. 1903, Recherches sur le développement des Troques. Arch. Zool. exp. sér. 3 v. 10, p. $269-538$ t. 19-42. Paris.

ROBERTSON, A. 1900, The Bryozoa. Pap. Harriman Alaska Exped. no. 6. Proc. Washington Acad. Sci. v. 2, p. 315-340 t. 19-21. Washington, D. C.

- 1900a, Studies in Pacific Coast Entoprocta. Proc. Ca. Ac. Sci. ser. 3, Zool. v 2, p. 323-348 t. 16. San Francisco.

- 1908, The incrusting Chilostomatous Bryozoa of the west coast of North America. Univ. Calif. Publ. Zool. v. 2 no. 5, p. 235-322 t. 4-16. Berkeley.

- 1921, Report on a collection of Bryozoa from the bay of Bengal, etc. Rec. Ind. Mus. v. 22 part I no. 8, p. 33-65. Calcutta.

ROEHRICH, O 1910, Description d'un Alcyonidium nouveau (A. topsenti, n. sp.) Arch. Zool. exp. sér. 5 v. 5, Notes et Rev., p. 164-167 f. I-3. Paris.

ROEMER, O. 1906, Untersuchungen über die Knospung. Bryozoen. Zeitschr. wissenschaftl. Zool. v. 84, p. $446-478$ †. 20-21. Leipzig.

SAKAKURA, K. 1935, Pliocene and pleistocene Bryozoa from the Bôsô Peninsula I. Journ. Fac. Sci. Tokyo sect. 2 v. 4 part I, p. 1-48 t. 1-7. Tokyo.

SALENSKY, W. 1874, Untersuchungen an Seebryozoen. Zeitschr. wissenschaftl. Zool. v. 24, p. 343-348 t. 32 f. 1-3. Leipzig.

- 1877, Etudes sur les Bryozoaires Entoproctes. Ann. Sci. nat. Zool. sér. 6 v. 5, p. 27-60 t. 12-15. Paris.

SARS, M. 1835, Beskrivelser og lagtagelser over nogle maerkelige... Dyr etc. 81 p. 15 tab. Bergen.

SAUNDERS, A M. C. \& POOLE, M. 1910, The development of Aplysia punctata. Quart. Journ. micr. Sci. n. s. v. 55, p. 497-540 t. 22 . London.

SCHMIDT, O. 1876, Die Gattung Loxosoma. Arch. mikr. Anat. v. 12, p. I-14 t. 1-3. Bonn.

- 1878, Bemerkungen zu den Arbeiten über Loxosoma. Zeitschr. wissenschaftl. Zool. v. 31, p. 68-80. Leipzig.

SCHMIDT, W. J. 1924, Die Bausteine des Tierkörpers in polarisiertem Lichte. Bonn.

SCHNEIDER, K. C. 1902, Lehrbuch der vergleichenden Histologie der Tiere. Jena.

SCHULZ, K. 1901, Untersuchungen über den Bau der Bryozoen etc. Arch. Naturgesch. 67. Jahrgang v. I, p. II5-144 t. 6-7. Berlin.

SCHULZE, P. 1924, Der Nachweis und die Verbreitung des Chitins etc. Zeitschr. Morph. Oekol. v. 2. p. 643-666. Berlin. 
SCRIBAN, J. A. 1907. Notes histologiques sur les Hirudinées, Arch. Zool. exp. sér. 4 v. 7. p. 397-421. Paris.

SEELIGER, O. 1889, Die ungeschlechtliche Vermehrung der endoprokten Bryozoen. Zeitschr. wissenschaftl. Zool. v. 49, p. 168-208 t. 9-10. Leipzig.

- 1890, Bemerkungen zur Knospenentwicklung der Bryozoen. Zeitschr. wissenschaffl. Zool. v. 50, p. 560-599 t. 25-26. Leipzig.

- 1906, Ueber die Larven und Verwandtschaftsbeziehungen der Bryozoen. Zeitschr. wissenschaftl. Zool. v. 84, p. 1-78 t. I-4. Leipzig.

SHEARER, C. 1911, On the development and structure of the Trochophore of Hydroides uncinatus (Eupomatus). Quart. Journ. micr. Sci. n. s. v. 56, p. 543-590 t. 21-23. London.

SILBERMANN, S. 1906, Untersuchungen über den feineren Bau von Alcyonidium mytili. Arch. Naturgesch. 72. Jahrg. v. I, p. 265-310 t. 19-20. Berlin.

SILÉN, L. 1938, Zur Kenntnis des Polymorphismus der Bryozoen. Zool. Bidr. Uppsala v. 17. p. 149-366 t. 1-18. Uppsala.

SMITT, F. A. 1863, Bidrag till kännedommen on Hafs-Bryozoernas utveckling. Uppsala Univ. Aarsskrift 1863, p. 1-40. Uppsala.

- 1865, Om Hafs-Bryozoernas utveckling och fettkroppar. Ofvers. K. Vetensk. Ak. Handl. v. 22, p. 5-50 t. 7-7. Stockholm.

- 1865a, Kritisk Förteckning öfver Skandinaviens Hafs-Bryozoer. Ôfvers. K. Vetensk. Ak. Handl. v. 22, p. 115-142 (1866) t. 16. Stockholm

- 1867a, Kritisk Förteckning öfver Skandinaviens Hafs-Bryozoer. Ōfvers. K. Vetensk. Ak, Handl. v. 24, p. 279-429 t. 16-20. Stockholm.

- 1867, Kritisk Förteckning öfver Skandinaviens Hafs-Bryozoer. Ôfver. K. Vetensk. Ak. Handl. v. 24 Bihang, p. 3-230 t. 24-28. Stockholm.

- 1873, Floridan Bryozoa collected by Count L. F. de Pourtales. Part. II. K. Svensk. Vetensk. Ak. Handl. v. II no. 4, p. I-83 t. I-13. Stockholm.

SNODGRASS, R. E. 1938, Evolution of the Annelida, Onychophora and Arthropoda. Smithson. Miscell. Collect. v. 97 no. 6 p. I-I59. Washington, D. C.

StebBing, T. R. and others 1911, The terms Polyzoa and Bryozoa. Proc. Linn. Soc. London sess. 123 (1910-1911), p. 61-72. London.

STIASNY, G. 1904, Beitrag zur Kenntnis des Exkretionsapparates der Entoprocta. Arb. Zool. Inst. Wien v. 15, p. 183-196 t. 13 (1905). Wien.

SURFACE, F. M. 1907, The early development of a Polyclad, Planocera inquilina Wh. Proc. Ac. Nat. Sci. Philadelphia, p. 5/4-559 t. 35-40. Philadelphia.

Thornely, L. R. 1905, Report on the Polyzoa... at Ceylon. Herdman, Rep. Ceylon Pearl Oyster Fish. v. 4 Suppl. Rep. no. 26, p. 107-130 t. (1)i corrections: v. 5 no. 6 , p. 449-450. London.

- 1907, Report on the marine Polyzoa in the collection of the Indian Museum. Rec. Ind. Mus. 'v. I no. 13, p. 179-196. Calcutta.

VERRILL, A. E. 1873, Report upon the Invertebrate animals of Vinieyard Sound etc. U. S. Fish. Comm. Rep. 187/-1872; Bryozoa p. 707-7/4 t. 33-34. Washington, D. C.

VIGELIUS, W. J. 1884, Die Bryozoen... 3. \& 4. Polarfahrt des "Willem Barents" etc. Bijdr. Dierk. v. II, p. 1-104 t. I-8. Amsterdam. 
VOGT, C. 1876, Sur le Loxosome des Phascolosomes (Loxosoma phascoloscmatum). Arch. Zool. exp. v. 5, p. 305-356 t. 11-14. Paris.

WATERS, A. W. 1879, On the Bryozoa (polyzoa) of the bay of Naples. Ann. Mag. Nat. Hist. ser. 5 v. 3, p. 28-43; ||4-126; 192-202; 267-28| t. 8-II; 12-15-23-24. London.

- 1881, On Fossil Chilostomatous Bryozoa from South-west Victoria, Australia. Qu. J. Geol. Soc. v. 37, p. 309-347 t. 14-18. London.

- 1885, On the use of the avicularian mandible in the determination of the Chilostomatous Bryozoa. Journ. R. micr. Soc. ser. 2 v. 5, no. 17, p. 1-6 t. 14. London.

- 1887, On Tertiary Cyclostomatous Bryozoa from New Zealand. Quart. Journ. Geol. Soc. London v. 43, p. 337-350 t. 18. London.

- 1887a, Bryozoa from New South Wales, North Australia, etc. Ann. Mag. Nat. Hist. ser. 5 v. 20 , p. $81-95 ; 181-203 ; 253-265$ t. $4-7$. London.

- 1888, Supplementary Report on the Polyzoa... "Challenger" etc. Rep. Zool. Chall. Exped. v. 31 part 79, p. 1-41 t. 1-3. London.

- 1889. Bryozoa from New South Wales. Part 4. Ann. Mag. Nat. Hist. ser $6 \vee 4$. p. 1-24 t. 1-3. London.

- 1892, Observations on the gland-like bodies in the Bryozoa. Journ. Linn. Soc. London Zool. v. 24 (1894), p. 272-278 t. 19. London.

- 1896, Notes on Bryozoa from Rapallo etc. Journ. Linn. Soc. London Zool. v. 26, p. $|-2|$ t. $\mid-2$. London.

-- 1898, Observations on Membraniporidae. Journ. Linn. Soc. London. Zool. v. 26, p. 654-693 t. 47-49. London.

- 1899, Bryozoa from Madeira. Journ R. micr. Soc. 1899, p. 6-16 t. 3. London.

- 1900, Bryozoa from Franz-Josef Land etc. Journ. Linn. Soc. London Zool. v. 28, p. 43-105 t. 7-12. London.

- 1904, Bryozoa, Expéd. antarct. Belge, p. 1-114 t. 1-9. Anvers.

- 1904a, Bryozoa from Franz-Josef Land etc. Part II. Journ. Linn. Soc. London Zool. v. 29. p. 161-184 t. 19-21. London.

- 1905, Notes on some recent Bryozoa in d'Orbigny's collection. Ann. Mag. Nat. Hist. ser. 7 v. 15, p. 1-16 t. I. London.

- 1909, The Bryozoa, part 1: Cheilostomata. Rep. Sudanese Red Sea etc. Journ. Linn. Soc. London Zool. v. 31, p. 123-181 t. 10-18. London.

- 1910, The Bryozoa, part 11: Cyclostomata, Ctenostomata and Endoprocta. Journ. Linn. Soc. Zool. v. 31, p. 23I-256 t. 24-25. London.

- 1912, A structure in Adeonella etc. Ann. Mag. Nat. Hist. ser. 8 v. 9, p. 489-500 t. 10-11. London.

- 1913, Bryozoa - Cheilostomata. Marine Fauna of Brit. East Africa and Zanzibar etc. Proc. Zool. Soc. London 1913, p. 458-537 t. 64-73. London.

- 1914, Bryozoa - Cyclostomata, Ctenostomata and Endoprocta. Proc. Zool. Soc. London 1914, p. $831-858$ t. 1-4. London.

- 1918, Bryozoa, Collect. Littoral Marine Fauna of the Cape Veide Islands, made by Crril Crossland. Journ. Linn. Soc. London Zool. v. 34, p. I-44. t. 1-4. Londsn. 
- 1921, Observations upon the Relationships of the (Bryozoa) Selenariadae, etc. Journ. Linn. Soc. London Zool. v. 34, p. 399-427 t. 29-30. London.

- 1925, Ancestrulae of Cheilostomatous Bryozoa. Part 111. Ann. Mag. Nat. Hist. ser. 9 v. 16, p. 529-545 t. 28-29. London.

WEBER, H. 1933, Lehrbuch der Entomologie. Jena.

WHITELEGGE, T. 1889, List of the marine and fresh water Invertebrate fauna of Port Jackson etc. Journ. Proc, R. Soc. N. S. Wales v. 23, p. 163-323 (Bryozoa: p. 2822931. Sydney.

WILSON, Ch. B. 1900, The habits and early development of Cerebratulus lacteus (Verr.). Quart. Journ. micr. Sci. n. s. v. 43, p. 97-198 t. 9-11. London.

WILSON, E. B. 1898, Considerations on cell-lineage and ancestral reminiscence etc. Ann. New York Ac. Sci. v. 11 no. I, p. 1-27. New York.

- 1934, The Cell in Development and Heredity. 3. ${ }^{\circ}$ ed. New York.

ZERNECKE, E. 1895, Untersuchungen über den feineren Bau der Cestoden. Zool. Jahrb. Anat. v. 9, p. 92-161 t. 8-15. Jena.

ZSCHIESCHE, A. 1909, Untersuchungen über die Metamorphose von Alcyonidium mytili. Zool. Jahrb. Anat. v. 28, p. 1-72 t. 1-5. Jena. 


\section{E.}

\section{REGISTRO DOS NOMES DOS GENEROS E DAS ESPECIES}

Os algarismos em negritos indicam as respectivas paginas nas quaes começam as diagnoses. Não havendo taes algarismos trata-se de uma especie que apparece nas listas dos synonymos, nas discussões systematicas ou na parte geral.

abyssicola, Sarsiflustra 186

Adeona 147

aegyptiacum, Synnotum 183, 191, 193, 194, 198, 201, 203, 204, 205

Aetea 137

alatus, Loxocalyx 117

albidum, Alcyonidium 162, 166

albirostris, Holoporella 160, 161

Alcyonidium 162

alvẹolata, Buguila 180

Amathia 180, 271

americana, Hippodiplosia 185, 192, 206

anatirostris, Mucronella 159

anguina, Aetea 113, 182

annelidicola, Loxosoma 118

annulatum, Loxosoma 118

antarcticum, Alcyonidium 166

Antropora 186, 187

apiculata, Holoporella 159

arctata, Acanthodesia 186, 187

arctica, Hippothoa divaricata var. 136 armata, Biflustra 204

armata, Buskia 168

armata, Caulibugula 203

Ascopodaria 210

athleticus, Chitaspis 122

atlantica, Holoporella mamillata var. I6!

atlantica, Idmonea 113, 114

auriculata, Schizomavella 206

avicularia, Bugula 177, 191, 194 175, 198

Barentsia 175, 210, 222

barleei, Flustra 191

belgica, Barentsia 211

bellula, Electra 113, 182

benedeni, Barentsia 211, 212, :15, ilb; $218,224,225$

bicornis, Bugula 204

Biflustra 204

birostrata, Dendrobeania 191, 193, 200. 201, 207 
boryi, Caberea 194

Bowerbankia I/4, 27I

brucei, Alcyonidium 165

Bugula 199, 202

bursaria, Epistomia 194

Buskia 167

buskii, Steganoporella 187

Caberea 183, 187, 194

californica, Microporella 146

capensis, Holoporella 159

carbasea, Carbasea 204

carinata, Hippothoa divaricata f. 136

carvalhoi, Holoporella 158, 185, 206

carvalhoi, Schizoporella 204, 27I

Catenicella 270

caudata, Bowerbankia 1/4

Caulibugula 203, 207

Cellaria 134, 186, 270

cellarioides, Alcyonidium 166

cernua, Pedicellina 175, 210 e seg.

cervicornis, Alcyonidium 165

cervicornis, Porella 175

cervicornis, Scrupocellaria 183

chelata, Scruparia 270

Chitaspis 122

chondroides, Alcyonidium 166

ciliata, Bicellariella 203

ciliata, Microporella 189, 200, 205, 207, 208

ciliata var. coronata, Microporella 146

cirriferum, Loxosoma 118

claviforme, Loxosoma 209

cocciforme, Loxosoma 119

cochlear, Loxocalyx 117

colonialis, Loxosomatoides 121, 211

columbianum, Alcyonidium 166

commensale, Conopeum 126, 172

conferta, Hippothoa divaricata f. 135

Conopeum 126, 189

contei, Catenicella 1|3, 137, 270

confracta, Perigastrella 205

corniculata, Flustrella 165

cornigera, Scrupocellaria 183

coronata, Microporella ciliata var. 146

costazii, Siniopelta 157, 172, 195, 197-199,

206, 207

costifera, Escharoides 113

crassicauda, Loxosoma 118, 210, 249

Crassimarginatella 269

Crepis 185

Cristatella 177, 178

crustulenta, Electra 177

crystallinus, Lophopus 178

cucullata, Watersipora 189

Cupularia 192

Cylindroecium 168

davenporti, Loxosoma 119, 209

decussata, Crepis 185

Dendrobeania 191, 199, 200 denticulata, Membranipora 129

descostilsii, Holoporella 159

diadema, Scrupocellaria 183

dichotoma, Cellepora 156

dilatata, Nolella I/4

diota, Siniopelta 156, 157, 206

disciforme, Alcyonidium 166

discreta, Barentsia 175, 210, 211 214, 217.

$218,220,224,225$

disjunctum, Alcyonidium 166

distans, Amathia 181

distans, Hippothoa 136

ditrupae, Bugula 194, 198, 199, 200

ditrupae, Spathipora 172

divaricata, Hippothoa II3, I34

dizodoensis, Thalamoporella 131

duplex, Alcyonidium 164, 166

dutertrei, Mastigophora I43

eburnea, Gemellipora 141

echinata, Pedicellina 212

effusum, Alcyonidium 166

elegans, Vittaticella 194, 198, 205, 207

elmwoodiae, Schizoporella 140

erectorostris, Holoporella 159

Escharina 138

evelinae, Arachnoidea 121

evelinae, Loxosomatoides 120, 212, 214

evelinae, Thalamoporella 129, 182, 270

excavatum, Alcyonidium 166

expansa, Hypophorella 176

Farcimia 134

Farrella 168, 176

feegeensis, Hippopodina I/4

fibrosum, Arachnidium 162

firmata, Mimosella verticillata var. 1/4, 171, 180

fissa, Adeona |5|

flabellata, Bugula 180, 194

flabelliforme, Alcyonidium 166

flagellum, Hippothoa 136

Flustra 186, 191, 193

Flustrella 165, 182, 243, 269

flustrelloides, Alcyonidium 165

flustroides, Alcyonidium 166

foliacea, Flustra 186, 191, 196, 197, 198

foliacea, Mastigophora dutertrei var. I44

Fredericella 177, 178

fungosa, Plumatella 165, 176, 179

fusca, Membranipora 129

gelatinosa, Pectinatella 177

gelatinosum, Alcyonidium 163, 166

Gemelliporina 140

gigantea, Nolella ||4, 27|

glabra, Gemelliporina 113, 140

glabra, Pedicellina $2 / 2$

gorgonensis, Hippoporella 172, 27|

gothica var. prominens, Thalamoporella 130 
gracilis, Barentsia 211,214, 215,216, 218 , 225

gracilis, Urnatella 173, 208

grandicella. Mastigophora 144

granulifera, Antropora 186

harmeri, Thalamoporella 130

hauffi, Alcyonidium 164

heckeli, Adeona 150

hirsuta, Pedicellina $2 / 2$

hirsutum, Alcyonidium 166, 180

hispida, Flustrella 182, 243

Holoporella $\mathbf{1 5 8}$

honolulensis, Mastigophora 144

horsti, Schizoporella 139, 185, 206

hosteensis, Lacerna 140

hyadesi, Membranipora 128

hyalina, Hippothoa 136

hyndmanni, Mastigophora 144

Idmonea 1/3, I/4

imbellis, Holoporella 161

insidiosa, Adeona violacea var. 149

intermedia, Beania 113, 182, 191, 193, 194,

198-202, 206

Kinetoskias 180

krampi, Escharina 138

Lacerna 139

laevis, Loxosomatoides 121

lafontii, Savignyella 195, 207, 27I

lanceolata, Hippothoa 137

langei, Siniopelta 155, 172

laxa, Barentsia 212, 213, 214

lendigera, Amathia 271

leptoclini, Loxocalyx 117, 228, 237

leucocypha, Crassimarginatella 172, 182,

183, 185, 187-191, 193, 197, 198, 208,

269

lineare, Alcyonidium 162, 165

linearis, Thalamoporella 131

lineatus, Loxocalyx 117

lioticha, Thalamoporella 130, 190, 191

Liriozoa 138

longicauda, Hippothoa 137

longirostre, Rhynchozoon 154

longirostris, Exochella 172

Lophopus 178, 219, 266

lorica, Scuticella 194, 198, 205, 207

loricatum, Loxosoma 119

lowei, Cupularia 192

loxa, Smittina trispinosa var. 144

loxalinum, Loxosoma 119, 209

Loxocalyx 115

Loxosoma 117, 208, 215, 222, 225, 238, 241,259

Loxosomatoides $120,211,212$

Loxosomella 209 macropus, Barentsia 175, 210

magellanica, Beania 200, 202, 203

magnifica, Holoporella 159, 161

magnilabris, Steganoporella 187

magnirostris, Cellepora 159

maior, Barentsia 2II

major, Stomatopora 1/3, 123

mamillata var. atlantica, Holopo:ella 161

mamillatum, Alcyonidium 162, 166, 172, 180

marginella, Antropora 186

Mastigophora 142

membranacea, Membranipora 126, 176

membranaceo-truncata, Flustra 176, 191, 194

Membranipora 125

inicroporella 146

mirabilis, Beania 182

mordax, Holoporella 198, 206

mortenseni, Caulibugula 203

mucedo, Cristatella 177, 178

murrayana, Dendrobeania $191 \quad 193 \quad 199$, 205

mytili, Alcyonidium 163, 165

nannoda, Pedicellina 214,215, 217

nasutum, Rhynchozoon 155

neapolitanus, Loxocalyx 117, 208

Nellia |3|

nelliiformis, Acanthodesia 186. .37

neritina, Bugula 120,121

nitens, Buskia 167

nitschei, Loxosoma 119

Nolella 269, 27I

obesum, Loxosoma 119, 216, 222

obliqua, Adeona 151

oculata, Nellia 113, 126, 131

ofto-mülleriana var, parva, Hippodiplosia 172

pallasiana, Hippodiplosia 182

Paludicella 176, 192, 27|

papillatum, Alcyonidium 166

papyrea, Flustra 204

Paralcyonidium 166

parasiticum, Alcyonidium 166

parva, Hippodiplosia ofto-mülleriana var. 172

parviseta, Mastigophora 144

P.asythea 137, |41

patagonica, Hippothoa divaricata f. 136

paulensis, Acanthodesia 189

Pectinatella 177, 178, 263

Pedicellina $175,210,212 \mathrm{e}$ seg.

pedunculatum, Alcyonidium 166

pellucidum, Zoobotryon 182

Perigastrella 205

pes, Loxocalyx 117

pes-anseris, Mastigophora 142, 172 
phascolosomatum, Loxosoma 209

Pherusa 165

phrynoglossum, Rhynchozoon 183, 185, 198 ,

199, 206 207, 208

pigmentaria, Holoporella 161

pilosa, Buskia 168

pilosa, Electra 163, 177, 180

plagiopora, Adeona violacea var. 149

Plumatella 179

plumosa, Bugula 194

polyoum, Alcyonidium 163, 166, 177, 182, 271

porosa, Mastigophora 144

prominens, Thalamoporella gothica var. 130

pseudosolena, Crisevia 113, 180

punctata, Cellaria 186

pungens, Schizoporella 144

pusilla, Holoporella 159, 161

pusillum, Loxosoma 118

pustulosa, Bowerbankia 27I

pygmaea, Holoporella 161

quadrispinosa, Holoporella 159

raja, Loxocalyx 117

recta, Aetea 137

repens, Buskia 1/4, 167

repiachowi, Tendra 269

reticulata, Bugula 204

reticulum, Conopeum 127, 172, 182, 189

rhomboidale, Alcyonidium 166

Rhynchozoon 153

rostratum, Rhynchozoon 154

sabatieri, Bugula 182, 194, 198, 200

saltans, Loxosoma 119

Sarsiflustra 186

savartii, Acanthodesia 172

Savignyella 195, 271

sawayai, Loxocalyx 115, 210, 214

Schizomavella 140, 206

Schizoporella 139, 271

schubarti, Holoporella 114, 159

scopae, Mastigophora 144

Scrupocellaria 183, 187

scruposa, Scrupocellaria 194, 195, 200

Scuticella 194

securifrons, Flustra 191, 192, 193, 194,

$195,196,197,198$

serrata, Acanthodesia 185

setigera, Buskia 168

sibogae, Victorella 121 sica, Aetea 137

signata, Smittina 139

singulare, Loxosoma 117, 208, 209

Siniopelta $\mathbf{1 5 5}$

smitti, Kinetoskias 180

Smittina 139, 144

socialis, Buskia 168

spinifera, Alcyonidium 165

Steganoporella 185, 187, 188, 190

Stomatopora 113, 123

subviride, Alcyonidium 166

sultana, Fredericella 177

Synnotum 123, 191, 198, 202, 204

tehuelcha, Membranipora 127

Tiendra 269

tenella, Cellaria 134

tenuirostre, Copidozoum 172

tenuis, Acanthodesia 172, 179, 180, 189

tethyae, Loxocalyx. I17, 209, 237, 240, 243

Thalamoporella 129, 190, 270

topsenti, Alcyonidium 166

tractabilis, Microporella 147

triforia, Membranipora 186

tripora, Smittina 145

trispinosa, var. loxa, Smittina 144

tuberculata, Membranipora 113, 125, 127

tubulifera, Adeona 152, 172

tubulosa, Pherusa 165

tulipifera, Pasythea 137

Tubulipora 125

turrita, Bugula 133, 194, 195, 198, 199

turrita, Holoporella 161

unicornis, Schizoporella 180

Urnatella 122, 173, 208

variabilis, Escharella 180

variegatum, Alcyonidium 166

velatum, Loxosoma 118

venusta, Trypostega 172

vermiculare, Paralcyonidium 166

verrilli, Alcyonidium 166

verruculatum, Rhynchozoon 153, 185

verticillata var. firmata, Mimosella II4,

171, 180

violacea, Adeona 147

vitrea, Cellepora 159

Vittaticella 194

Zoobotryon 182

zostericola, Tendra 269 
F.

\section{ESTAMPAS}

\section{ESTAMPA V}

Fig. I - Loxocalyx sawayai spec. nov. 7 individuos em varios aspectos sobre o tecido e as espiculas de uma esponja ( $\mathrm{M}$ y c ale); gi glandula do pé; o, ovario.

Fig. 2 - Loxosomatoides evelinae, spec. nov. A, parte de uma colonia ramificada sobre B u g ula neritina (L.). B, of vista do lado posterior (aboral). $\quad C_{1}$ o , vista lateral; $a$, anus; $b$, bocca; e, embryão na bolsa incubadora; $f$, "figado" i. é, epithelio alto no tecto do intestino; g, gonada; $r$, recto; $t$, tentaculos encurvados para dentro.

Fig. 3 - na estampa VII. 
ERNST MARCUS - Bryozoarios Marinhos Brasileiros - III

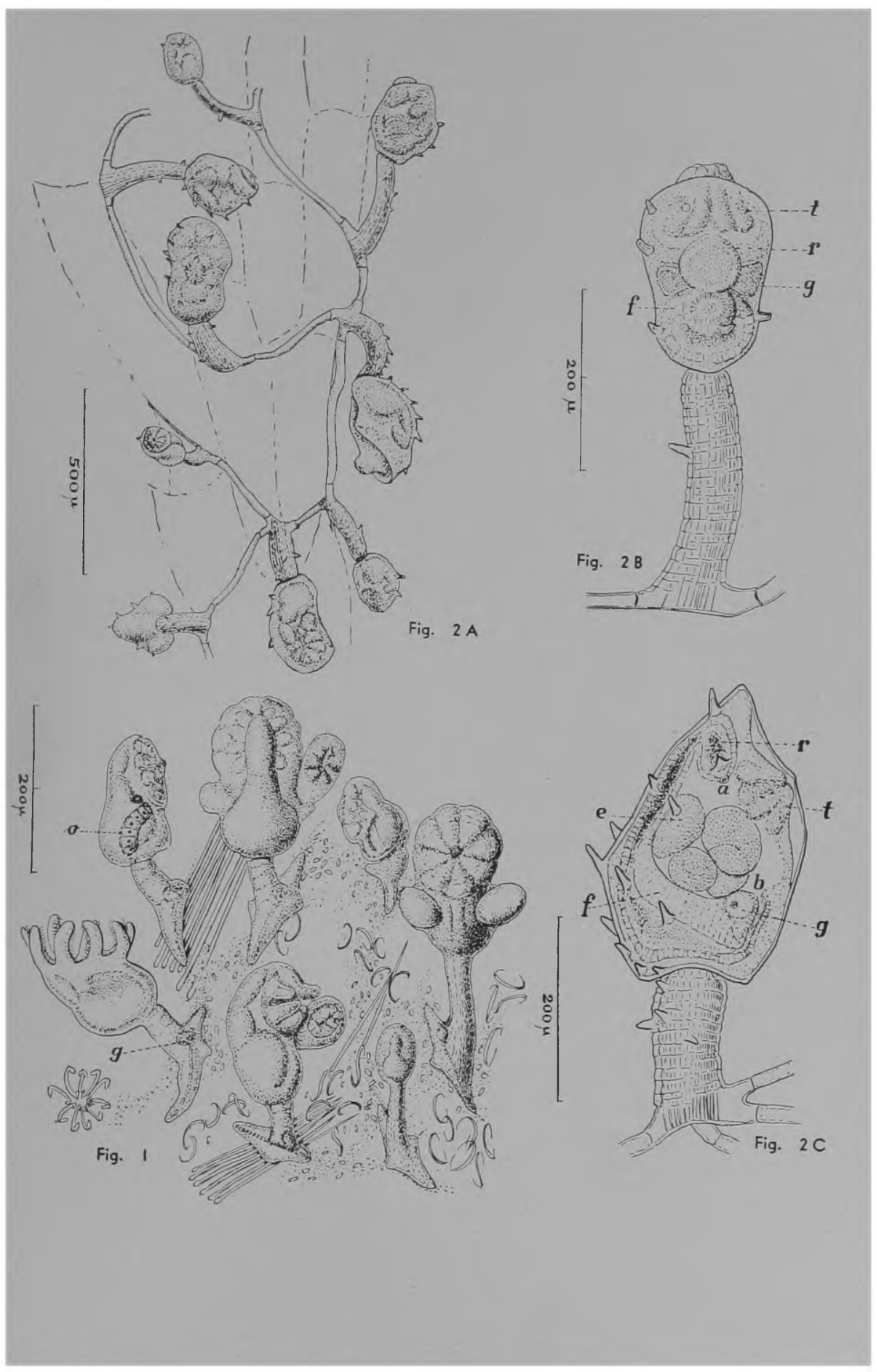




\section{ESTAMPA VI}

Fig. 4 - Membranipora tuberculata (Bosc). $A$, vista lateral. B, vista basal da parte proximal de um zoécio com os espaços chitinicos (c) das paredes, os pentezinhos calcareos $(p)$ e espinhos internos (e).

Fig. 5 - Conopeum commensale Kirkp. \& Metz., zoécios com tuberculos da gymnocysta separados. A, membrana frontal provida de espinhos chit:nicos. B, espinhos frontaes ausentes.

Fig. 6 - Conopeum commensale Kirkp. \& Metz., vista lateral de alguns zoécios com tuberculos da gymnocysta quasi confluentes.

Fig. 7 - Conopeum reticulum (L.), vista lateral de alguns zoécios com espinhos marginaes da cryptocysta. 
ERNST MARCUS - Bryozoarios Marinhos Brasileiros - III ESTAMPA VI

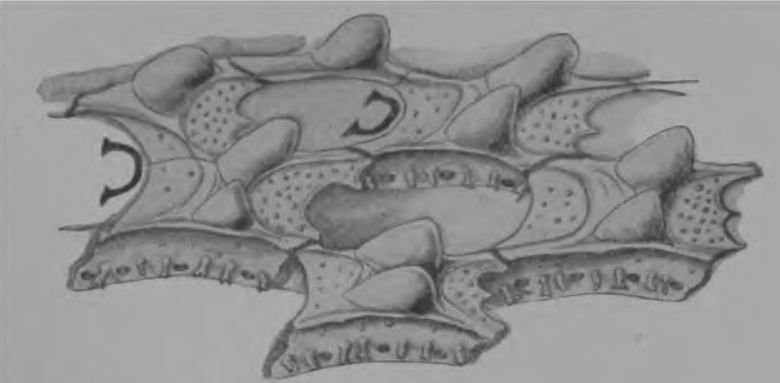

Fig. $4 \mathrm{~A}$
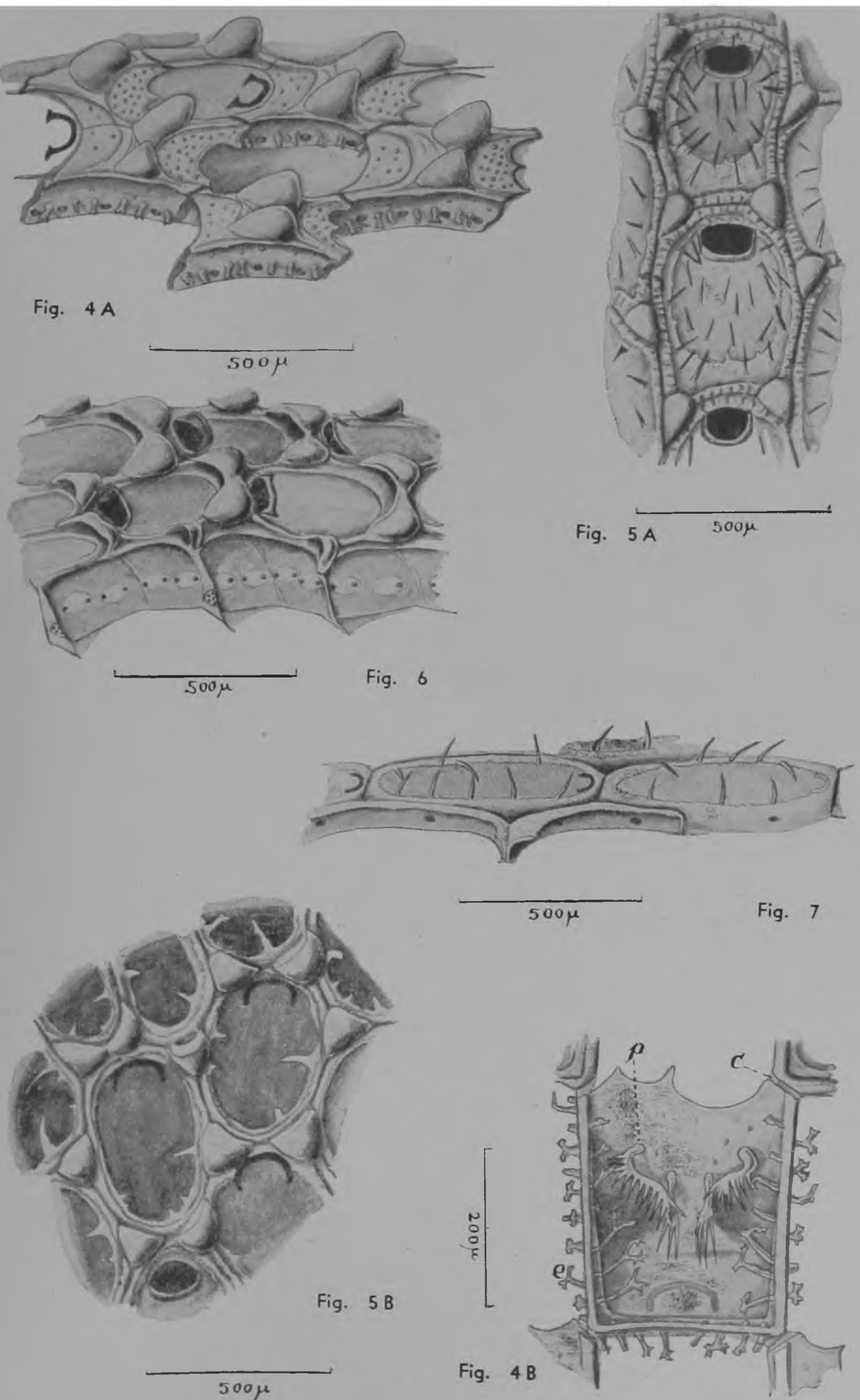


\section{ESTAMPA VII}

Fig. 3 - Stomatopora major (Johnst.). A, colonia com gonozoidio. $B$, face basal com o desenvolvimento das faixas adhesivas.

Fig. 8 - Thalamoporella evelinae, spec. nov. $A$ autozoécios e oécio. $B$, face basal com as linhas de inserção das opesiulas. 
ERNST MARCUS - Bryozoarios Marinhos Brasileiros - III ESTAMPA VII

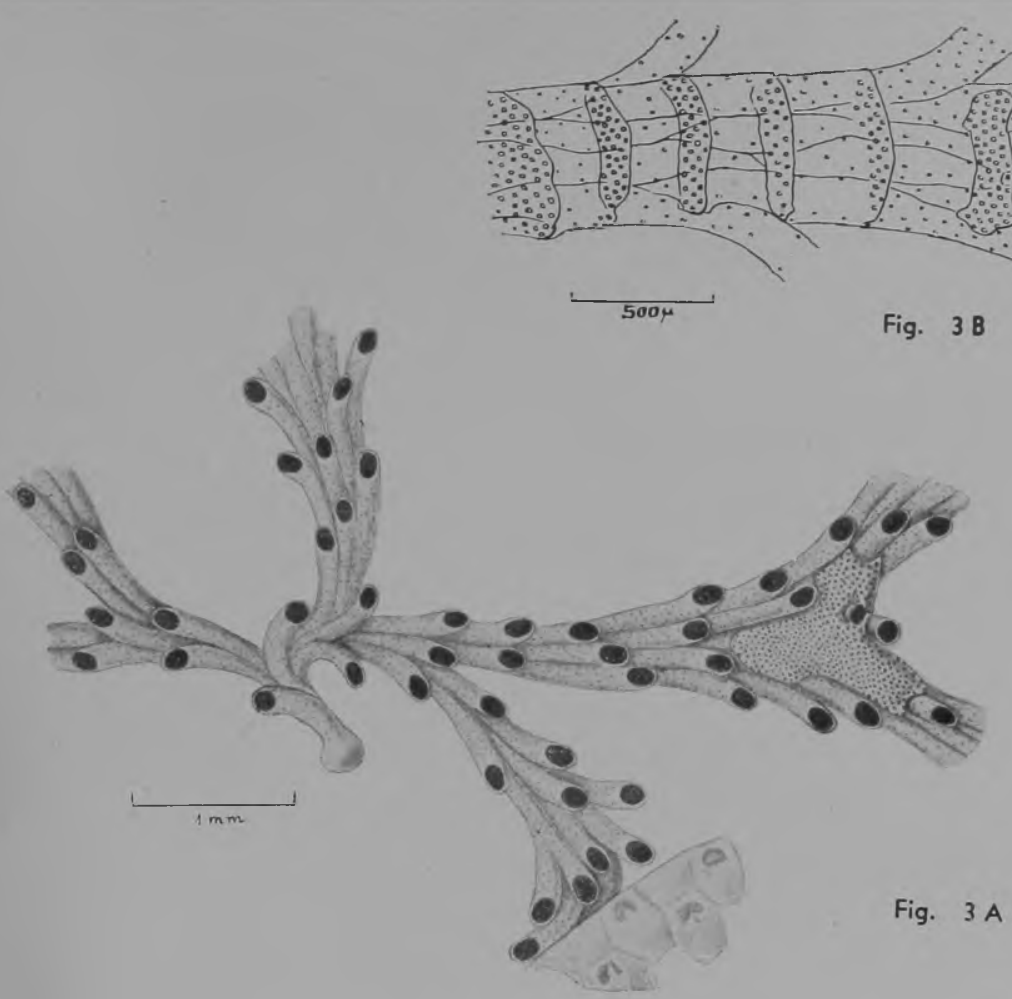

Fig. $8 \mathrm{~A}$
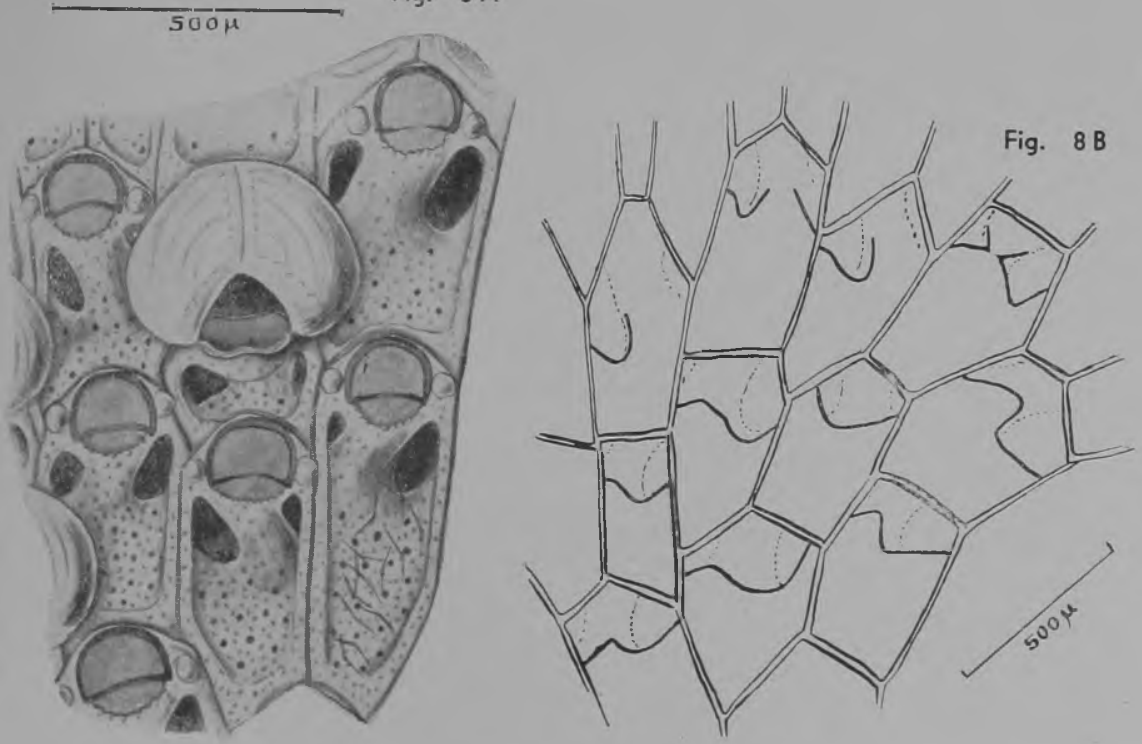


\section{ESTAMPA VIII}

Fig. 9 - Nellia oculata Busk. $A_{1}$ parte de uma colonia. $B$, uma parte com augmento maior; $s$, septula de communicação transparente. $C_{1}$ ramificação; A-H, os zoécios, veja no texto p. 133; $r$, fibra radicular; $t, t$ tubos chitinicos de articulação.

Fig. 10 - Hippothoa divaricata Lmx. Parte de uma colonia com ancestrula (a) e individuos femininos ( 9 ).

Fig. II - Pasythea tulipifera (Ell. Sol.). A, parte de uma colonia com o estolão rasteiro e ramos com triades de zoécios. C, operculo. 
ERNST MARCUS - Bryozoarios Marinhos Brasileiros - III ESTAMPA VIII

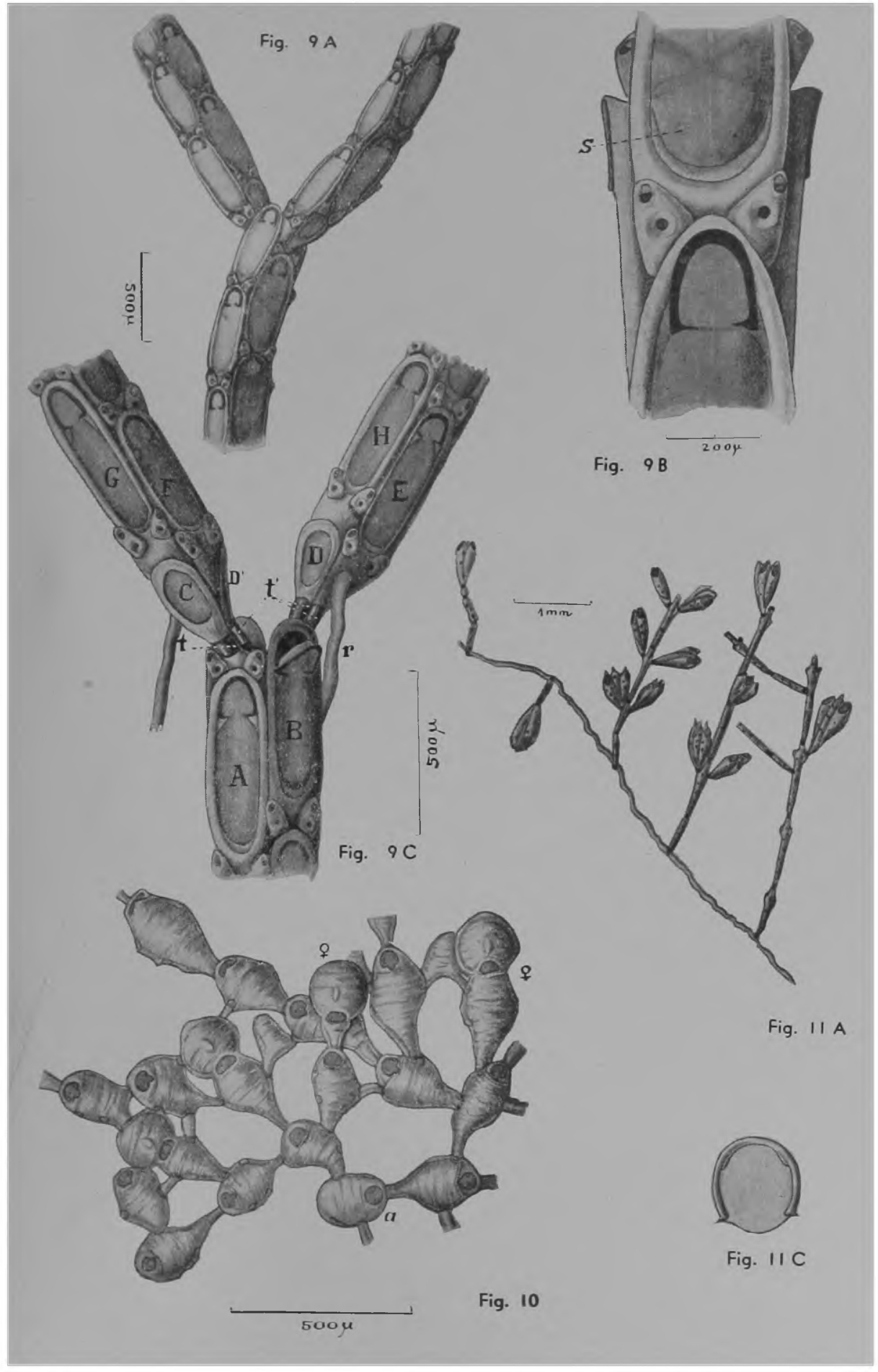




\section{ESTAMPA IX}

Fig.. II B - Pasythea tulipifera (Ell. Sol.) Vista lateral de uma triade de zoécios.

Fig. 12 - Escharina krampi Marc. A, aspecto frontal de alguns zoécios. B, zoécio visto do lado basal; $C_{1}$ corpos brunos; g, glandula oral impar.

Fig. 13 - Schizoporella horsti (Osb.). Operculo com esclerito (c), glandulas oraes (g) e avicularia (a).

Fig. 14 - Gemelliporina glabra (Smitt). A, parte jovem de um ramo. $B$, operculo com tendão e musculo occlusor do lado direito. 
ERNST MARCUS - Bryozoarios Marinhos Brasileiros -- III ESTAMPA IX

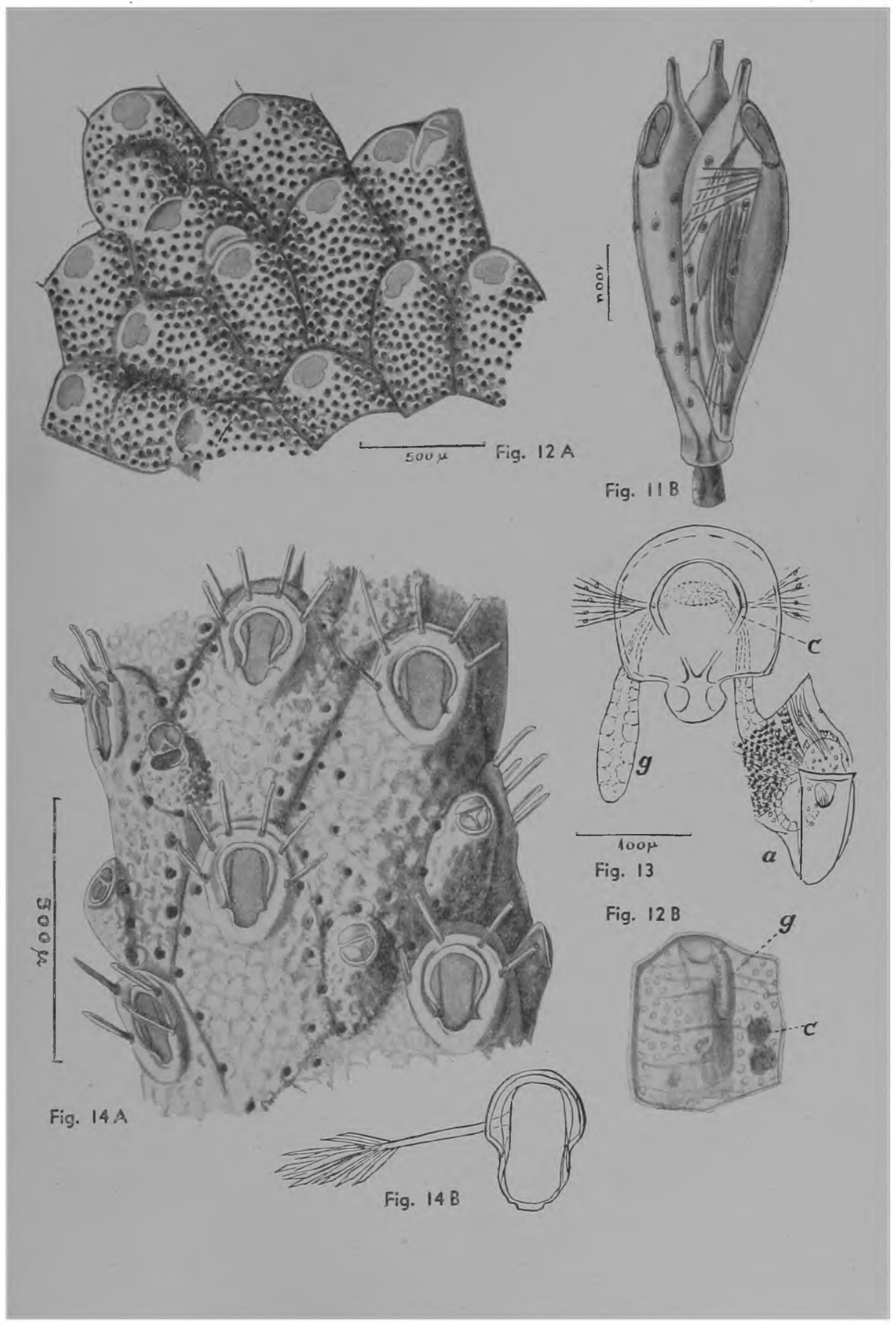




\section{ESTAMPA $X$}

Fig. 15 - Mastigophora pes anseris (Smitt). $A$, zoécios sem mandibulas da ilha de São Sebastião. B, operculo. C, um zoécio da ilha de Sta. Helena com mandibulas.

Fig. 16 - Smittina trispinosa (Johnst.) var. Io$x$ a Marc. Sector de uma colonia com grande avicularia espatulada.

Fig. 17 - Microporella ciliata (Pall.) var. co ronata (Aud.) da região de Vancouver.

Fig. 18 - Adeona violacea (Johnst.). Material sem mandibulas das avicularias. 
ER NST MARCUS - Bryozoarios Marinhos Brasileiros - III ESTAMPA X
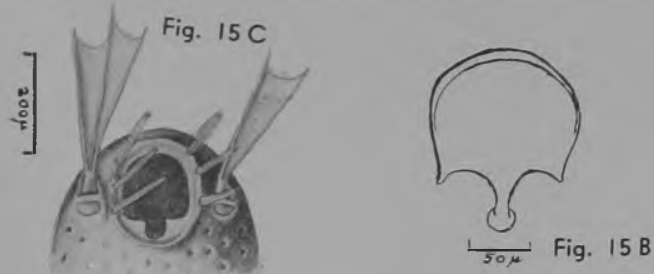

Fig. $15 \mathrm{~A}$

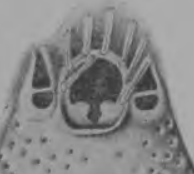

Fig. 17

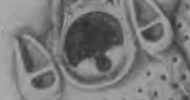

1.
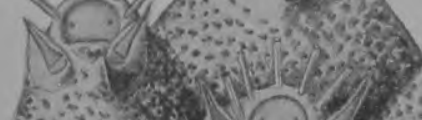

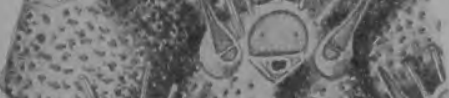

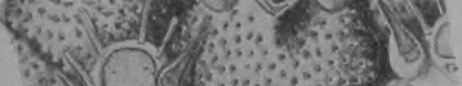

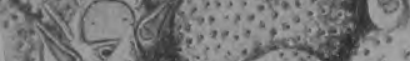
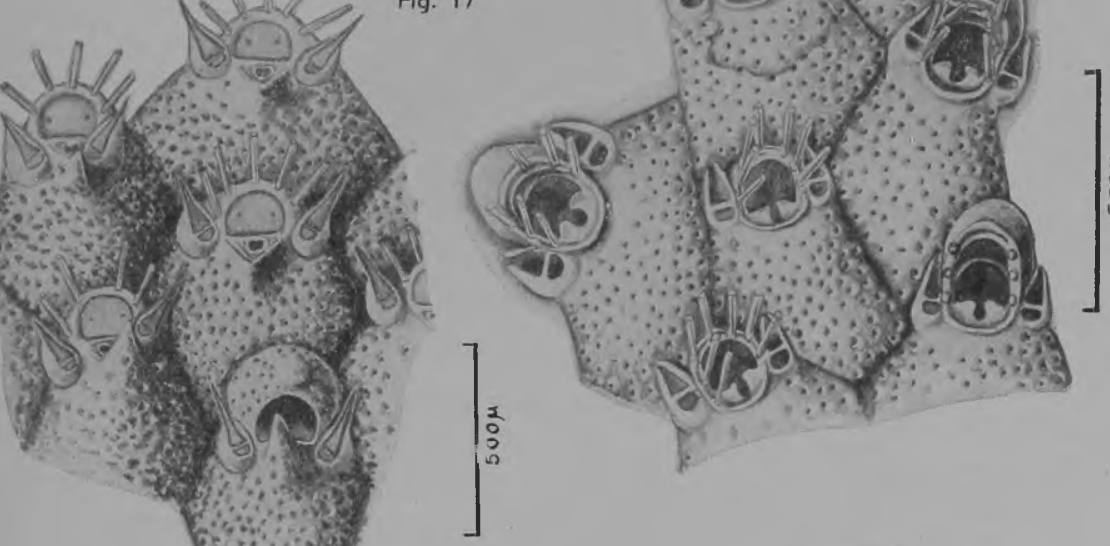

9. $3+2$ (ए)

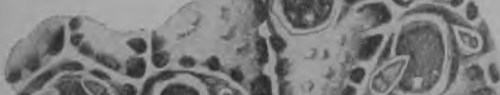
(8) G) \&.3 boagl (a) 009 . I.

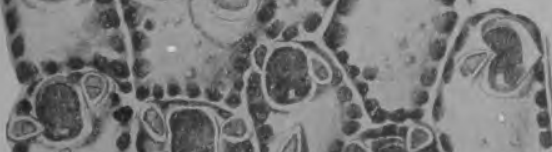
* 2.0 (a)

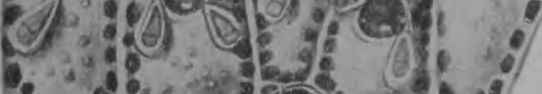

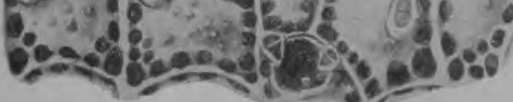

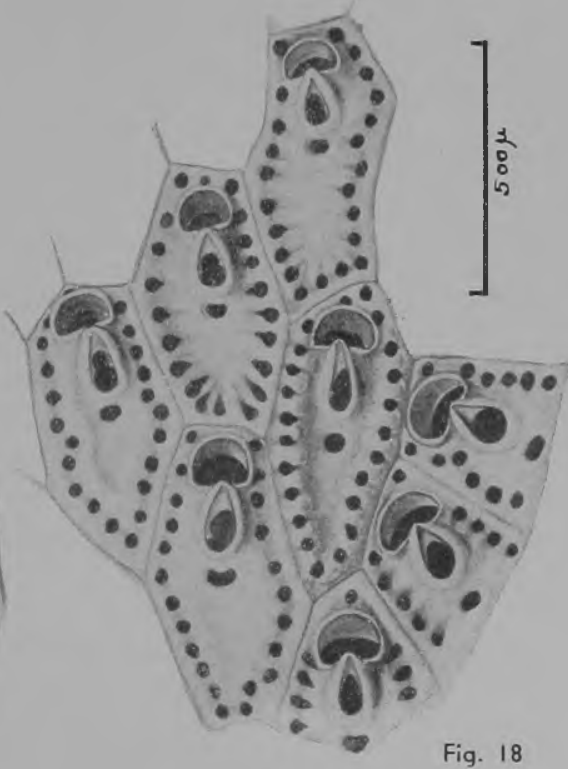

Fig. 16 


\section{ESTAMPA XI}

Fig. 19 - Adeona tubulifera Canu \& Bassler. $A$, zoécios sem mandibulas. $B$, ancestrula-gémea.

Fig. 20 - Rhynchozoon verruculatum (Smitt). $A$, sector de uma colonia perto da zona de gemmação. B, operculo com os pontos de inserção (i) dos occlusores e os entaltios de suspensão, "hinge-notches" (e). C mandibula com um tendão collectivo (t) dos dois musc. occlusores (adductores, d).

Fig. 21 - Siniopelta langei, spec. nov. A, colonia adulta. 

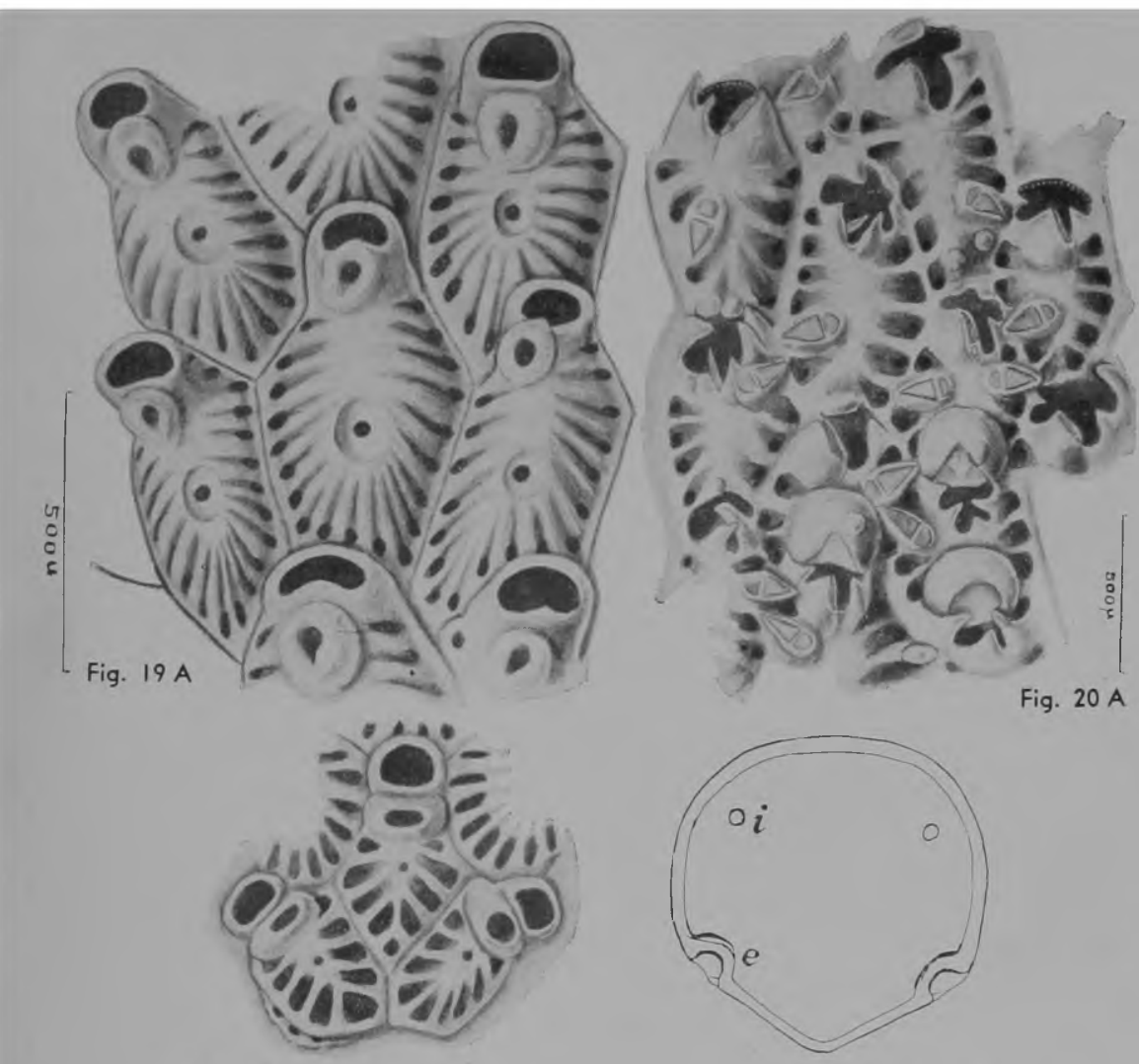

Fig. $19 B-\frac{}{2004}$

Fig. $20 \mathrm{~B}$

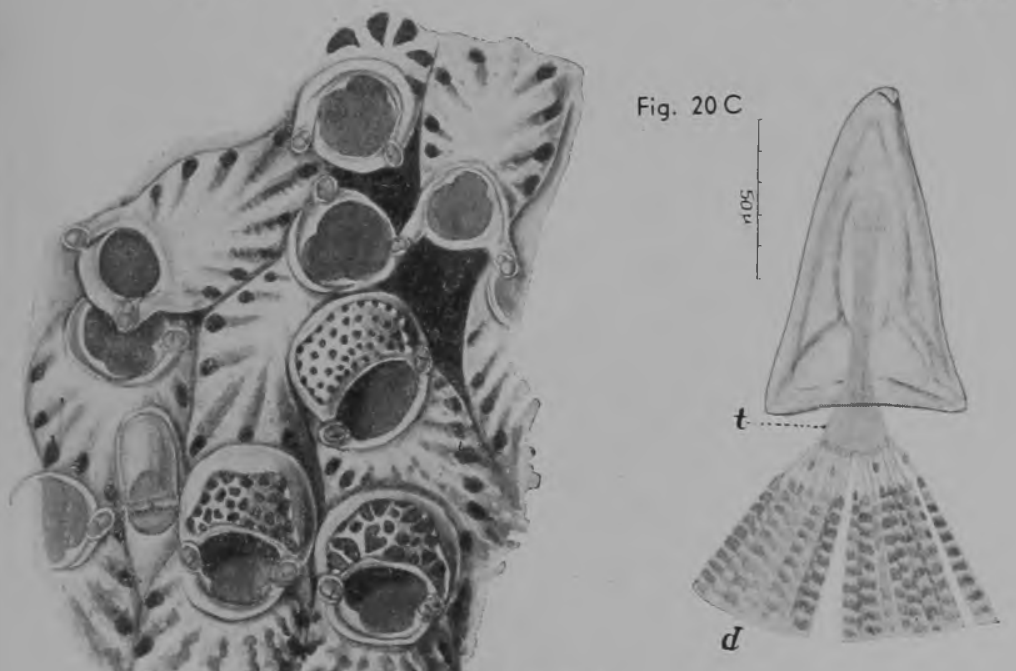

Fig. $21 \mathrm{~A}$ 


\section{ESTAMPA XII}

Fig. 21 - Siniopelta langei, spec. nov. B, oper.. culo. C, mandibula da avicularia dependente. D, mandibula da avicularia vicaria.

Fig. 22 - Siniopelta costazii (Aud.). A, operculo. B, C, mandibulas de avicularias dependentes. D, mandibula da avicularia vicaria.

Fig. 23 - Holoporella carvaihoi, spec. nov. A, sector de uma colonia com zoécios jovens (i), de idade media $(\mathrm{m})$ e de calcificação completa (c) e dois typos de avicularias. B, operculo. C, mandibula da avicularia vicaria; $i_{1}$ inserção de um dos tendões dos occlusores; u, lucida. D, mandibula da avicularia dependente (zoécial); no bordo distal da lucida (u) o unico tendão dos 2 occlusores.

Fig. 24 - Holoporella schubarti, spec. nov. $A_{\text {, }}$ colonia adulta. B, operculo. C, mandibula da avicularia dependente. D, mandibula da avicularia vicaria. 
ERNST MARCUS - Bryozoarios Marinhos Brasileiros - III ESTAMPA XII

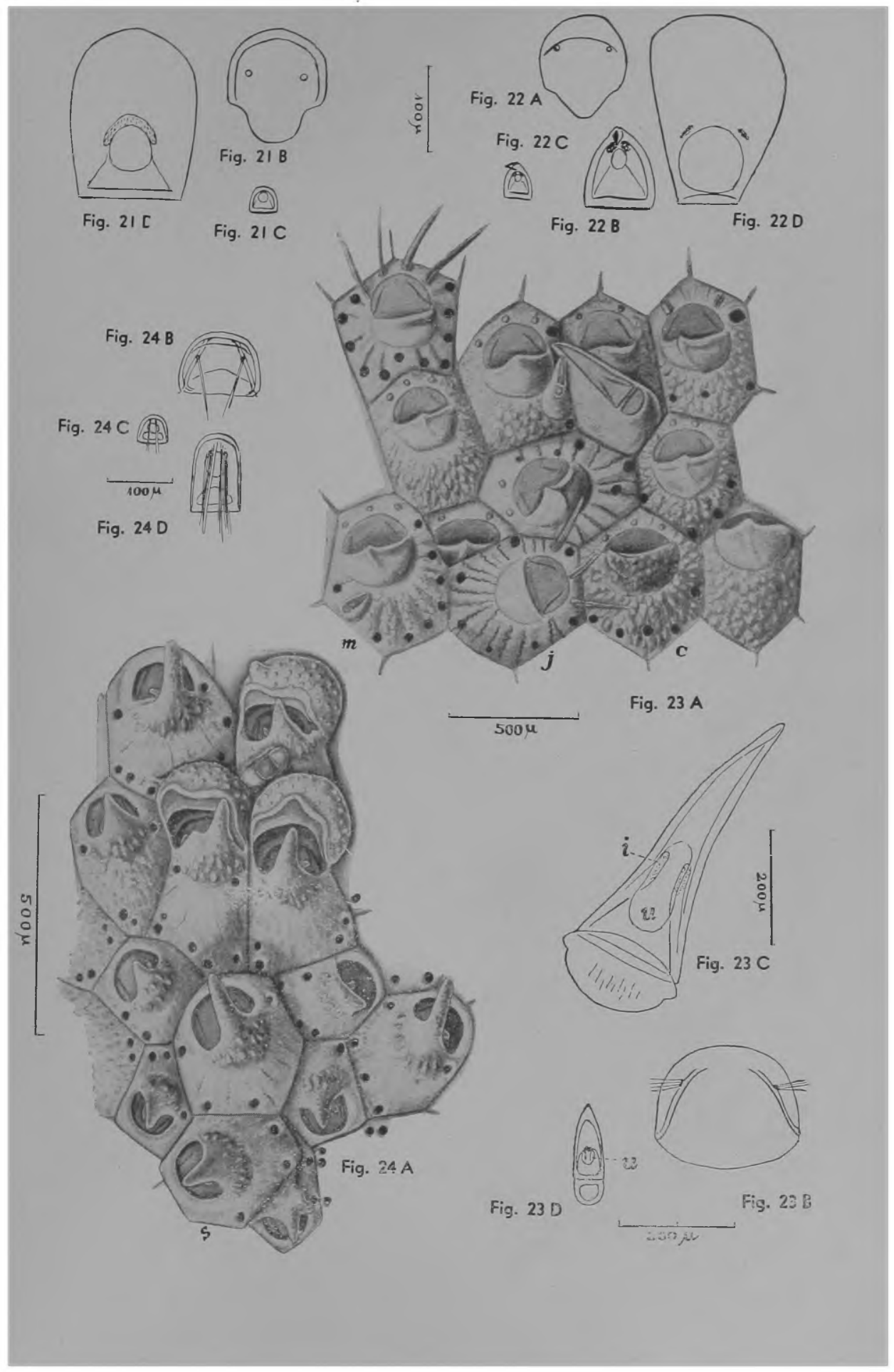




\section{ESTAMPA XIII}

Fig. 25 - Alcyonidium mamillatum Ald. A, colonia em forma de tufo de musgo. B, parte de uma colonia decumbente, reticulada; $a$, autozoécios regulares; $b$, botão polypidial em zoécios cegos $(z) ; \quad c$, autozoécio oriundo de um zoécio cego; $d_{1}$ autozoécio com inversão $d a$ polaridade polypidial; $m$, malha colonial; $r$, autozoécio com corpo bruno e botão regenerativo. C duplicidade e triplicidade dos cônes orificiaes regenerados em uma colonia decumbente; $d$, zoécio com inversão da polaridade do polypidio regenerado.

Fig. $2 t$ - Alcyonidium hauffi, spec. nov. $A$, parte da 2." colonia (p. 164). B, disposição dos zoécios em redor do substrato $\left(3 .^{2}\right.$ colonia, p. (65). 


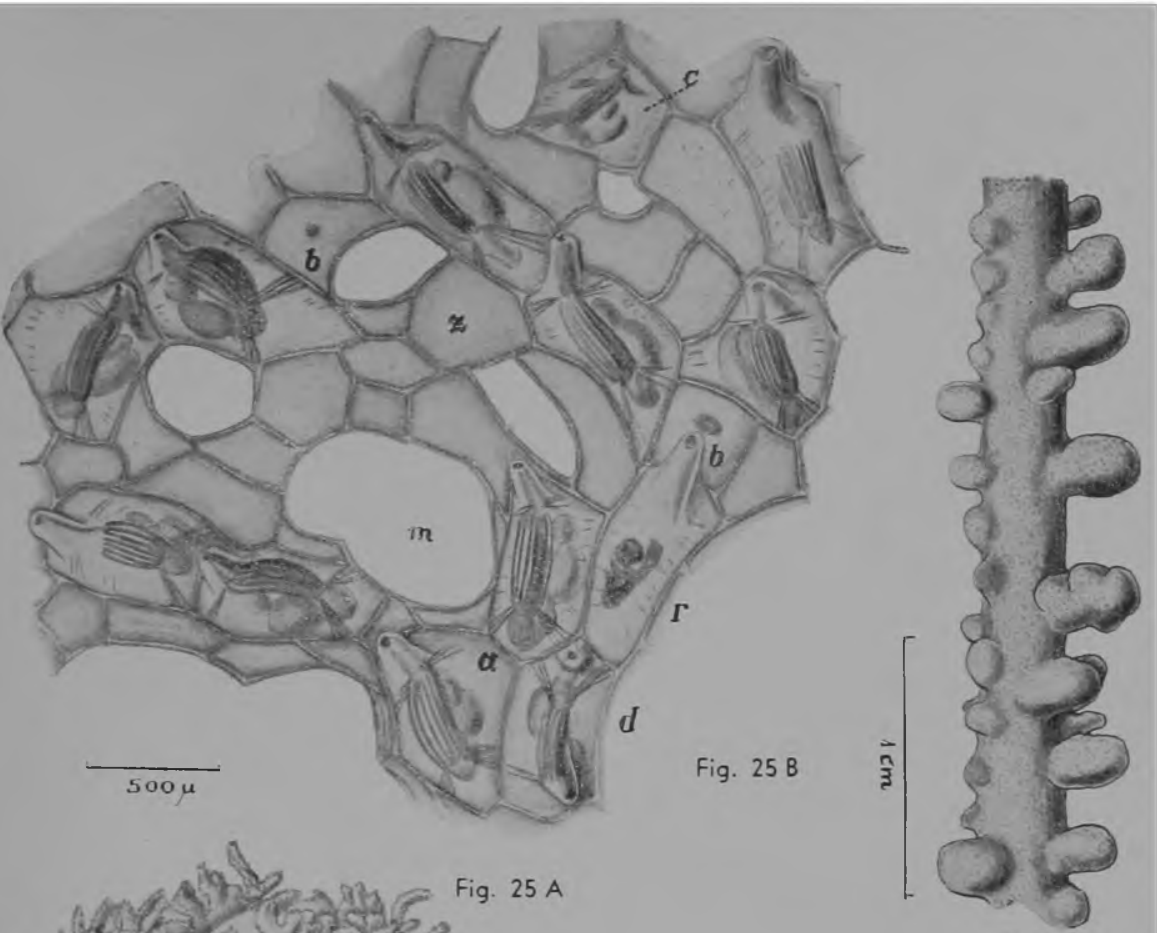

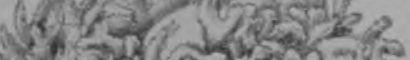

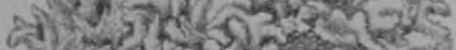
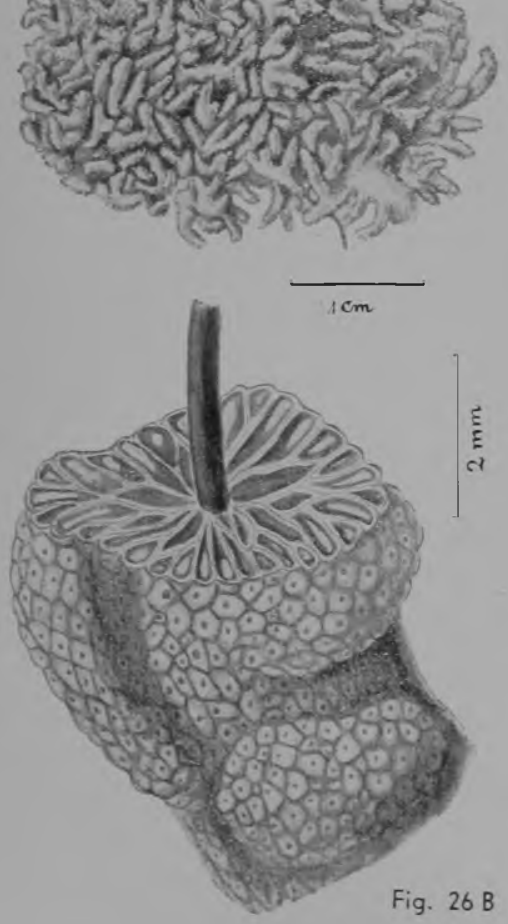

Fig. $26 \mathrm{~A}$

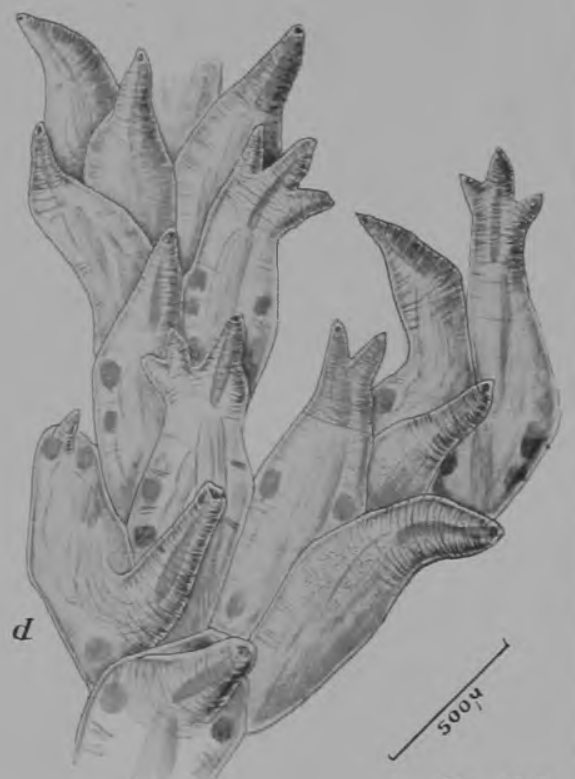

Fig. $25 \mathrm{C}$ 


\section{ESTAMPA XIV}

Fig. 27 - Buskia repens (O'Don.). A, parte de uma colonia. $B$, tres zoécios com augmento maior.

Fig. 28 - Cortes transversal (A) e longitudinal (B) do pedunculo de Pedicellina cernua (Pall.). c cuticula; $d$, diatomacea adherente á cuticula; $e_{1}$ epiderme; $m$, cellulas musculares; $t$, cellulas tubiformes.

Fig. 29 - Corte tangencial do ceco de Cristatella mucedo Cuv. (material de Berlin)i o corte passa sómente atravez das dobras da membrana sustentadora.

Fig. 30 - Corte transversal da pharynge de A ca nthodesia tenuis (Des.). a, tres anneis da musculatura annelar situados em planos differentes; $r$, porções de algumas cellulas do retractor, sendo as estrias em a e $r$ resultados da differenciação incompleta da hematoxylina ferrea. Nas cellulas do epithelio pharyngeano ha estriação verdadeira.

Fig. 31 - Corte longitudinal optico da pharynge de Mimosella verticillata (Hell.) var. firmata Marc. a, musculatura annelari $u_{1}$ nucleos das cellulas do epithelio pharyngeano providas de zonas transversalmente estriadas e vacuolos $(\mathrm{v})$. 
ERNST MARCUS - Bryozoarios Marinhos Brasileiros - III ESTAMPA XIV
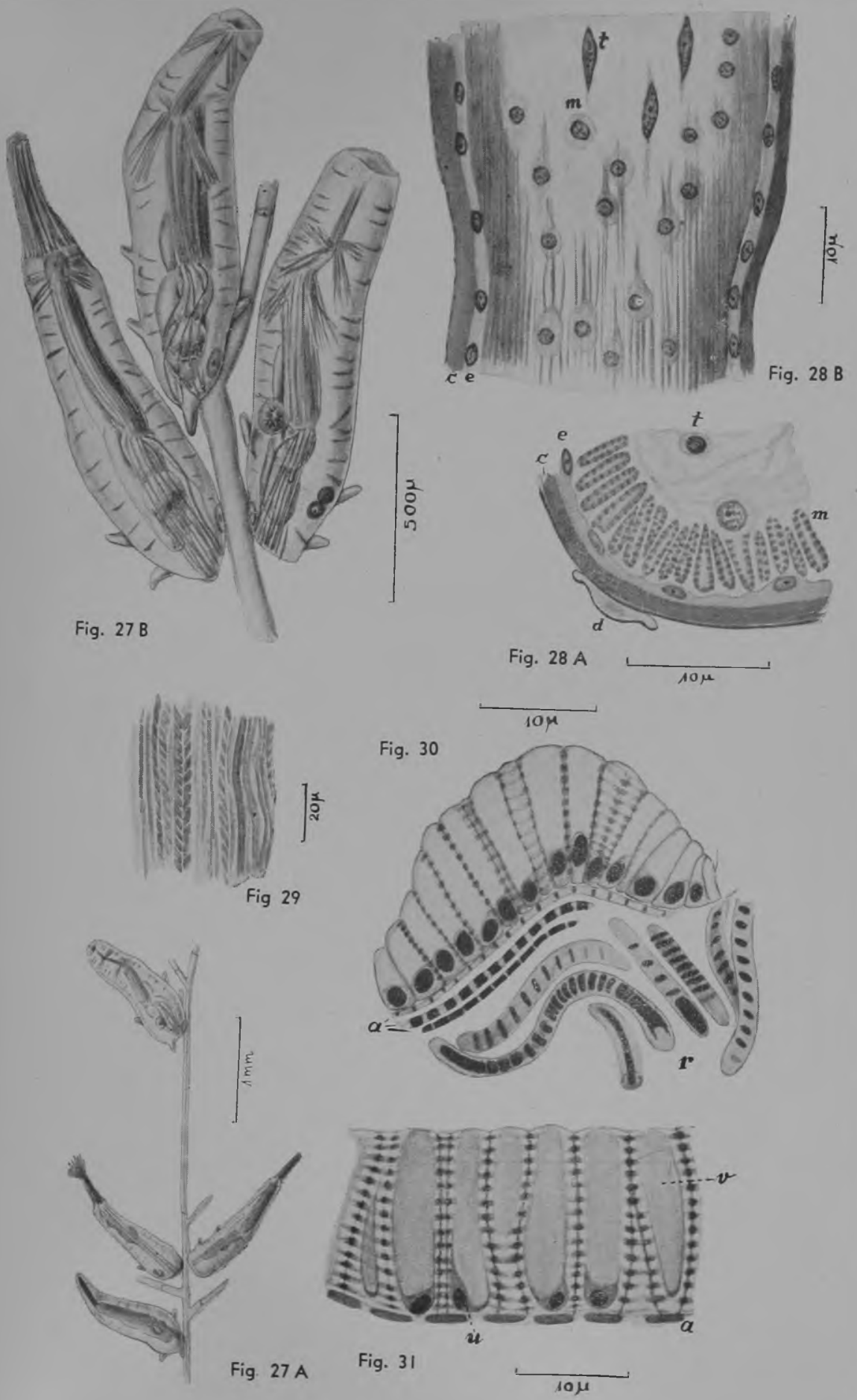


\section{ESTAMPA XV}

Fig. 32 - Estomago mastigador de A mathia distans Bsk. Metade anal do corte optico, metade abanal no aspecto externo. $d_{1}$ esqueleto dum Radiolario (grupo: Stephoidea)i $e_{1}$ esplanchnopleura; $m$, musculosi $r$, recto; $s$, epithelio do estomago.

Fig. 33 - Tracto intestinal de Aete a anguina (L.). c, cardia; e, esophago; g, ganglio; $O$, ceco; $p_{1}$ pharynge; $r$, recto; $y$, pyloro.

Fig. 34 - Scrupocellaria cornigera (Pourt.). $A_{1}$ vista lateral da vibracula descalcificada. Hematoxylina-Orange. $b$, musc. abductor; $c$, cerda; $d$ musc. adductor; $e_{1}$ escleritos na base da cerda, em quaes os musculos inserem; $p_{1}$ botão ou polypidio. B, implantação da cerda na camara da vibracula; $i$, dilatação lateral da base da cerda; m, moente da camara.

Fig. 35 - Hippodiplosia americana (Verr.): mandibula $(\mathrm{m})$ com $\circ$ epithelio vestibular $(\mathrm{e}) \in$ - tendão collectivo (t) composto por fibras epitheliaes ( $f$ ) dos musc. adductores (d). 

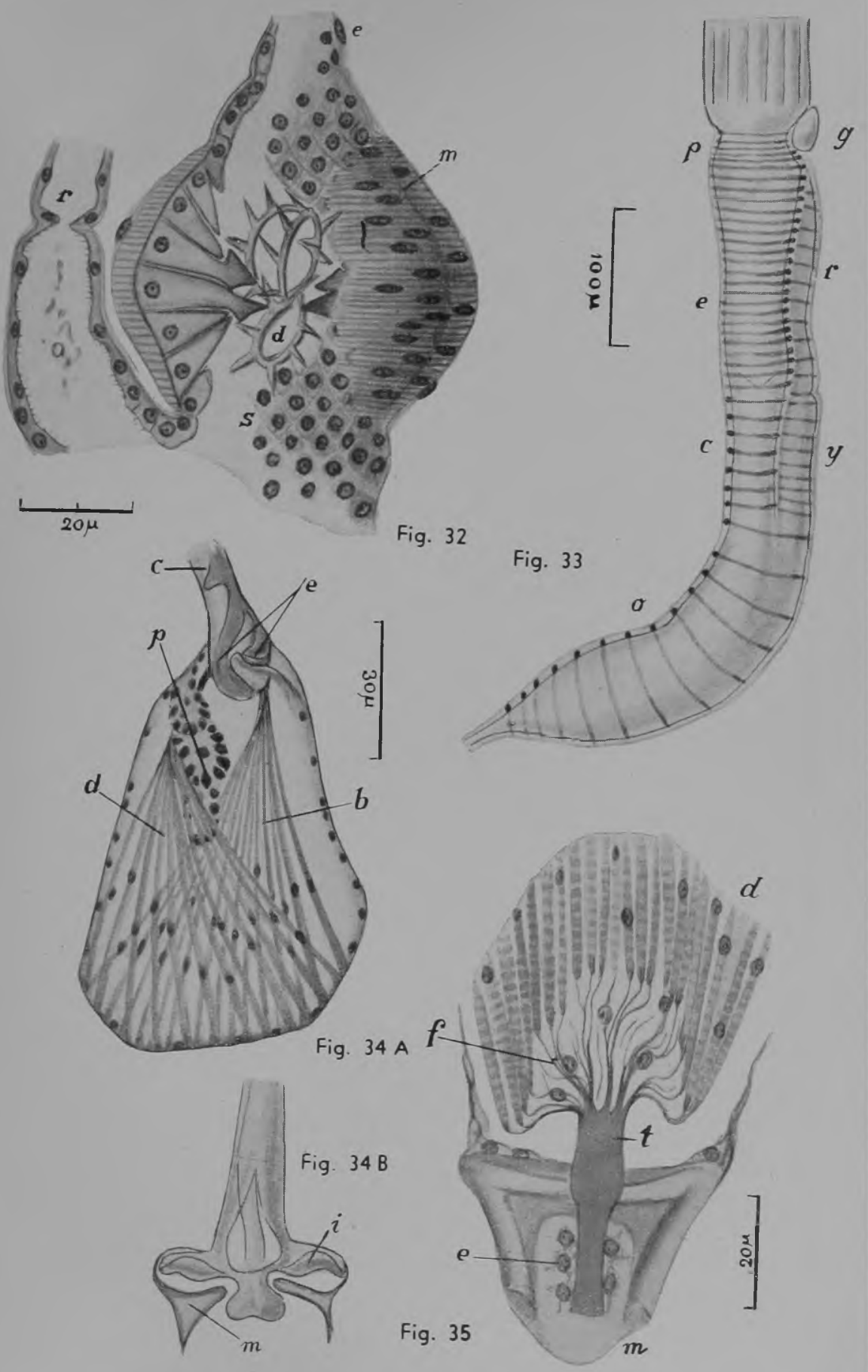

Fig. 32

Fig. $34 \mathrm{~A}$

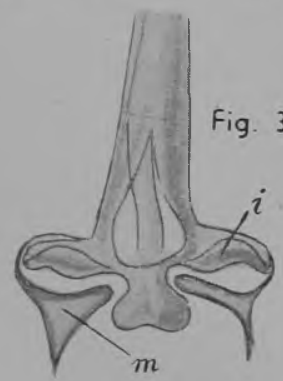

Fig. 35 


\section{ESTAMPA XVI}

Fig. 36 - Rhynchozoon phrynoglossum Marc. $A$, mandibula (longura 135 $\mu$, largura $72 \mu$ ) com um tendão collectivo ( $t$ ) dos musc. adductores. $B_{1}$ outra mandibula (longura $150 \mu$, largura $108 \mu)$ com dois tendões collectivos ( $t$ ) de inserção commum (i) dos musc. occlusores; p, botão ou polypidio da avicularia; para as outras letras veja Fig. 35.

Fig. 37 - Crassimarginatella leucocypha Marc., sector da colonia descalcificada com autozoécio (1), avicularia polypidifera (2), e avicularia vicaria normal (3); $b$, abductores da mandibula; $\mathrm{m}^{2}, \mathrm{~m}^{3}$ mandibulas das avicularias correspondentes; $m p^{1}, m p^{2}$ musculos parietaes (depressores) da membrana frontal; o, operculo; oc, musc. occlusores do operculo; $p^{1}, p^{2} p^{3}$, polypidios do autozoécio e das avicularias respectivamente; $r$, musc. retractor.

Fig. 38 - Inserção das fibras abductores (b) na membrana frontal da avicularia de Crassimarginatella leucocypha, indicando as settas as direcções para dentro e para fora da membrana frontal e da mandibula (m) respectivamente, c, cuticula frontal; $e$, epithelio frontal; $n$, nucleos das cellulas epitheliaes que formam o tendão; o, cordão de ligação entre o abductor e a bainha tentacular da avicularia (veja tambem Fig. $40 \mathrm{~B}$ ); $s$, esclerito basal da mandibula; $v$, membrana vestibular; $x$, fibra sem tendão; $y, 3$ fibras que inserem por um tendão.

Fig. 39 - Inserção do tendão collectivo (t) na cuticula mandibular (c) de uma avicularia de Siniopelta costazii (Aud.): i, os cônes chitinicos de inserção. 
ERNST MARCUS - Bryozoarios Marinhos Brasileiros - III

ESTAMPA XVP.

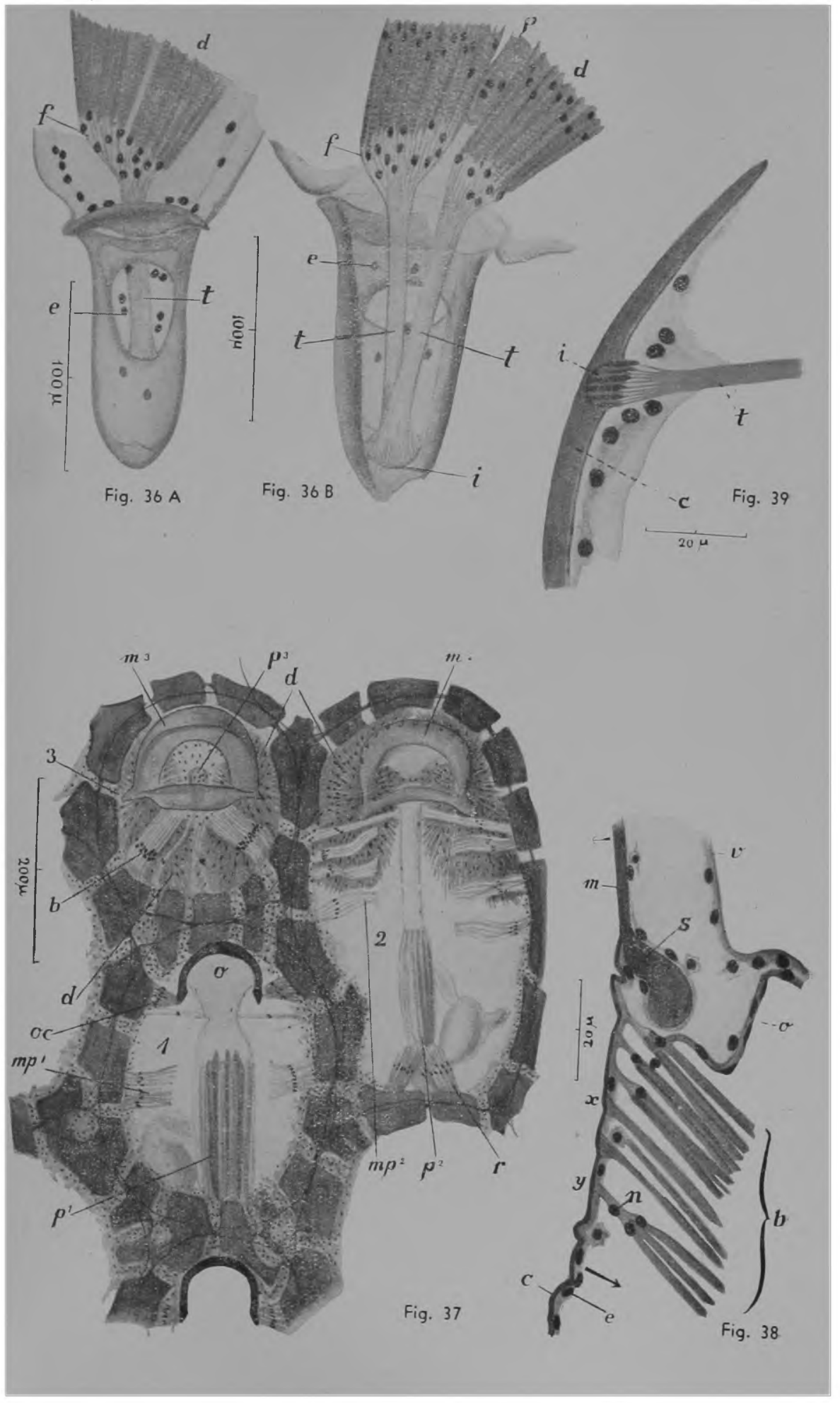




\section{ESTAMPA XVII}

Fig. 40 - Avicularia de Flustra securifrons (Pall.) (material de Helgoland). Hematoxylina-Éosina. A, corte sagittal; $B$, corte mediano. a, parede basal; $b$, musc. abductores; $c$, cryptocysta; $d$, musc. occlusores ou adductores; $e$, cordão de ligação entre a bainha tentacular e a parede distal; $f$, parede frontal; $g$, ganglio; $i$, diaphragma; $m$, mandibula; $n b$, nucleos dos tendões singulares dos abductores; nd, nucleos do tendão collectivo do adductor; o, cordão de ligação entre a bainha tentacular e o abductor; $p$, orgão setoso ou polypidio; $r$, retractor do polypidio; $s$, parede distal; $t$, tendão collectivo dos occlusores; $u$, bainha tentacular; $v$, vestibulo; $\mathrm{x}$, parede proximal.

Fig. 41 - Corte mediano do orgão setifero da avicularia de Flustra securifrons (Pall.). Hematoxylina-Orange. e, ectoderma; $g$, ganglio; $i$, diaphragma; $s$, somatopleura; $u$, bainha tentacular; v, vestibulo.

Fig. 42 - Avicularias de mandibula aberta (A) e fechada (B) de Bugula ditrupae Bsk. a, articulação da mandibula; $b^{1}$, musc. abductor proximal; $b^{2}$. musc. abductor distal; $c$, campo de abertura; $d_{1}$ musc. adductores ou occlusores; $e_{\text {, }}$ dobra entre tubo e socco aviculariaes; $f_{1}$ tecido frouxo no pedunculo; $m$, mandibula; $o$, tubo do pedunculo; $p$, socco do pedunculo; $s$, septo entre o autozoécio e a avicularia; $t_{\text {, tendões }}$ dos musc. occlusores; $v_{1}$ epithelio vestibular; $x_{1}$ fibras musculosas basaes do pedunculo; $y_{i}$ fibras musculosas frontaes do pedunculo. 
ER NST MARCUS - Bryozoarios Marinhos Brasileiros - III

ESTAMPA XVI!

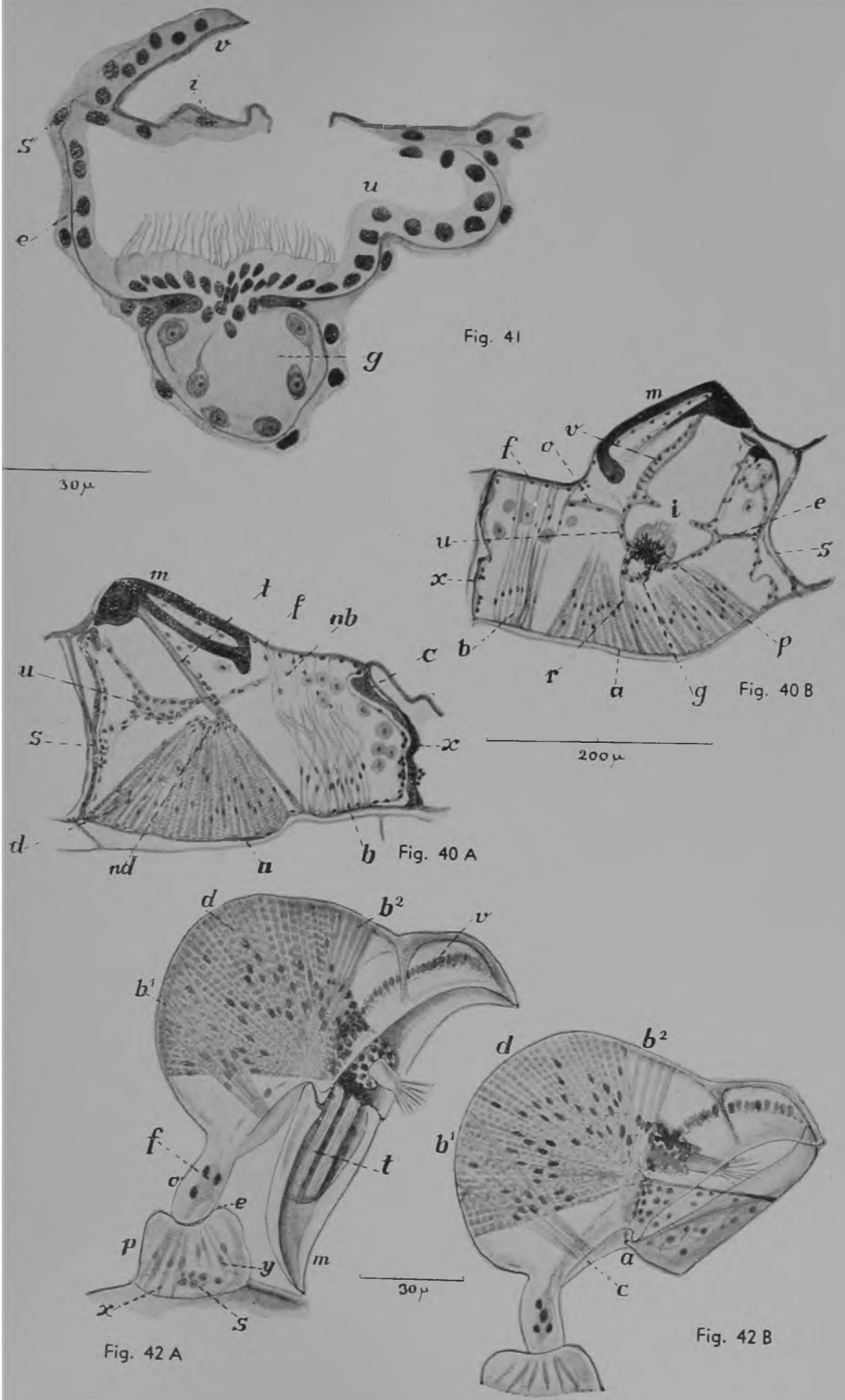




\section{ESTAMPA XVIII}

Fig. 43 - Corte transversal da avicularia de Bugula avicularia (L.) (material dinamarquez). Hematoxylina-Orange. $b$, musc. abductor; $c$, cerdas; $d$, musc. adductor; g, ganglio; $s$, nucleo da esplanchnopleura; u, bainha tentacular; $v$, membrana vestibular; $y$, gymnocysta.

Fig. 44 - Corte sagittal da avicularia de Be ania inte rme di a (Hcks.). Hematoxylina-Orange. $b$, musc. abductor; $d$, musc. adductores; g, ganglio; $i$, diaphragma; o, cordão de ligação entre a bainha tentacular e o abductor; s, septo entre - autozoécio e a avicularia; $t$, tendão de um dos adductores; u, bainha tentacular; $v$, epithelio do vestibulo.

Fig. 45 - Avicularias pedunculada $(A)$ e sessil $(B)$ de $S$ y nnotum aegyptiacum (Aud.). b, musc. abductor; $c$, base das cerdas do orgão setifero; $d$, musc. adductores; e, dobra externa no pedunculo (autozoecial) da avicularia; g, glandula da avicularia; $m$, mandibula; o, cordão de ligação entre o orgão setifero e o abductor; $s$, septo entre o pedunculo e a camara da avicularia. 
ERNST MARCUS - Bryozoarios Marinhos Brasileiros - III ESTAMPA XVIII

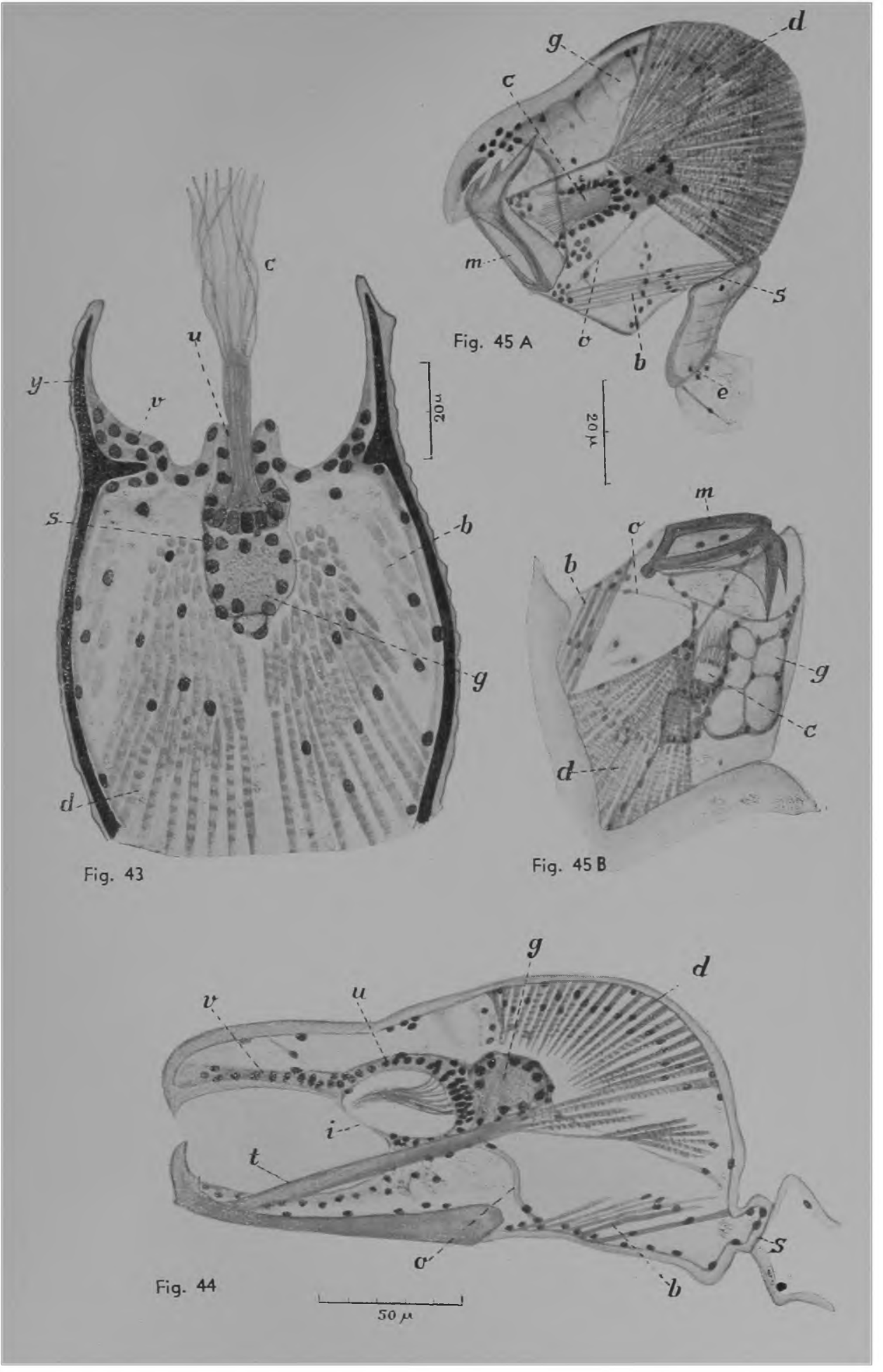




\section{ESTAMPA XIX}

Fig. 46 - Schema da glandula e do polypidio aviculariaes de Bugula ditrupae (a), Rhynchozoon phrynoglossum (b), Synnotum aegyptiacum (c). Microporella ciliata(d), Siniopelta diota (e). Schizoporella carvalhoi (f), Perigastrella contracta (g).

Fig. 47 - Corte sagittal da avicularia dependente de Rhynchozoon phrynoglossum Marc. Coloração segundo Mallory. $b$, musc. abductores; $d$ musc. adductores; $e$, membrana entre a placa frontal e a mandibula; $g$, ganglio; $m_{1}$ mandibula; $n$ glandula; $n b$, nucleos dos tendões do abductor; nd, nucleos do tendão do occlusor; o, p, cordões de ligação (veja no texto, p. 198); $r$, retractor do polypidio; $s$, placa frontal; u, bainha tentacular; v, vestibulo.

Fig. 48 - Schema da avicularia dependente de Rhynchozoon phrynoglossum Marc. com a mandibula fechada $(A)$ e aberta (B). t, tendão dos occlusores; para as letras restantes veja Fig. 47.

Fig. 49 - Corte sagittal da avicularia vicaria de Siniopelta costazi i (Aud.). Hematoxylina ferrea-Eosina. b, musc. abductores; $c$, cerdas; $d$, musc. adductores (occlusores); $i_{1}$ diaphragma; $r_{1}$ fibras retractoras do "polypidio"; $t_{1}$ tendão collectivo de um dos occlusores; u, bainha tentacular; v, vestibulo. 

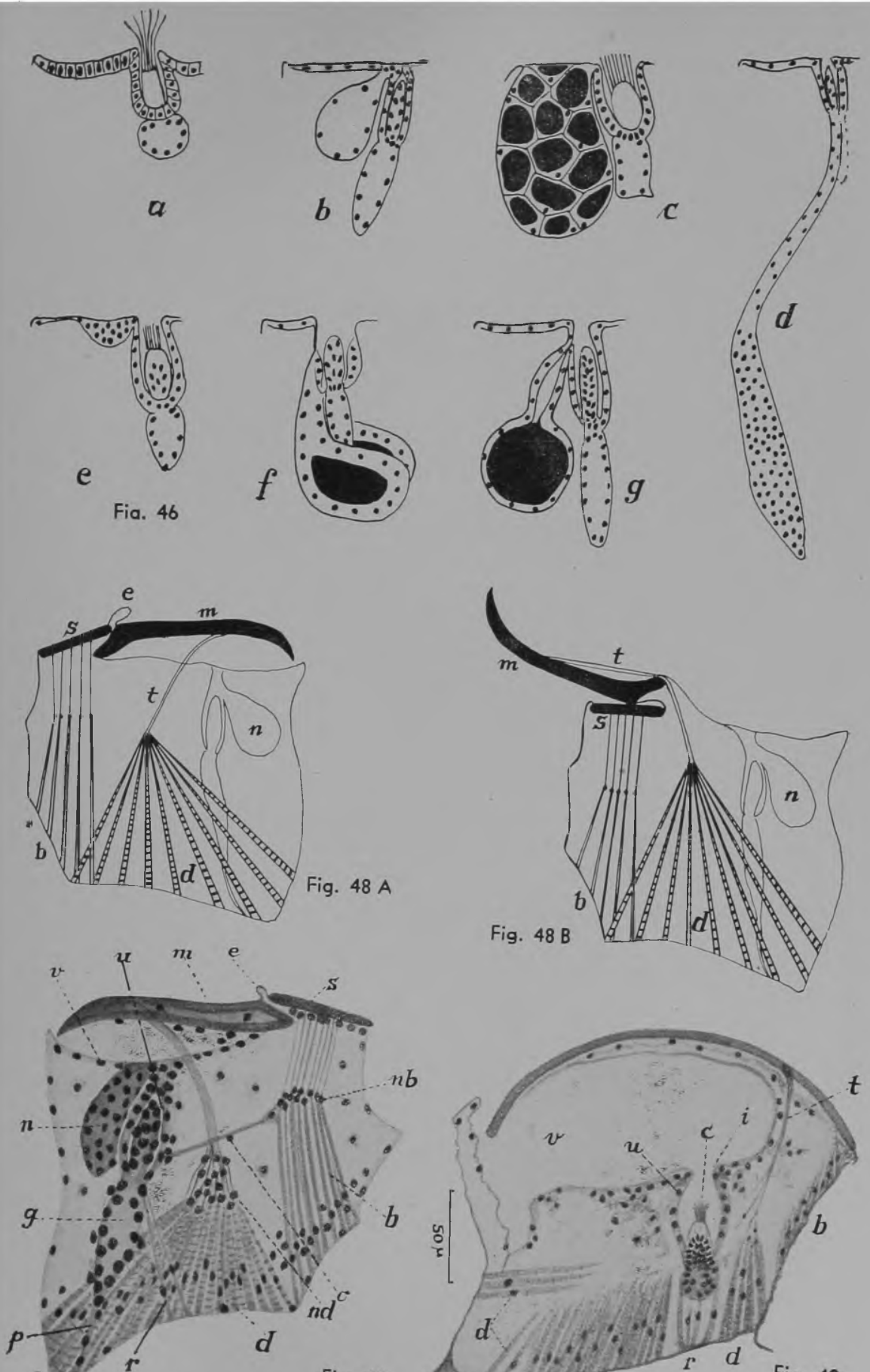

Fig. 47

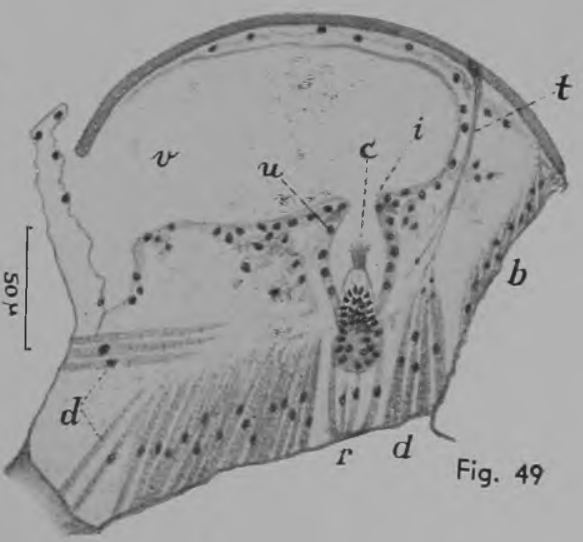




\section{ESTAMPA XX}

Fig. 50 - Corte sagittal de uma avicularia de Microporella ciliata (Pall.). $b^{1}, b^{2}$, musc. abductores proximal e distal; $c$, tendão collectivo do musc. abductor distal; $d_{1}$ musc. adductores ou occlusores; i fibras isoladas do tendão; $m$, mandibula; o, cordão de ligação entre a bainha tentacular e o abductor; $p$, polypidio; $r$, rede dos tendões; s, placa frontali t, tendão collectivo do adductori $y$, tendão curto.

Fig. 5I - Barentsia laxa Kirkp. Femea com ovario direito (o) e 4 embryões na bolsa incubadora; g, ganglio.

Fig. 52 - Topographia da metade esquerda de um calice de Pedicellina cernua ô $t_{\text {, testiculo }}$ esquerdo, estendido do lado oral (o) até o anal (a). O protonephridio foi esquematicamente encurtado.

Fig. 53 - Topographia da metade esquerda de um calice de Pedicellina cernua $q$ com ovos e embryões no atrio. o, ovario esquerdo. O protonephridio foi esquematicamente encurtado. 


\section{ENST MARCUS - Bryozoarios Marinhos Brasileiros - III ESTAMPA XX}
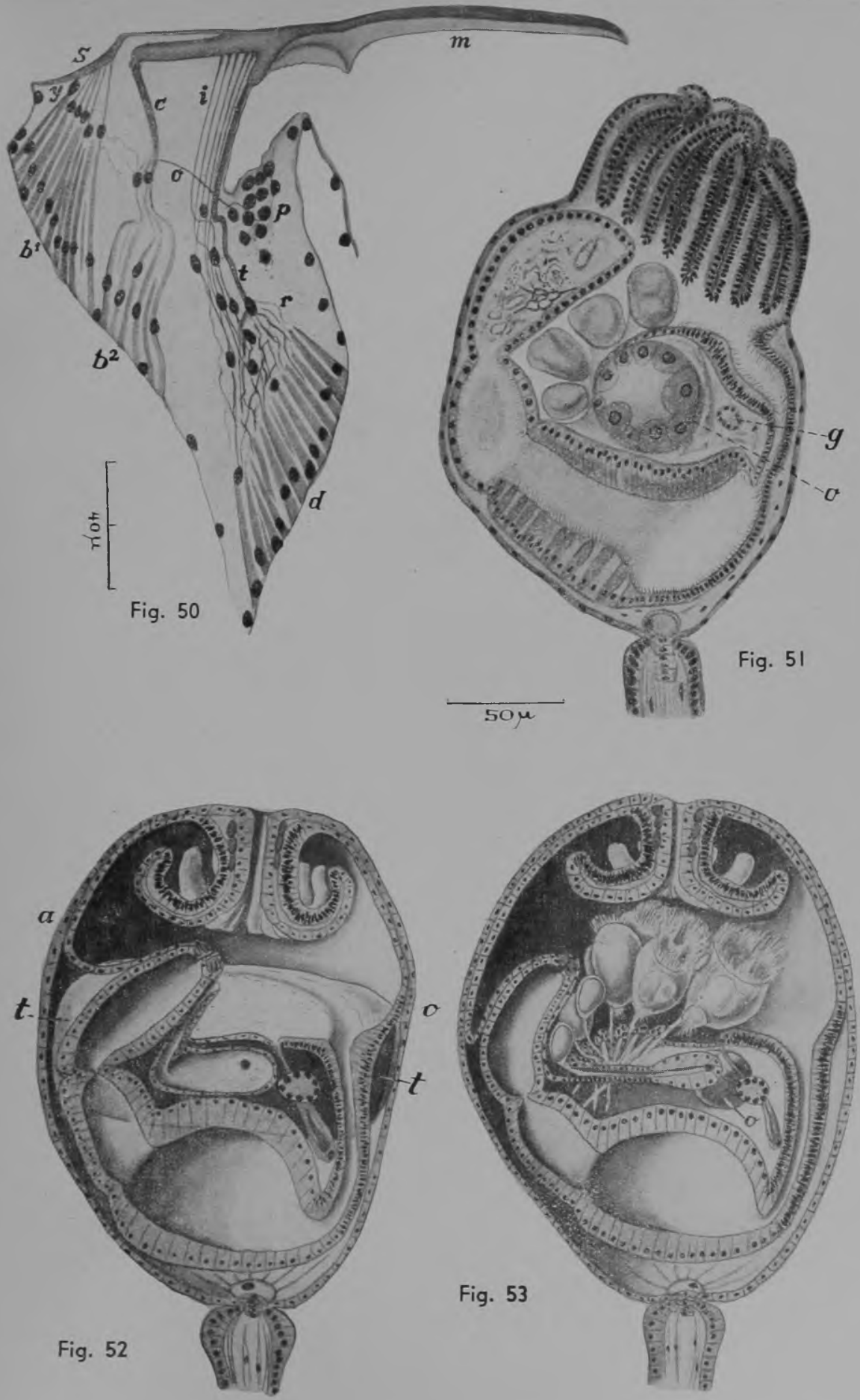


\section{ESTAMPA XXI}

Fig. 54 - Corte horizontal de um macho de Pedicellina cernua com os 2 testiculos $(t)$ que centralmente circumdam a vesicula seminal, oralmente o ganglio. $e_{1}$ orgão excretor; $n$, intestino; 0 , esophago.

Fig. 55 - na estampa XXII.

Fig. 56 - Corte longitudinal da parte actinal do calice de Pedicellina cernua $\hat{o} \quad a_{\text {, epithelio }}$ atrial; $c_{1}$ cône anali $d_{1}$ orificio externo do ducto ejaculatorio; e, poro do orgão excretor; g, ganglio; $r$, conteudo do recto; $s$, vesicula seminal com espermatozoides agglomerados; $t$, tecto do estomago.

Fig. 57 - Espermatogonias de Pedicellina cernua, uma em divisão.

Fig. 58 - Varias phases da espermatogenese de Pedicellina cernua, veja texto p. 218 i d, phase provavelmente diplotenia; $m_{1}$ aggregado de mitochondrios; p, peça media. 
ERNST MARCUS - Bryozoarios Marinhos Brasileiros - III ESTAMPA XXI

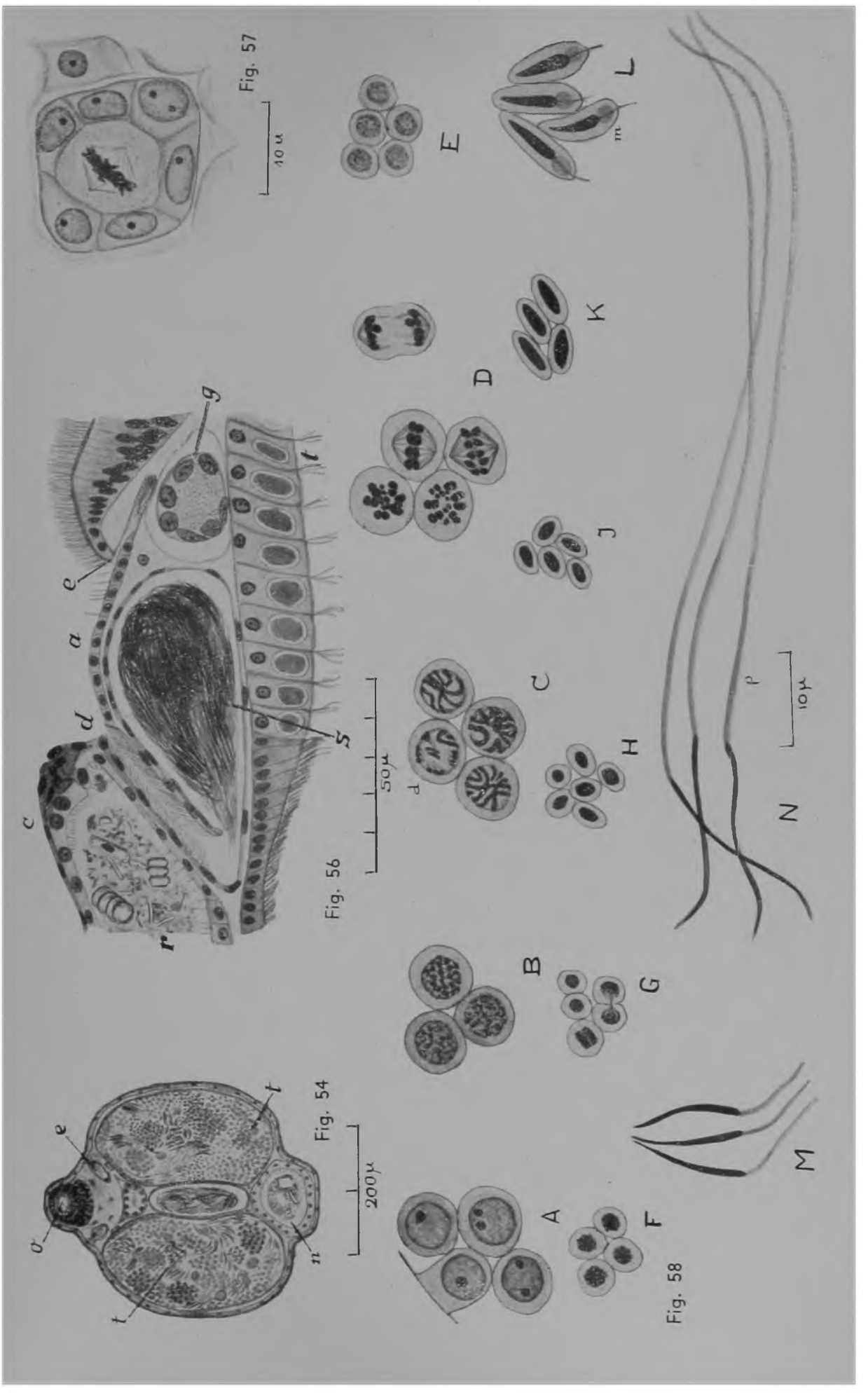




\section{ESTAMPA XXII}

Fig. 55 - Corte horizontal de um macho de Pedicellina cernua; corte da mesma serie como em Fig. 54, $40 \mu$ mais para o lado actinal. Espermatozoides migram dos testiculos $(\dagger)$ para dentro da vesicula seminal. $b$, bocca; $d$, ducto ejaculatorio; $e$, orgãos excretores; $r$, recto.

Fig. 59 - Corte horizontal de uma femea jovem de Pedicellina cernua. a, atrio; $b$, bocca; $g$. ganglio; $n_{1}$ intestino; $o$, ovocyto no inicio da 2. ${ }^{2}$ phase de crescimento; $v_{1}$ vagina; $x_{1}$ orgão excretor.

Fig. 60 - A, corte transversal de uma femea de Pedicellina cernua com 2 dos embryões (e) no atrio (a) e um ovocyto seminado. casca ovular; d, glandula de casca; $i$, oviducto; $m$, ectoderma do embryão; op, ovocyto na I. $^{a}$ phase de crescimento; $s_{1}$ espermatozoide; $t_{1}$ epithelio do estomago. B, um ovocyto na phase de op, augmento maior.

Fig. 61 - Ovocyto de Pedicellina cernua. A, nucleo no fim da prophase da l. ${ }^{a}$ mitose de maturação. $B$, nuçleo em diakinesis. $C$, placa equatorial da l. ${ }^{a}$ mitose de maturação em vista lateral; $d$, glandula de casca; $i$, oviducto; $s_{1}$ nucleo do espermatozoide; $t_{1}$ tecto do estomago. 


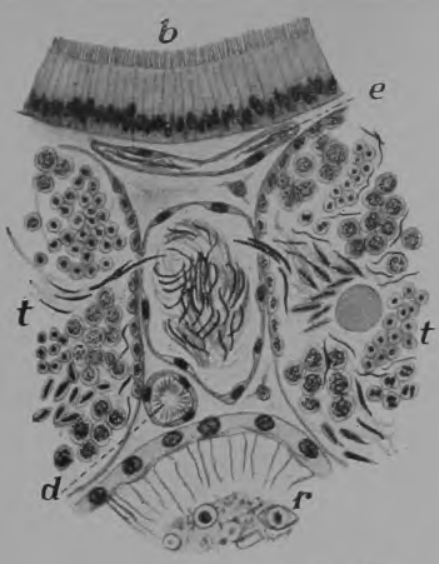

Fig. 55
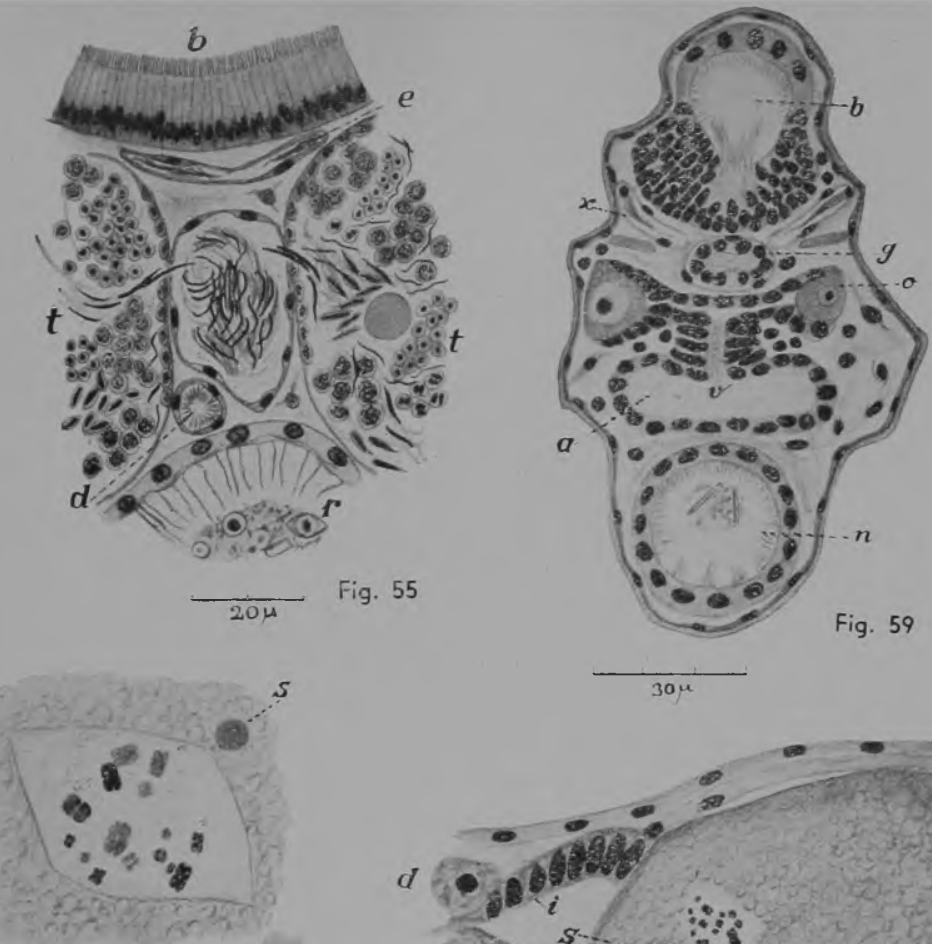

Fig. $61 \mathrm{~B}$

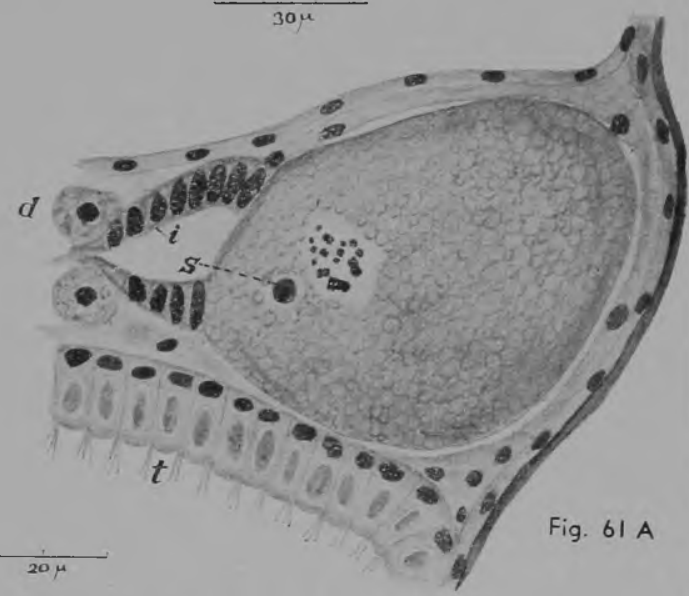

Fig. $61 \mathrm{C}$

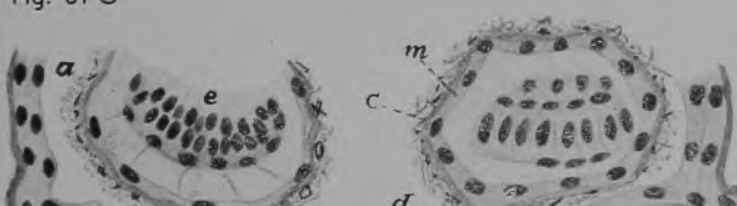

lo -200

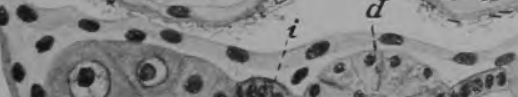

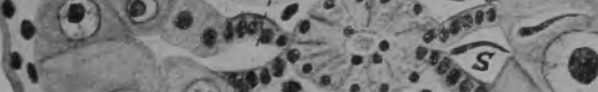

1. $0.0 \%: \div \%$

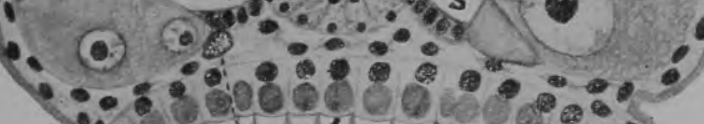

$$
\text { in op } 1 \text { in }
$$$$
\{0
$$

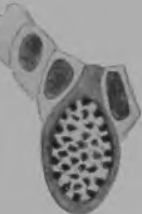

Fig. $60 \mathrm{~B}$ 


\section{ESTAMPA XXIII}

Fig. 62 - Ovocyto de 2.a ordem de Pedicellina cernua no fim da anaphase da $2 .^{\text {a }}$ divisão de

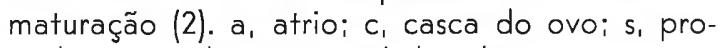

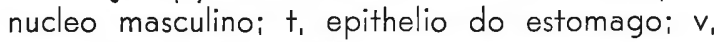
vagina; I, primeiro polocyto.

Fig. 63 - Corte transversal de uma femea de PedicelI ina cernua pelo atrio (a) com tentaculos encurvados (t) e embryões (y) fixados no embryophoro (e) pelos pedunculos (p) da casca. $f$, fenda ciliada do atrio; s, estomago; $v$, vagina.

Fig. 64 - Corte longitudinal da parte actinal de Pedicellina cernua $\&$ I-III, embryões; $b$, bocca; $c$ glandula de casca; e, embryophoro: $g$ ganglio; $n$, intéstino; $o$, esophago; $p$, pedun-

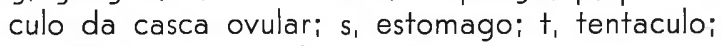
$v_{1}$ orificio externo da vagina.

Fig. 65 - Hermaphrodita lateral de Pedicellin a cernua, somaticamente feminino, corte horizontal. a, atrio; g, glandula de casca; $i$, oviducto; $m$, microsporidio; $n$, intestino; $o$, ovario; $t$, testiculo. 


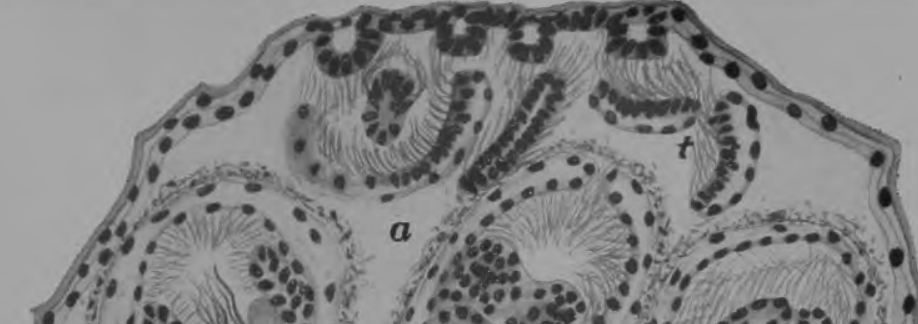

1 is 10 H.

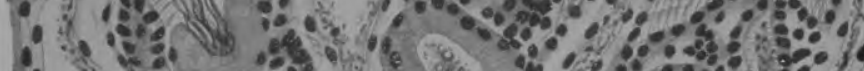

- 18 .

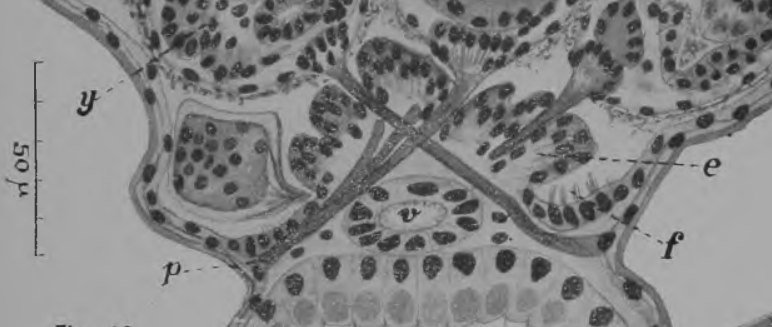

Fig. 63

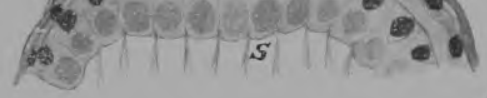

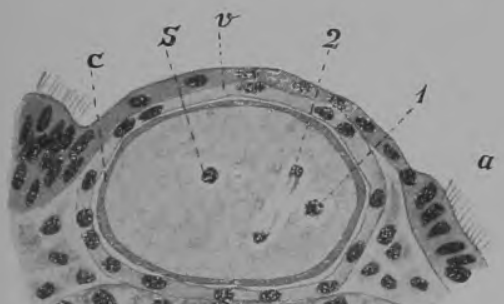

* का का क्ष

$t$ alg (1) $117 \%$

$30 \mu$

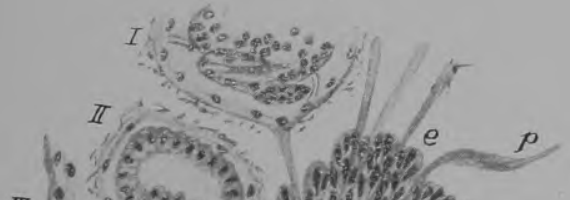

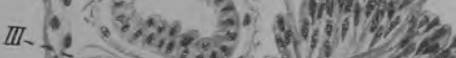

in:

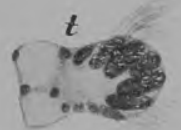

a.
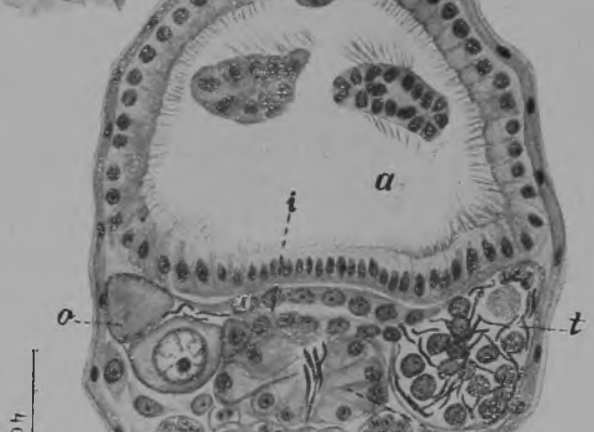

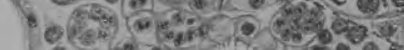

(27)

$$
m
$$

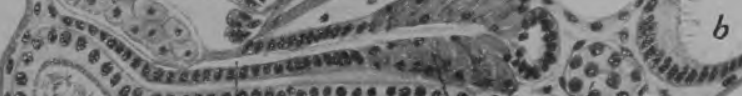

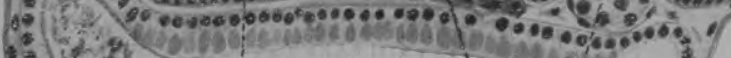

F (kig)

is is

c

乌́

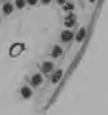

Fig. 64 


\section{ESTAMPA XXIV}

Fig. 66 - $P$ cernua, I. a clivagem do ovo, vista lateral com a casca do ovo e os polocytos.

Fig. 67 - P. ce rnua, ovo com os fusos da 2.a clivagem. A, vista lateral. B, vista do polo animal. $C$, vista por diante ou por detras.

Fig. 68 - $P$ cernua, phase de 4 cellulas.

Fig. 69 - P. cernua, embryão de 7 cellulas com um fuso de divisão da 3. a clivagem. A, vista do polo animal. B, vista lateral.

Fig. 70 - $\mathrm{P}$ cernua, phase de 8 cellulas. A, vista do polo animal. B, vista do polo vegetativo. C. vista lateral. 


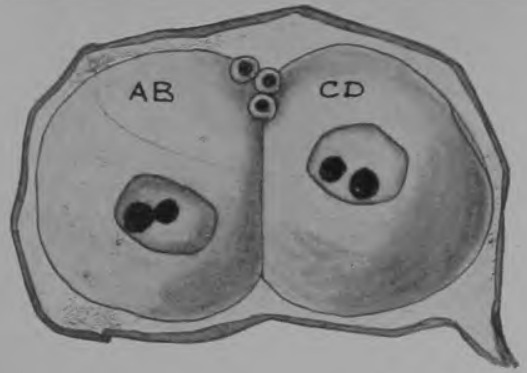

L. Fig. 66
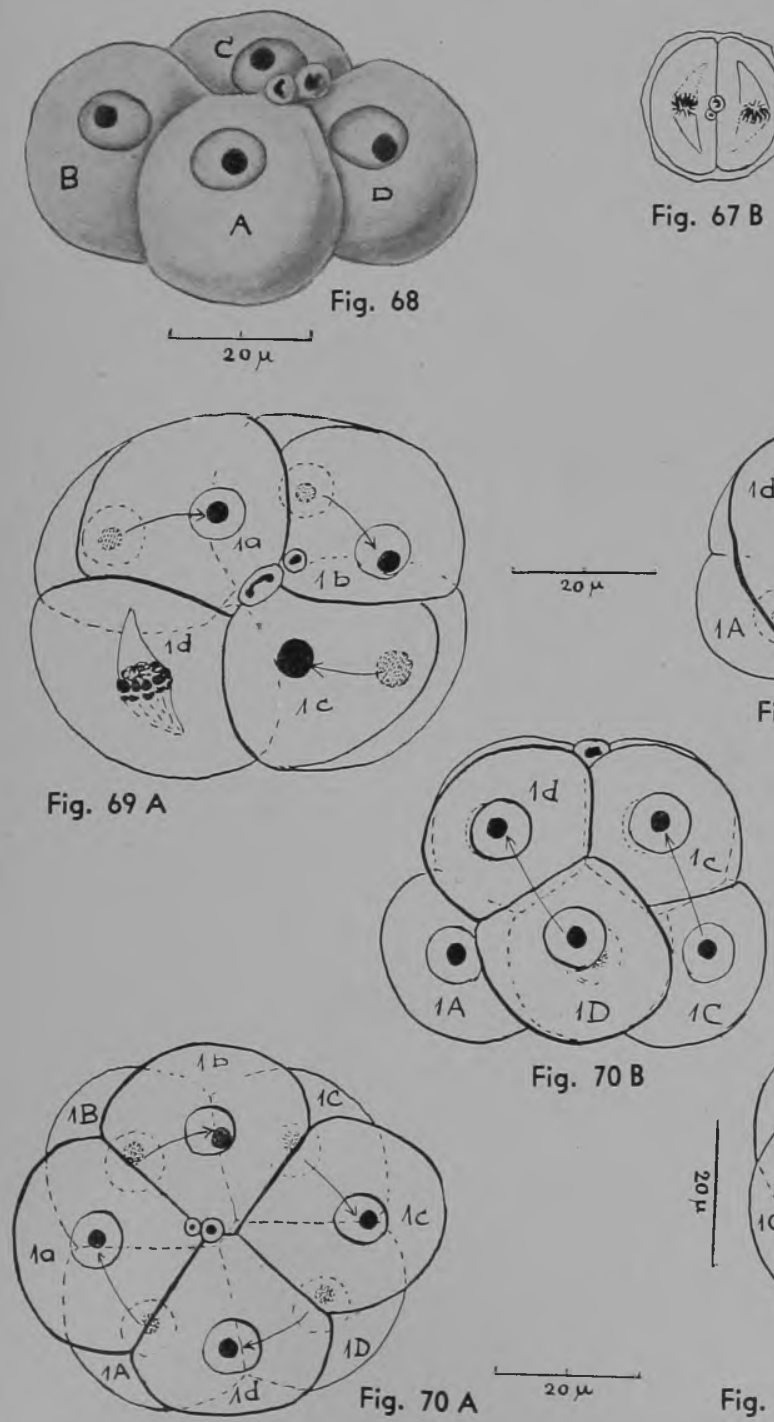

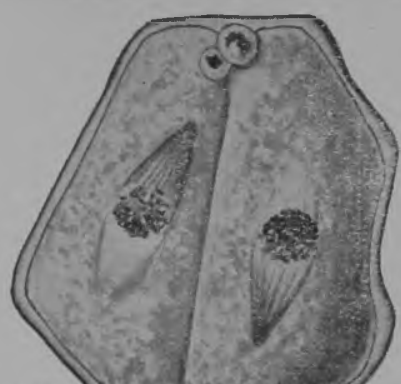

Fig. $67 \mathrm{~A}$

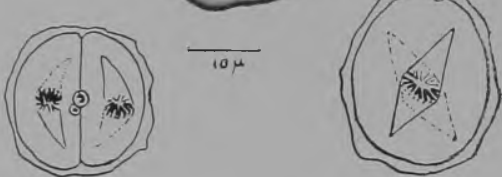

Fig. 67 B

Fig. $67 \mathrm{C}$

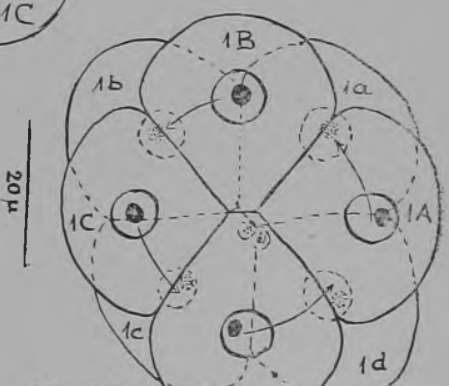

Fig. $70 \mathrm{C}$ iD 


\section{ESTAMPA XXV}

Fig. 7I - P cernua, phase de 16 cellulas. $A, D$, vista do polo animal. $B, E$, vista do polo vegetativo. C, vista lateral. $A, B, C$, ovo lenticular. D, E, ovo globular.

Fig. 72 - P. cernua, phase de 32 cellulas. A, vista do polo animal. $B$, vista do polo vegetativo:

Fig. 73 - P. cernua, embryão composto por 36 blastomeros, vista lateral. 
ERNST MARCUS - Bryozoarios Marinhos Brasileiros - III ESTAMPA XXV
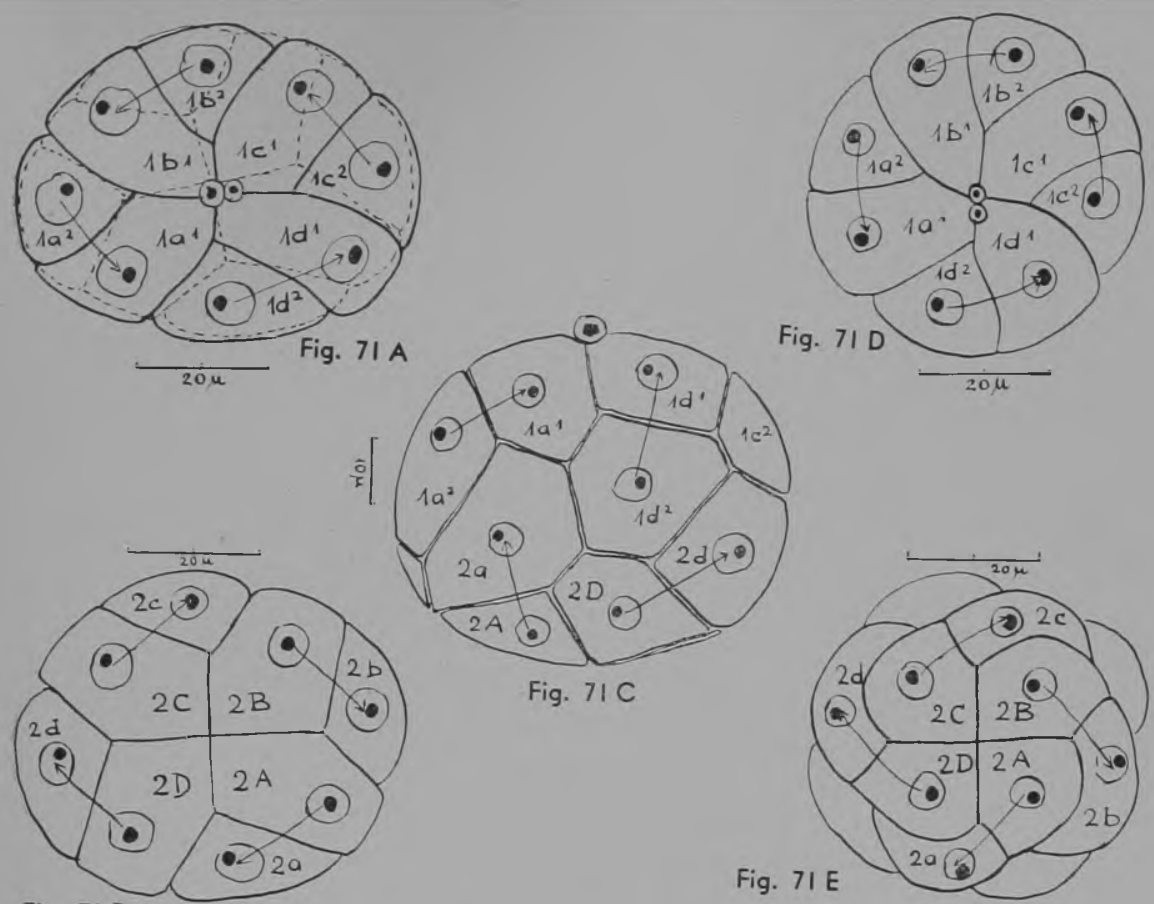

Fig. $71 \mathrm{~B}$
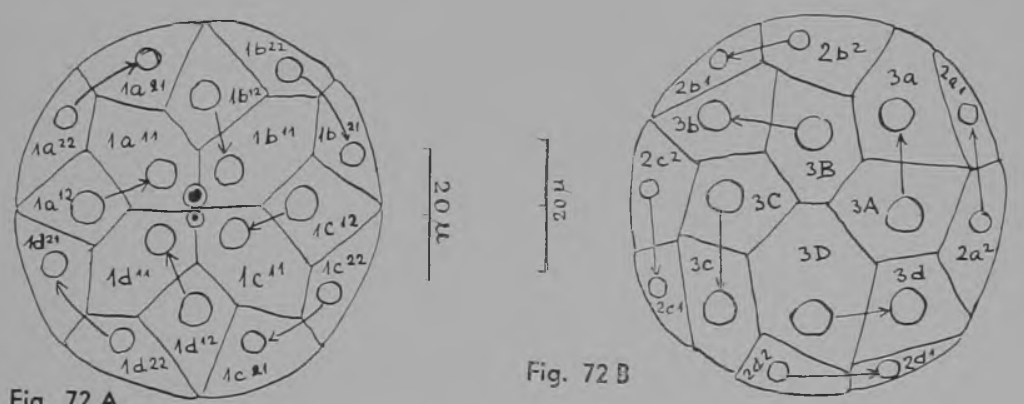

Fig. $72 \mathrm{~A}$

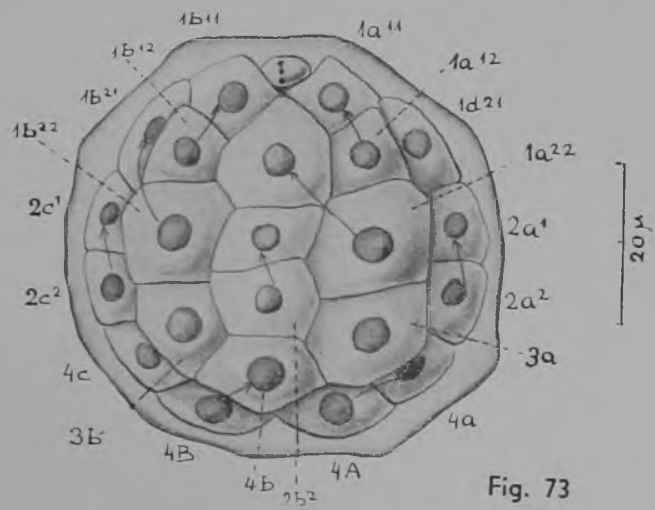




\section{ESTAMPA XXVI}

Fig. 74 - P. cernua, embryão composto por 40-44 blastomeros, em parte marcados com pontos para facilitar a resenha. A, vista do polo animal. B, vista do polo vegetativo.

Fig. 75 - P cernua, phase de 48 cellulas. A, vista do polo animal. B, vista do polo vegetativo; o endomesoblasto $4 d$ está deslocando-se para dentro.

Fig. 76 - P. cernua, phase de 56 cellulas, vista lateral.

Fig. 77 - P. cernua, blastula de 67 cellulas. A, corte mediano. B, o corte confinante com o mediano. a, cellulas da presumptiva placa apicali $b$, blastocela: $c$, polocyto; $p$, pedunculo fixador da casca ovular.

Fig. 78 - $\mathrm{P}$ cernua, inicio da gastrulação (90-100 cellulas). $a_{1}$ ce!lulas da presumptiva placa apicali $n$, um dos 2 entomeros (do $4 .^{\circ}$ quarteto) futuramente situados perto do apice do mesodeo: 3, dois ectomeros, possivelmente pertencentes ao 3. ${ }^{\circ}$ quarteto. Riscazinhas: $4 d^{1}$ e $4 d^{2}$; pontinhos: os entomeros; pontinhos densos: os macromeros divididos. 


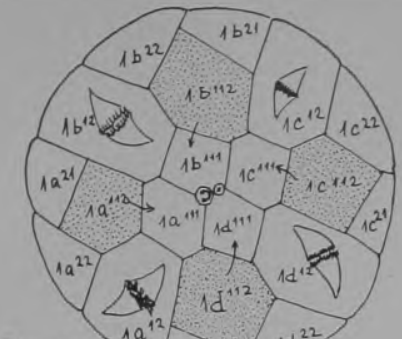

Fig. $74 \mathrm{~A} / 1 a^{12} 1 d^{21}+1 d^{22}$

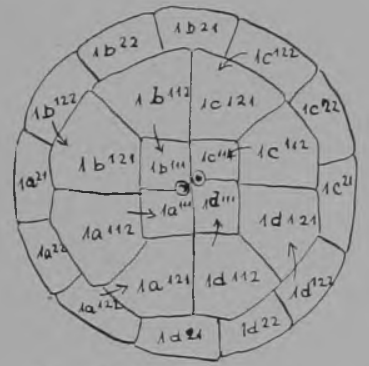

Fig. $75 \mathrm{~A}$
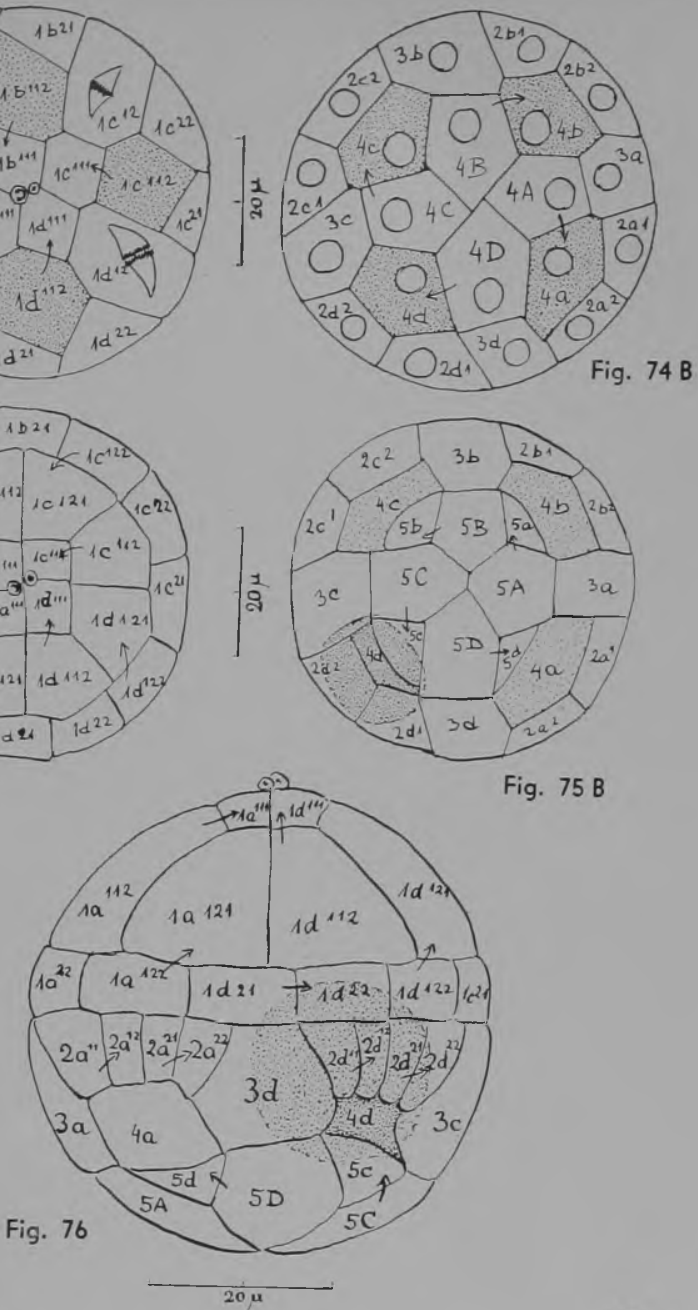

Fig. 75 B

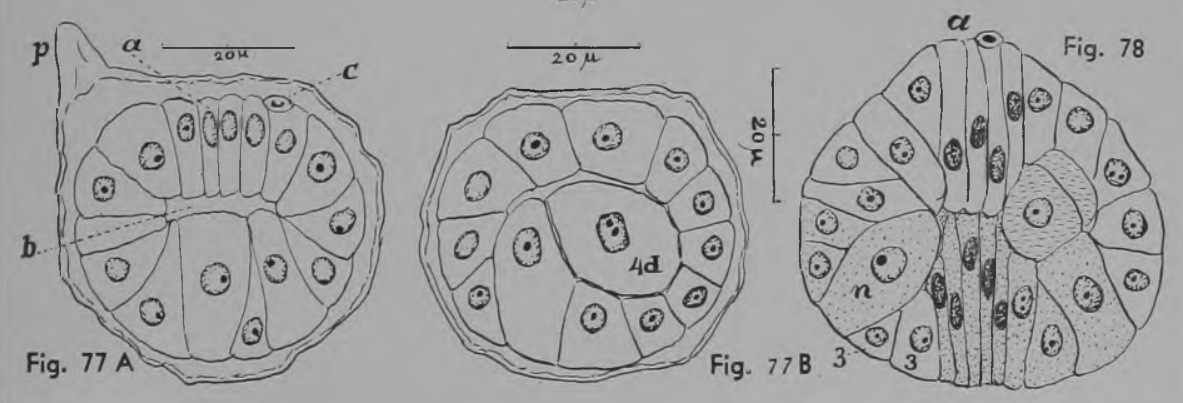




\section{ESTAMPA XXVII}

Fig. 79 - P cernua, gastrulação (ca. de 120 cellulas). As indicações como na figura 78.

Fig. 80 - P. cernua, $\circ 4 .^{\circ}$ de 7 cortes da gastrula (ca. de 130 cellulas); as cellulas $n$ acham-se situadas nos cortes vizinhos por serem dispostos lateralmente.

Fig. $8 \mathrm{I}$ - P. cernua, cortes mediano (A) e paramediano (B) do embryão (ca. de 180-200 cellulas). a, placa apical; $n$, cellula $n ; o$, primordio do orgão preorali s, estomodeo.

Fig. 82 - Corte paramediano do embryão de P. c e rn u a com estomodeo (s) tubuliforme. $d$, endomesenchyma; $m$, mesodeo.

Fig. 83 - Corte transversal do embryão de P c ernua com estomodeo ciliado (s) e formação do ectomesenchyma. (entre estomodeo e parede do corpo). a, orgão apical; e, mesodeo; $m$, endomesenchyma; $n$, cellulas $n$.

Fig. 84 - Corte mediano do embryão de P. cernua com invaginação do proctodeo (r). a, placa apical; $d_{1}$ endomesenchyma; o, orgão preoral; $s$, estomodeo. 
t:KNS I MARCUS - Bryozoarios Marinhos Brasileiros - III ESTAMPA XXVII
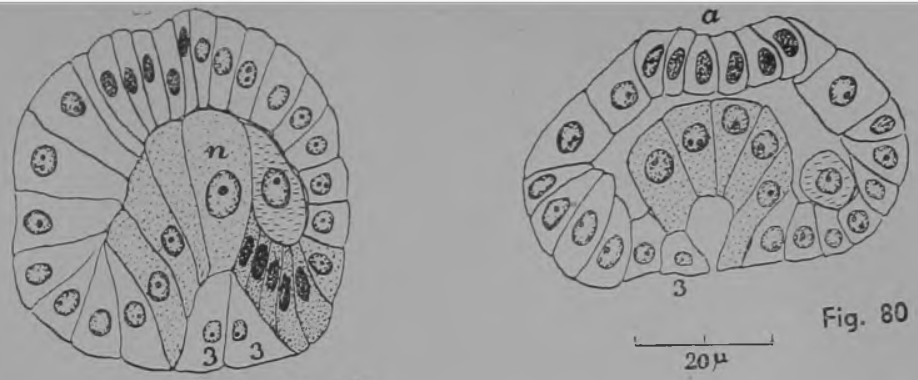

Fig. 79
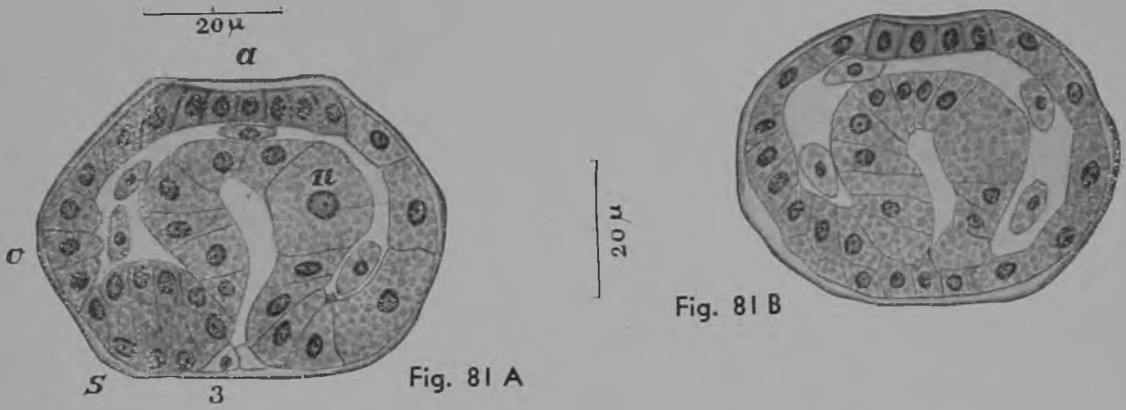

Fig. $81 \mathrm{~A}$

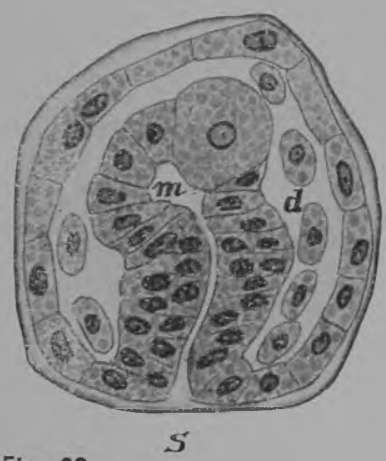

Fig. 82
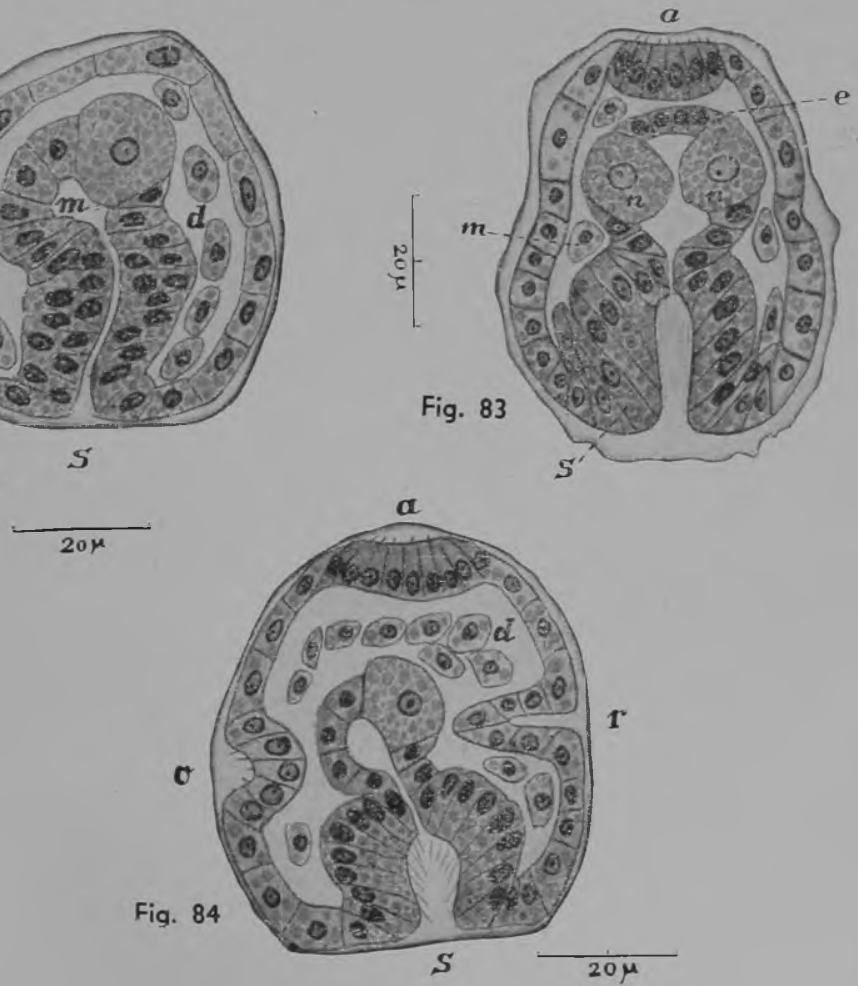


\section{ESTAMPA XXVIII}

Fig. 85 - Corte mediano de um embryão de P cernu a com o primordio do atrio (t). $a_{1}$ orgão apical;

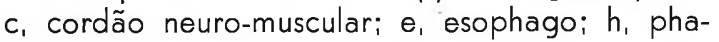
rynge; $i$, intestino; $m$, metatrochio; $o$, orgão preoral; $p$, prototrochio; $r$, recto; $s$, estomago.

Fig. 86 - Corte horizontal de um embryão de P. cern u a com dois lobulos do atrio (t); as letras restantes como em Fig. 85.

Fig. 87 - Corte mediano de um embryão de P. ce rn u a com os orgãos advestibulares. $A$, orgão apical; $c$, cordão neuro-muscular; $g$, orgão advestibular basal; $m$, metatrochio; o orgão preoral; $p$, prototrochio; $v$, orgão advestibular rectal; $x_{1}$ incrustações do ectoderma; $z_{1}$ epistoma.

Fig. 88 - Corte horizontal de um embryão de P c e rn u a com os orgãos advestibulares e a fenda atrial (a). d, orgão advestibular esophageano; $e_{1}$ esophago; $g$, orgão advestibular basal; 0 , orgão preoral, $r$, recto; $u$, labio inferior; $v$, orgão advestibular rectal. 
ERNST MARCUS - Bryozoarios Marinhos Brasileiros - III ESTAMPA XXVIII
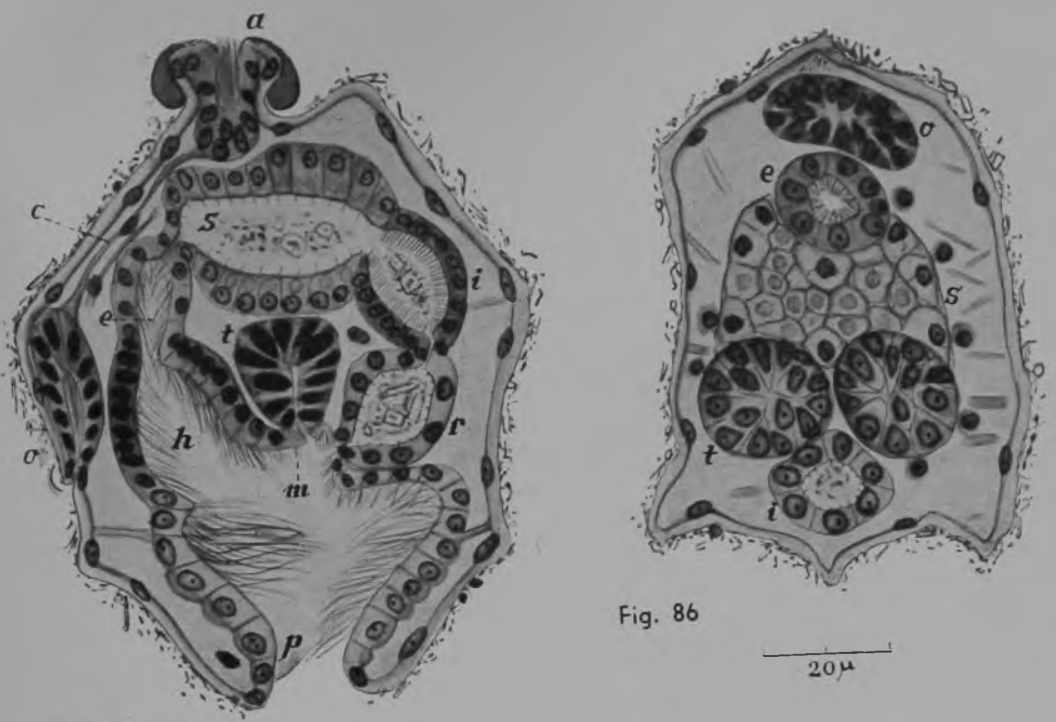

Fig. 86

Fig. 85

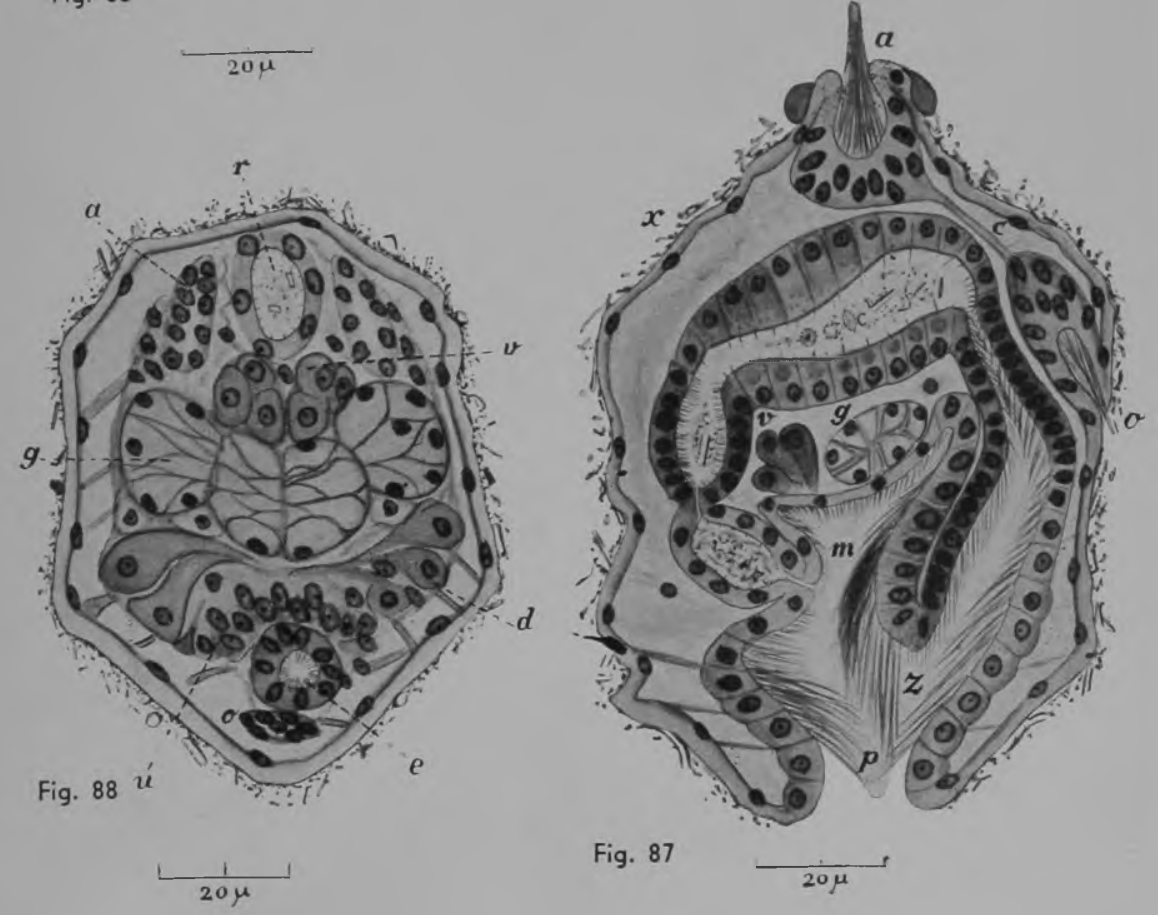




\section{ESTAMPA XXIX}

Fig. 89 - Corte horizontal de um embryão de $P$. c e rn u a com os protonephridios (n). $d$, orgão advestibular esophageano; $\varepsilon_{1}$ esophago; $g$, orgão advestibular basal; $i_{1}$ intestino; o, orgão preoral; u, labio inferior; $v_{1}$ orgão advestibular rectal.

Fig. 90 - na esfampa XXX.

Fig. 91 - Varias phases do movimento da larva de Thala moporella evelinae. 1, 3, 7, vistas lateraes; 2, vista apical; 4, vista basali 5, 8, vistas frontaes; 6, larva contrahida. 
Fig. 89
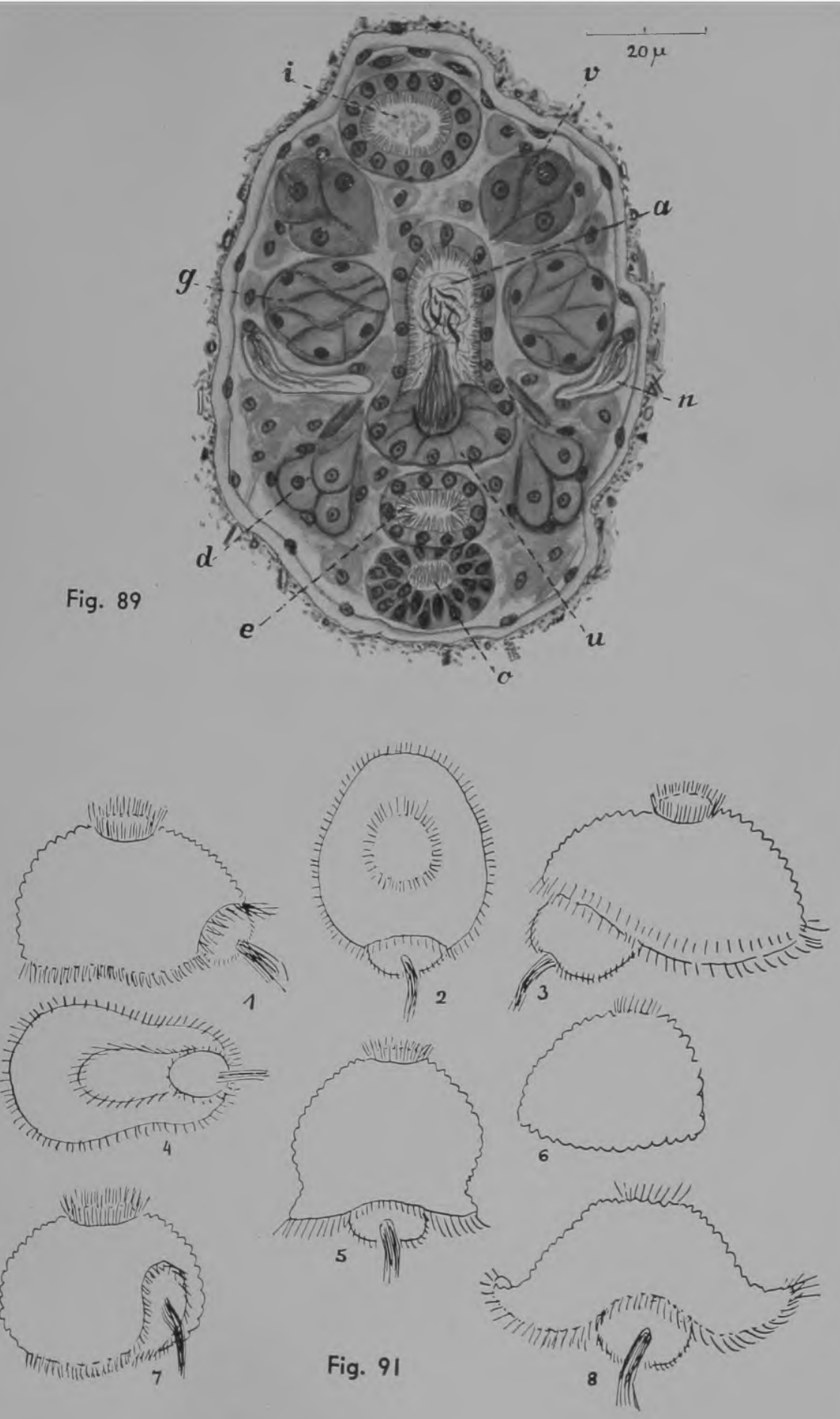


\section{ESTAMPA XXX}

Fig. 90 - Larvas e metamorphoses dos Phoronidea (|-3). Entroprocta (4-6), Phylactolaemata (8-9) e Gymnolaemata (10-11). Trochophora (7). a, apice, an, polo animal; $b$, botão; $c$, corpo da Phoronis adulta; $d$, lado dorsal; $p$, extremidade posterior; v, lado ventral; ve. pelo vegetativo. 
ERNST MARCUS - bryozoarios Marinhos Brasileiros - III
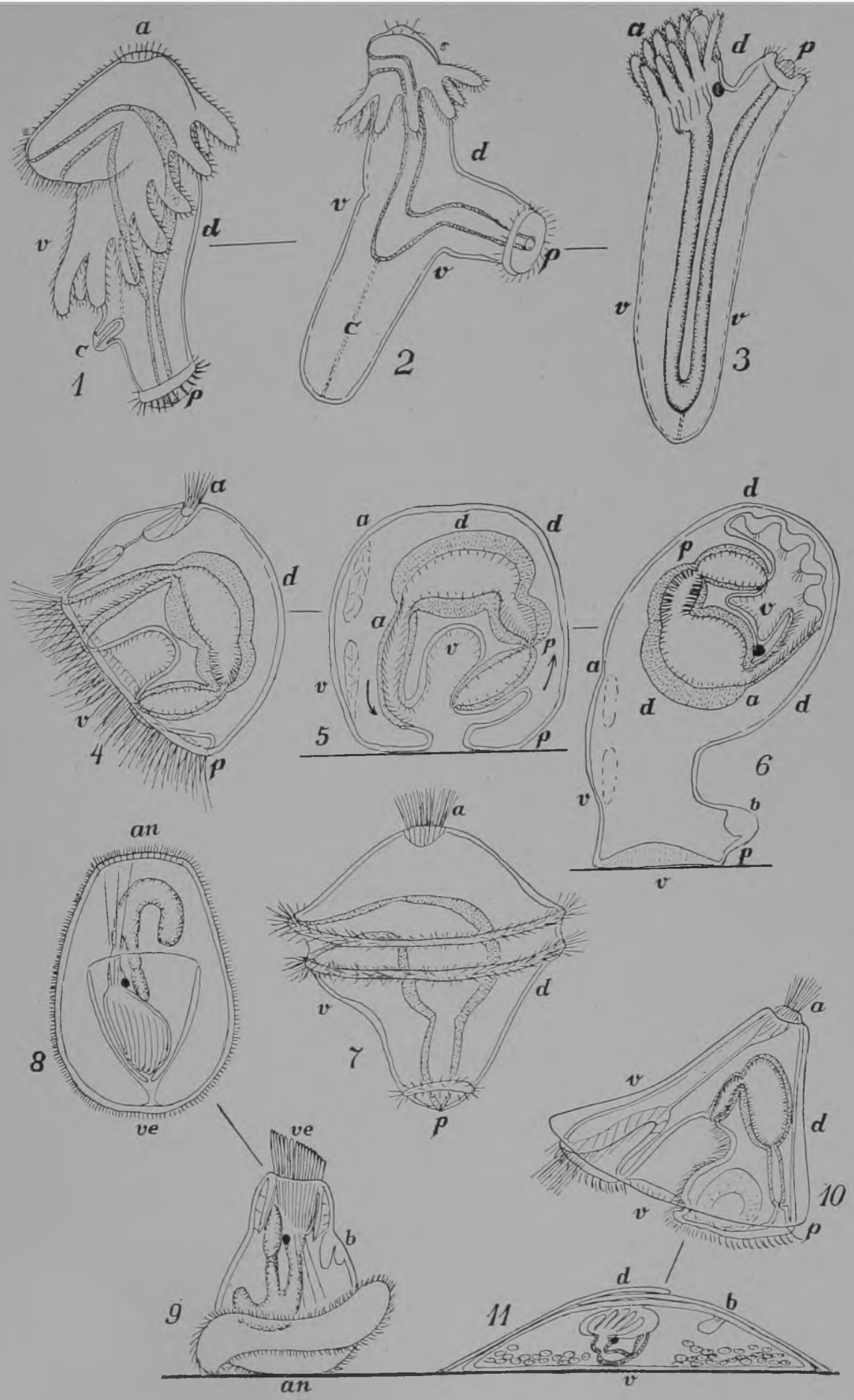


\section{ESTAMPA XXXI}

Larvas viventes de Ectoprocta, desenhos coloridos ao natural. I, Crassimargina tella leucocypha Marc., vista latero-frontal; 2. Thalamoporella evelinae Marc., vista lateral; 3, 4, Savignyella la fonti $\mathrm{i}$ (Aud.) 3, vista apical, 4, vista laterali 5, C a tenicella contei (Aud.) vista lateral; 6, Nolella gigantea (Bsk.), vista frontali 7. Schizoporella carvalhoi Marc., vista lateral; 8, Hippoporella gorgonensis Hast., vista latero-frontal. 
EKNSI MARCUS - Bryozoarios Marinhos Brasileiros - III. ESTAMPA XXXI

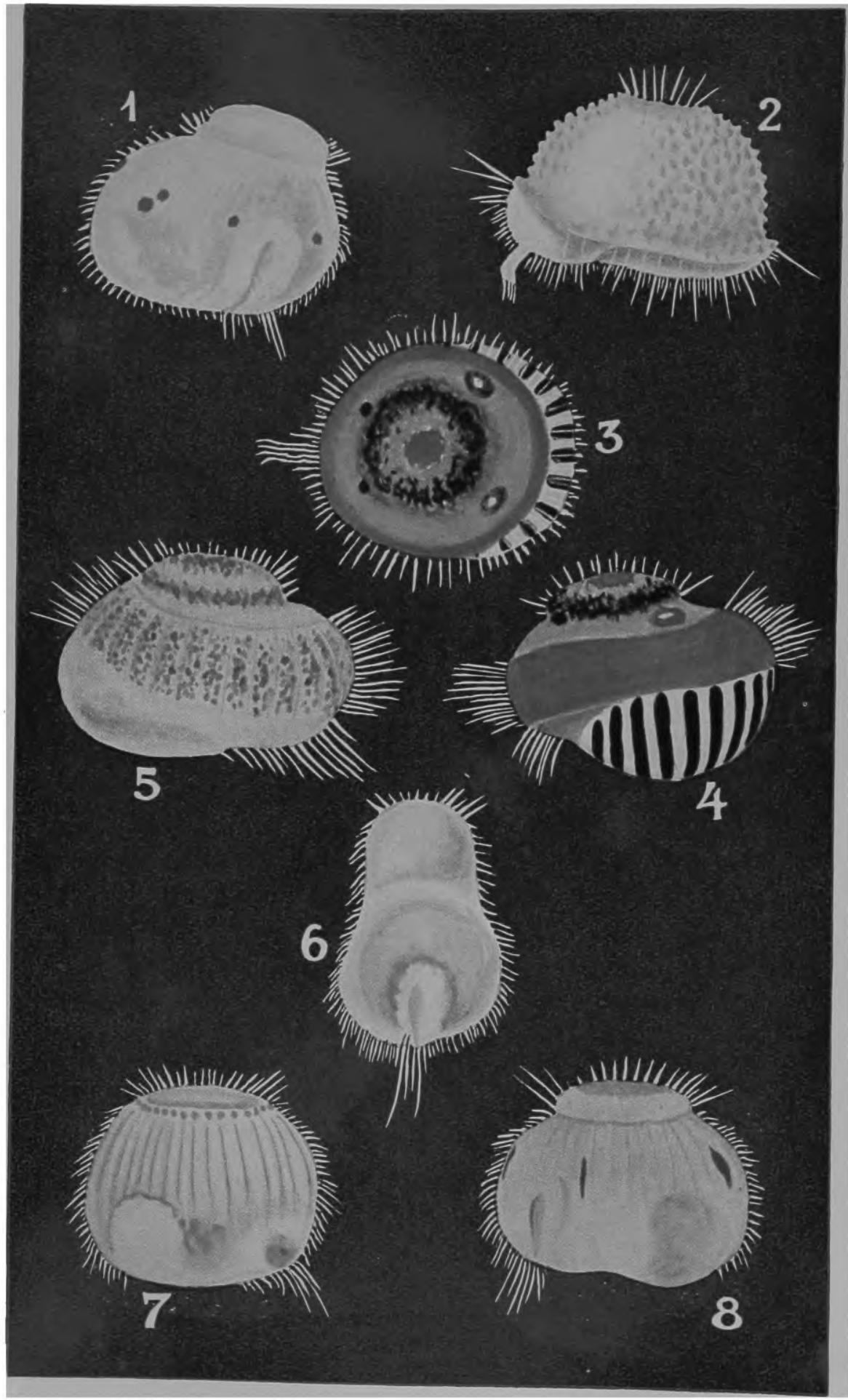

